\title{
INL Results for Phases I and III of the OECD/NEA MHTGR-350 Benchmark
}

Gerhard Strydom Javier Ortensi

Sonat Sen

Hans Hammer

September 2013

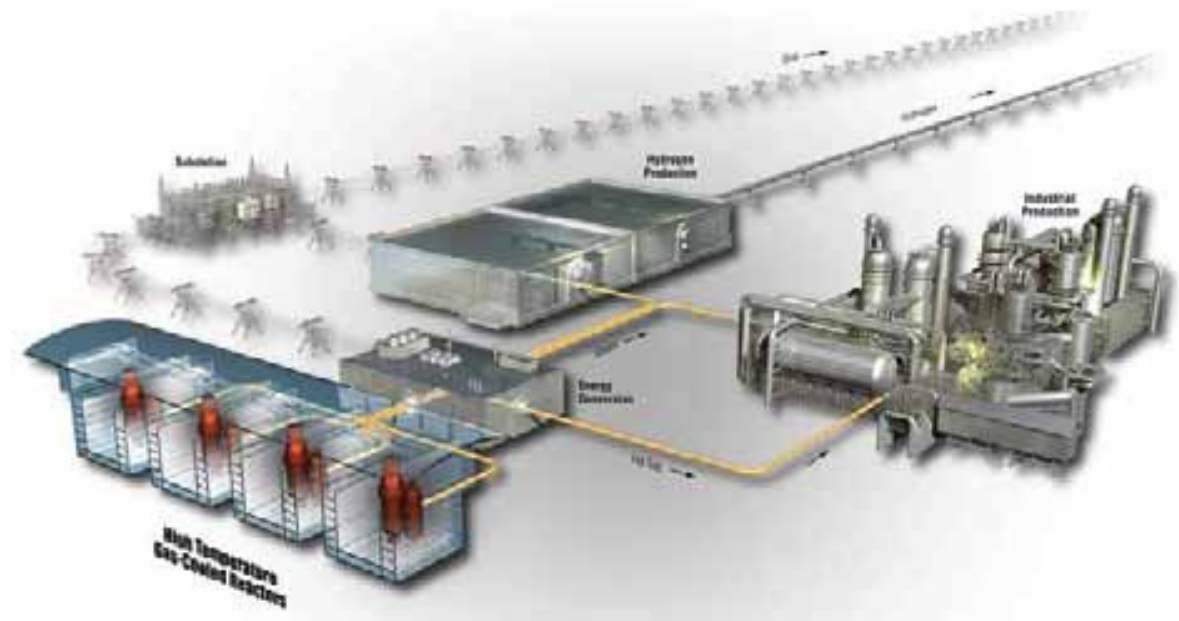

Idaho National Laboratory 


\section{DISCLAIMER}

This information was prepared as an account of work sponsored by an agency of the U.S. Government. Neither the U.S. Government nor any agency thereof, nor any of their employees, makes any warranty, expressed or implied, or assumes any legal liability or responsibility for the accuracy, completeness, or usefulness, of any information, apparatus, product, or process disclosed, or represents that its use would not infringe privately owned rights. References herein to any specific commercial product, process, or service by trade name, trade mark, manufacturer, or otherwise, does not necessarily constitute or imply its endorsement, recommendation, or favoring by the U.S. Government or any agency thereof. The views and opinions of authors expressed herein do not necessarily state or reflect those of the U.S. Government or any agency thereof. 
INL/EXT-13-30176

Revision 0

\title{
INL Results for Phases I and III of the OECD/NEA MHTGR-350 Benchmark
}

\author{
Gerhard Strydom \\ Javier Ortensi \\ Sonat Sen \\ Hans Hammer
}

September 2013

\begin{abstract}
Idaho National Laboratory
VHTR TDO Program

Idaho Falls, Idaho 83415
\end{abstract}

http://www.inl.gov

\author{
Prepared for the \\ U.S. Department of Energy \\ Office of Nuclear Energy \\ Under DOE Idaho Operations Office \\ Contract DE-AC07-05ID14517
}



VHTR TDO Program

INL Results for Phases I and III of the OECD/NEA MHTGR-350 Benchmark

INL/EXT-13-30176

Revision 0

September 2013

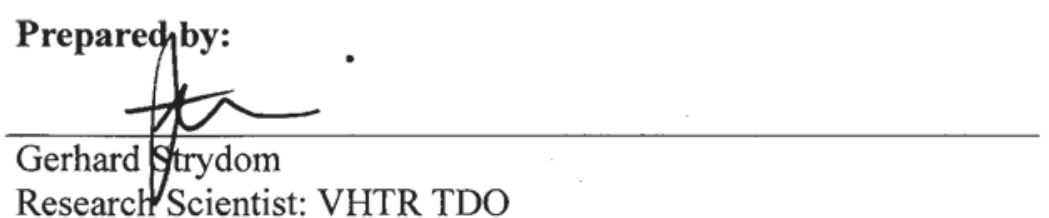

Research Scientist: VHTR TDO

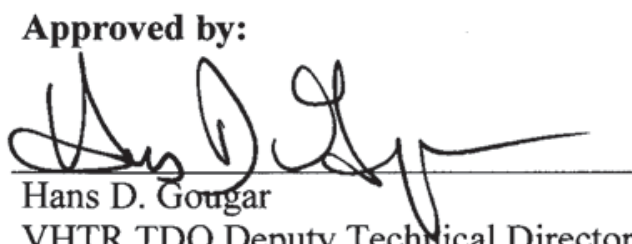

VHTR TDO Deputy TechNical Director

Dian Varas

Diane V. Croon

VHTR TDO Deputy Director

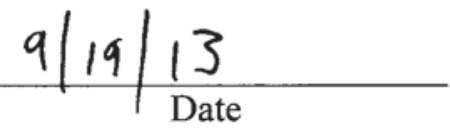

$\frac{9 / 19 / 13}{\text { Date }}$

$9 / 19 / 13$

$\frac{9 / 19 / 13}{\text { Date }}$

Kirk W. Bailey

VHTR TDO Quality Assurance 



\section{ABSTRACT}

The Idaho National Laboratory (INL) Very High Temperature Reactor (VHTR) Technology Development Office (TDO) Methods Core Simulation group led the construction of the Organization for Economic Cooperation and Development (OECD) Modular High Temperature Reactor (MHTGR) 350 MW benchmark for comparing and evaluating prismatic VHTR analysis codes. The benchmark is sponsored by the OECD's Nuclear Energy Agency (NEA), and the project will yield a set of reference steady-state, transient, and lattice depletion problems that can be used by the Department of Energy (DOE), the Nuclear Regulatory Commission (NRC), and vendors to assess their code suits. The Methods group is responsible for defining the benchmark specifications, leading the data collection and comparison activities, and chairing the annual technical workshops.

This report summarizes the latest INL results for Phase I (steady state) and Phase III (lattice depletion) of the benchmark. The INSTANT, Pronghorn and RattleS $\mathrm{n}_{\mathrm{n}}$ ake codes were used for the standalone core neutronics modeling of Exercise 1, and the results obtained from these codes are compared in Section 4. Exercise 2 of Phase I requires the standalone steady-state thermal fluids modeling of the MHTGR-350 design, and the results for the systems code RELAP5-3D are discussed in Section 5. The coupled neutronics and thermal fluids steady-state solution for Exercise 3 are reported in Section 6, utilizing the newly developed Parallel and Highly Innovative Simulation for INL Code System (PHISICS)/RELAP5-3D code suit. Finally, the lattice depletion models and results obtained for Phase III are compared in Section 7.

The MHTGR-350 benchmark proved to be a challenging simulation set of problems to model accurately, and even with the simplifications introduced in the benchmark specification this activity is an important step in the code-to-code verification of modern prismatic VHTR codes. A final OECD/NEA comparison report will compare the Phase I and III results of all other international participants in 2014, while the remaining Phase II transient case results will be reported in 2015. 


\section{ACKNOWLEDGEMENTS}

The authors wish to acknowledge the significant contributions made to this project by the following persons:

- Aaron Epiney and Andrea Alfonsi (PHISICS/RELAP5-3D coupling and model methodology)

- Ivor Clifford (Pronghorn meshing and methodology)

- Avery Guild-Bingham (earlier Pronghorn development work). 


\section{CONTENTS}

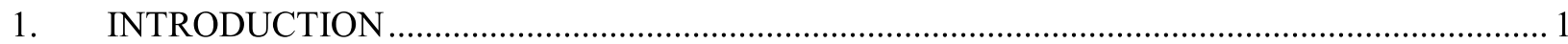

2. OECD/NEA MHTGR-350 BENCHMARK OVERVIEW ….................................................. 2

3. PHISICS/RELAP-5 3D CODE AND MODEL DESCRIPTIONS ……..................................... 7

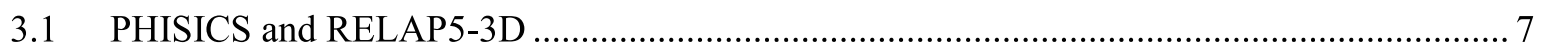

3.1.1 The Coupling of RELAP5-3D and PHISICS ................................................... 7

3.1.2 Overview of the PHISICS/RELAP5-3D Benchmark Model ................................... 9

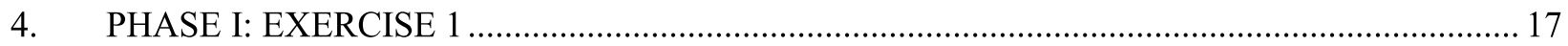

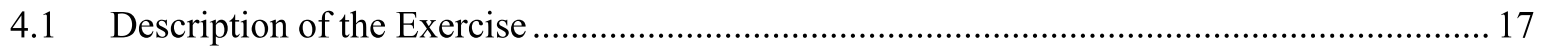

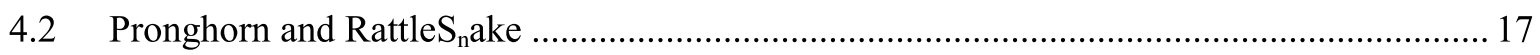

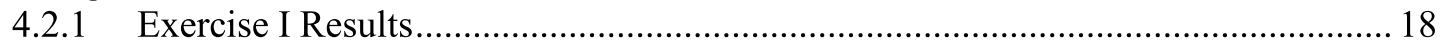

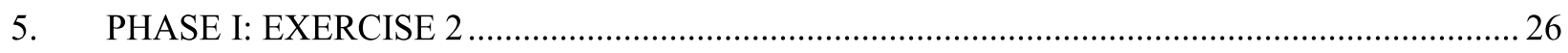

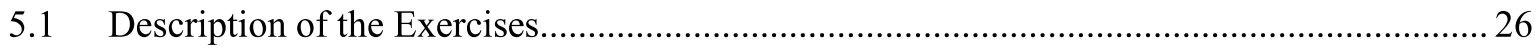

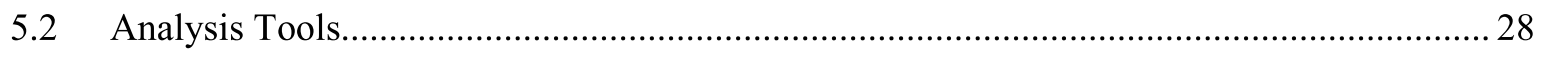

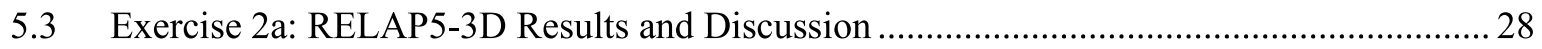

5.4 Exercise 2b: RELAP5-3D Results and Discussion .......................................................... 37

5.5 Exercise 2c: RELAP5-3D Results and Discussion ............................................................ 40

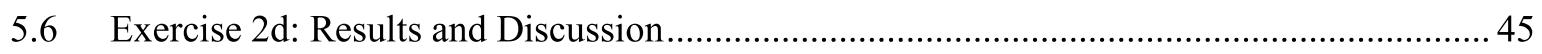

6. PHISICS/RELAP5-3D RESULTS FOR PHASE I: EXERCISE 3 ….......................................... 48

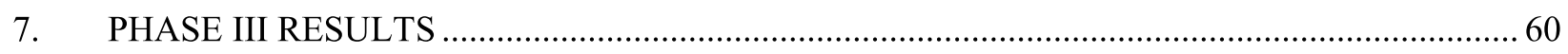

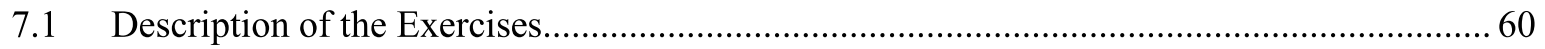

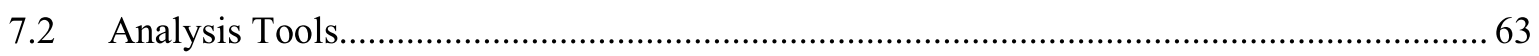

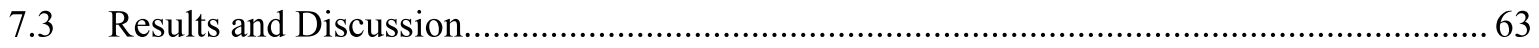

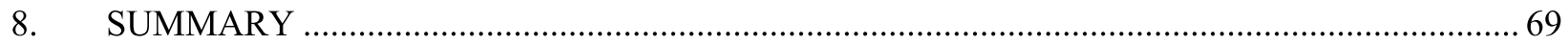

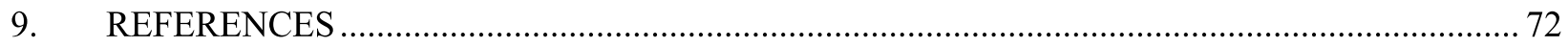

Appendix A Benchmark Data Analysis and Comparison Tools............................................................ 74

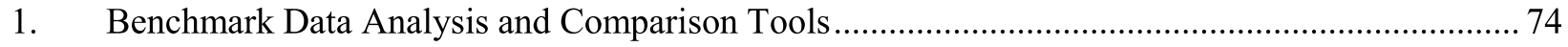

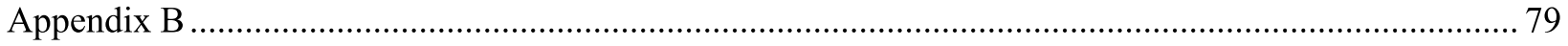

1. Pronghorn Application to Exercise 2a of the MHTGR-350 Benchmark...................................... 79

FIGURES

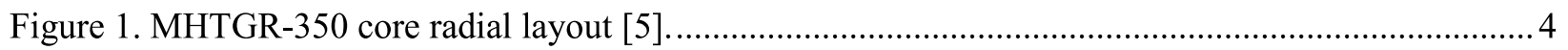

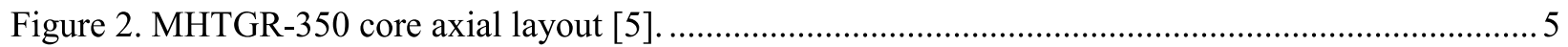

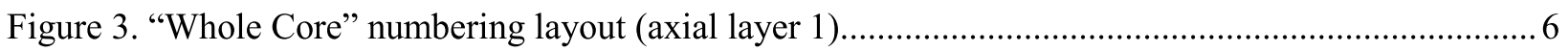


Figure 4. "Active Core" numbering layout (axial layer 1) .................................................................... 6

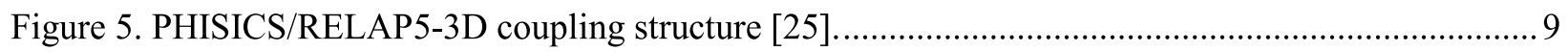

Figure 6. RELAP5-3D MHTGR-350 MW “ring” model radial representation......................................... 10

Figure 7. RELAP5-3D reactor vessel model nodalization................................................................ 11

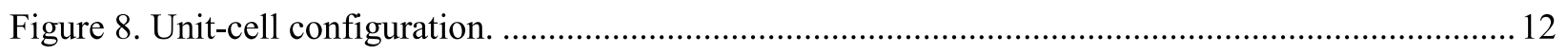

Figure 9. Conduction and radiation connections within the core region. ............................................... 13

Figure 10. Ring and triangular geometry utilized in the RELAP5-3D model. ........................................ 14

Figure 11. Conduction and radiation enclosures in the RELAP5-3D model............................................ 16

Figure 12. MHTGR-350 Exercise 1 Pronghorn and RattleS ${ }_{\mathrm{n}}$ ake analysis mesh. .................................... 18

Figure 13. Axial distribution of the average power density at each active core layer. ............................ 19

Figure 14. Radial flux profiles for the case with the control bank fully inserted......................................20

Figure 15. Whole core neutronics layout for Active Core Layer 10 ......................................................22

Figure 16. Exercise 1 - INSTANT Power density $\left(\mathrm{W} / \mathrm{cm}^{3}\right)$ distribution on Axial Level 1 (bottom of core)

Figure 17. Exercise 1 - INSTANT power density $\left(\mathrm{W} / \mathrm{cm}^{3}\right)$ distribution on Axial Level 7......................24

Figure 18. Exercise 1 - INSTANT Group 2 (of 26) whole core flux distribution on Axial Level 7

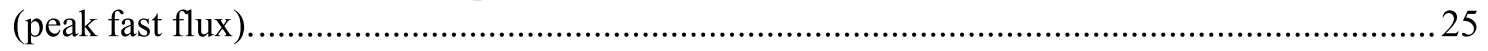

Figure 19. Exercise 1 - INSTANT Group 20 (of 26) whole core flux distribution on Axial Level 7

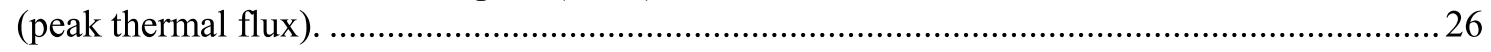

Figure 20. Thermal Conductivity of Grade H-451 Graphite [3] .........................................................2 28

Figure 21. Exercise $2 \mathrm{a}$ - Helium gas temperature $\left({ }^{\circ} \mathrm{C}\right)$ distribution on Axial Level 3 (first bottom

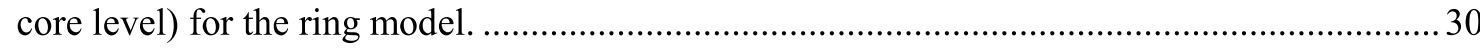

Figure 22. Exercise $2 \mathrm{a}$ - Helium gas temperature $\left({ }^{\circ} \mathrm{C}\right)$ distribution on Axial Level 3 (first bottom core level) for the block model.

Figure 23. Exercise $2 \mathrm{a}$ - Average fuel temperature $\left({ }^{\circ} \mathrm{C}\right)$ distribution on Axial Level 1 (first bottom core level) for the ring model

Figure 24. Exercise $2 \mathrm{a}$ - Average fuel temperature $\left({ }^{\circ} \mathrm{C}\right)$ distribution on Axial Level 1 (first bottom core level) for the block model.

Figure 25. Exercise $2 \mathrm{a}-$ Average graphite temperature $\left({ }^{\circ} \mathrm{C}\right)$ distribution for all graphite structures in the ring model on Axial Level 1 (first bottom core level).

Figure 26. Exercise $2 \mathrm{a}-$ Average graphite temperature $\left({ }^{\circ} \mathrm{C}\right)$ distribution for all graphite structures in the block model on Axial Level 1 (first bottom core level).

Figure 27. Exercise $2 \mathrm{a}$ - Triangular element, block and ring 1 average fuel temperatures for Block $9\left({ }^{\circ} \mathrm{C}\right)$

Figure 28. Exercise $2 \mathrm{~b}$ - Average graphite temperature $\left({ }^{\circ} \mathrm{C}\right)$ distribution for all graphite structures in the ring model on Axial Level 1 (first bottom core level).

Figure 29. Average graphite temperature difference (\%) between Exercise $2 \mathrm{a}$ and Exercise $2 \mathrm{~b}$ for all graphite structures in the ring model on Axial Level 1 (first bottom core level). 
Figure 30. Average graphite temperature difference (\%) between Exercise 2a and Exercise $2 \mathrm{~b}$ for all graphite structures in the block model on Axial Level 1 (first bottom core level).

Figure 31. Average fuel temperature difference $\left({ }^{\circ} \mathrm{C}\right)$ between Exercise $2 \mathrm{a}$ and Exercise $2 \mathrm{~b}$ on Axial Level 1 (first bottom core level) for the block model.

Figure 32. Exercise 2c - Thermal conductivity (W/m.K) distribution on Axial Level 7 (ring model).

Figure 33. Exercise 2c - Thermal conductivity (W/m.K) distribution on Axial Level 7 (block model).

Figure 34. Average graphite temperature $\left({ }^{\circ} \mathrm{C}\right)$ distribution for all graphite structures in the ring model on Axial Level 1 (first bottom core level).

Figure 35. Average graphite temperature difference (\%) between Exercise $2 b$ and Exercise $2 c$ on Axial Level (first bottom core level) for the block model.

Figure 36. Average fuel temperature difference (\%) between Exercise $2 b$ and Exercise $2 c$ on Axial Level 10 (top of core level) for the block model.

Figure 37. Average helium temperature difference (\%) between Exercise 2c and Exercise 2d on Axial Level 1 (first bottom core level) for the block model.

Figure 38. Average graphite temperature difference (\%) between Exercise $2 \mathrm{c}$ and Exercise $2 \mathrm{~d}$ on Axial Level 1 (first bottom core level) for the block model.

Figure 39. Average fuel temperature difference (\%) between Exercise $2 \mathrm{c}$ and Exercise $2 \mathrm{~d}$ on Axial Level 1 (first bottom core level) for the block model.

Figure 40. Exercise 3a - Power density $\left(\mathrm{W} / \mathrm{cm}^{3}\right)$ distribution on Axial Level 8 for the block model.

Figure 41. Exercise 3b - Power density $\left(\mathrm{W} / \mathrm{cm}^{3}\right)$ distribution on Axial Level 8 for the block model.

Figure 42. Exercise 3a-Group 2 flux distribution on Axial Level 8 for the block model (fast peak value).

Figure 43. Exercise 3a-Group 21 flux distribution on Axial Level 8 for the block model (thermal peak value).

Figure 44. Average helium temperature difference (\%) between Exercise $2 \mathrm{~d}$ and Exercise $3 \mathrm{~b}$ on Axial Level 1 (first bottom core level) for the block model.

Figure 45. Average helium temperature difference (\%) between Exercise $2 \mathrm{~d}$ and Exercise $3 \mathrm{~b}$ on Axial Level 10 (top of core) for the block model.

Figure 46. Average fuel temperature difference (\%) between Exercise $2 \mathrm{~d}$ and Exercise $3 \mathrm{~b}$ on Axial Level 1(first bottom core level) for the block model.

Figure 47. Average fuel temperature difference (\%) between Exercise $2 \mathrm{~d}$ and Exercise $3 \mathrm{~b}$ on Axial Level 10 (top of core) for the block model. .58

Figure 49. Comparison of Block 9 power density profiles $\left(\mathrm{W} / \mathrm{cm}^{3}\right)$ for Exercises $1,2 \mathrm{~d}, 3 \mathrm{a}$ and $3 \mathrm{~b}$. .59

Figure 50. Phase III supercell geometry.

Figure 51. Phase III reporting locations 62

Figure 52. Reactivity curves for Exercises $2 \mathrm{a}$ and $2 \mathrm{~b}$. 
Figure 53. B-10 depletion for Exercise 2b.

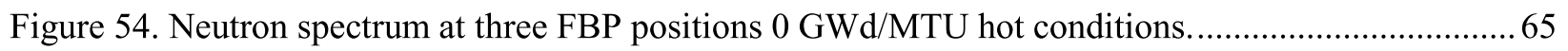

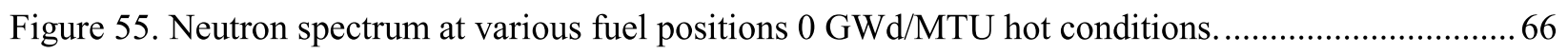

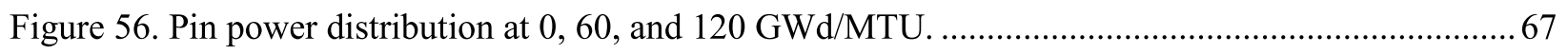

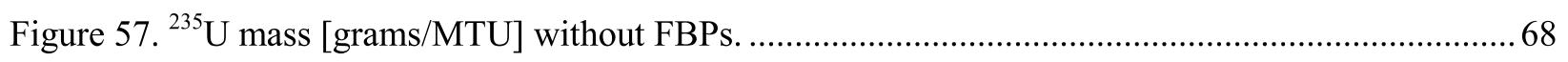

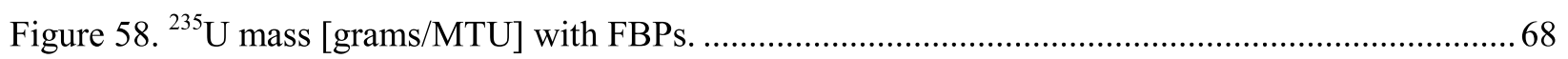

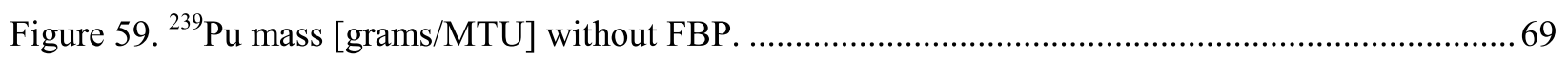

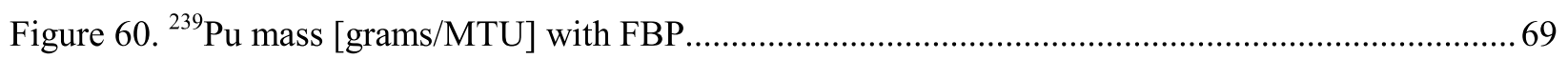

Figure 61. General benchmark data process flow............................................................................. 74

Figure 62. Data base structure for a subset of the Phase I Exercise 3 data............................................. 75

Figure 63. Data base structure for a subset of the Phase III data.......................................................... 76

Figure 64. Overview of Python package flow for Phases I-III. .............................................................. 78

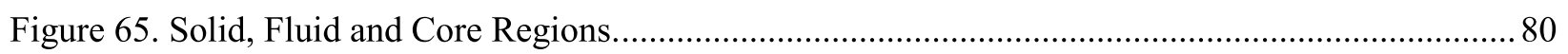

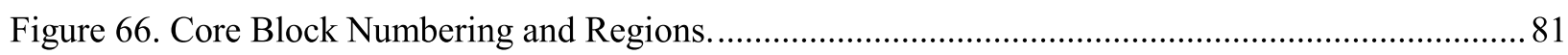

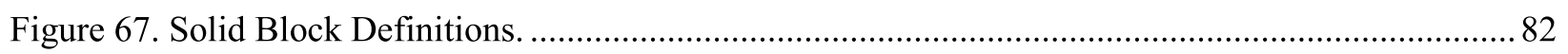

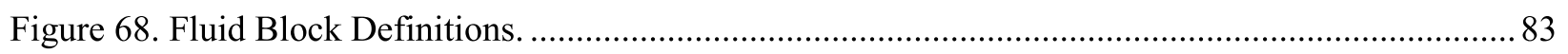

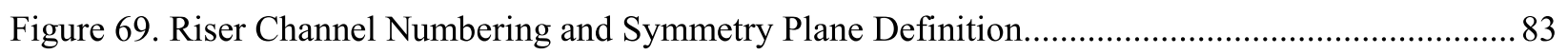

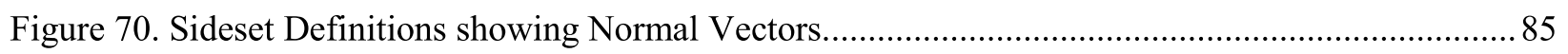

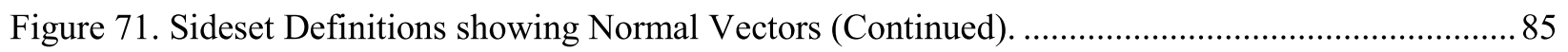

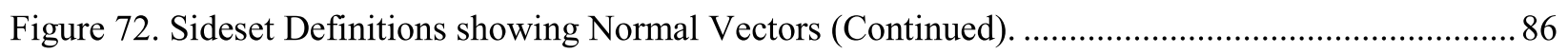

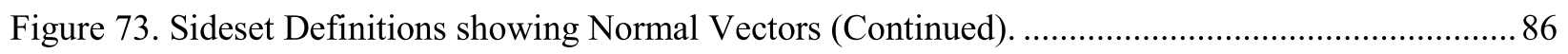

Figure 74. Solid temperatures of the HEX Block test model. 7 HEX blocks in a cylinder 4 producing power. The center HEX block contains a coolant channel........................................ 88

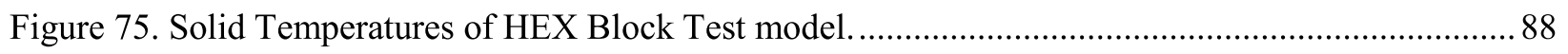

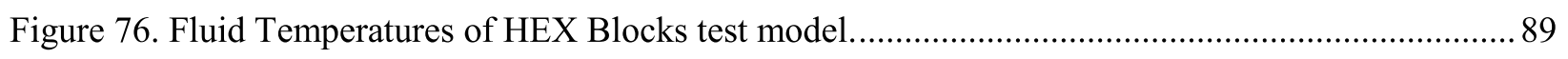

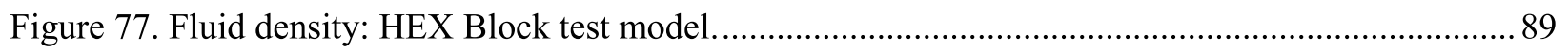

Figure 78. The fluid temperatures for the "lid driven cavity" test, for $\mathrm{t}=0.01 \mathrm{~s}, \mathrm{t}=0.04 \mathrm{~s}$ and

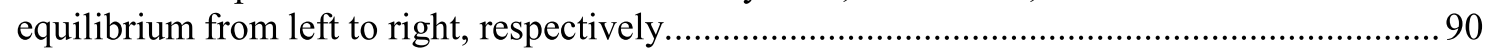

Figure 79. The $\mathrm{x}$-direction velocity for the "lid driven cavity" test, for $\mathrm{t}=0.01 \mathrm{~s}, \mathrm{t}=0.04 \mathrm{~s}$ and equilibrium from left to right, respectively....................................................................... 90

Figure 80. The y-direction velocity for the "lid driven cavity" test, for $\mathrm{t}=0.01 \mathrm{~s}, \mathrm{t}=0.04 \mathrm{~s}$ and

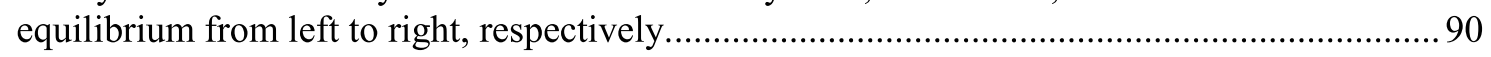

Figure 81. Results for the INS kernels cylindrical pipe flow test case. Left: Fluid temperature, and

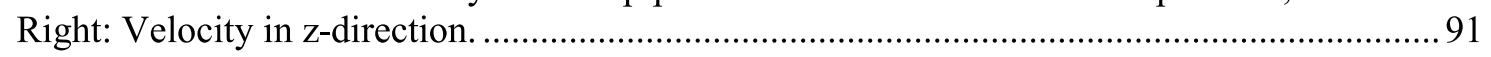

Figure 82. Natural convection cubic test case: Solid Temperatures. ................................................... 92 
Figure 83. The $\mathrm{x}$ (left), $\mathrm{y}$ (middle), and the $\mathrm{z}$ (right) direction momentum in natural convection cubic test case.

Figure 84. Solid temperatures, $\mathrm{z}, \mathrm{y}$, and $\mathrm{x}$ direction momentum from left to right, respectively, in the annular natural convection test case.

Figure 85. Pebble Bed Test Model Solid Temperatures. (left: no CHT Boundary condition, right: with CHT Boundary condition).

\section{TABLES}

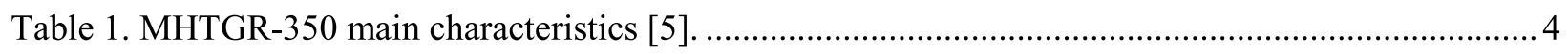

Table 2. Comparison of NESTLE and current PHISICS capabilites [21] ............................................ 8

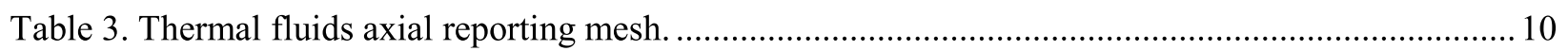

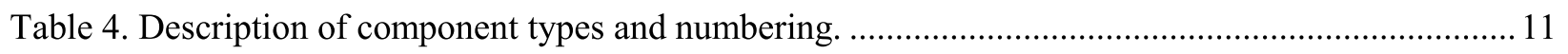

Table 5. Summary of RELAP5-3D and INSTANT feedback mapping ............................................... 15

Table 6. Comparison of the PHISICS/RELAP5-3D ring and block model metrics ................................. 16

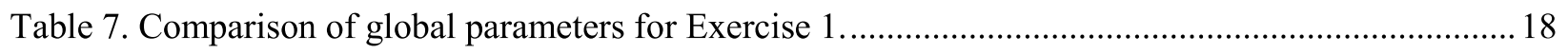

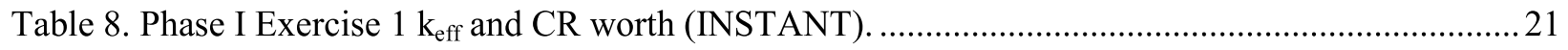

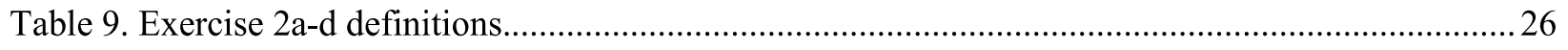

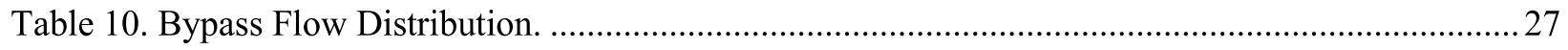

Table 11. Fixed thermophysical properties for Exercise 2a.................................................................2 27

Table 12. Comparison of Phase I Exercise 2 PHISICS/RELAP5-3D thermal fluid results for the ring model.

Table 13. Comparison of Phase I Exercise 2 and Exercise 3 PHISICS/RELAP5-3D global

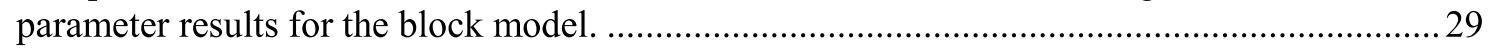

Table 14. Comparison of block 9 triangular average fuel temperatures $\left({ }^{\circ} \mathrm{C}\right)$........................................ 36

Table 15. Comparison of RELAP5-3D bypass flows ( $\%$ of total flow) obtained for Exercise $2 \mathrm{c}$ and Exercise 2d.

Table 16. Comparison of PHISICS/RELAP5-3D keff and CR worths for Exercise $3 a$ and $3 b$ ring and block models .

Table 17. Comparison of Phase I Exercise 2 and Exercise 3 PHISICS/RELAP5-3D thermal fluid results for the ring model.

Table 18. Dimensions for supercell calculations. 61

Table 19. Serpent infinite multiplication comparisons to MCNP5. .63

Table 20. Infinite multiplication factors. 


\section{ACRONYMS}

\begin{tabular}{|c|c|}
\hline ARI & all rods in \\
\hline $\mathrm{BDB}$ & beyond design basis \\
\hline $\mathrm{BP}$ & burnable poisons \\
\hline $\mathrm{CB}$ & core barrel \\
\hline CFD & computational fluid dynamics \\
\hline CHT & conjugate heat transfer \\
\hline $\mathrm{CR}$ & control rod(s) \\
\hline DCC & depressurized conduction cooldown \\
\hline DH & doubly heterogeneous \\
\hline DOE & Department of Energy \\
\hline DoF & Degrees of Freedom \\
\hline FBP & fixed burnable poisons \\
\hline FEM & finite element mesh \\
\hline FPB & fixed burnable poisons \\
\hline GPT & Generalized Perturbation Theory \\
\hline HEX & hexagonal \\
\hline HTGR & high temperature gas-cooled reactor \\
\hline HTTR & high temperature test reactor \\
\hline INL & Idaho National Laboratory \\
\hline INS & Incompressible Navier-Stokes \\
\hline INSTANT & intelligent nodal and semi-structured treatment for advanced neutron transport \\
\hline LWR & light water reactors \\
\hline MHTGR & modular high temperature gas-cooled reactor \\
\hline MOOSE & multiphysics object oriented simulation environment \\
\hline MRTAU & Multi-Reactor Transmutation Analysis Utility \\
\hline NEA & Nuclear Energy Agency \\
\hline NGNP & Next Generation Nuclear Plant \\
\hline $\mathrm{NRC}$ & Nuclear Regulatory Commission \\
\hline OECD & Organization for Economic Cooperation and Development \\
\hline PCC & Pressurized Conduction Cooldown \\
\hline PHISICS & Parallel and Highly Innovative Simulation for INL Code System \\
\hline RDBMS & relational data base management system \\
\hline RELAP & Reactor Excursions and Leak Analysis Program \\
\hline
\end{tabular}




$\begin{array}{ll}\text { RPV } & \text { reactor pressure vessel } \\ \text { RSC } & \text { reserve shutdown control } \\ \text { RV } & \text { reactor vessel } \\ \text { SQL } & \text { Structured Query Language } \\ \text { TDO } & \text { Technology Development Office } \\ \text { TRISO } & \text { tristructural isotropic } \\ \text { VHTR } & \text { very high temperature reactor } \\ \text { VHTRC } & \text { Very High Temperature Reactor Critical } \\ \text { xml } & \text { Extendible Markup Language }\end{array}$




\section{INL Results for Phases I and III of the OECD/NEA MHTGR-350 Benchmark}

\section{INTRODUCTION}

The Very High Temperature Reactor (VHTR) Technology Development Office (TDO) Design Methods and Validation research program, operating under a NQA-1-2008; 1a-2009 nuclear quality assurance program, focuses on the development and validation of tools to assess the neutronic and thermal fluid behavior of the Next Generation Nuclear Plant (NGNP) design. Following the selection of the prismatic design as the preferred NGNP High Temperature Gas-Cooled Reactor (HTGR) design in 2012, the Methods Core Simulation program was scaled down to focus on prismatic HTGR research and benchmarking newly-developed simulation capabilities. The accurate predictive modeling of prismatic high temperature reactors for depletion and transient analysis, including the rigorous treatment of uncertainties propagated through all phases of core simulation, remains a challenge. The treatment of both neutron scattering and resonance capture in graphite are complex and not adequately captured by using the methods traditionally used in HTGRs and commonly used in light water reactors (LWRs). For depletion calculations, a second level of heterogeneity must be resolved to capture the local effects of burnable poisons and fuel compacts while accurately propagating their effects on a significantly larger spatial scale than the traditional LWR approach. Temperature feedback in HTGRs is a function of the tristructural isotropic (TRISO) fuel form but full core models cannot resolve phenomena at this scale without careful averaging over space and energy. To achieve reasonable benchmark results, different approaches were developed in the way that reactors are modeled using the core simulation tools available at Idaho National Laboratory (INL) and elsewhere.

One of the focus areas in 2013 was on the development and testing of sophisticated lattice physics calculations to generate appropriate few-group cross-sections that can be used with confidence in full core depletion and transient simulations such as those specified for this Organization for Economic Cooperation and Development (OECD) benchmark. Accurate depletion calculations in prismatic fuel require transport calculations that account for inter-block leakage and a correct representation of burnable poisons. Traditional methods rely upon assumptions about these phenomena that are of questionable validity and unknown accuracy. Modern lattice and Monte Carlo tools were applied to the problem in a series of comparison and sensitivity studies that yielded an approach to cross-section generation that can be used with confidence. To allow for the considerable uncertainty in homogenized cross-section preparation methods and computational limits, acceptance criteria used in previous prismatic HTGR neutronics benchmarks have included large error bands [2]. A series of supercell depletion studies were conducted to delineate an analysis approach for the prismatic modular reactor design [3]. These studies showed that the traditional two-step method of analysis is not accurate enough to represent the neutronic effects present in the prismatic high temperature reactor concept. The long-range spectral effects induced by the presence of reflectors, burnable poisons (BPs), and operational control rods (CRs) are transformed into significant spatial effects due to the long migration lengths of the neutrons in graphite-moderated reactors.

An HTGR lattice calculation validation study is also being performed in 2013 on the Very High Temperature Reactor Critical (VHTRC) experimental dataset [4], where lattice cross-section generation and depletion results are compared on single block, super cell and core geometries using stochastic (MCNP [5] and Serpent [6]) and deterministic codes (Helios [7], DRAGON [8], Pronghorn [9]). The VHTRC facility was constructed and operated in Japan in support of the design of the High Temperature Test Reactor (HTTR [10]), and it featured a simpler geometry and operated at low temperatures to facilitate accurate validation of HTGR physics codes. 
In the area of verification activities, the VHTR TDO Methods Core Simulation group led the construction of the OECD MHTGR-350 Transient Benchmark for comparing and evaluating prismatic HTGR analysis codes [11]. The benchmark is sponsored by the OECD's Nuclear Energy Agency (NEA), and the project will yield a set of reference steady-state, transient, and lattice problems that can be used by Department of Energy (DOE), Nuclear Regulatory Commission (NRC), and vendors to assess their codes. The Methods group is responsible for defining the benchmark specifications, leading the data collection and comparison activities, and chairing the annual technical workshops. Participants from Korea, Germany, and the U.S. will remain involved in this activity until 2015, if funding permits. The Methods group has based several code development and verification activities were based on the MHTGR-350 benchmark, and two conference publications on the preliminary results for Phase I have already been completed [11],[12]. As part of the benchmark simulation activities, the Parallel and Highly Innovative Simulation for INL Code System (PHISICS) reactor physics package was coupled to the system thermal fluid code RELAP5-3D to enable temperature feedback in core simulations. RELAP5-3D does not provide the spatial resolution of higher fidelity thermal fluid codes but it does have a powerful plant simulation capability. A detailed study was performed on the spatial resolution required in flux and temperature profiles to support accurate depletion and transient analyses by comparing the traditional ring model approach with a much more detailed triangular geometry model.

In a separate effort, INL has developed the MOOSE (Multiphysics Object Oriented Simulation Environment) for efficient development of simulation tools that can run on supercomputers as well as standalone workstations [15]. Although MOOSE was initially applied to fuels performance modeling, a modest effort to model the neutronics and thermal-hydraulics of high temperature reactor cores was successfully completed in 2010 [9]. With some NGNP Methods funding in 2013, the Pronghorn code is now being applied to prismatic analysis and testing against the OECD MHTGR-350 benchmark, and the Pronghorn results for Phase I Exercise 1 is included in this report.

\section{OECD/NEA MHTGR-350 BENCHMARK OVERVIEW}

The MHTGR-350 MW benchmark specification [11] was developed in cooperation with General Atomics to compare different codes and methods, since validation data from current or past prismatic VHTR experimental facilities or reactors are severely limited. The benchmark was launched on March 1, 2012 for international participation after formal approval was received from the Nuclear Energy Agency (NEA) of the OECD. The scope of the benchmark is to establish a well-defined problem based on a common given data set, and to compare methods and tools in core simulation and thermal hydraulic analysis with a specific focus on transient events through a set of multi-dimensional computational test problems. The depletion capabilities of various lattice physics codes available for prismatic reactors will also be compared to establish the current state-of-art, in conjunction of the INL validation effort to model the VHTRC experimental facility.

The MHTGR-350 MW benchmark is based on the approach followed for the OECD/NEA PBMR-400 MW benchmark [16]. The benchmark consist of three Phase I steady-state Exercises, four Phase II transient Exercises, and a single Phase III depletion Exercise, as summarized below.

\section{- Phase I}

- Exercise 1: Neutronics only steady-state solution for the 350 MW End of Equilibrium Cycle (EOEC) MHTGR core, using the provided geometry, material descriptions, and detailed cross-section libraries.

- Exercise 2: Thermal hydraulics only steady-state core solution. Four sub-cases are defined, depending on the core bypass flow type and the use of fixed or variable thermophysical material properties. Participants are expected to provide steady-state solutions for each of these sub-cases according to their codes' capabilities. A defined core power distribution map must be used, since no neutronics are involved in this Exercise. 
- Exercise 3: Coupled neutronics-thermal hydraulic core steady state. This Exercise is a combination the first two Exercises and the coupled steady-state solution must be calculated using the provided temperature dependent cross-section library, burnup and fluence distributions. The participants are expected to compute the xenon equilibrium for the steady-state solution as well.

\section{- Phase II}

- Exercise 1: Depressurized Conduction Cooldown (DCC) transient, with and without reactor trip to allow for re-criticality to occur. Initial conditions for the transients are obtained from the steady-state solution of Phase I Exercise 3.

- Exercise 2: Pressurized Conduction Cooldown (PCC) to an equalization pressure of $5 \mathrm{MPa}$ with a reactor trip.

- Exercise 3: Water ingress with reactor trip. Two variations of a multiple steam generator tube rupture accident are defined. In these transients $125.4 \mathrm{~kg}$ steam is injected into the primary system over 2 and 22 seconds, respectively. The former case is included in the benchmark set as a theoretical Beyond Design Basis (BDB) example of a prompt critical transient event.

- Exercise 4: Xenon stability test. Participants are expected to simulate a $100 \%-80 \%-100 \%$ power load follow transient that tracks the buildup and decay of xenon and the subsequent core reactivity behavior over 72 hours.

\section{- Phase III}

- Exercise 1: "Assembly-level" depletion calculation, consisting of a fresh fuel block surrounded by a "super-cell" of depleted fuel blocks on the left boundary and reflector blocks on the right boundary. Two sub-cases are defined, one with and without burnable poison compact in the corner nodes of the fresh fuel block.

Only the INL results for Phases I and III are presented in this report, since the benchmark agreement with the OECD/NEA specifies that no comparison results between participants can be published before the formal OECD/NEA report is released. The INL results for Phase II will be reported at the end of Fiscal Year 2014, and the final OECD/NEA report is expected to be completed by September 2015.

The radial and axial core layouts of the MHTGR-350 are shown in Figure 1 and Figure 2, respectively, and the major core characteristics are summarized in Table 1. A detailed description of the MHTGR-350 design can be found in the benchmark specification document [11] that will be formally released by the OECD/NEA in December 2013. The axial neutronic mesh extends from the top reflector and core restraint element interface to the graphite core support structure (just above the outlet plenum). Radially the inner radius of the core barrel forms the outer radial neutronic boundary.

Two numbering systems are utilized for the whole and active core regions, and are organized in layers and columns. The whole and active core regions numbering for the $1 / 3$ core are shown in Figure 3 and Figure 4, respectively. The bottom reflector is defined as layer 1, and radially the central column is column 1- the rest of the numbering follows the various radial rings up to 91 columns. There are 22 fuel blocks on each $1 / 3$ axial layer for a total of 660 in the full core. Replaceable H-451 graphite blocks make up the inner and outer reflectors (rings 1-3 and 7-8), and grade 2020 graphite is used for the permanent reflector in rings 9 and 10, as indicated in Figure 4. There is only one CR group inserted in this End of Equilibrium Cycle (EOEC) core above block 15 (Figure 4). The insertion depth is one block height, so the $\mathrm{CR}$ is inserted one fuel block into the active core from the top reflector. 


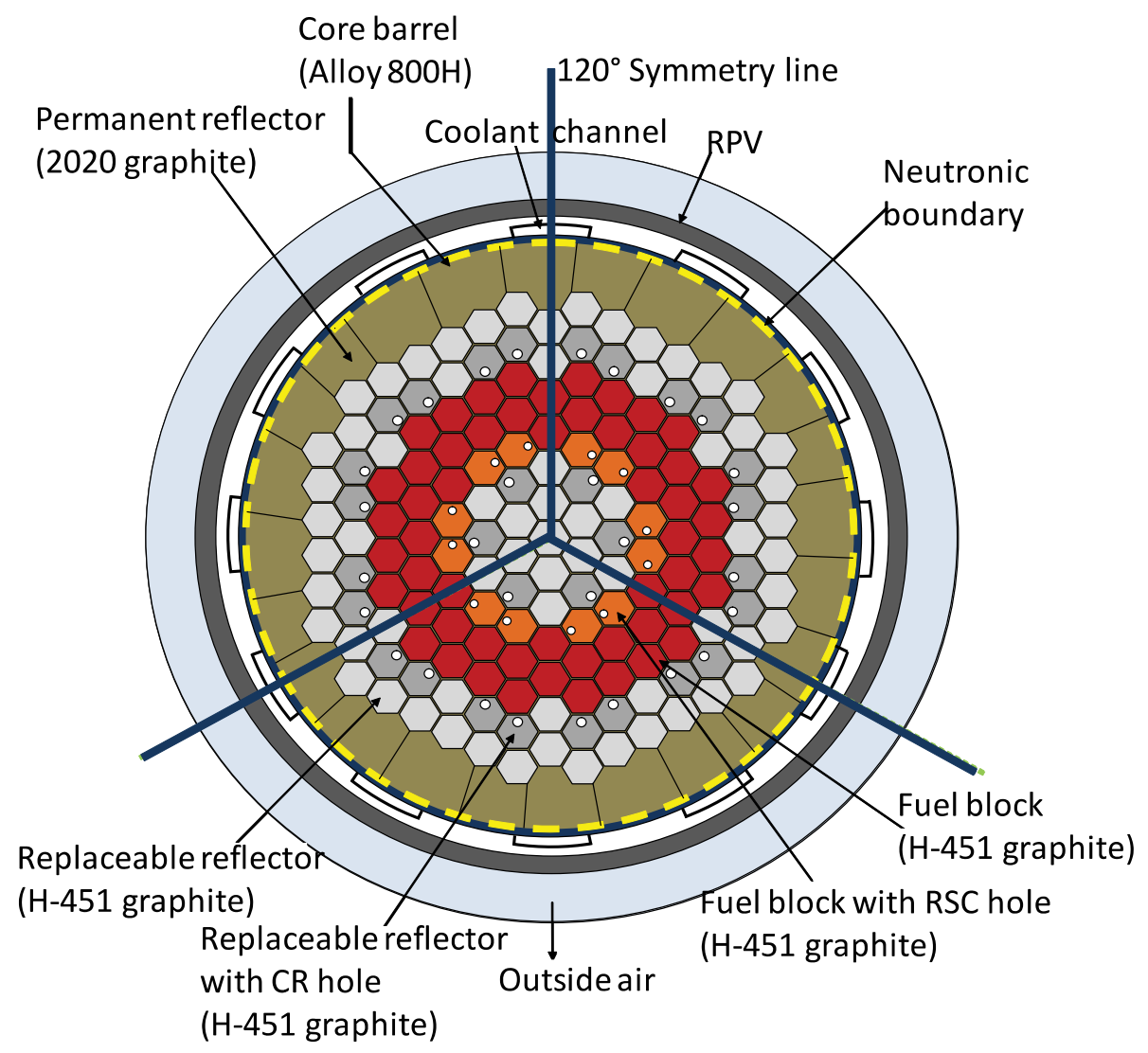

Figure 1. MHTGR-350 core radial layout [5].

Table 1. MHTGR-350 main characteristics [5].

\begin{tabular}{|l|l|l|}
\hline \multicolumn{1}{|c|}{ Core Parameter } & \multicolumn{1}{c|}{ Value } & \multicolumn{1}{c|}{ Unit } \\
\hline Thermal Power & 350 & $\mathrm{MW}($ thermal) \\
\hline Core Power Density & 5.93 & $\mathrm{MW} / \mathrm{m}^{3}$ \\
\hline Number of Fuel Columns & 66 & \\
\hline Effective Inner Diameter of Active Core & 1.65 & $\mathrm{~m}$ \\
\hline Effective Outer Diameter of Active Core & 3.5 & $\mathrm{~m}$ \\
\hline Active Core Height & 7.93 & $\mathrm{~m}$ \\
\hline Number of Fuel Elements (Standard/Reserve Shutdown Control [RSC]) & $540 / 120$ & \\
\hline Number of Control Rods (Inner/Outer) & $6 / 24$ & \\
\hline He Inlet Temperature & 259.0 & ${ }^{\circ} \mathrm{C}$ \\
\hline He Outlet Temperature & $\sim 687.0$ & ${ }^{\circ} \mathrm{C}$ \\
\hline Total Inlet Mass Flow Rate & 157.1 & $\mathrm{~kg} / \mathrm{s}$ \\
\hline Outlet Pressure & 6.39 & $\mathrm{MPa}$ \\
\hline
\end{tabular}




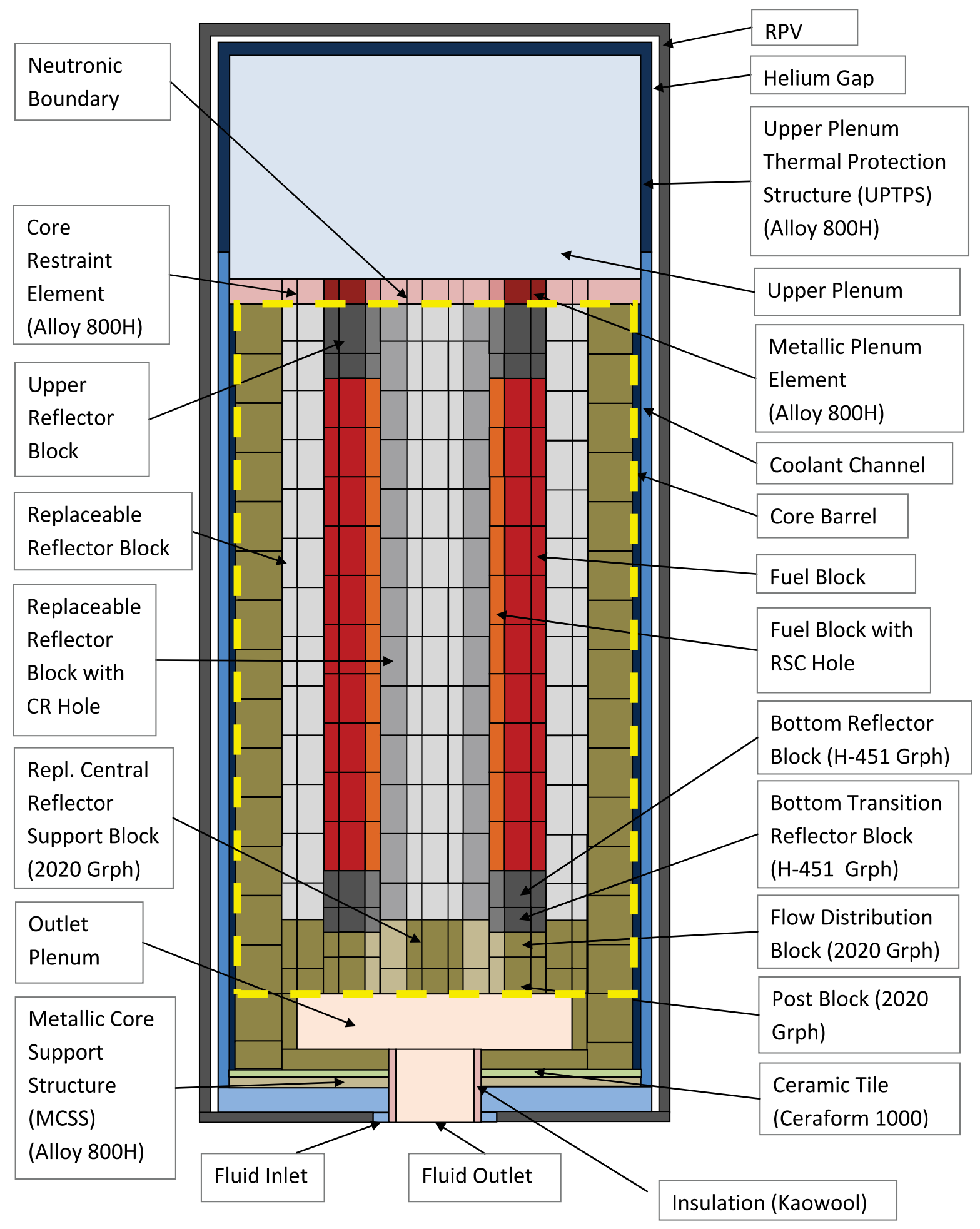

Figure 2. MHTGR-350 core axial layout [5]. 


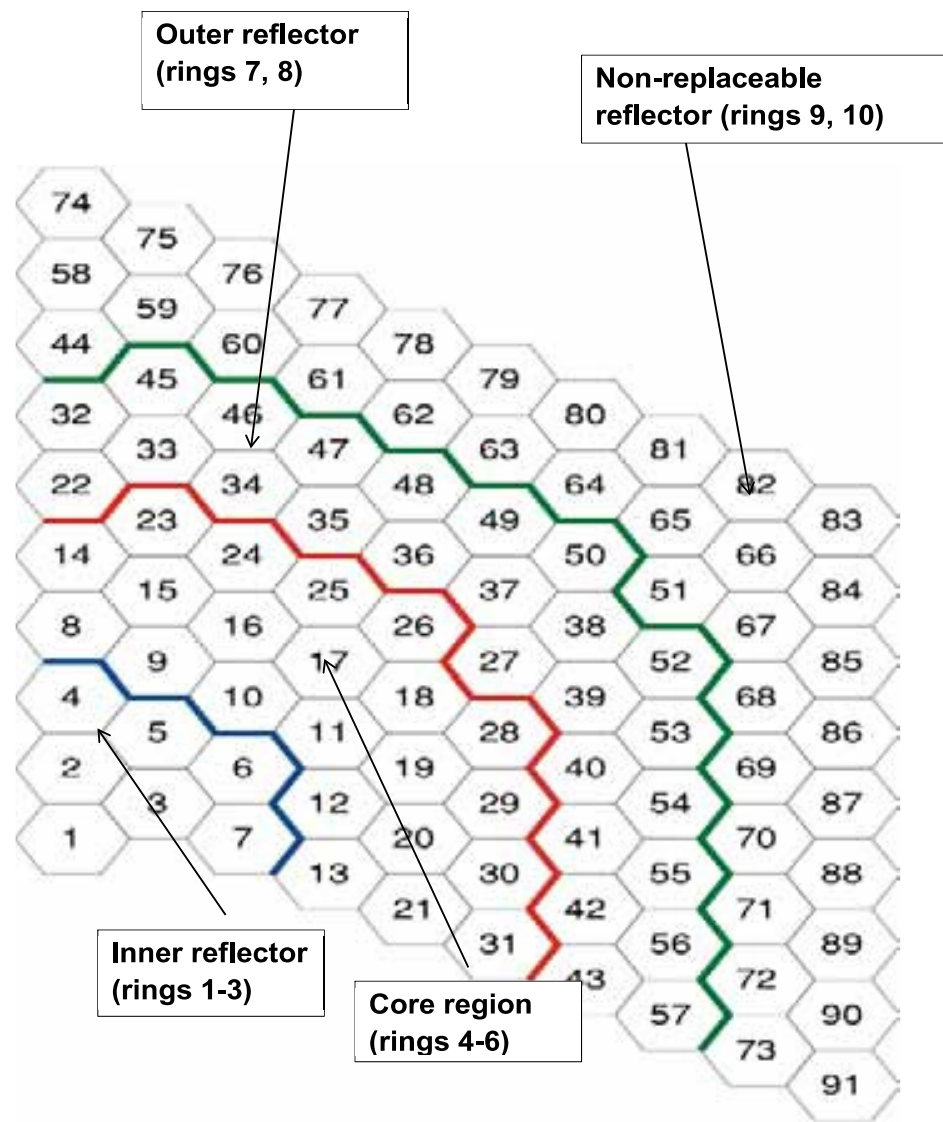

Figure 3. "Whole Core" numbering layout (axial layer 1).

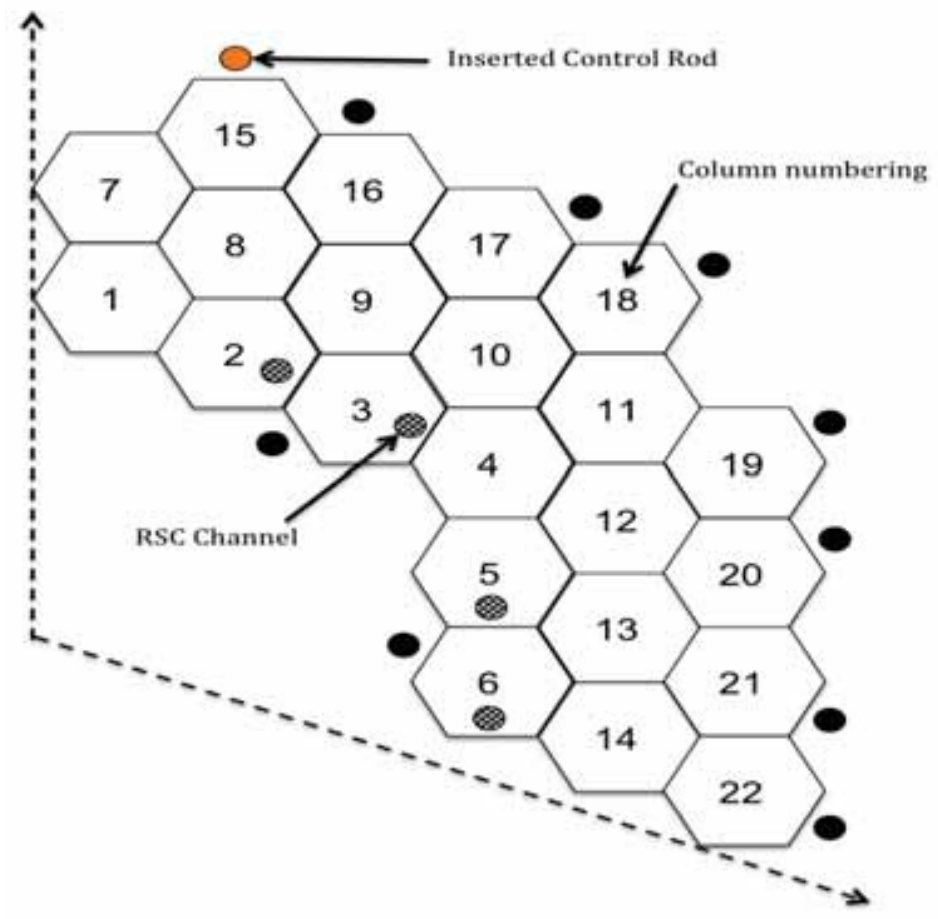

Figure 4. "Active Core" numbering layout (axial layer 1). 


\section{PHISICS/RELAP-5 3D CODE AND MODEL DESCRIPTIONS}

This section provides an overview of the PHISICS/RELAP5-3D code suite utilized for Exercises 1-3 of this benchmark by the VHTR TDO Methods Core Simulation group, as well as a discussion of the models developed and major assumptions that were made.

\subsection{PHISICS and RELAP5-3D}

\subsubsection{The Coupling of RELAP5-3D and PHISICS}

The simulation of complex phenomena for advanced reactors such as Generation IV systems poses a challenge to existing thermal fluid system codes like RELAP5-3D [14]. (Note that the term thermal fluid is preferred in the context of helium cooled gas reactors, where the use of the water-based "hydraulic" term does not apply). For the analysis of the MHTGR-350 design more advanced neutronic capabilities are required compared to the available NESTLE neutronics package in RELAP5-3D, since the benchmark specifies the use of 26 energy groups (NESTLE is limited to four groups). The RELAP5-3D code was developed for best-estimate transient simulation of LWRs. The code is able to model coupled behavior of the reactor core and the secondary system of the power plant. Applications of the code include simulations of transients such as loss of coolant, anticipated transients without scram, and operational transients such as loss of feed water, etc.

The multi-dimensional neutron kinetics model in RELAP5-3D is based on the NESTLE code [17], which solves the two or four group neutron diffusion equations in either Cartesian or hexagonal geometry using the nodal expansion method. A diffusion solution of the flux in 4 energy groups may not be sufficient to get an accurate representation of the power distribution for the MHTGR. In addition, linear cross-section feedbacks on thermal hydraulic state parameters (such as fuel/moderator temperature) as supported by NESTLE/RELAP5-3D are not detailed enough to capture the complex MTHGR crosssection behavior.

PHISICS (Parallel and Highly Innovative Simulation for INL Code System) is a neutronics code system being developed at INL [18]. The different modules for PHISICS are a nodal and semi-structured spherical harmonics based transport core solver (INSTANT [19]) for steady-state and time-dependent problems, a depletion module (MRTAU) and a cross-section mixer-interpolator (MIXER) module. This package provides the functionality to cope with the neutronic challenges of the MHTGR design on core simulation level, and it follows a modular approach to simplify development and long term maintenance of the code. Each different module of PHISICS contains a kernel (module) that solves a basic problem. A local driver is assigned to each kernel which is able to run it in standalone mode. Communication between the kernels is managed by the use of global data types that hold global information (cross-section data, mesh, fluxes, etc.) that are needed by more than one kernel to perform complex calculations involving different kernels. Global drivers solving a complex problem calling different kernels can be developed easily with this flexible software structure. Table 2 shows a comparison of the NESTLE/RELAP5-3D and PHISICS/RELAP5-3D capabilities at this point in the development cycle. Possible further extensions to the code suit include the stochastic or a non-Generalized Perturbation Theory (GPT) treatment of uncertainties, as well as refinements to the time-dependent solution scheme. 
Table 2. Comparison of NESTLE and current PHISICS capabilites [21].

\begin{tabular}{|l|c|c|}
\hline \multicolumn{1}{|c|}{ Feature } & NESTLE/RELAP5-3D & PHISICS/RELAP5-3D \\
\hline Energy Groups & 2 or 4 & $\begin{array}{l}\text { Limited only by available } \\
\text { memory resources }\end{array}$ \\
\hline Diffusion & Yes & Yes \\
\hline Transport & No & Yes \\
\hline Triangular Mesh & No & Yes \\
\hline Unstructured Mesh & No & Yes \\
\hline Adjoint Solution & No & Yes \\
\hline Depletion & No & Yes \\
\hline $\begin{array}{l}\text { Multi-Dimensional Cross-Section } \\
\text { Tables }\end{array}$ & No & Yes \\
\hline Multiprocessor & No & Pes \\
\hline
\end{tabular}

The transport core solver INSTANT [19] (Intelligent Nodal and Semi-structured Treatment for Advanced Neutron Transport) is the most developed kernel of the PHISICS framework. INSTANT is parallelized and is designed to take full advantage of medium to large clusters (10 to 1000 processors). INSTANT is based on the second order formulation of the transport equation discretized in angle by spherical harmonics while in space it uses orthonormal polynomials of an arbitrary order [20]. In order to be able to solve transient problems, a time dependent scheme has recently been implemented as a new module for the PHISICS suite, based on a second order backward Euler scheme with explicit delayed neutron treatment ([21], [22]).

Multi-Reactor Transmutation Analysis Utility (MRTAU) is a generic depletion code developed at INL [23]. The code tracks the time evolution of the isotopic concentration of a given material accounting for nuclear reaction happening in presence of neutron flux and also due to natural decay (Bateman equation). MRTAU utilizes a Taylor series expansion based algorithm of arbitrary order and the Chebyshev Rational Approximation Method for computation of the exponential matrix [24]. A criticality search option is also available, where the boron concentration is for example changed in a region to simulate CR movement.

The MIXER module performs all the cross-section handling for the different kernels. This module can treat macroscopic, microscopic and "mixed" cross-sections. A macroscopic cross-section library can typically contain macroscopic cross-sections for each type of material used in the calculation (fuel, reflector, etc.) tabulated for the state parameters (temperature, burn-up, CR position, etc.). The MIXER then interpolates these cross-sections at the requested state parameters. No limits in tabulation dimensions or neutron energy groups exist, apart from available memory resources on the computational platform. A microscopic or "mixed" cross-section library contains the tabulated cross-sections for each isotope considered in the calculation. It is also possible to provide the macroscopic absorption cross-sections without xenon for a material and the microscopic xenon absorption cross-section together with a xenon density. The mixer will calculate the xenon contribution for the absorption and add it to the macroscopic cross-section. The MIXER module can read cross-section data in the ampx and isotxs library formats, or a simple XML structure can be used if cross-sections are available in text format from any source.

During the development planning of the coupling of PHISICS to RELAP5-3D, it was decided to couple the different modules of PHISICS directly to RELAP5-3D, i.e., PHISICS is integrated with RELAP5-3D as a set of subroutines. This gives the user access to the full capability of PHISICS from within RELAP5-3D. The PHISICS part of coupled calculations can be parallelized on multiple processors (the RELAP5-3D part still only runs on a single processor). The calculation is controlled by RELAP5-3D, i.e., the RELAP5-3D input reader determines if modules of PHISICS are needed and calls the 
PHISICS/RELAP5-3D driver accordingly. The driver collects the available input data from RELAP5-3D (geometry, calculation options) and adds, if needed, data from PHISICS.xml input files to complete the required calculation. Once all the inputs are collected, the PHISICS/RELAP5-3D driver calls the required modules like INSTANT, MRTAU, or the MIXER and feeds back the power distribution to RELAP5-3D for the next iteration. The general input data flows between two packages are shown in Figure 5.

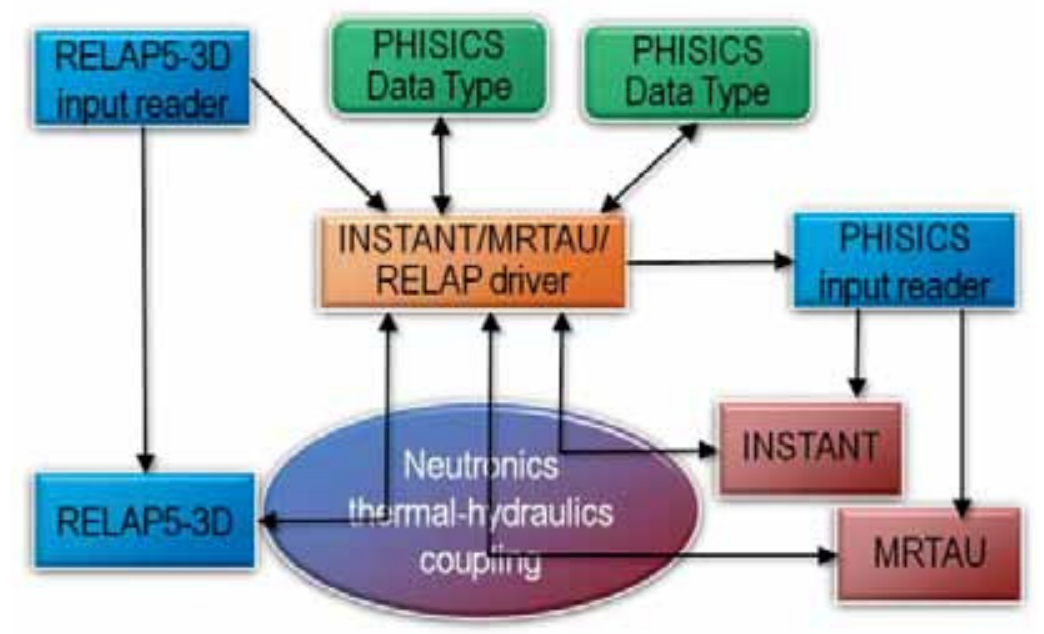

Figure 5. PHISICS/RELAP5-3D coupling structure [25].

This "direct" coupling allows the user to run existing RELAP5-3D input decks with INSTANT as the core solver (this option is made accessible from within RELAP5-3D through the new keyword "instant"). The coupling is compatible with the existing RELAP5-3D cross-section and feedback options. Existing cross-section inputs, mappings from kinetic nodes to thermal hydraulic zones and the CR model can be used with the INSTANT option. In addition, the coupling supports a new cross-section option which lifts the RELAP5-3D limitation of four energy groups. Multigroup cross-sections for this new option support an unlimited number of tabulation dimensions (fuel temperature, moderator temperature, CR position, xenon density, etc.) and an unlimited number of tabulation points per dimension.

The depletion code MRTAU is also coupled to RELAP5-3D as part of the PHISICS suite. It can be used to perform core depletion calculations with coupled thermal hydraulic feedbacks. In addition, MRTAU is able to burn the core to a desired depletion level, or to perform cooling (decay), before a transient is initiated. MRTAU can also be used for decay heat calculation and poison tracking during transients. Several possible calculation paths can be obtained by combining INSTANT, MRTAU and RELAP5-3D. The calculation paths utilized so far in a variety of calculations are presented in more detail in [21], and a summary of the calculation path used for Phase I of the OECD/NEA MHTGR-350 MW benchmark can be found in [25].

\subsubsection{Overview of the PHISICS/RELAP5-3D Benchmark Model}

The RELAP5-3D primary system radial representation is shown in Figure 6 (the benchmark does not require the modeling of the secondary system). The inner reflector, core region, and outer reflector are modeled as nine rings in cylindrical coordinates, with three additional rings representing the core barrel (CB), reactor pressure vessel (RPV) and outer air boundary layer. The RELAP5-3D coarse mesh axial discretization is indicated in Table 3 - further axial refinements are performed within each of these axial meshes. 


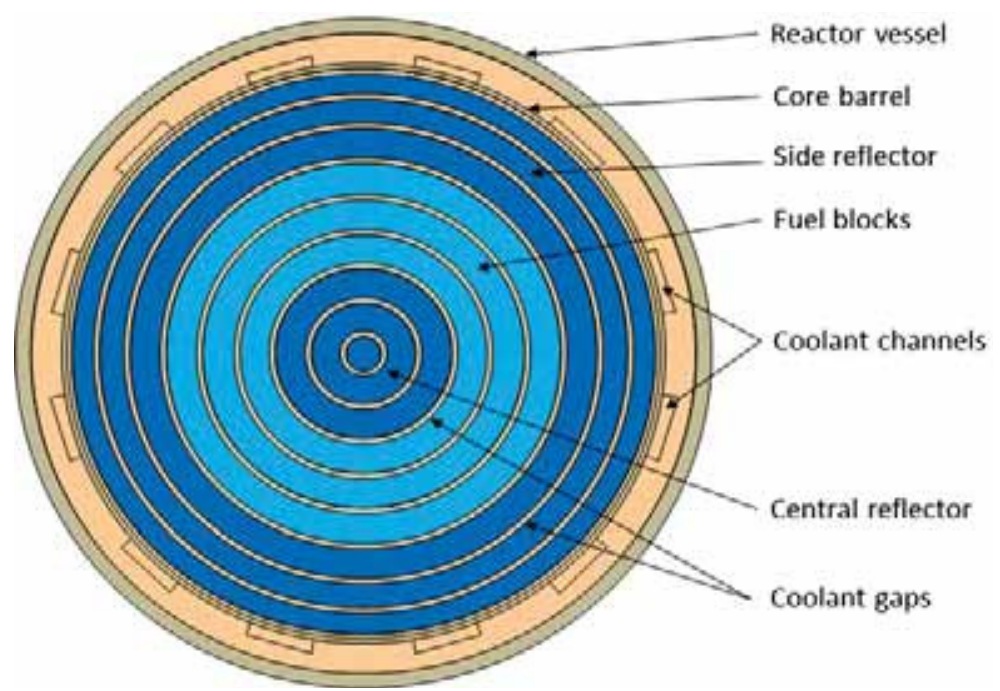

Figure 6. RELAP5-3D MHTGR-350 MW "ring" model radial representation.

Table 3. Thermal fluids axial reporting mesh.

\begin{tabular}{|c|c|c|l|}
\hline $\begin{array}{c}\text { Absolute } \\
\text { location (cm) }\end{array}$ & $\begin{array}{c}\text { Height } \\
\text { (cm) }\end{array}$ & Layer & \multicolumn{1}{|c|}{ Description } \\
\hline 293 & 99 & 1 & Bottom Reflector \\
\hline 392 & 99 & 2 & Bottom Reflector \\
\hline 471 & 79 & 3 & Active Core \\
\hline 550 & 79 & 4 & Active Core \\
\hline 630 & 79 & 5 & Active Core \\
\hline 709 & 79 & 6 & Active Core \\
\hline 788 & 79 & 7 & Active Core \\
\hline 868 & 79 & 8 & Active Core \\
\hline 947 & 79 & 9 & Active Core \\
\hline 1026 & 79 & 10 & Active Core \\
\hline 1106 & 79 & 11 & Active Core \\
\hline 1185 & 79 & 12 & Active Core \\
\hline 1224 & 40 & 13 & Top Reflector \\
\hline 1304 & 79 & 14 & Top Reflector \\
\hline 1343 & 40 & 15 & Core Restraint Element \\
\hline 1618 & 274 & 16 & Upper Plenum \\
\hline 1664 & 47 & 17 & $\begin{array}{l}\text { Upper Plenum Thermal } \\
\text { Protection System }\end{array}$ \\
\hline 1732 & 68 & 18 & Helium Gap \\
\hline 1746 & 13 & 19 & $\begin{array}{l}\text { Reactor Vessel Top } \\
\text { Plate }\end{array}$ \\
\hline
\end{tabular}


The RELAP5-3D model nodalization is presented in Figure 7, with a description of the component numbering indicated in Table 4 . The time-dependent junction \#255 adjusts the inflow helium mass flow rate to obtain a target outlet helium temperature of $687^{\circ} \mathrm{C}$ through a control variable that combines the outlet pressure $(6.39 \mathrm{MPa})$, inlet helium temperature $\left(259^{\circ} \mathrm{C}\right)$ and the total thermal power $(350 \mathrm{MW})$ boundary conditions.

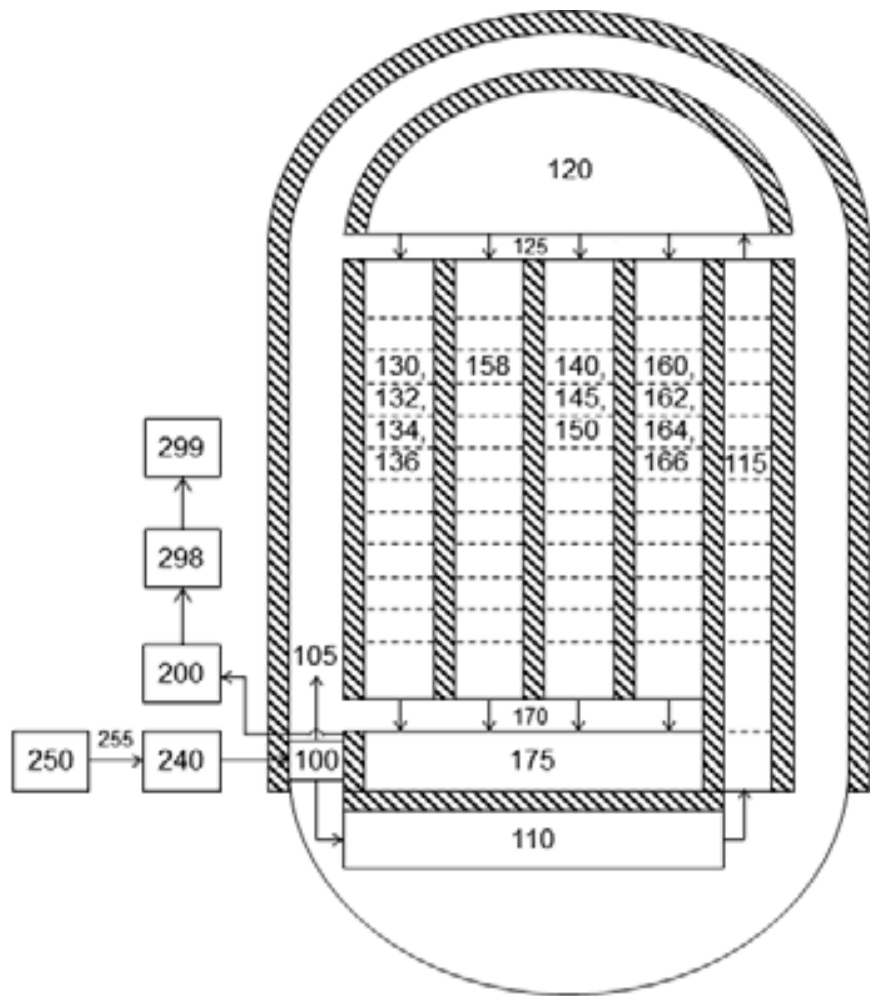

Figure 7. RELAP5-3D reactor vessel model nodalization.

Table 4. Description of component types and numbering.

\begin{tabular}{|l|l|}
\hline \multicolumn{1}{|c|}{ Component \# } & \multicolumn{1}{c|}{ Component Type and Description } \\
\hline 250 & Time dependent volume: inlet \\
\hline 255 & Time dependent junction: inlet mass flow rate adjustment \\
\hline 240 & Pipe: cold inlet duct \\
\hline $100,110,120,175$ & $\begin{array}{l}\text { Branches: to vessel gap (\#105), bottom core support (\#110), top inlet (\#120) and } \\
\text { bottom outlet (\#175) volumes }\end{array}$ \\
\hline 115 & Pipe: coolant riser channels in permanent side reflector \\
\hline 125,170 & Multiple junctions: core inlet and outlet for core and bypass flow pipe connections \\
\hline $130-136,158,160-166$ & Pipes: bypass flows in inner reflector, core and outer reflectors \\
\hline $140,145,150$ & Pipes: inner, center and outer ring core flows \\
\hline 200 & Pipe: hot outlet duct \\
\hline 298 & Single junction: flow outlet \\
\hline 299 & Time-dependent volume: outlet \\
\hline
\end{tabular}


The radii of rings are calculated to represent the correct graphite volumes in each of the structures, and it includes corrections for the $2 \mathrm{~mm}$ gaps between the reflector blocks and the $3 \mathrm{~mm}$ gap between the outer reflector and the metallic CB. A total of seven core bypass flow channels through these gaps are included in the benchmark specification (see Section 5.2), and these are included in the RELAP5-3D model as part of the 1-D hydrodynamics flow network. A sub-channel "unit-cell" approach is utilized for the three fuel rings to distinguish better between the fuel and moderator temperatures. The cylindrical unit cell consists of a fuel compact, its surrounding matrix graphite and a helium coolant channel (Figure 8). At this stage detailed results for the TRISO structure within a fuel compact is not available yet in the RELAP5-3D model, but preliminary investigations have been performed using an additional heat structure to represent the layers within the TRISO kernels.

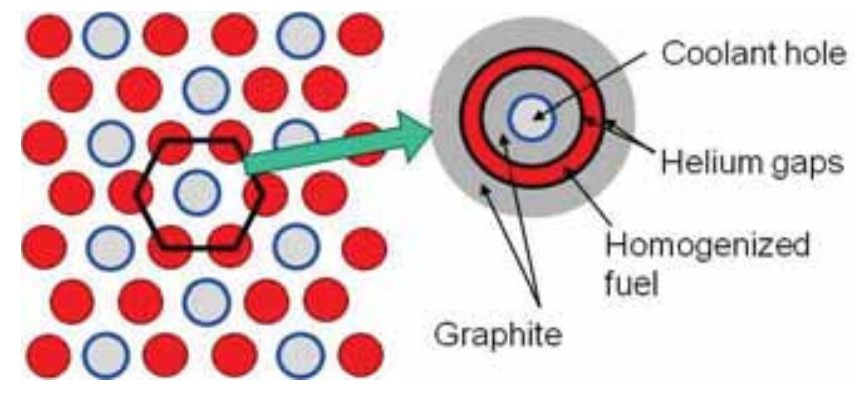

Figure 8. Unit-cell configuration.

The homogenized unit cell can be utilized in two spatial representations of the core geometry; the traditional "ring" model described above, or a much more detailed "block" model. In the block model, a hexagonal block can be explicitly represented by dividing it into six triangular elements, as shown in Figure 9. Each of the block faces can then be connected to a RELAP5-3D pipe element that provides the helium mass flow rates, velocities and temperatures along the axial height of the core. The corresponding triangular RELAP5-3D heat structure region connected to this pipe provides the heat source information in the case of the core fuel blocks. Heat transfer between the triangular elements occurs in two ways: internally via conduction, and externally via radiation across the 2-mm gap between the block faces. In the RELAP5-3D model, these connections (shown in Figure 9 as green and red lines, respectively) are defined as part of the conduction and radiation enclosure sets. This "block" model can therefore provide a much more detailed temperature distribution compared to the smeared-out ring model shown in Figure 6. In the case of the first fuel ring, for example, Blocks 8-13 in Figure 3 can now be represented with $6 * 6=36$ triangular elements, which provides 36 data points compared to only one value for the ring model (per axial layer). 


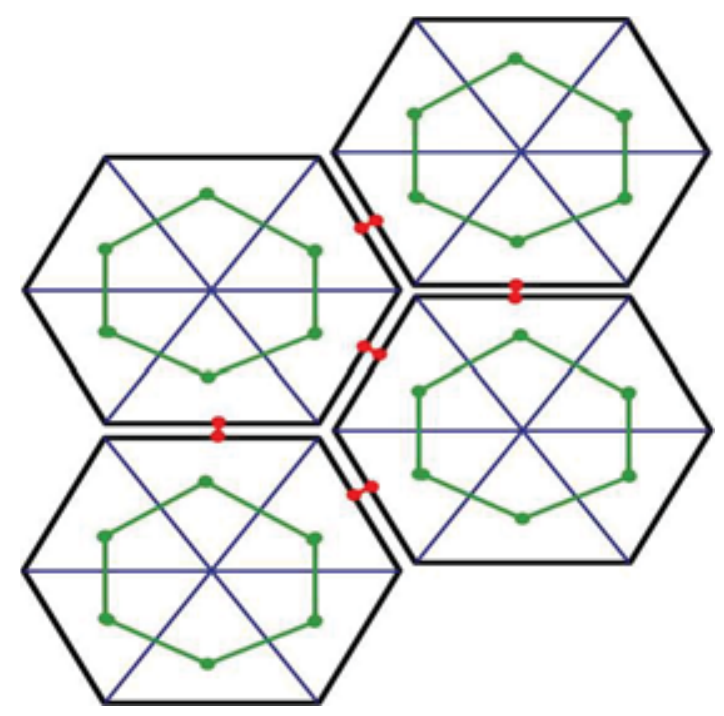

Figure 9. Conduction and radiation connections within the core region.

Exchange of data in RELAP5-3D is defined between the fluid, solid and neutronics/kinetics parameters using hydrodynamic components, heat structures, and kinetic feedback zones, respectively. There is however a limit on the number of these data types that the code can process. A further restriction also requires that the left or right side of a heat structure can only be included in one type of enclosure, i.e., the left side of a triangular region cannot be connected to a conduction and radiation enclosure simultaneously. It was therefore decided to focus the RELAP5-3D triangular sub-division on the important regions of the active core region (Rings 4-6) and the two reflector rings next to the core (Rings 3 and 7). The RELAP5-3D block model (Figure 10) therefore consists of "smeared-out" representation in Rings 1 and 2 (Blocks 1-3) and 8-10 (Blocks 44-91), and a detailed triangular resolution in Rings 3-7 (Blocks 8-43). 


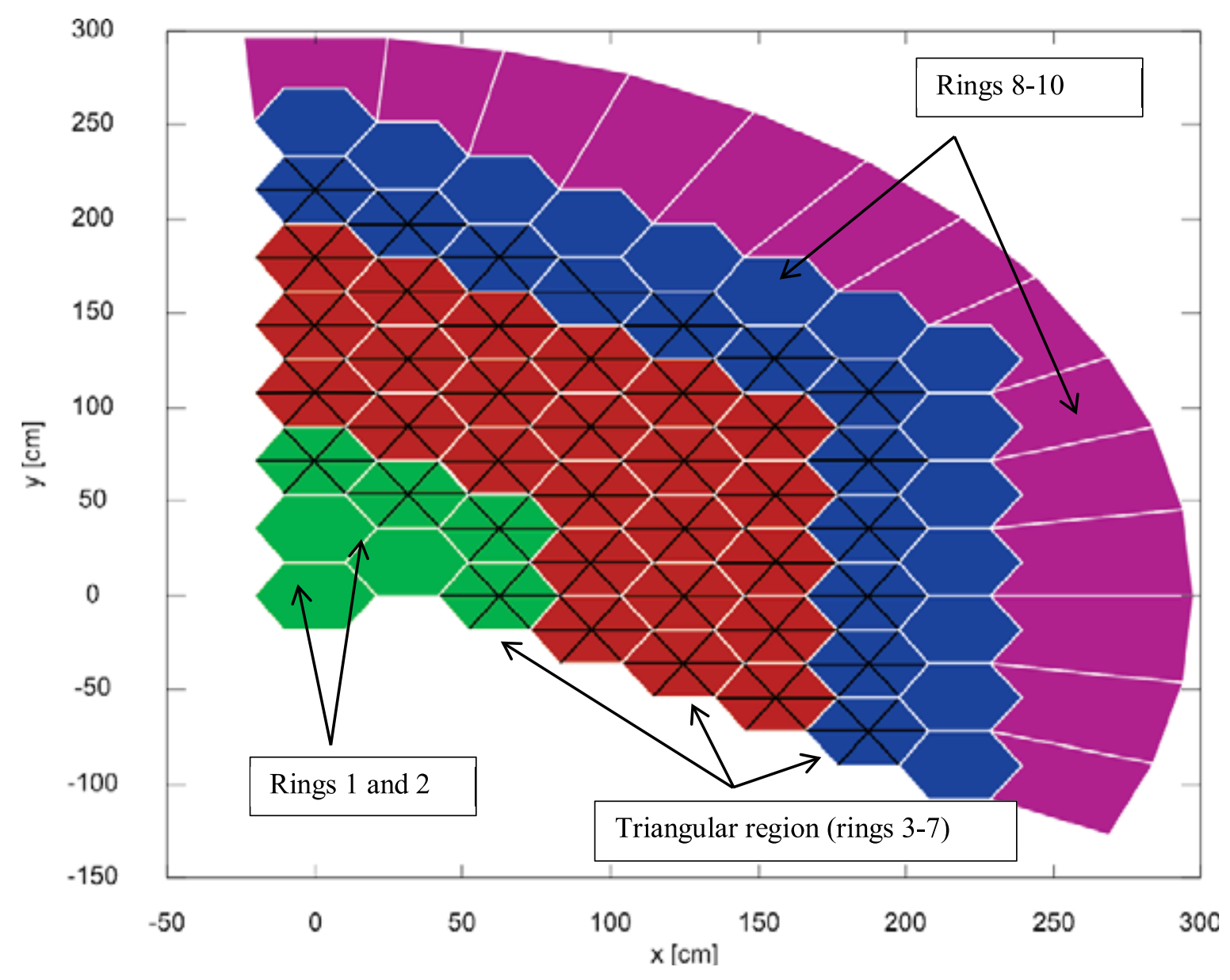

Figure 10. Ring and triangular geometry utilized in the RELAP5-3D model.

For the kinetic zone coupling between INSTANT and RELAP5-3D it was initially envisaged to couple the triangular feedback elements on a one-to-one basis, i.e., one triangular node in RELAP5-3D would provide temperature data to a triangular node in INSTANT, which would then pass back the triangular power distribution to RELAP5-3D for the next iteration. Since the modeling of the full MHTGR-350 core graphite structures in a triangular geometry requires 7,644 kinetic nodes (91 blocks on 14 layers with six triangles each), a full core triangular model was not an option due the limitations in the number of kinetic zones available in RELAP5-3D. (There are in fact 7,644*2=15,288 nodes required if the both the fuel and moderator temperature are to be resolved separately). On the neutronics side of the coupling, INSTANT therefore uses a hexagonal mesh for the neutronics solution corresponding to a fuel or reflector block. The mapping of feedback parameters between RELAP5-3D and INSTANT is summarized for the ring and block models in Table 5.

The 26 energy group cross-section library is read as separate data structures, and updates are performed on these base cross-section sets during the steady-state convergence process in the MIXER module of PHISICS. The four-dimensional cross-section tables (contained in the lib.xml file) are designed to cover the initial steady-state conditions and the expected ranges of the four selected instantaneous feedback parameters in the transients to be simulated in the benchmark. The set was generated from the DRAGON 4 lattice code using the end of equilibrium core number densities with 26 energy groups. The following values were selected: 
- $\quad$ Fuel temperature (Doppler temperature): 293K, 800K, 1400K, 2000K

- Moderator temperature: 293K, 600K, 800K, 1000K, 1200K, 1600K, 2000K

- Xenon-135 concentrations expressed as homogenized concentrations: 0.0, 2.0E-11, 5.0E-10 [\#/barn-cm]

- Hydrogen-1 concentration: 0.0, 3.0E-4, 7.5E-4 of the H-1 inventory in the core void volumes [\#/barn-cm].

Table 5. Summary of RELAP5-3D and INSTANT feedback mapping

\begin{tabular}{|l|c|l|l|}
\hline Ring \# & $\begin{array}{c}\text { INSTANT power } \\
\text { representation }\end{array}$ & \multicolumn{1}{|c|}{$\begin{array}{c}\text { RELAP5-3D temperature } \\
\text { representation }\end{array}$} & \multicolumn{1}{c|}{ Kinetics mapping } \\
\hline 1,2 & Blocks & Rings & $\begin{array}{l}\text { Ring graphite temperatures to INSTANT. No } \\
\text { power generated in reflectors. }\end{array}$ \\
\hline $3-7$ & Blocks & $\begin{array}{l}\text { Rings (ring model) } \\
\text { Triangles (block model) }\end{array}$ & $\begin{array}{l}\text { 1. Ring model: moderator and fuel } \\
\text { temperatures to INSTANT blocks. Power } \\
\text { density to RELAP5-3D rings. } \\
\text { Block model: moderator and fuel } \\
\text { temperatures to INSTANT blocks. Power } \\
\text { density to RELAP5-3D triangles. }\end{array}$ \\
\hline $8-10$ & Blocks & Rings & $\begin{array}{l}\text { Ring graphite temperatures to INSTANT. No } \\
\text { power generated in reflectors. }\end{array}$ \\
\hline
\end{tabular}

In addition to the internal conduction in the triangular elements and the radiation heat transfer between block faces, a number of conduction and radiation sets are included in the model to account for radial conduction and axial radiation between the graphite structures in the inner, outer, top and bottom reflectors. Radial radiation heat transfer is also modeled between the outer reflector surface and the CB, and from the outer surface of the reactor vessel to the boundary air layer, as shown in Figure 11.

Adiabatic boundary conditions are applied at the top and bottom model boundaries, and the outer radial air layer is defined to be at a constant temperature of $30^{\circ} \mathrm{C}$. 


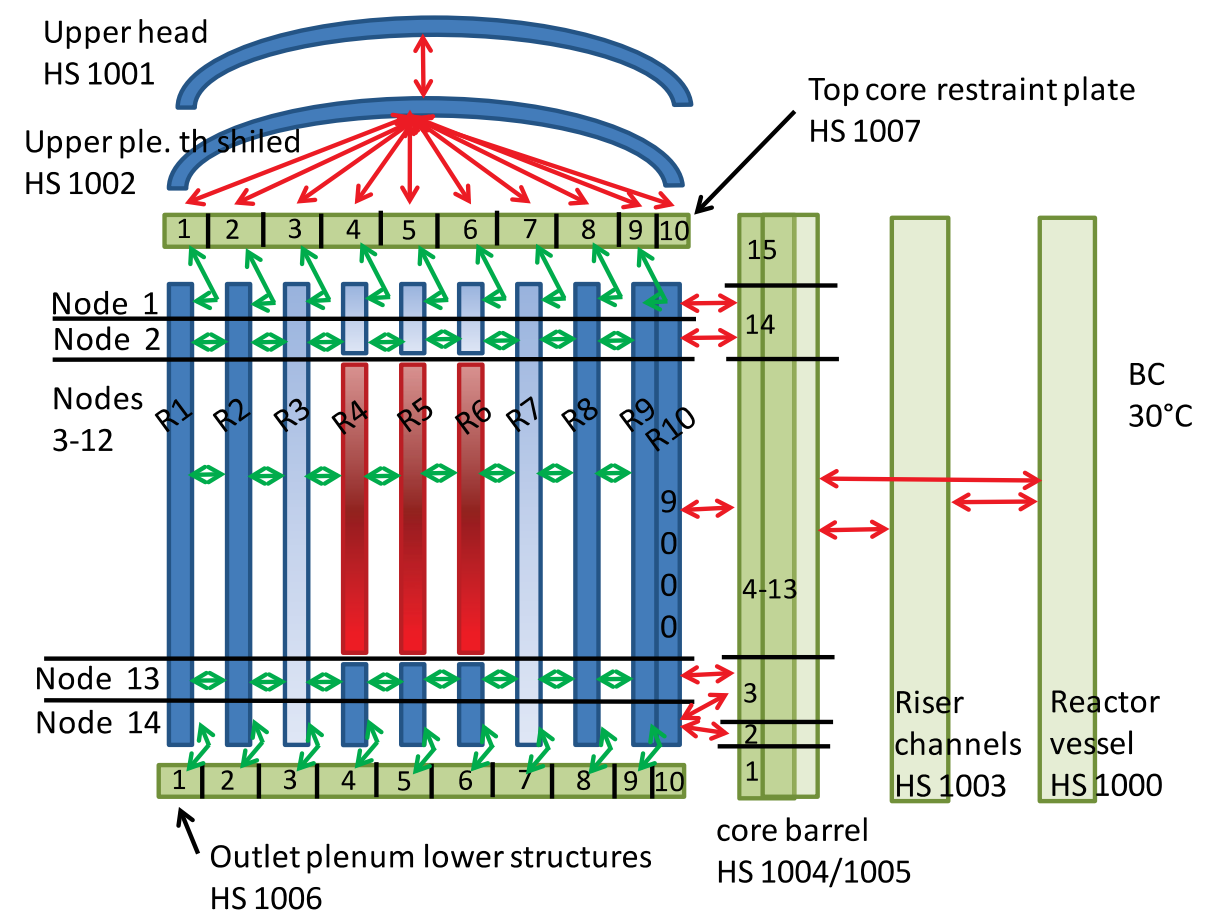

Figure 11. Conduction and radiation enclosures in the RELAP5-3D model.

The increase in model resolution and the subsequent higher fidelity temperature and power data sets require a significant penalty in terms of model simulation time and size. A comparison of the two PHISICS/RELAP5-3D models is presented in Table 6, which shows that the run time of a typical converged RELAP5-3D steady-state solution increased by a factor of 50 for the standalone thermal fluids Exercise 2, and a factor of 1.9 for the coupled neutronics Exercise 3. This run time includes the use of 28 processors in parallel for Exercise 3, compared to a single processor for Exercise 2.

Table 6. Comparison of the PHISICS/RELAP5-3D ring and block model metrics

\begin{tabular}{|l|l|l|}
\hline \multicolumn{1}{|c|}{ Description } & \multicolumn{1}{|c|}{ Ring Model } & \multicolumn{1}{c|}{ Block Model } \\
\hline Hydrodynamic components & $\sim 20$ & 251 \\
\hline Heat structures & 20 & $\sim 1,100$ \\
\hline Materials & 9 (constant properties) & $\begin{array}{l}\sim 100 \text { (temperature and fluence } \\
\text { dependent) }\end{array}$ \\
\hline Kinetic feedback zones & 170 & $\sim 4,700$ \\
\hline $\begin{array}{l}\text { Radiation and conduction } \\
\text { enclosures }\end{array}$ & 17 enclosures with 350 surfaces & 88 enclosures with $>7,000$ surfaces \\
\hline $\begin{array}{l}\text { Decay heat treatment } \\
\text { Input file size (\# of lines) }\end{array}$ & $\begin{array}{l}\text { table (global core power vs. } \\
\text { time) }\end{array}$ & $\begin{array}{l}220 \text { tables (individual core block } \\
\text { power vs. time) }\end{array}$ \\
\hline $\begin{array}{l}\text { Real time required for converged } \\
\text { steady-state (hours) }\end{array}$ & $\begin{array}{l}\text { Exercise 2 (RELAP5-3D only): 0.1 } \\
\text { Exercise 3 } \\
\text { (PHISICS/RELAP5-3D): 11 }\end{array}$ & $\begin{array}{l}\text { Exercise 2 (RELAP5-3D only): 5 } \\
\text { Exercise 3 (PHISICS/RELAP5-3D): } \\
\text { 20 }\end{array}$ \\
\hline
\end{tabular}




\section{PHASE I: EXERCISE 1}

\subsection{Description of the Exercise}

Exercise 1 of Phase I is a neutronics-only steady-state simulation of the MTHGR core. Different macroscopic cross-sections for each of the 22 fuel assemblies on each of the 10 core axial levels are provided in 26 groups as part of the benchmark specifications. In addition, reflector cross-section sets are provided together with a load map for the core. The library distributed to the benchmark participants contains the cross-section data generated with the DRAGON 4 lattice code.

\subsection{Pronghorn and RattleS $\mathrm{n}_{\mathrm{n}}$ ake}

In the past two years various neutronics capabilities within the MOOSE framework have been added into the MOOSE neutronics kernel library Yak. The neutron diffusion models initially developed for Pronghorn have been either rendered obsolete or incorporated into Yak. In addition, the meshing capabilities developed for the prismatic reactor in Pronghorn have also been migrated into Yak. The main idea behind this move is the unification of the neutronics kernels and tools into a common library. This allows all MOOSE-based applications to benefit from the tools being developed by other teams at INL. Rattle $\mathrm{S}_{\mathrm{n}}$ ake has become the primary tool for solving the linearized Boltzmann neutron transport equation within MOOSE and relies heavily on the use of Yak. There are a variety of solvers available under RattleS $_{\mathrm{n}}$ ake including low-order multigroup diffusion, spherical harmonics $(\mathrm{Pn})$ transport, and discrete ordinates (Sn) transport all solved over either a continuous and discontinuous finite element mesh (FEM). Rattle $\mathrm{S}_{\mathrm{n}}$ ake will be used as the primary neutronics solver for MOOSE based tools in this benchmark. Pronghorn will remain as the thermal fluids solver for high temperature reactors.

As both Rattle $\mathrm{S}_{\mathrm{n}}$ ake and the diffusion solver originally developed for Pronghorn were developed on the MOOSE platform, they employ the Yak kernel library and produce the same exact results when the continuous FEM multigroup diffusion option is chosen in Rattle $_{n}$ ake. The main differences arise from in the post-processing capabilities that have been added to the Rattle $\mathrm{S}_{\mathrm{n}}$ ake solver, which ease the computation of reactor analysis metrics (axial offsets, pin powers, maximum power densities, etc.). The mesh shown in Figure 12 was built with the Yak prismatic tools. It consists of one-third core symmetric mesh with 30,294 base wedge elements. The permanent reflector is also represented with extruded wedge elements. A fine spatial discretization of the model is achieved by using one level of refinement and a second order LaGrange representation of the 26 primary flux variables. With the finite element discretization these settings produce a problem with 26,195,806 Degrees of Freedom (DoF). 


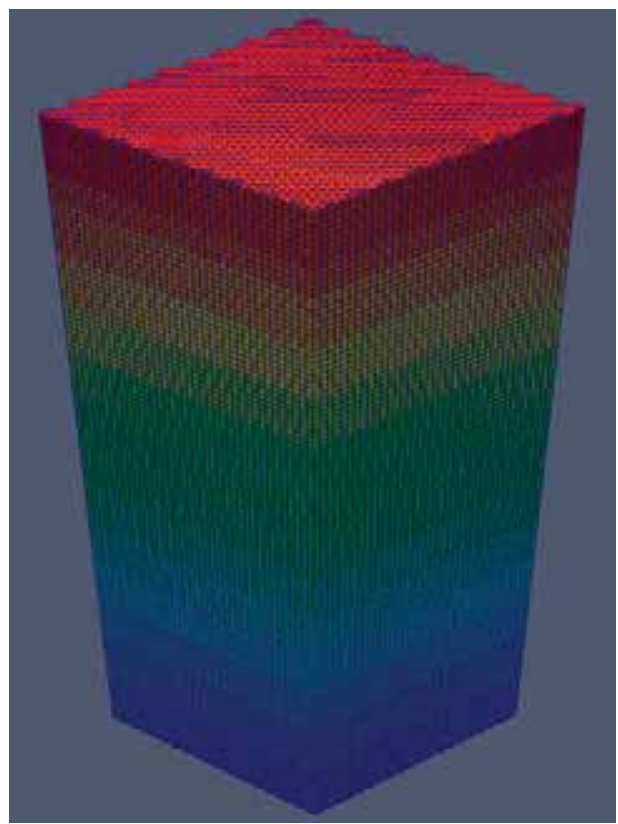

Figure 12. MHTGR-350 Exercise 1 Pronghorn and RattleS $\mathrm{n}_{\mathrm{n}}$ ake analysis mesh.

\subsubsection{Exercise I Results}

The global parameters requested in Exercise 1 are included in Table 7. Results from Rattle $S_{n}$ ake, INSTANT, and Pronghorn are provided for comparison. There is agreement (within $30 \mathrm{pcm}$ ) between the diffusion solutions (Rattle $\mathrm{S}_{\mathrm{n}}$ ake and Pronghorn) and the INSTANT $\mathrm{P}_{1}$ results for both the nominal eigenvalue and the $\mathrm{CR}$ worth calculations. Differences arise from the spatial discretization since the diffusion solutions use a finer mesh. The cross-sections used in INSTANT have been modified to return the diffusion solution.

According to the benchmark specification, the axial offset is defined as

$$
\mathrm{AO}=\left(\mathrm{TP}_{\text {top }}-\mathrm{TP}_{\text {bottom }}\right) /\left(\mathrm{TP}_{\text {top }}+\mathrm{TP}_{\text {bottom }}\right)
$$

where $\mathrm{TP}_{\text {top }}=$ total power produced in the top half of the core, and $\mathrm{TP}_{\text {bottom }}=$ total power produced in the bottom half of the core. The axial offset indicates that the core power distribution for this Exercise is top peaked with approximately $14-15 \%$ more power shifted above the midplane. The identical average power density computed confirms that both codes compute this value correctly.

Table 7. Comparison of global parameters for Exercise 1.

\begin{tabular}{|l|c|c|c|c|c|}
\hline \multicolumn{1}{|c|}{ Code } & $\mathrm{k}_{\mathrm{eff}}$ & $\begin{array}{c}\text { CR- worth } \\
{[\mathrm{pcm}]}\end{array}$ & $\begin{array}{c}\text { Axial } \\
\text { offset }\end{array}$ & $\begin{array}{c}\text { Avg. power } \\
\text { density } \\
{\left[\mathrm{MW} / \mathrm{m}^{3}\right]}\end{array}$ & $\begin{array}{c}\text { Max. power } \\
\text { density } \\
{\left[\mathrm{MW} / \mathrm{m}^{3}\right]}\end{array}$ \\
\hline RattleS $_{\mathrm{n}}$ ake (Diffusion) & 1.06671 & 1168 & 0.15 & 6.0 & 17.3 \\
\hline INSTANT ( $\left.\mathrm{P}_{\mathrm{N}}\right)$ & 1.06645 & 1140 & 0.14 & 6.0 & 17.5 \\
\hline Pronghorn (Diffusion) & 1.06671 & 1168 & - & - & - \\
\hline
\end{tabular}

The axial offset is better illustrated in Figure 13, which shows the radially averaged axial distribution of the power density for each core layer. (The layers are shown here for the active core region only, i.e., layers 3-12 in Table 3). Some small differences can be observed between the INSTANT and RattleS ${ }_{\mathrm{n}}$ ake 
results and are most likely due to the difference in axial refinement. The peak axial value is approximately $7.7 \mathrm{MW} / \mathrm{m}^{3}$.

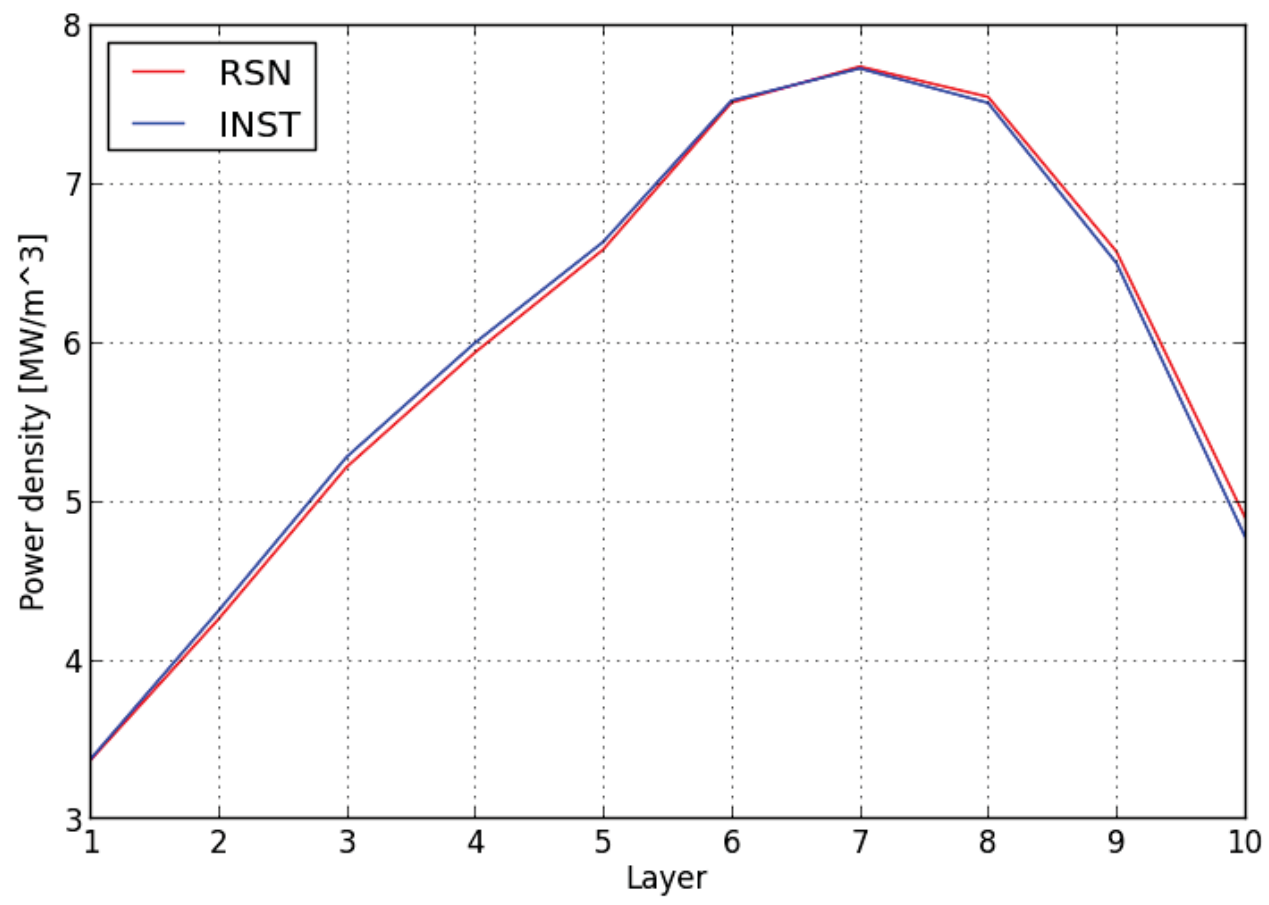

Figure 13. Axial distribution of the average power density at each active core layer.

Figure 14 includes three radial distributions of the scalar flux for fast Group 1 and thermal Groups 19 and 26. The fast energy group is peaked inside the active core region, since this is where the fuel resides and fast neutrons are born. These fast neutrons start slowing down in the active core and quickly diffuse into the reflector regions. The fast flux is slightly affected by the depression in the thermal flux that occurs near the CR to the left side of the domain, thus imposing a tilt in the power and the fast neutron source. The location of the CR becomes more apparent in the thermal group plots.

The flux distribution for Group 19 shows a flatter profile in the active core and replaceable reflector regions. The geometric configuration of the core, with a vacuum boundary at the periphery, generates a region with a large magnitude in the central reflector and one with lower magnitude in the permanent reflector. The last thermal Group 26 suffers a large depression in the active core, since these thermal neutrons are readily absorbed in the fuel. The effect of the CR is apparent in the plot with the largest flux depression away from the boundary. 


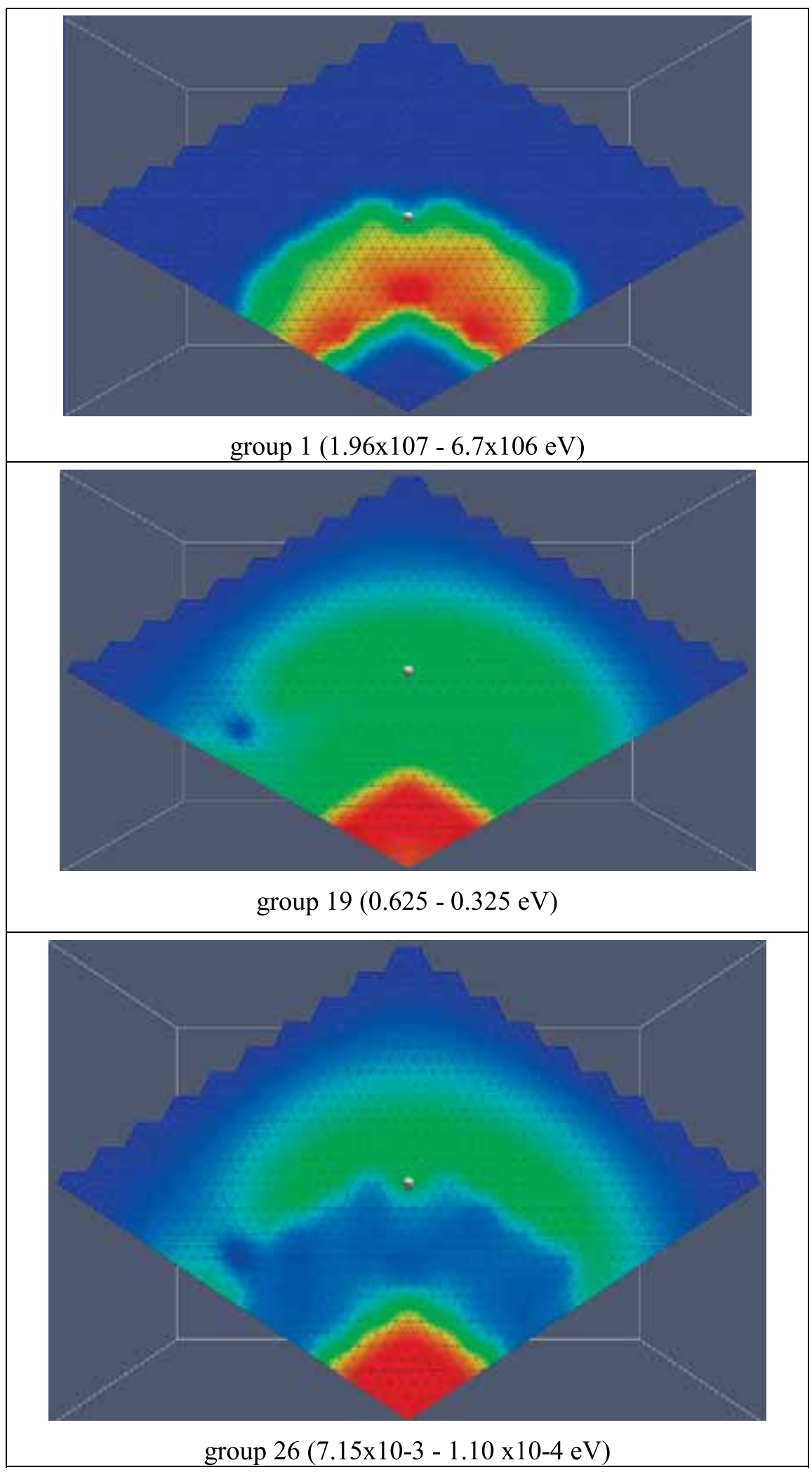

Figure 14. Radial flux profiles for the case with the control bank fully inserted. 
INSTANT in standalone mode has been used to solve this problem using both the hexagonal (block) and triangular spatial resolution. An additional comparison study between the $\mathrm{P}_{1}, \mathrm{P}_{3}$ and $\mathrm{P}_{5}$ results are still in progress. The eigenvalue results for four CR positions are compared in Table 8: nominal (one fuel mesh inserted), fully inserted (bottom of active core) and fully extracted (top of active core), as well as a calculation without any poison in the model (i.e., rods not present). All cases utilized $\mathrm{P}_{1}$ with first order surface and $3^{\text {rd }}$ order source expansion, and the flux convergence criteria where set to $1 \mathrm{E}-6$ for the outer iterations and 1E-4 for the inner iterations. The number of up-scattering iterations was limited to FIVE to improve the balance between fidelity and run-time performance.

Table 8. Phase I Exercise $1 \mathrm{k}_{\mathrm{eff}}$ and CR worth (INSTANT).

\begin{tabular}{|l|l|l|l|l|c|}
\hline \multicolumn{1}{|c|}{ INSTANT } & \multicolumn{1}{|c|}{ No CR } & \multicolumn{1}{c|}{ CR all out } & \multicolumn{1}{c|}{ CR nominal } & \multicolumn{1}{c|}{ CR all in } & $\begin{array}{c}\text { CR Worth } \\
\text { (delta k/k) }\end{array}$ \\
\hline Hexagonal & 1.06768 & 1.06754 & 1.06694 & 1.05826 & 870 \\
\hline Triangular & 1.06742 & 1.06722 & 1.06645 & 1.05505 & 1140 \\
\hline delta $\mathrm{k}$ & 25 & 33 & 50 & 321 & - \\
\hline
\end{tabular}

The $\mathrm{k}_{\text {eff }}$ value of the "no CR" case represent a slight bias of $25 \mathrm{pcm}$ caused by the different methods implemented for the hexagonal and triangular solvers in INSTANT - the hexagonal solutions should approach the triangular solution if a sufficient spatial refinement is performed. A significant fraction of the $33 \mathrm{pcm}$ difference between the hexagonal and triangular models for the "CR out" case can therefore be attributed to this bias. Since the CRs are only inserted one axial level into the core for the MHTGR350 state point, the differences in the two models for the nominal case is also minimal $(50 \mathrm{pcm})$. The largest difference of $321 \mathrm{pcm}$ occurs when the "smeared" out hexagonal CR region is inserted fully over the height of the core. This larger difference for the inserted CRs can be expected from the modeling approach, since a CR in the triangular model is homogenized inside a single triangle (region 234 in Figure 15), whereas a CR in the hexagonal model is homogenized over the entire block volume (region 232). The difference in fully inserted eigenvalues is also the main cause of the CR worth difference between the two models.

In addition to the axial profile of the hexagonal power density shown in Figure 13, the active core power density distribution is presented in Figure 16 and Figure 17 for axial level 1 (core bottom) and level 7 (power peak location), respectively. The power generation in the fresh fuel Blocks 9, 11 and 13 in the inner fuel ring is significantly higher than the power densities in the depleted fuel blocks next to them due to the MHTGR-350 core loading scheme. The radial variation in power density between fuel Rings 1, 2 and 3 can also be observed in these two figures. 


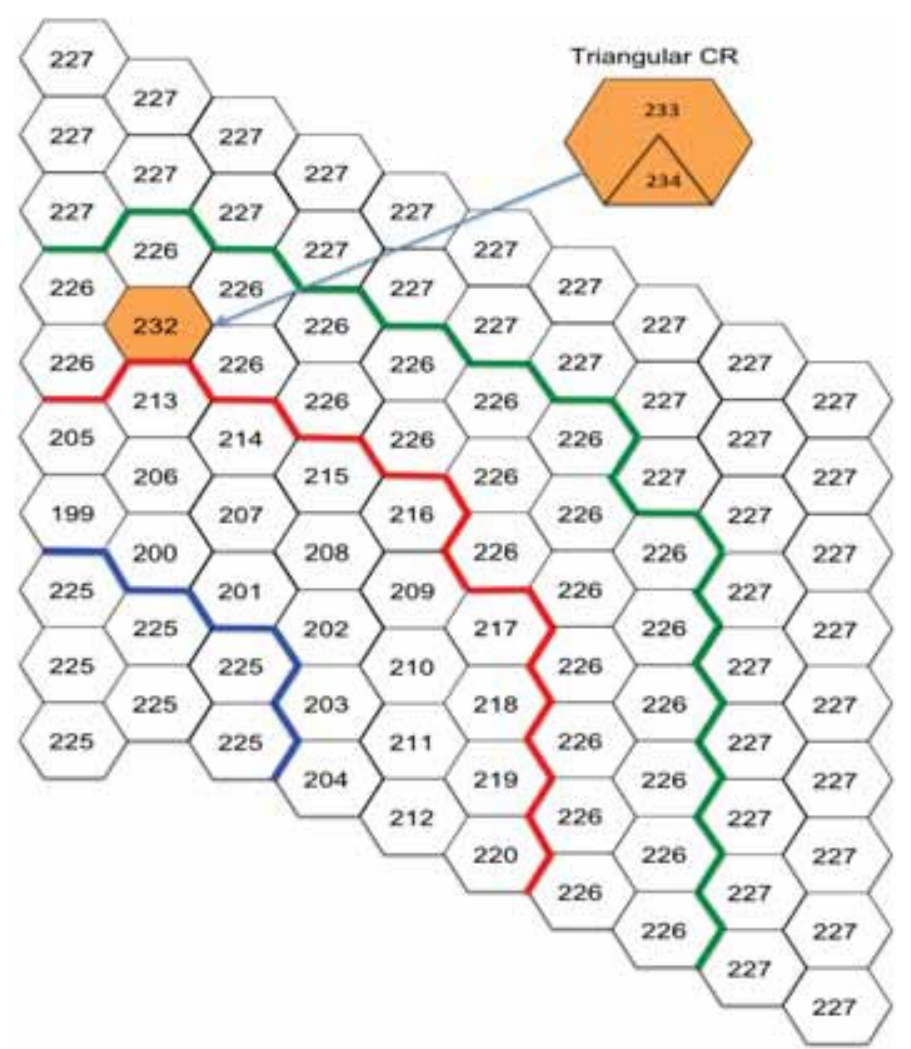

Figure 15. Whole core neutronics layout for Active Core Layer 10. 


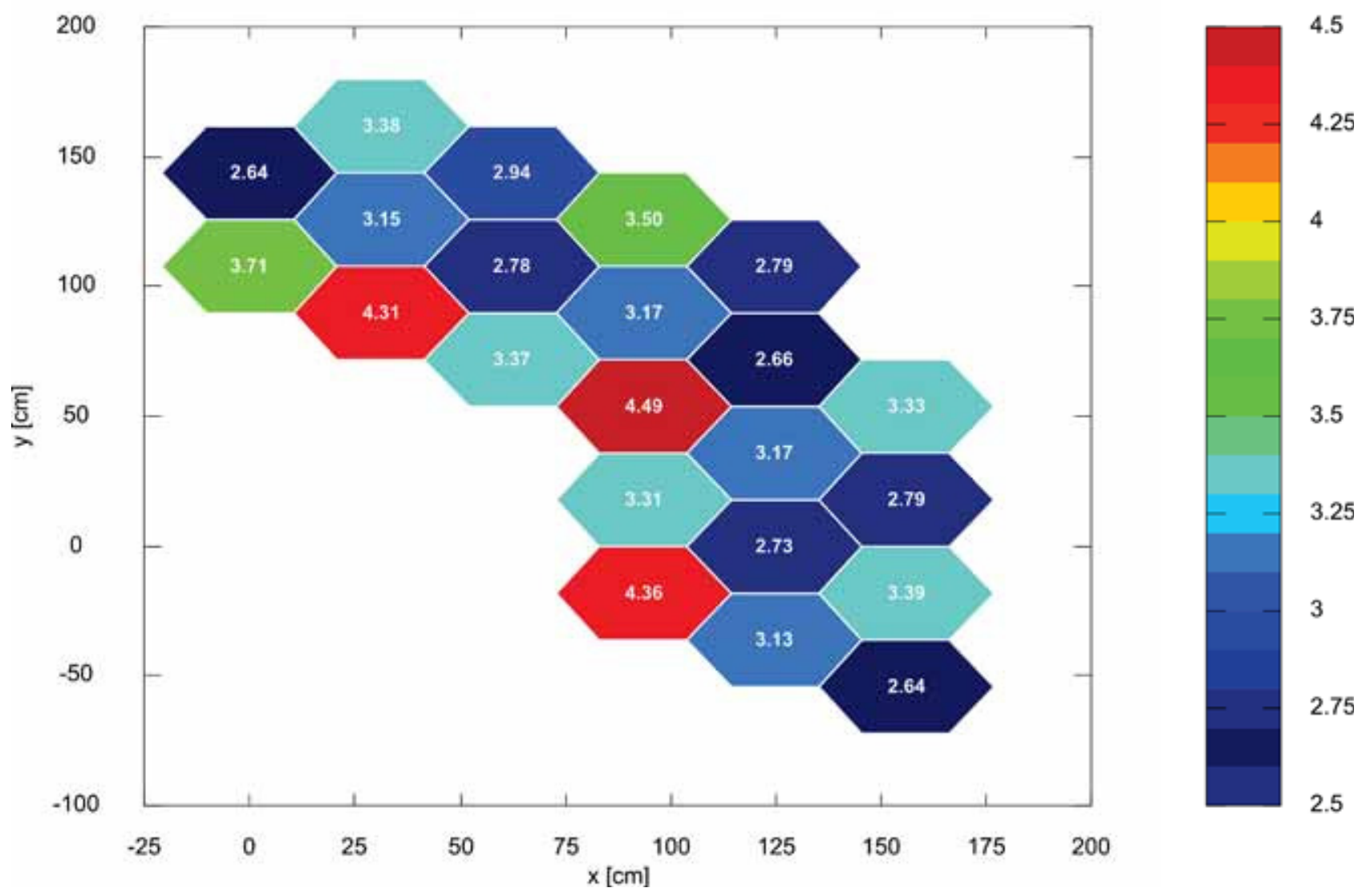

Figure 16. Exercise 1 - INSTANT Power density $\left(\mathrm{W} / \mathrm{cm}^{3}\right)$ distribution on Axial Level 1 (bottom of core). 

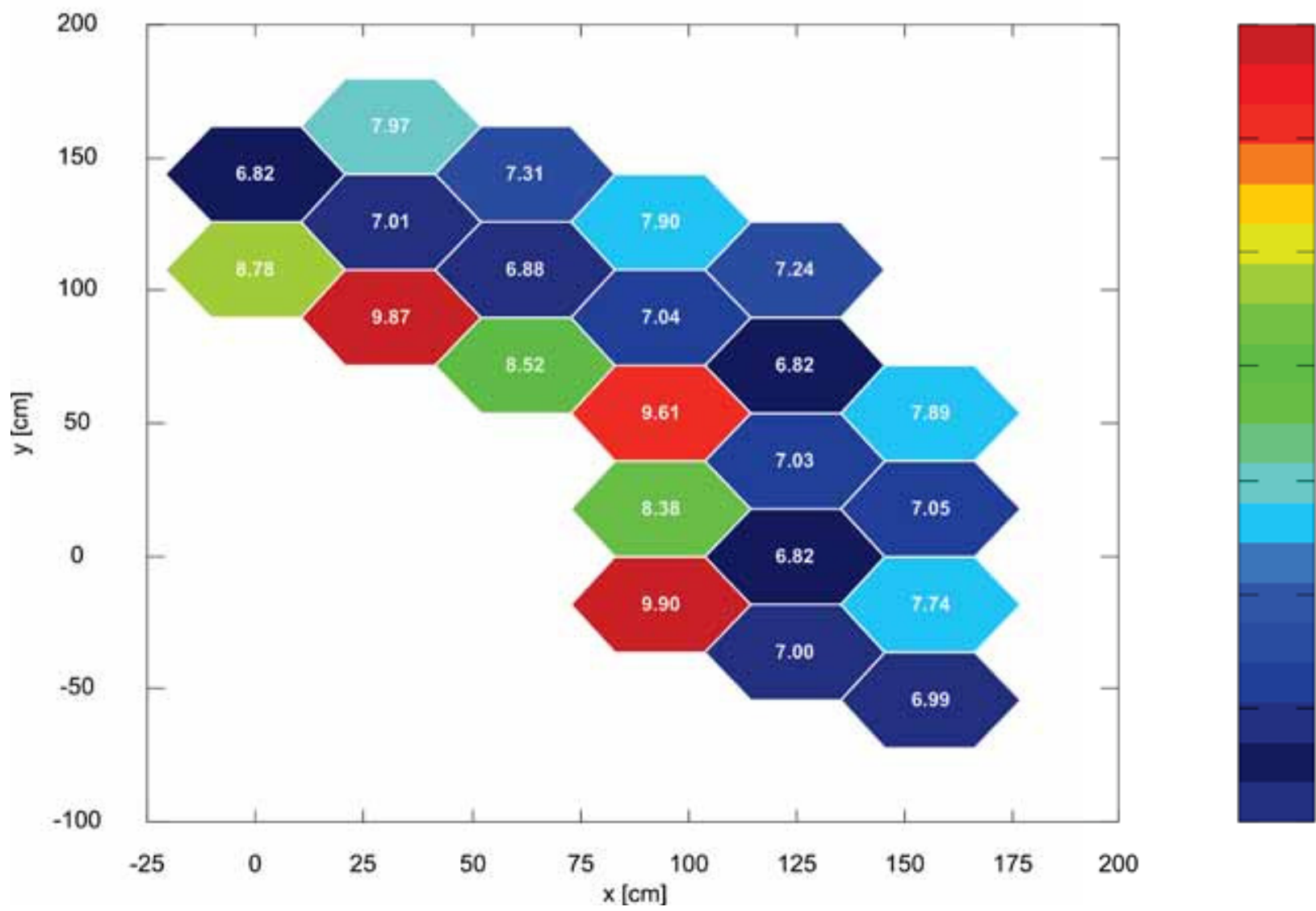

Figure 17. Exercise 1 - INSTANT power density $\left(\mathrm{W} / \mathrm{cm}^{3}\right)$ distribution on Axial Level 7.

The significant difference between the INSTANT fast flux peak in the core region and the thermal flux peaks in the central and side reflectors is illustrated in Figure 18 and Figure 19. Two examples of the whole core INSTANT flux distributions are presented. The maximum fast flux values occur on Axial Layer 7 in Group 2 (Figure 18), whereas the maximum thermal flux values are contained in Group 20 (Figure 19). 


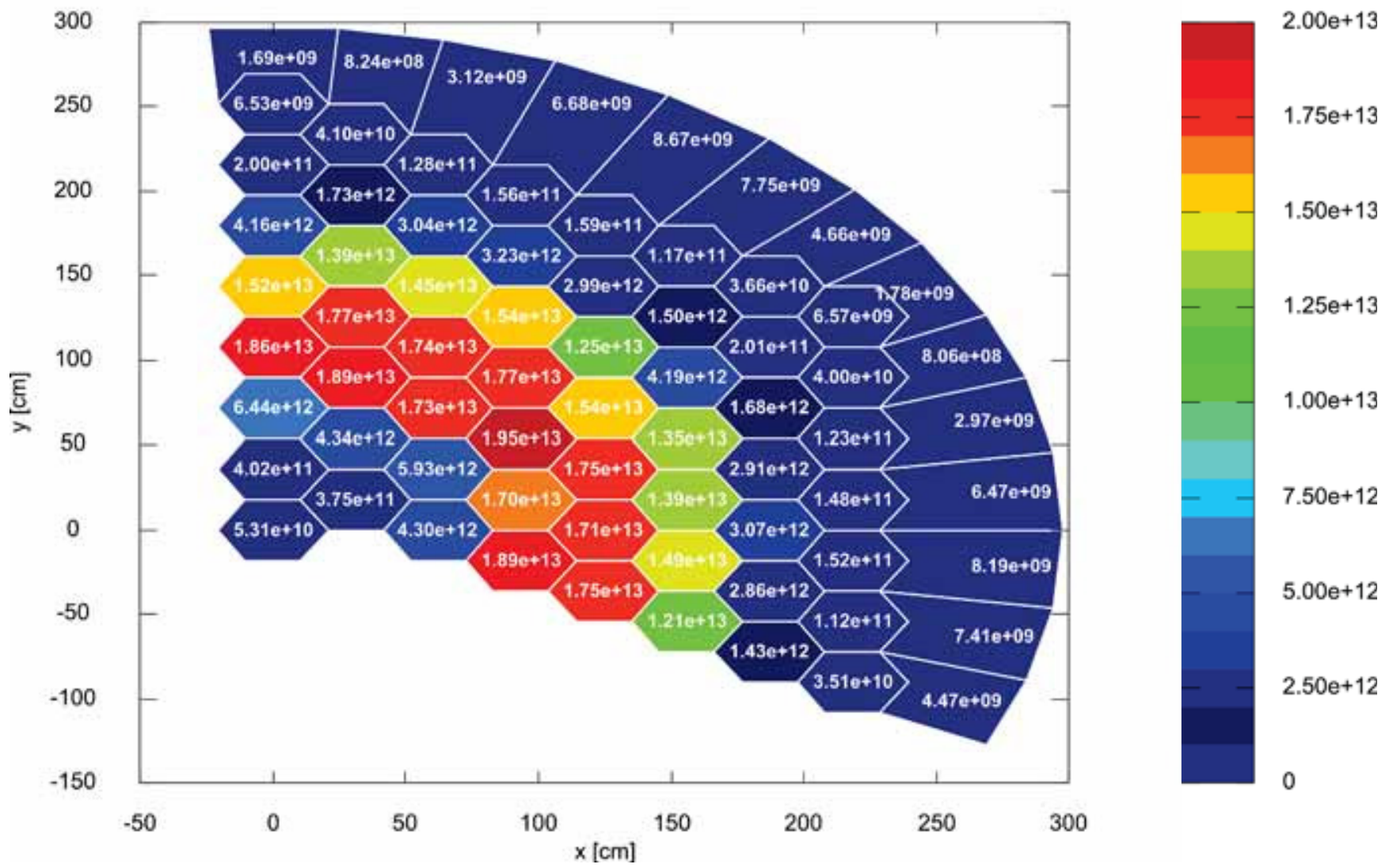

Figure 18. Exercise 1 - INSTANT Group 2 (of 26) whole core flux distribution on Axial Level 7 (peak fast flux). 

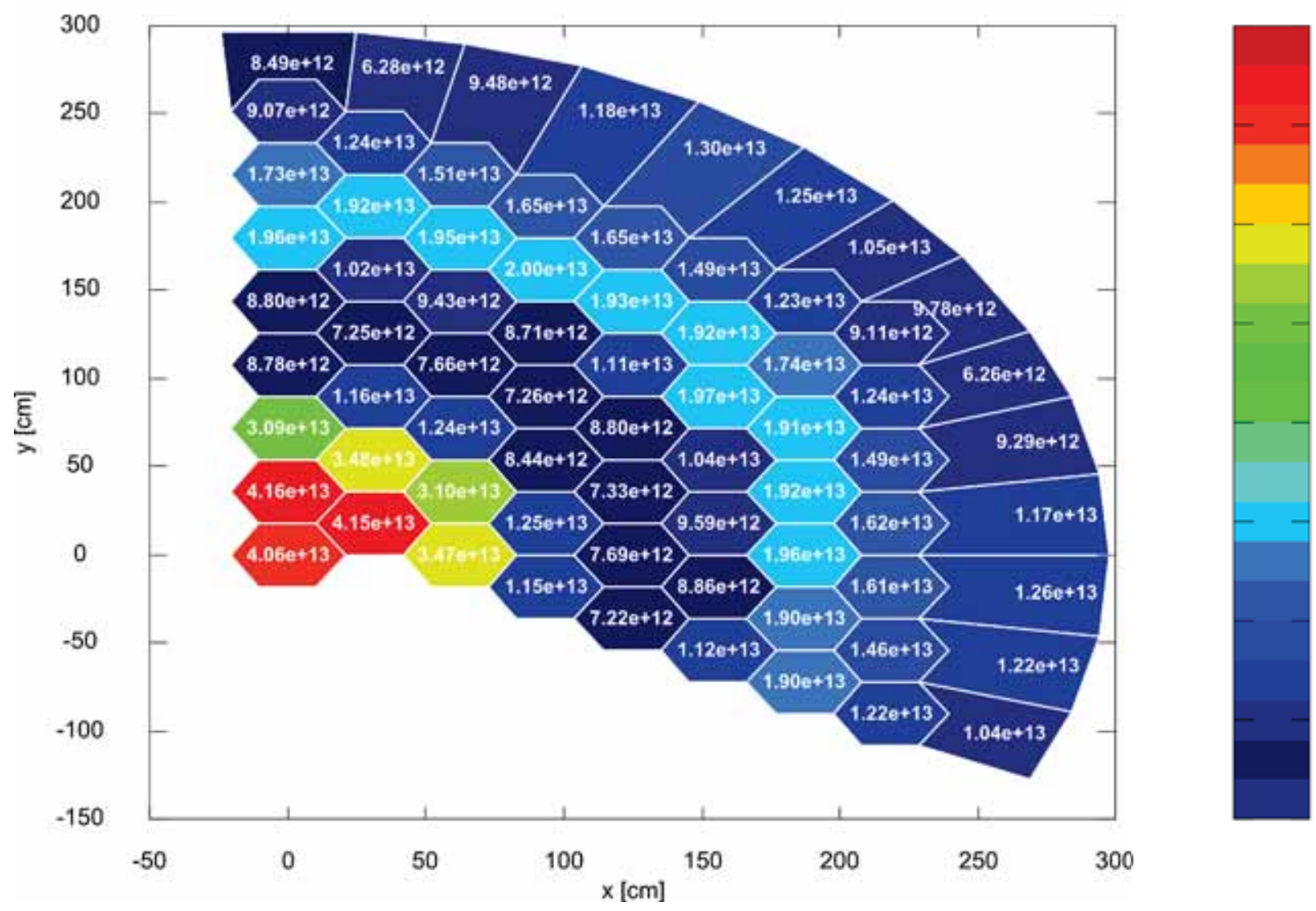

$4.00 \mathrm{e}+13$

$3.50 \mathrm{e}+13$

$3.00 \mathrm{e}+13$

$2.50 \mathrm{e}+13$

$2.00 \mathrm{e}+13$

$1.50 \mathrm{e}+13$

$1.00 \mathrm{e}+13$

$5.00 \mathrm{e}+12$

Figure 19. Exercise 1 - INSTANT Group 20 (of 26) whole core flux distribution on Axial Level 7 (peak thermal flux).

\section{PHASE I: EXERCISE 2}

\subsection{Description of the Exercises}

Exercise 2 is defined as a thermal fluids standalone calculation driven by a specified power density profile in the fuel region. The purpose of the second Exercise is to ensure that there are no significant differences in the thermal fluid models between participants that would affect subsequent coupled steady states (Exercise 3) and the Phase II transients. Four sub-cases are defined for Exercise 2 in order of increasing complexity (summarized in Table 9). The two factors that vary between the four sub-cases are the inclusion of helium flows that do not flow within the fuel coolant channels (bypass flows), and the use of fixed or variable thermophysical properties.

Table 9. Exercise 2a-d definitions.

\begin{tabular}{|c|c|l|}
\hline Exercise & $\begin{array}{c}\text { Bypass } \\
\text { Flow Type }\end{array}$ & $\begin{array}{c}\text { Thermophysical } \\
\text { Properties }\end{array}$ \\
\hline $2 \mathrm{a}$ & None & Fixed \\
\hline $2 \mathrm{~b}$ & I & Fixed \\
\hline $2 \mathrm{c}$ & I & Variable \\
\hline $2 \mathrm{~d}$ & II & Variable \\
\hline
\end{tabular}


Two types of flow specifications have been defined in the benchmark. Type I bypass flow requires the modeling of seven fixed bypass flow channels in the MHTGR-350 core, as shown in Table 10. The total bypass flow fraction is $11 \%$. For the Type II bypass flow, the bypass region geometries must be modeled explicitly and the bypass flow distribution through the 2-mm gaps between blocks is a calculated parameter.

This Exercise furthermore specifies the use of fixed or variable thermophysical properties. The fixed material properties (Exercise 2a) are presented in Table 11, and an example of the variable thermal conductivity of graphite H-451 with temperature and fluence is shown in Figure 20.

Table 10. Bypass Flow Distribution.

\begin{tabular}{|l|c|}
\hline \multicolumn{1}{|c|}{ Component } & $\%$ \\
\hline 1. In-core & 1.50 \\
\hline 2. Inner Reflector & 0.50 \\
\hline 3. Inner CR Cooling & 1.20 \\
\hline 4. Outer CR Cooling & 1.80 \\
\hline 5. Outer Reflector (First Ring) & 1.38 \\
\hline 6. Outer Reflector (Second Ring) & 1.62 \\
\hline 7. Permanent Side Reflector & 3.00 \\
\hline Total & 11.00 \\
\hline
\end{tabular}

Table 11. Fixed thermophysical properties for Exercise 2a.

\begin{tabular}{|l|c|c|}
\hline \multicolumn{1}{|c|}{ Material } & Conductivity & Emissivity \\
\hline Fuel compact & 20.0 & 0.85 \\
\hline Fuel block & 37.0 & 0.85 \\
\hline Grade H-451 graphite & 66.0 & 0.85 \\
\hline Grade 2020 graphite & 35.0 & 0.85 \\
\hline $\begin{array}{l}\text { CB } \\
\begin{array}{l}\text { Core restraint element } \\
\text { Upper plenum thermal protection system }\end{array}\end{array}$ & 17.8 & 0.85 \\
\hline Ceramic tile & 0.91 & \\
\hline Thermal insulation & 0.175 & 0.85 \\
\hline RPV & 40.0 & 0.85 \\
\hline Coolant & 0.41 & 0.85 \\
\hline Air & 0.068 & n.a. \\
\hline Heat sink & n.a. & 0.8 \\
\hline
\end{tabular}




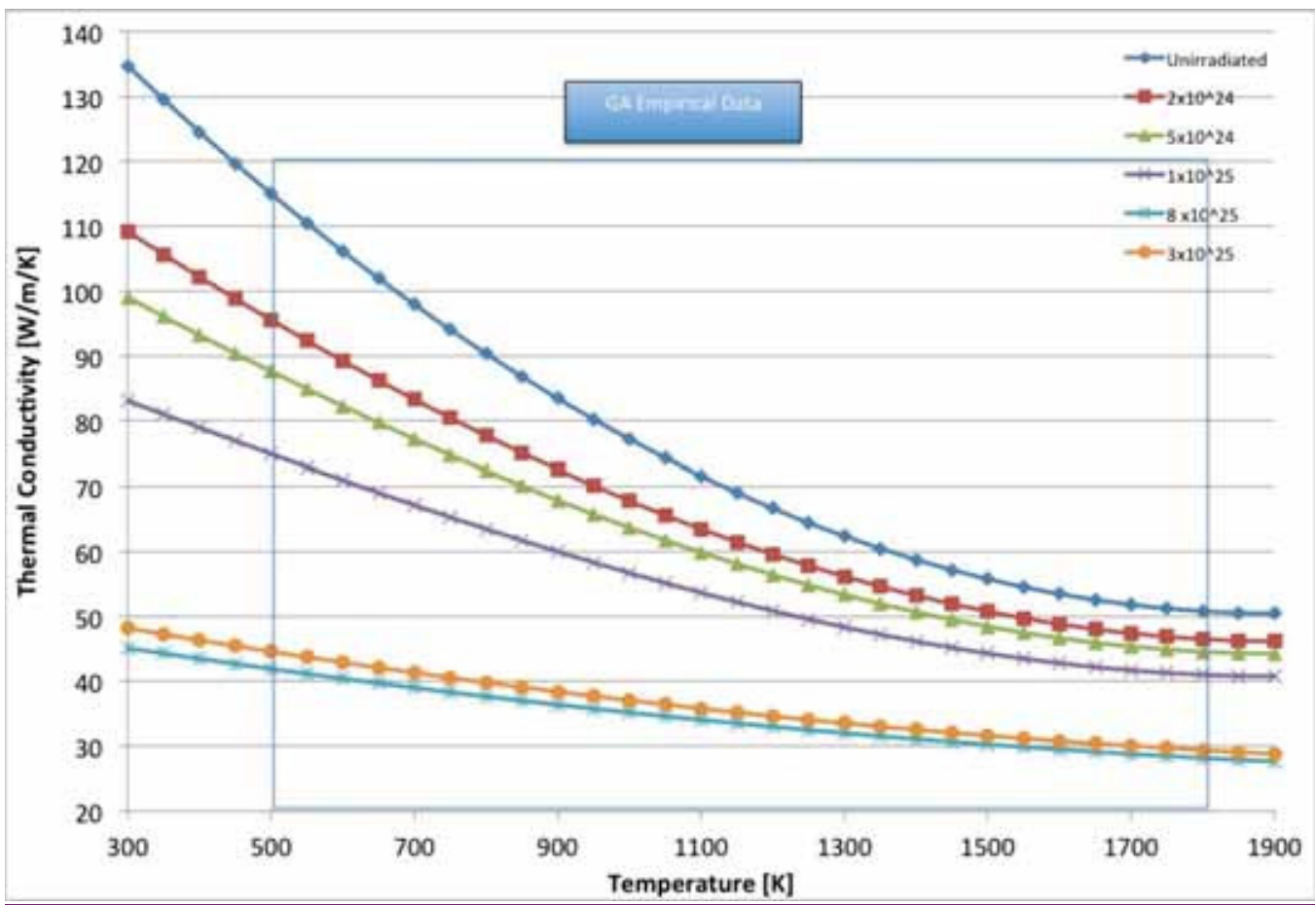

Figure 20. Thermal Conductivity of Grade H-451 Graphite [3].

\subsection{Analysis Tools}

The RELAP5-3D code and model description utilized for the simulation of Exercise 2 was discussed in section 4. The Pronghorn code is currently also being applied to the modeling of Exercise 2a, but a full set of results are not yet available. The latest development status, test problems and verification activities on Pronghorn is summarized in Appendix B.

\subsection{Exercise 2a: RELAP5-3D Results and Discussion}

The primary parameters of interest for Exercise 2 are the gas and solid temperatures and global parameters such as the pressure drop over the core and the inflow mass flow rate. The benchmark does however require participants to also report secondary parameters such as the calculated thermal conductivities, mass flow rate or velocities in bypass channels and heat transfer factors, since this data can be utilized to trace the source of possible differences in the primary parameters. In this report, only a subset of the available data will be presented to illustrate the main characteristics for each of the Exercises.

As indicated in Table 9, Exercise $2 \mathrm{a}$ is the most basic standalone thermal fluids variation in the Exercise 2 benchmark set. All material thermophysical properties are constant, and no bypass flows are assumed to be present (i.e., all helium flow is through the core coolant channels only). This set of boundary conditions is not realistic for the MHTGR-350 design at operating conditions, but it serves as a simplified departure point for comparing participants' data.

A few of the Exercise 2 global parameters of interest are reported in Table 12 (ring model) and Table 13 (bock model) for all four sub-cases. Most of the values are similar (especially inlet pressure and boundary heat loss), but the maximum CB and Reactor Vessel (RV) temperatures for Exercise 2a are higher than any of the other cases. The reason for this is the absence of any bypass flows in the reflector structures, which lead to higher temperatures everywhere outside the core region, as shown later in this 
section. The differences in these global values between the ring and block models are not significant, and a similar higher CB and RV temperature is calculated for the block model.

Table 12. Comparison of Phase I Exercise 2 PHISICS/RELAP5-3D thermal fluid results for the ring model.

\begin{tabular}{|l|c|c|c|c|c|}
\hline $\begin{array}{c}\text { Ring } \\
\text { Model }\end{array}$ & $\begin{array}{c}\text { Maximum CB } \\
\text { Temperature } \\
\left({ }^{\circ} \mathrm{C}\right)\end{array}$ & $\begin{array}{c}\text { Maximum RV } \\
\text { Temperature } \\
\left({ }^{\circ} \mathrm{C}\right)\end{array}$ & $\begin{array}{c}\text { System Inlet } \\
\text { Pressure } \\
(\mathrm{MPa})\end{array}$ & $\begin{array}{c}\text { Pressure Drop Over } \\
\text { Core } \\
(\mathrm{kPa})\end{array}$ & $\begin{array}{c}\text { Heat loss from } \\
\text { RV boundary } \\
(\mathrm{MW})\end{array}$ \\
\hline ex_2a & 320 & 215 & 6.416 & 25.8 & 0.771 \\
\hline ex_2b & 262 & 206 & 6.412 & 21.6 & 0.709 \\
\hline ex_2c & 266 & 206 & 6.412 & 21.6 & 0.710 \\
\hline ex_2d & 259 & 206 & 6.410 & 20.3 & 0.711 \\
\hline ex_3a & 263 & 206 & 6.412 & 22.1 & 0.712 \\
\hline ex_3b & 263 & 206 & 6.411 & 20.9 & 0.712 \\
\hline
\end{tabular}

Table 13. Comparison of Phase I Exercise 2 and Exercise 3 PHISICS/RELAP5-3D global parameter results for the block model.

\begin{tabular}{|l|c|c|c|c|c|}
\hline $\begin{array}{c}\text { Block } \\
\text { Model }\end{array}$ & $\begin{array}{c}\text { Maximum CB } \\
\text { Temperature } \\
\left({ }^{\circ} \mathrm{C}\right)\end{array}$ & $\begin{array}{c}\text { Maximum RV } \\
\text { Temperature } \\
\left({ }^{\circ} \mathrm{C}\right)\end{array}$ & $\begin{array}{c}\text { System Inlet } \\
\text { Pressure } \\
(\mathrm{MPa})\end{array}$ & $\begin{array}{c}\text { Pressure Drop Over } \\
\text { Core } \\
(\mathrm{kPa})\end{array}$ & $\begin{array}{c}\text { Heat Loss } \\
\text { from RV } \\
\text { Boundary } \\
(\mathrm{MW})\end{array}$ \\
\hline ex_2a & 310 & 213 & 6.416 & 25.8 & 0.756 \\
\hline ex_2b & 252 & 205 & 6.412 & 21.5 & 0.703 \\
\hline ex_2c & 257 & 205 & 6.412 & 21.5 & 0.705 \\
\hline ex_2d & 255 & 205 & 6.410 & 20.4 & 0.706 \\
\hline ex_3a & 255 & 205 & 6.412 & 21.7 & 0.706 \\
\hline ex_3b & 255 & 205 & 6.412 & 22.1 & 0.706 \\
\hline
\end{tabular}

The helium, fuel, and reflector temperature distributions shown in Figure 21 to Figure 26 for the bottom axial layer in the active core region illustrate the increased spatial resolution of the block model over the ring model. For all of these parameters a much more detailed distribution of temperatures is obtained on the triangular mesh, compared to as few as three values per axial layer for the ring model. As can be expected from the volume-averaged approach in the ring model, all temperatures are significantly under-estimated compared to the block model values. The block model predicts that the radial temperature variations between the three fuel rings are significant (more than $300^{\circ} \mathrm{C}$ in Figure 24). It should be noted that since the detail detailed TRISO sub-grid model is not yet implemented, the fuel temperature of the ring is assumed to be constant across and within all compacts in the ring. 


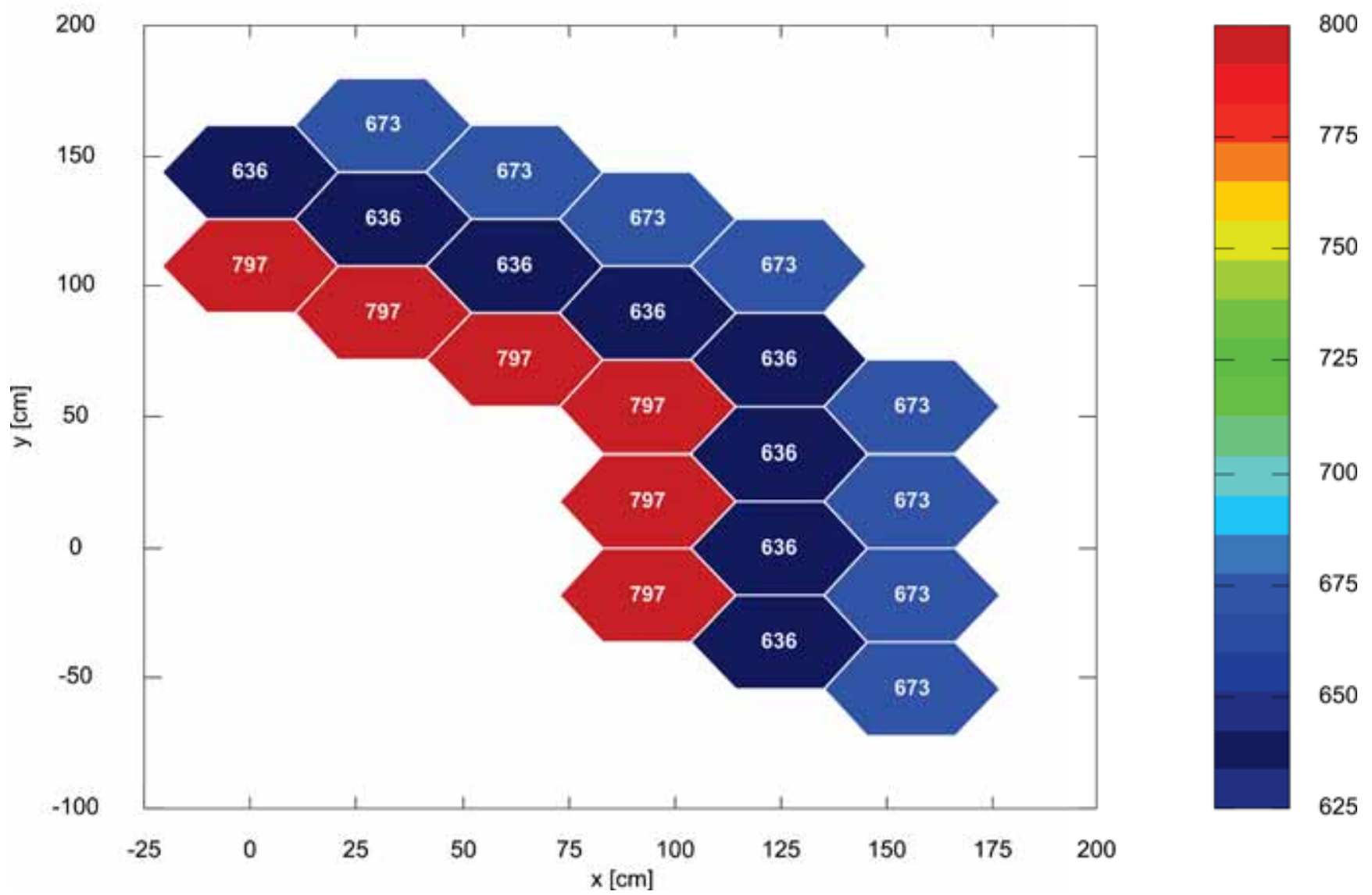

Figure 21. Exercise 2a - Helium gas temperature $\left({ }^{\circ} \mathrm{C}\right)$ distribution on Axial Level 3 (first bottom core level) for the ring model. 

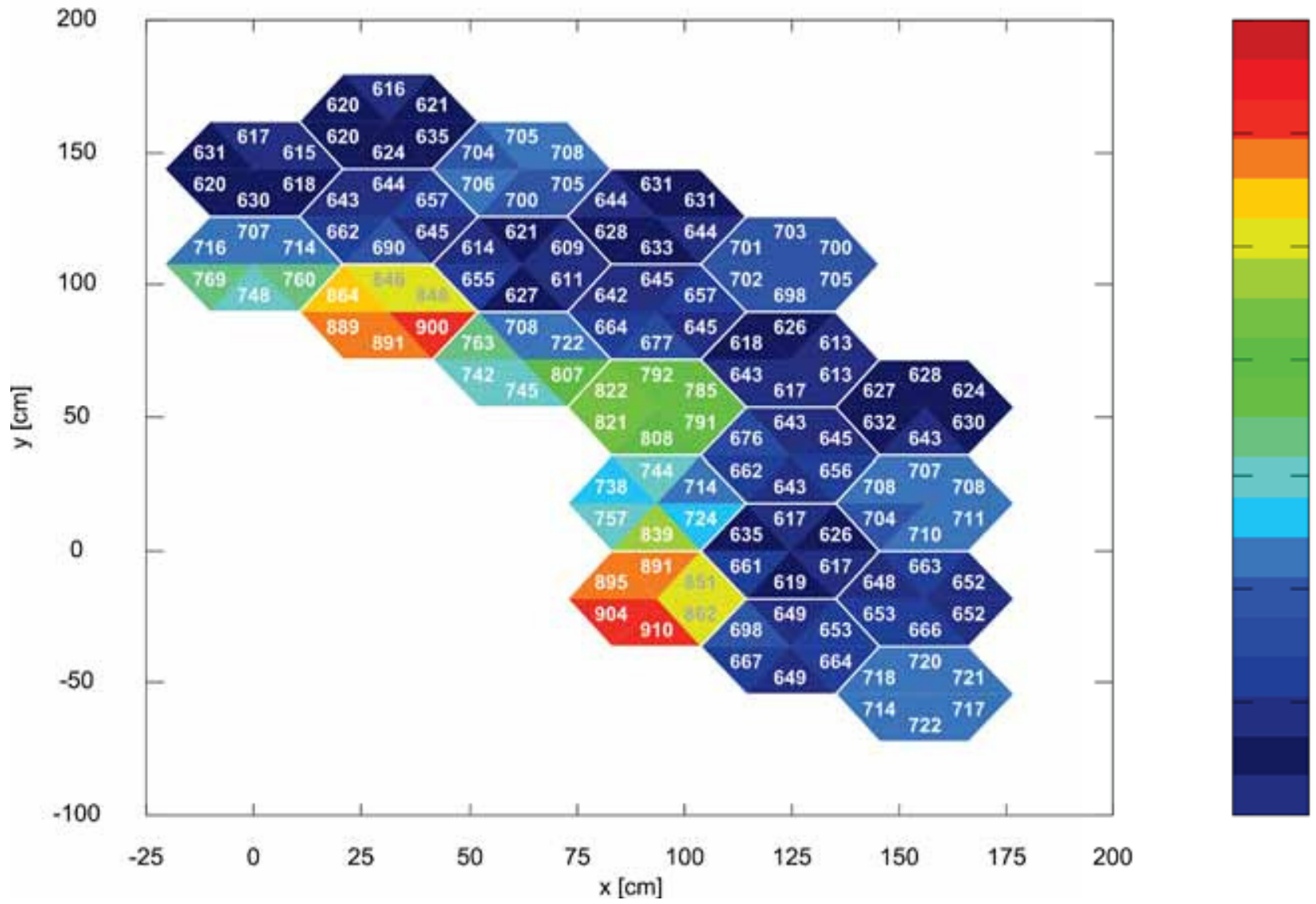

Figure 22. Exercise $2 \mathrm{a}$ - Helium gas temperature $\left({ }^{\circ} \mathrm{C}\right)$ distribution on Axial Level 3 (first bottom core level) for the block model.

Similar to the results shown in the discussion of the Exercise 1 results, the effect of the higher power generation in the fresh fuel blocks can be observed in all the temperature distributions. For Exercise 2, this power density data is given as input, and it matches the power shown in Figure 17. The blocks with the highest power density (\#9 and \#13) also produce the highest fuel, graphite and gas temperatures, as could be expected. This information is not available in the ring model, where the block power densities and temperatures are all averaged to one value per ring only (Figure 23). 

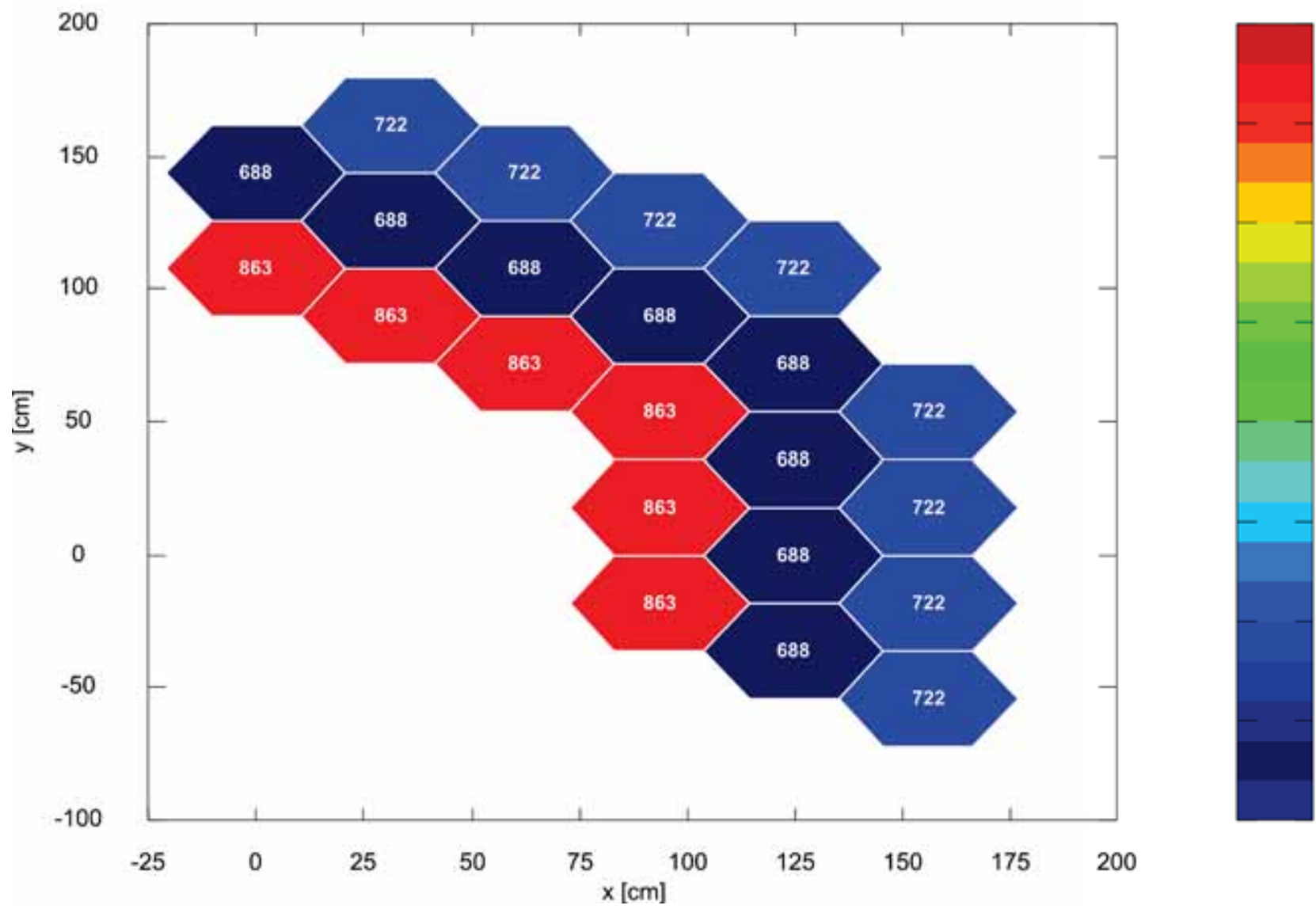

Figure 23. Exercise $2 \mathrm{a}$ - Average fuel temperature $\left({ }^{\circ} \mathrm{C}\right)$ distribution on Axial Level 1 (first bottom core level) for the ring model. 


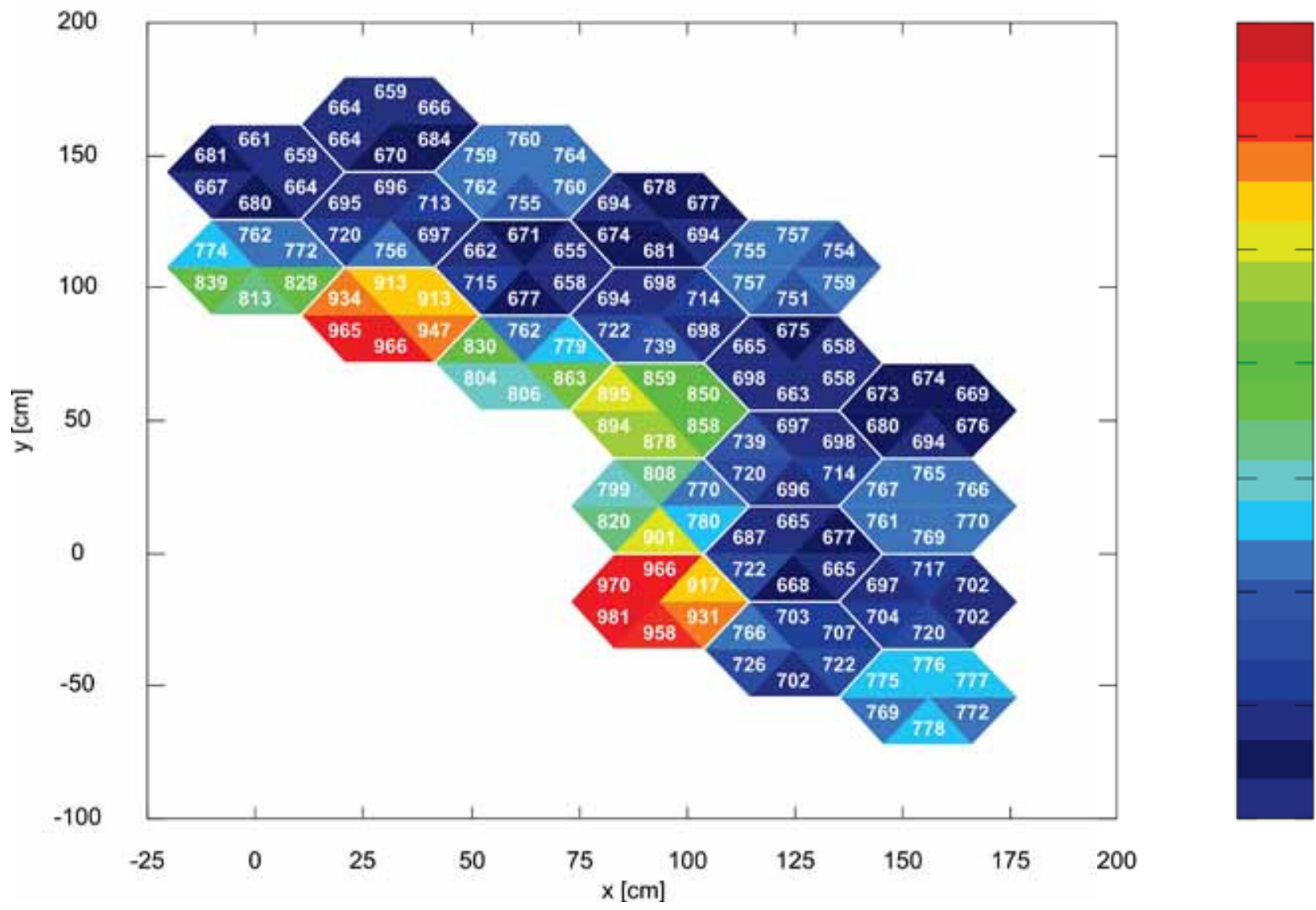

Figure 24. Exercise 2a - Average fuel temperature $\left({ }^{\circ} \mathrm{C}\right)$ distribution on Axial Level 1 (first bottom core level) for the block model.

The results presented in Figure 23 and Figure 24 illustrate that the ring-based model under-predicts the peak fuel temperature by as much as $100^{\circ} \mathrm{C}$ in some regions of the core compared to the detailed triangular model. This represents a significant non-conservative uncertainty $(11.5 \%$ for this example $)$ in the traditional system code analysis of HTGRs, and underlines the importance of higher fidelity modeling that should be applied in HTGR safety studies. It is also noteworthy to point out that even if the simulation time penalty is taken into account (as shown in Table 6), the variances in the data available from the more detailed block model is of sufficient importance to warrant the investment in higher fidelity model development.

The graphite temperature distribution is shown for the whole core region in Figure 25 (ring model) and Figure 26 (block model). (Note that the legend in Figure 26 has been removed to increase the relative size of the data overlaid on the plot - it is identical to the legend in Figure 25). The relatively high inner reflector temperatures can be seen in both figures, since this case did not include any bypass flow modeling in the reflectors. The block model (Figure 26) show six equal values in the areas where there is ring representation, e.g., Blocks 1 and 2, but the detailed information available from this model is again apparent in the fuel region of the core. 


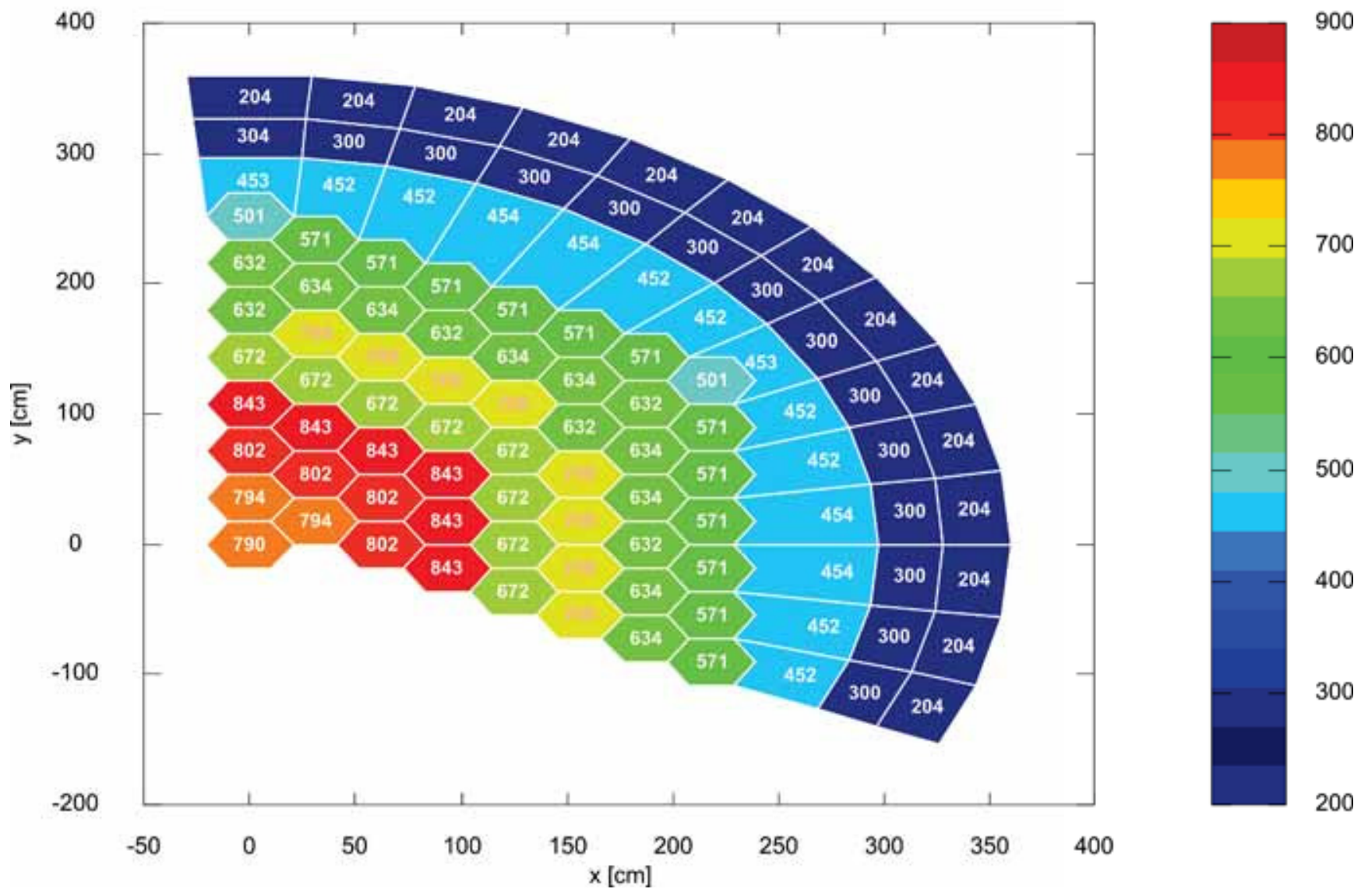

Figure 25. Exercise 2a-Average graphite temperature $\left({ }^{\circ} \mathrm{C}\right)$ distribution for all graphite structures in the ring model on Axial Level 1 (first bottom core level). 


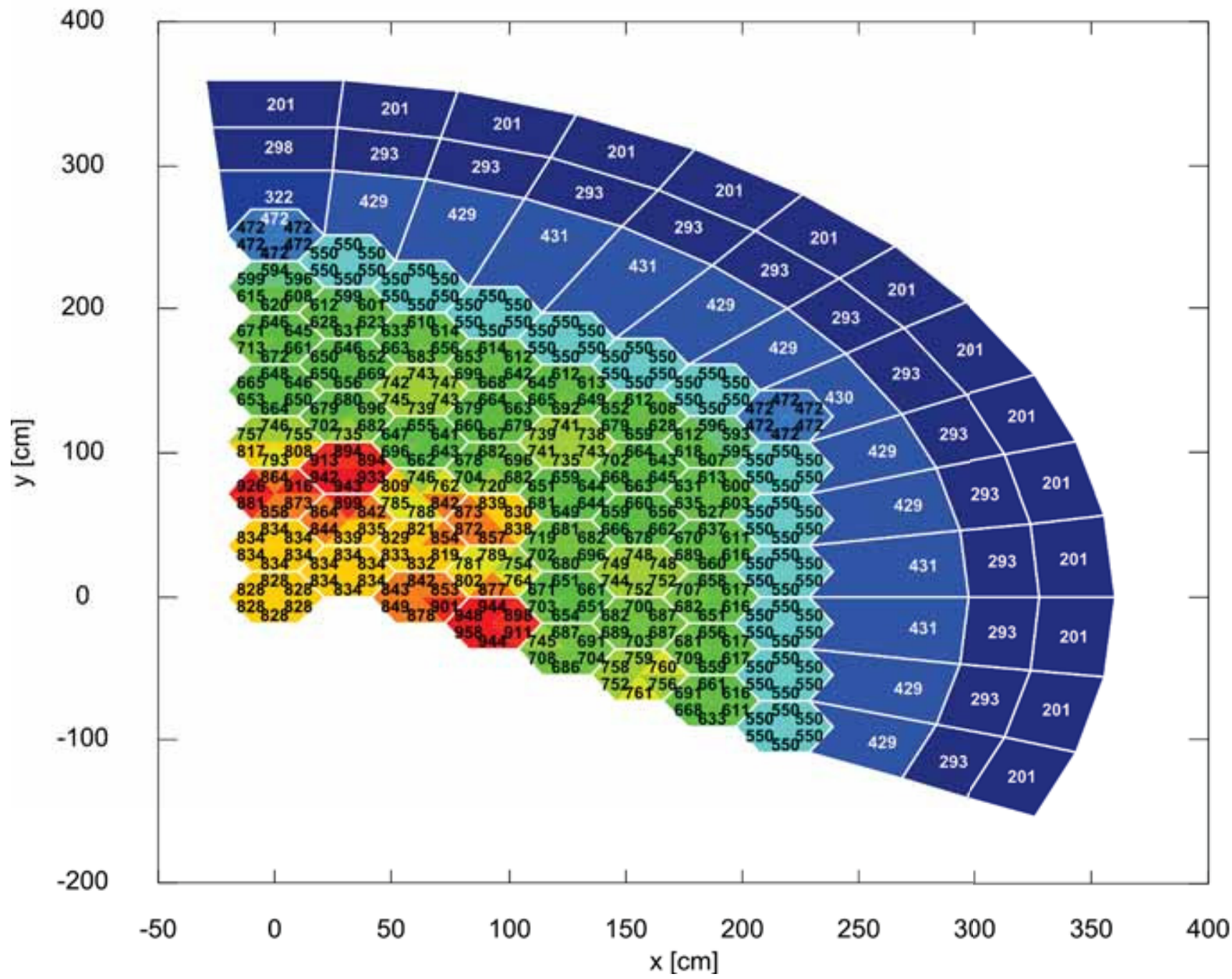

Figure 26. Exercise 2a-Average graphite temperature $\left({ }^{\circ} \mathrm{C}\right)$ distribution for all graphite structures in the block model on Axial Level 1 (first bottom core level).

As an example of the data that can be obtained from the detailed block model, the average fuel temperatures in the six triangular elements of block 9 is indicated for all 10 axial layers in Table 14. Average values can then be calculated at each axial level for each triangular node, and this can be compared with the ring model data at the same axial levels. The dataset shown in Table 14 also includes the peak value for the 6 triangles in block 9 per axial layer. The fuel temperatures in the 6 elements vary between $29^{\circ} \mathrm{C}$ and $53^{\circ} \mathrm{C}$ on layers $1-10$, but in layer 1 the difference between the peak block and ring model values reaches a maximum of $103^{\circ} \mathrm{C}$ - an under-prediction of $12 \%$. These differences can be clearly observed in Figure 27. 
Table 14. Comparison of block 9 triangular average fuel temperatures $\left({ }^{\circ} \mathrm{C}\right)$.

\begin{tabular}{|c|c|c|c|c|c|c|c|c|c|}
\hline \multirow{2}{*}{$\begin{array}{l}\text { Axial } \\
\text { layer }\end{array}$} & \multicolumn{6}{|c|}{ Triangular element fuel temperature } & \multirow{2}{*}{$\begin{array}{c}\text { Axial } \\
\text { average }\end{array}$} & \multirow{2}{*}{$\begin{array}{l}\text { Peak } \\
\text { value }\end{array}$} & \multirow{2}{*}{$\begin{array}{l}\text { Ring } \\
\text { model } \\
\text { value }\end{array}$} \\
\hline & $8-1$ & $8-2$ & $8-3$ & $8-4$ & $8-5$ & $8-6$ & & & \\
\hline 1 & 914 & 914 & 947 & 967 & 966 & 935 & 940 & 967 & 864 \\
\hline 2 & 898 & 899 & 935 & 949 & 948 & 918 & 924 & 949 & 847 \\
\hline 3 & 875 & 876 & 917 & 922 & 920 & 893 & 901 & 922 & 824 \\
\hline 4 & 847 & 848 & 893 & 889 & 887 & 863 & 871 & 893 & 796 \\
\hline 5 & 816 & 818 & 865 & 854 & 851 & 830 & 839 & 865 & 767 \\
\hline 6 & 786 & 788 & 838 & 818 & 816 & 798 & 807 & 838 & 739 \\
\hline 7 & 742 & 744 & 794 & 769 & 766 & 752 & 761 & 794 & 699 \\
\hline 8 & 683 & 686 & 732 & 704 & 702 & 691 & 700 & 732 & 645 \\
\hline 9 & 598 & 600 & 638 & 613 & 611 & 603 & 610 & 638 & 568 \\
\hline 10 & 478 & 480 & 507 & 487 & 486 & 482 & 487 & 507 & 460 \\
\hline
\end{tabular}

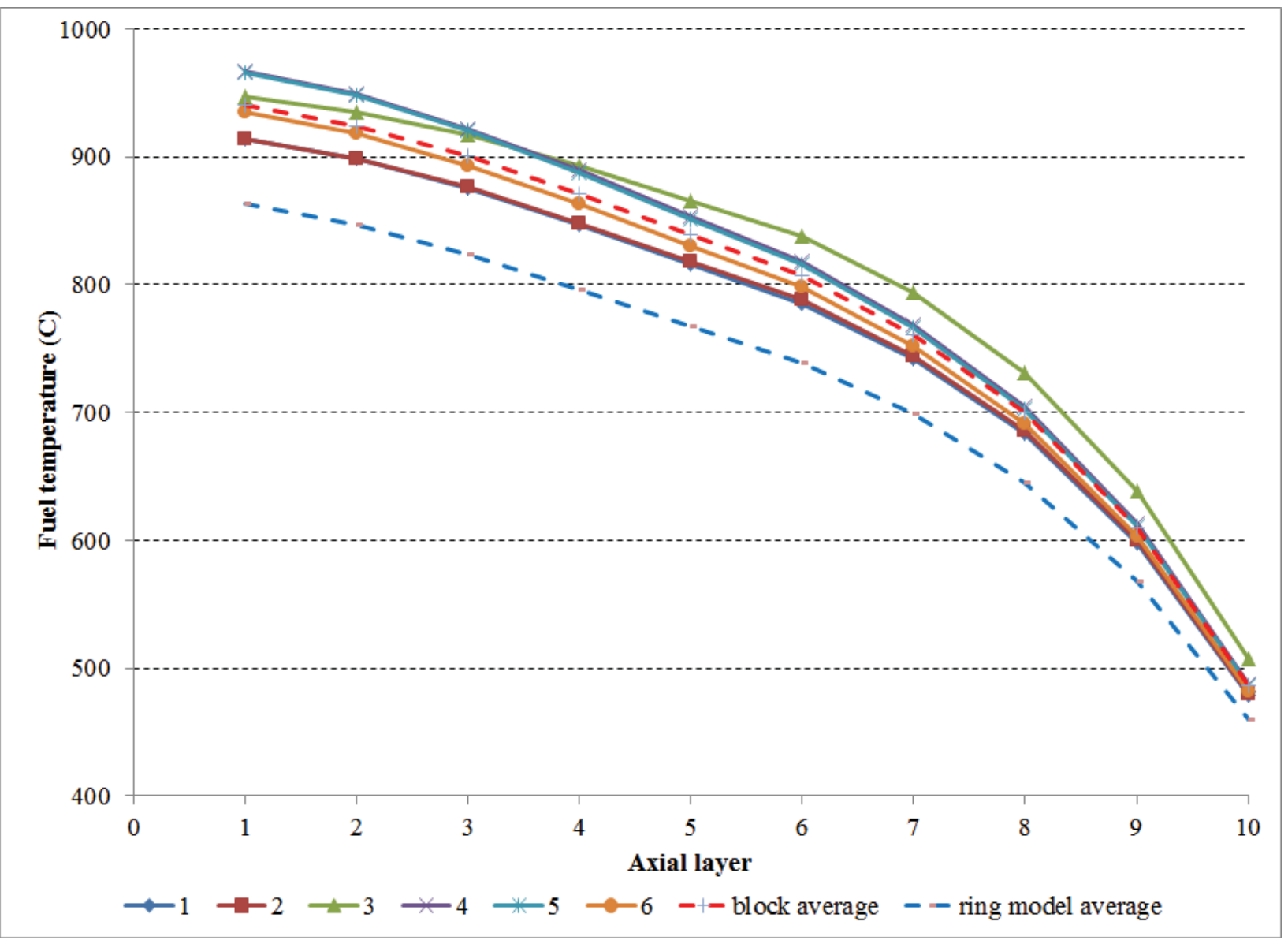

Figure 27. Exercise $2 \mathrm{a}$ - Triangular element, block and ring 1 average fuel temperatures for Block $9\left({ }^{\circ} \mathrm{C}\right)$. 


\subsection{Exercise 2b: RELAP5-3D Results and Discussion}

Exercise $2 \mathrm{~b}$ investigates the change in the reflector and fuel temperatures that occur when the $11 \%$ Type I bypass flow (see Table 10) is included in the MHTGR-350 model. Only a small subset of absolute and relative difference data between Exercise $2 \mathrm{a}$ and Exercise $2 \mathrm{~b}$ will be shown in this section compared to the more extensive discussion in Section 5.3. A significant decrease in the inner and outer graphite temperatures are observed with the addition of coolant flow in the reflector structures. A comparison of Figure 25 and Figure 28 show that the entire inner reflector temperature is lower than $500^{\circ} \mathrm{C}$ in the presence of bypass flows, compared to temperatures of $800^{\circ} \mathrm{C}$ for Exercise $2 \mathrm{a}$. The magnitude of the decrease for the ring model in the inner reflector vary between $41 \%$ and $52 \%$ (Figure 29), whereas the block model predicts up to $38 \%$ lower temperatures in the outer reflector region (Figure 30).

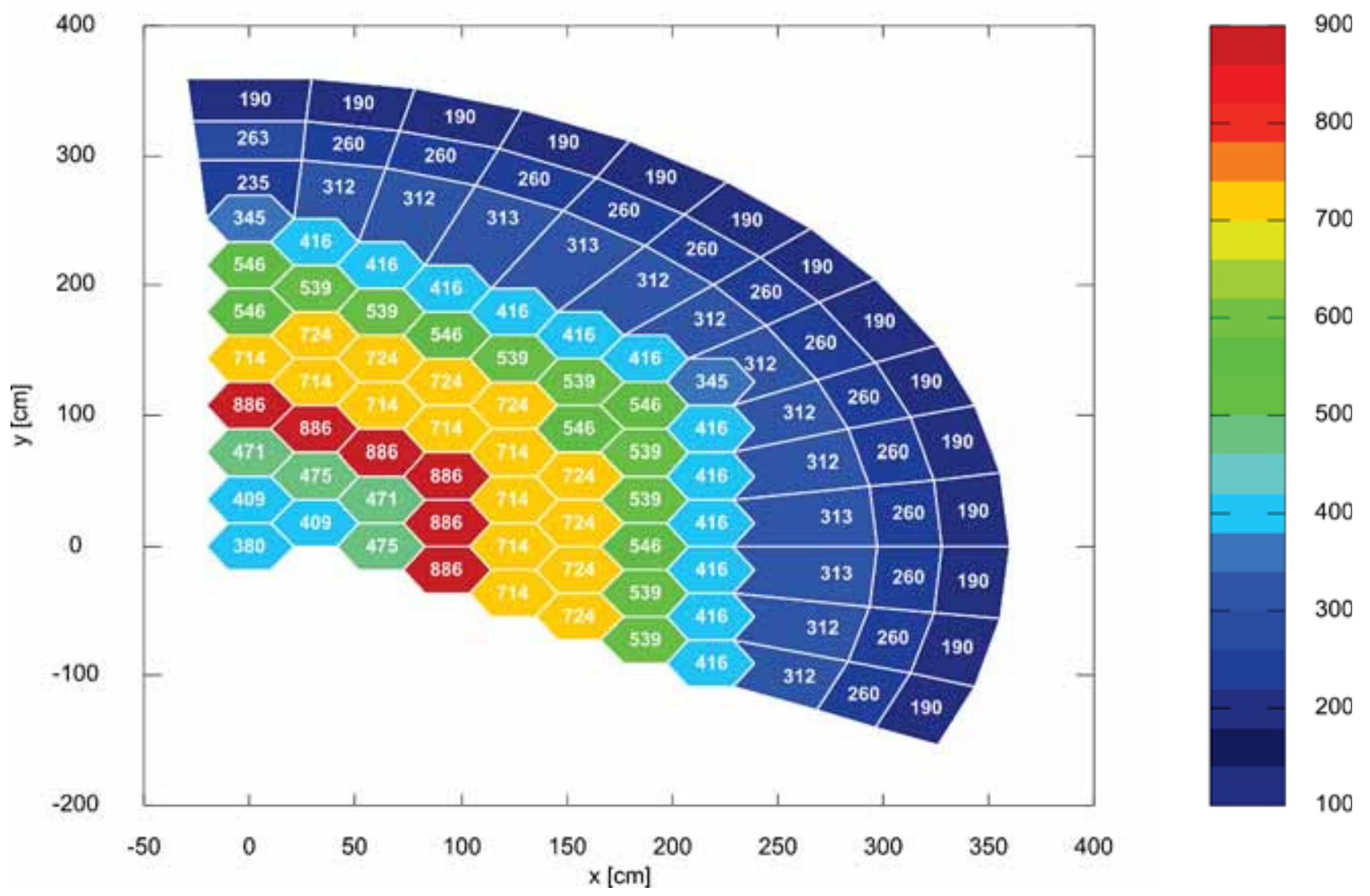

Figure 28. Exercise $2 \mathrm{~b}-$ Average graphite temperature $\left({ }^{\circ} \mathrm{C}\right)$ distribution for all graphite structures in the ring model on Axial Level 1 (first bottom core level). 


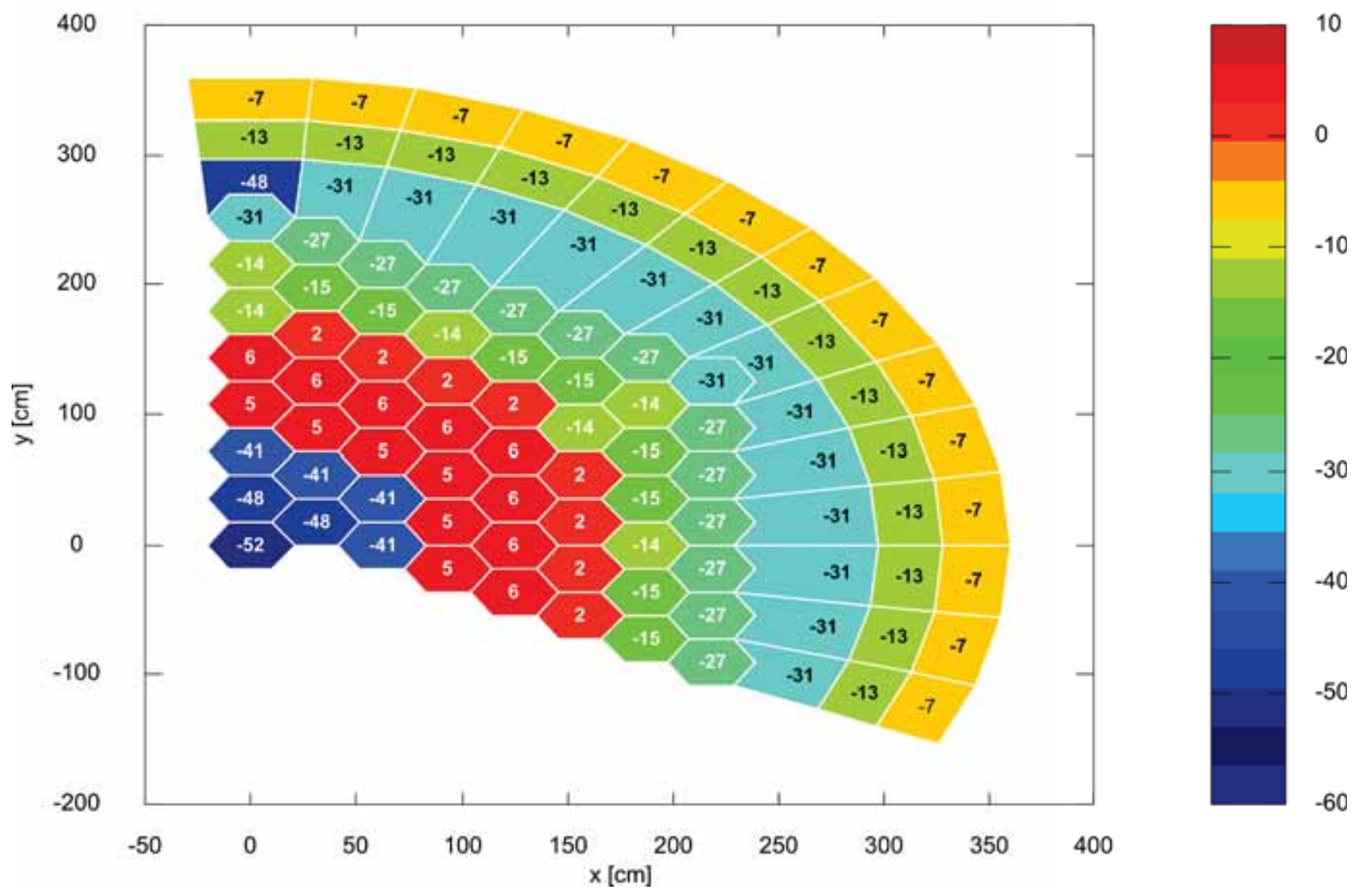

Figure 29. Average graphite temperature difference (\%) between Exercise 2a and Exercise $2 \mathrm{~b}$ for all graphite structures in the ring model on Axial Level 1 (first bottom core level). 


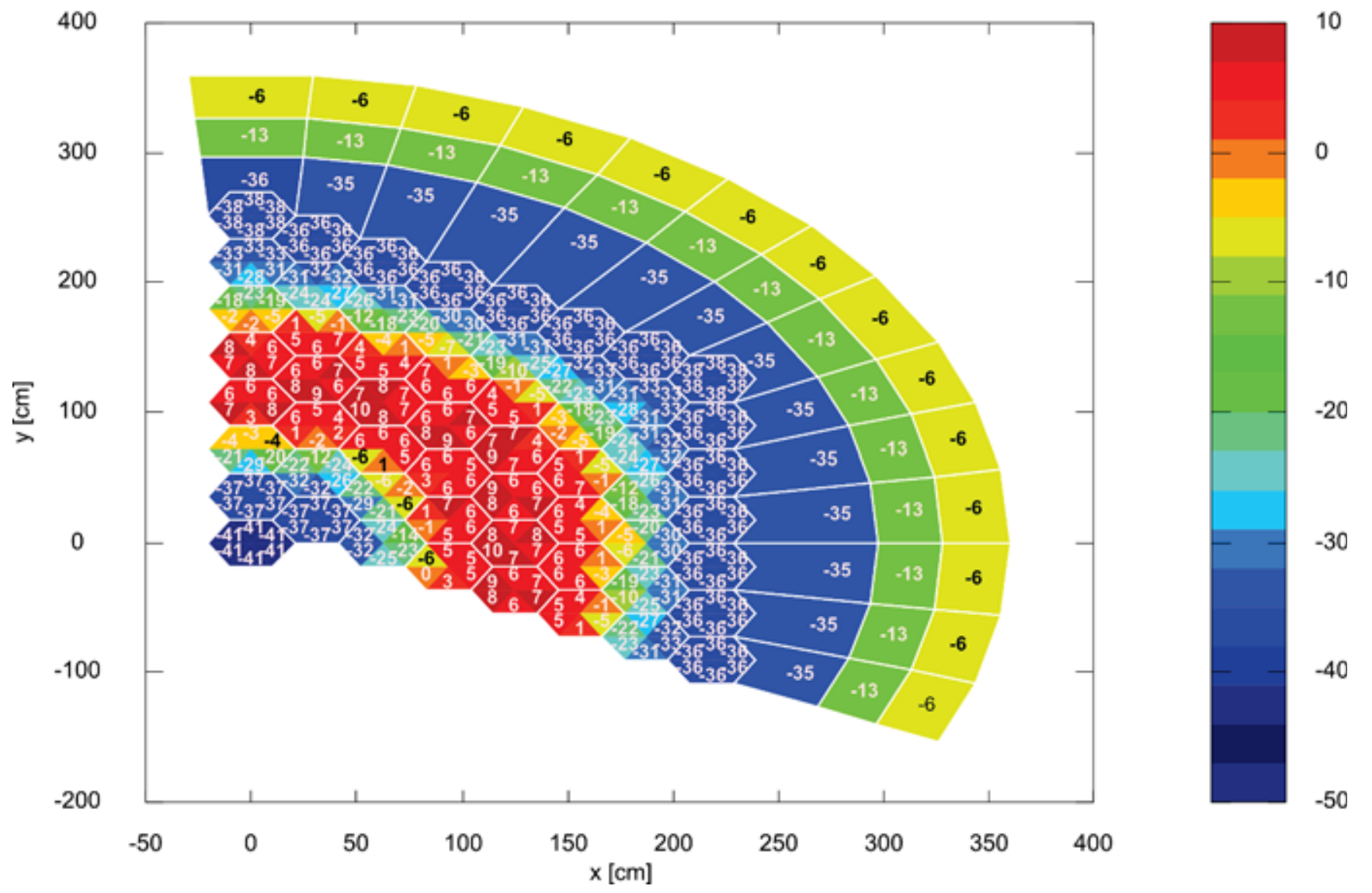

Figure 30. Average graphite temperature difference (\%) between Exercise 2a and Exercise $2 \mathrm{~b}$ for all graphite structures in the block model on Axial Level 1 (first bottom core level).

The effect on the fuel region is in the opposite direction (i.e., Exercise $2 \mathrm{~b}$ exhibits higher fuel temperatures), but comparatively small. This is because a decrease from $100 \%$ to $89 \%$ of the nominal helium flow rate still represents a very effective convective heat removal mechanism. The absolute difference between the average fuel temperatures for Exercise 2a and Exercise 2b (Figure 31) is less than $70^{\circ} \mathrm{C}$, but some large variations are predicated between the triangular elements of the fuel blocks next to the inner and outer reflectors. This sharp gradient in fuel blocks on the core/graphite reflector interface can be expect due to the increase in helium cooling in the reflectors. The effect of the increased resolution of the block model (Figure 31) compared to the ring model (Figure 29) is again illustrated with this example. 

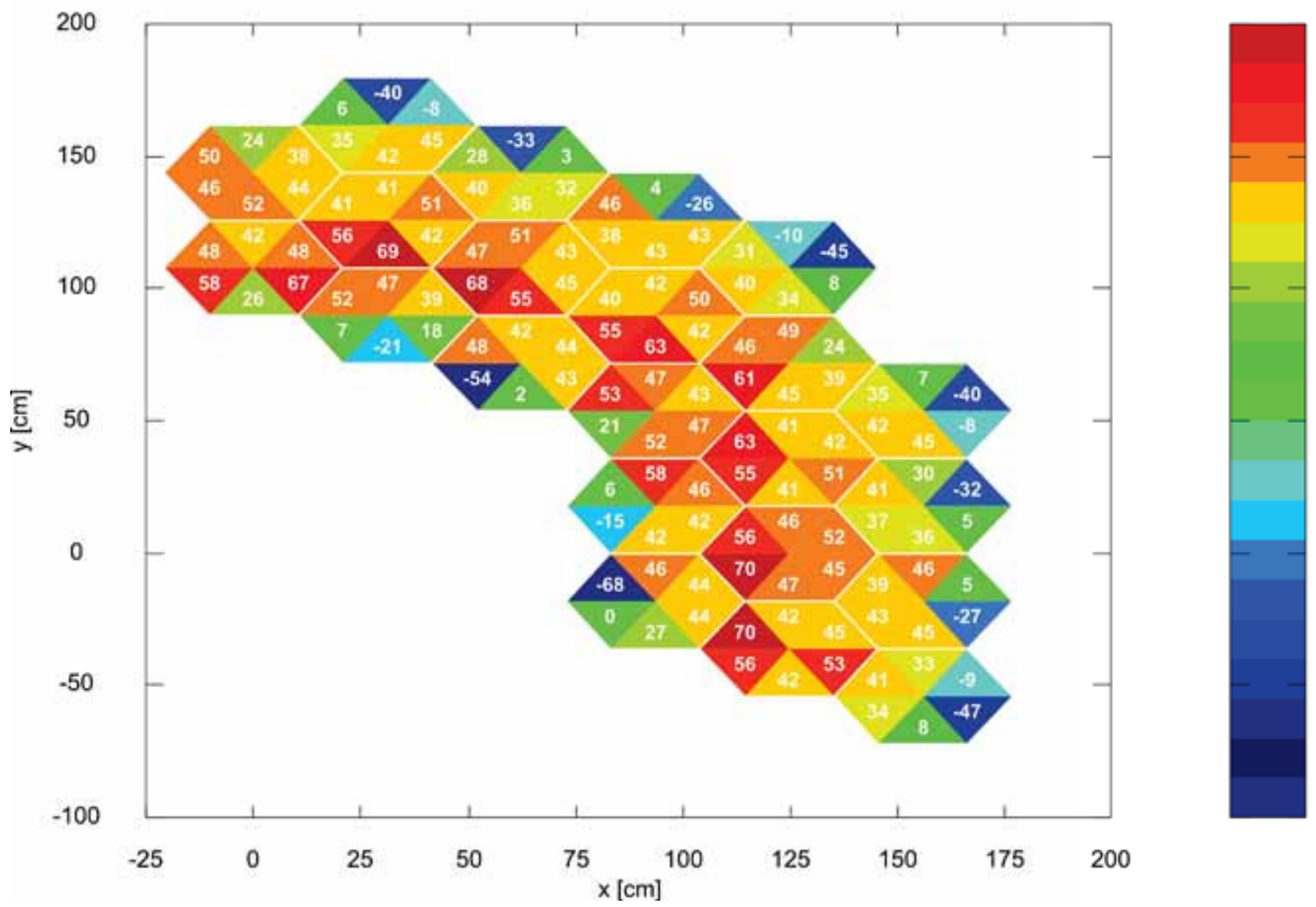

Figure 31. Average fuel temperature difference $\left({ }^{\circ} \mathrm{C}\right)$ between Exercise $2 \mathrm{a}$ and Exercise $2 \mathrm{~b}$ on Axial Level 1 (first bottom core level) for the block model.

The use of a simple volume-averaged ring model in Rings 1 and 2 of the inner reflector (for both models) to simulate the $1.7 \%(2.7 \mathrm{~kg} / \mathrm{s})$ bypass flow in this region can lead to either under- or overestimate of the heat removal rate in this region. This can however only be quantified when comparison data are available from higher fidelity codes at a later stage of the benchmark.

The benchmark specification indicates that the important physical phenomena of non-local heat deposition in the reflectors must not be taken into account by participants. It should be noted that Exercise $2 b$ therefore represents an unphysical MHTGR-350 scenario, since approximately $6 \%$ of all energy is deposited outside the fuel region in the reflectors via fast neutron and gamma interactions [21]. This will lead to much higher reflector temperatures, which will counter the effects of these reflector bypass flows presented here to some degree.

\subsection{Exercise 2c: RELAP5-3D Results and Discussion}

The only difference between Exercise $2 b$ and Exercise $2 c$ is the addition of the variable thermophysical properties. The RELAP5-3D MHTGR-350 benchmark model for Exercise 2c uses a number of additional graphite materials to account for the fluence dependent thermophysical properties, as prescribed in the benchmark specification. The proper modeling of the decrease in thermal conductivity with an increase in fast flux exposure is especially important for fuel and graphite temperatures during the loss of cooling transients in Phase II. The thermal conductivity and specific heat 
of graphite has been tabulated as a function of temperature, and the specified fluence distribution in the core was used to determine the number of fluent dependent RELAP5-3D materials that had to be created.

Only minor differences are observed between these two cases, since the convective heat transport of the active helium cooling during normal operation dominates the effects of changes in the material conductivity and specific heat. The difference between Exercise $2 b$ and Exercise $2 c$ will become more significant during the loss of cooling transients that will be performed for Phase II. The graphite thermal conductivity distribution in the whole core region is shown in Figure 32 (ring model) and Figure 33 (block model). The dependency of the graphite conductivity on temperature and fluence (compared to the constant values specified in Table 11) results in a large variation across the core. The highest graphite temperatures and fluence values occur inside the fuel region, resulting in the lowest conductivity values.

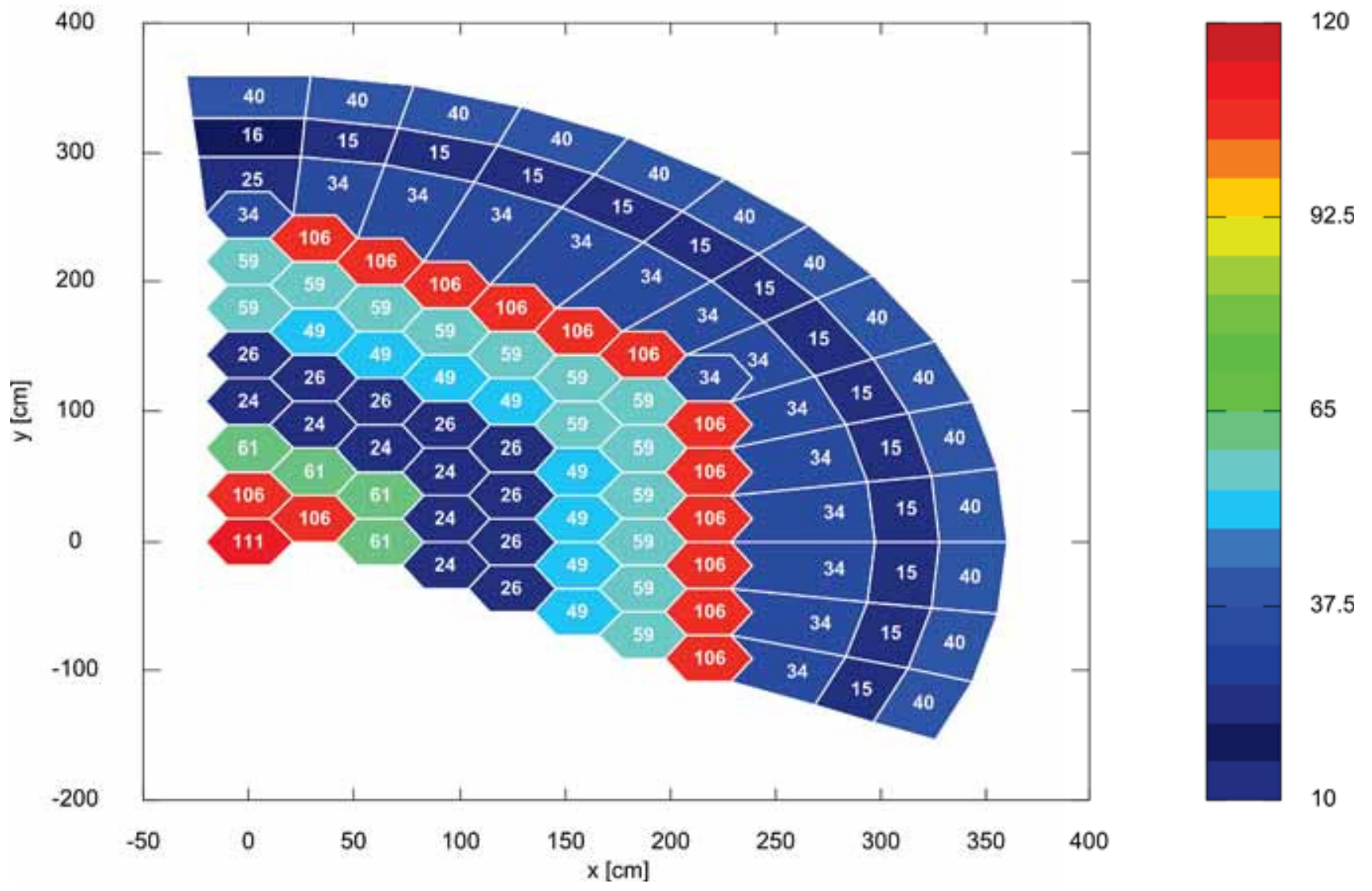

Figure 32. Exercise 2c - Thermal conductivity (W/m.K) distribution on Axial Level 7 (ring model). 

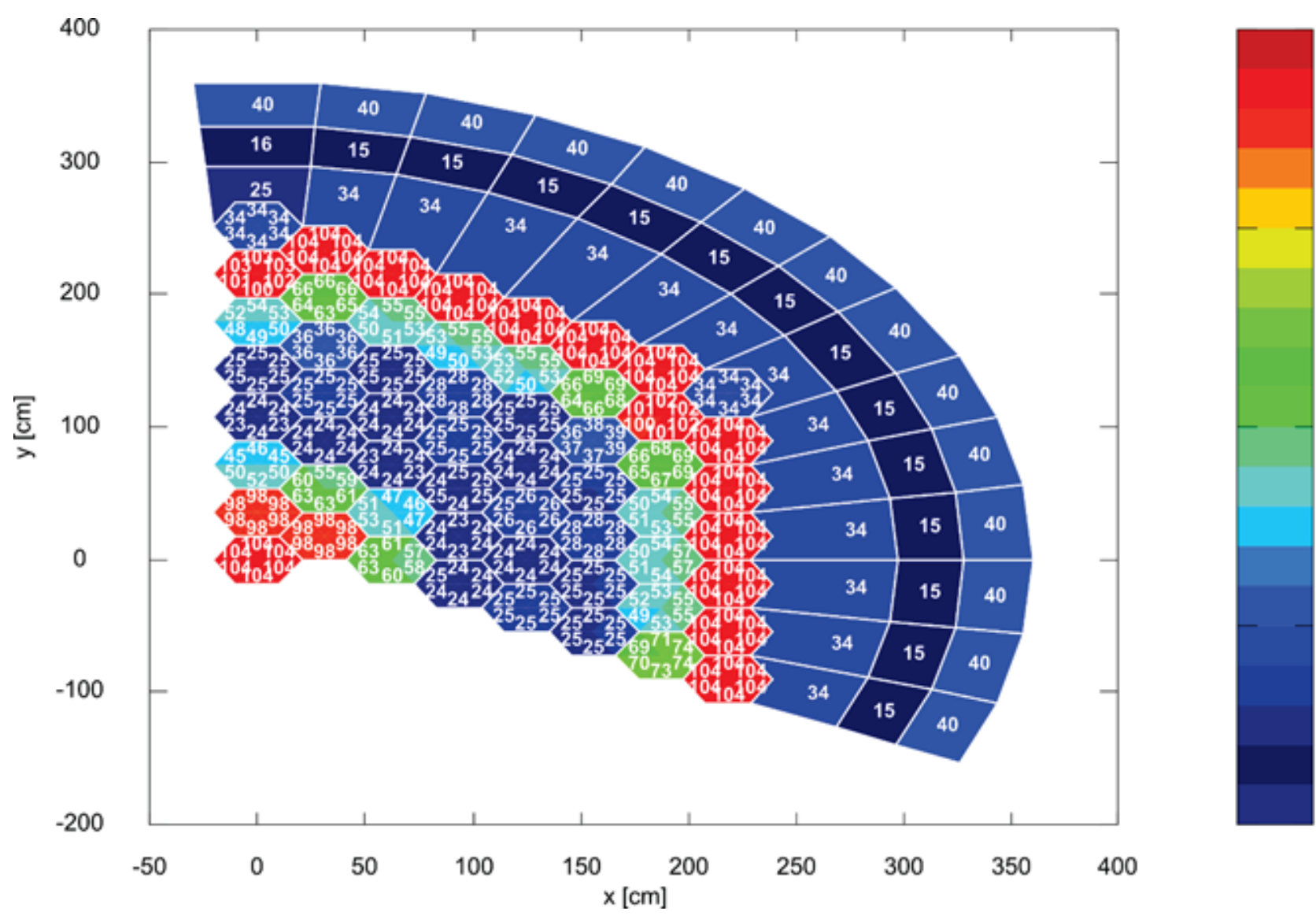

Figure 33. Exercise 2c - Thermal conductivity (W/m.K) distribution on Axial Level 7 (block model).

The Exercise 2c ring model graphite temperature data (Figure 34 ) is very similar to the values calculated for Exercise $2 \mathrm{~b}$ (Figure 28). The relative differences (\%) between Exercise $2 \mathrm{~b}$ and Exercise $2 \mathrm{c}$ can be observed in Figure 35 (graphite temperatures) and Figure 36 (fuel temperatures), where the largest difference of $5 \%$ occurs in the blocks of ring 8 . 

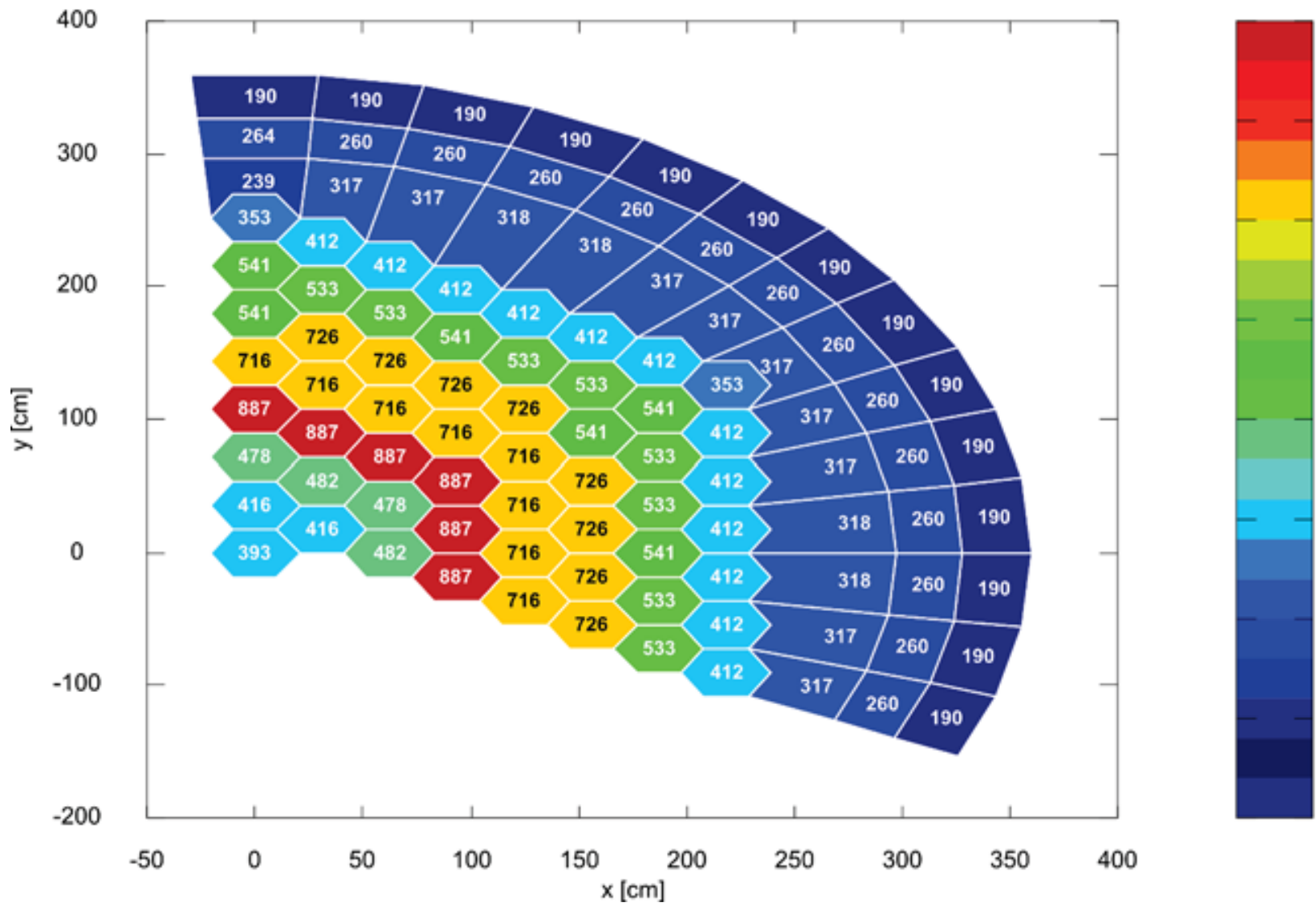

900

800

700

600

500

400

300

200

100

Figure 34. Average graphite temperature $\left({ }^{\circ} \mathrm{C}\right)$ distribution for all graphite structures in the ring model on Axial Level 1 (first bottom core level). 


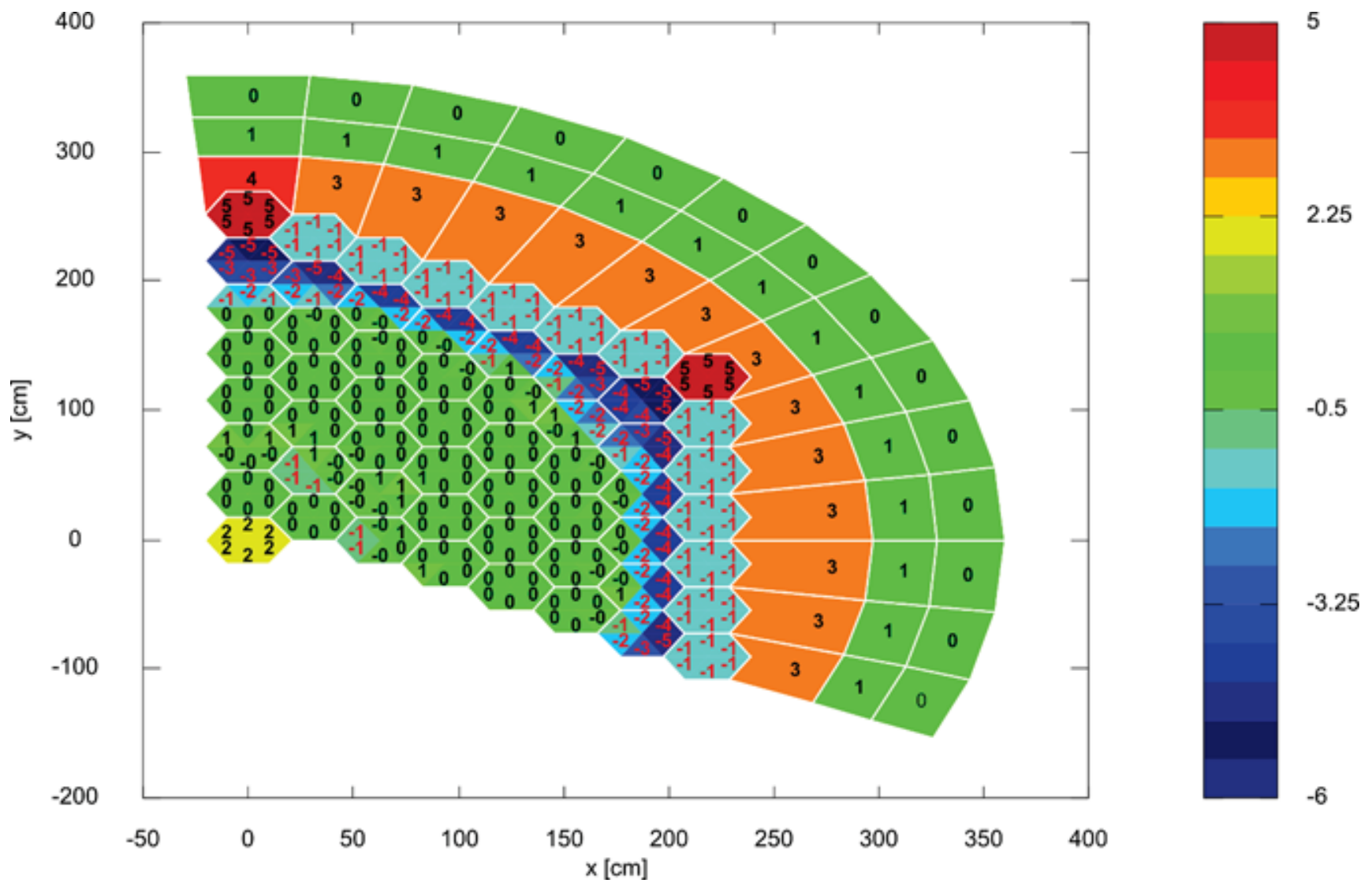

Figure 35. Average graphite temperature difference (\%) between Exercise $2 \mathrm{~b}$ and Exercise $2 \mathrm{c}$ on Axial Level (first bottom core level) for the block model. 


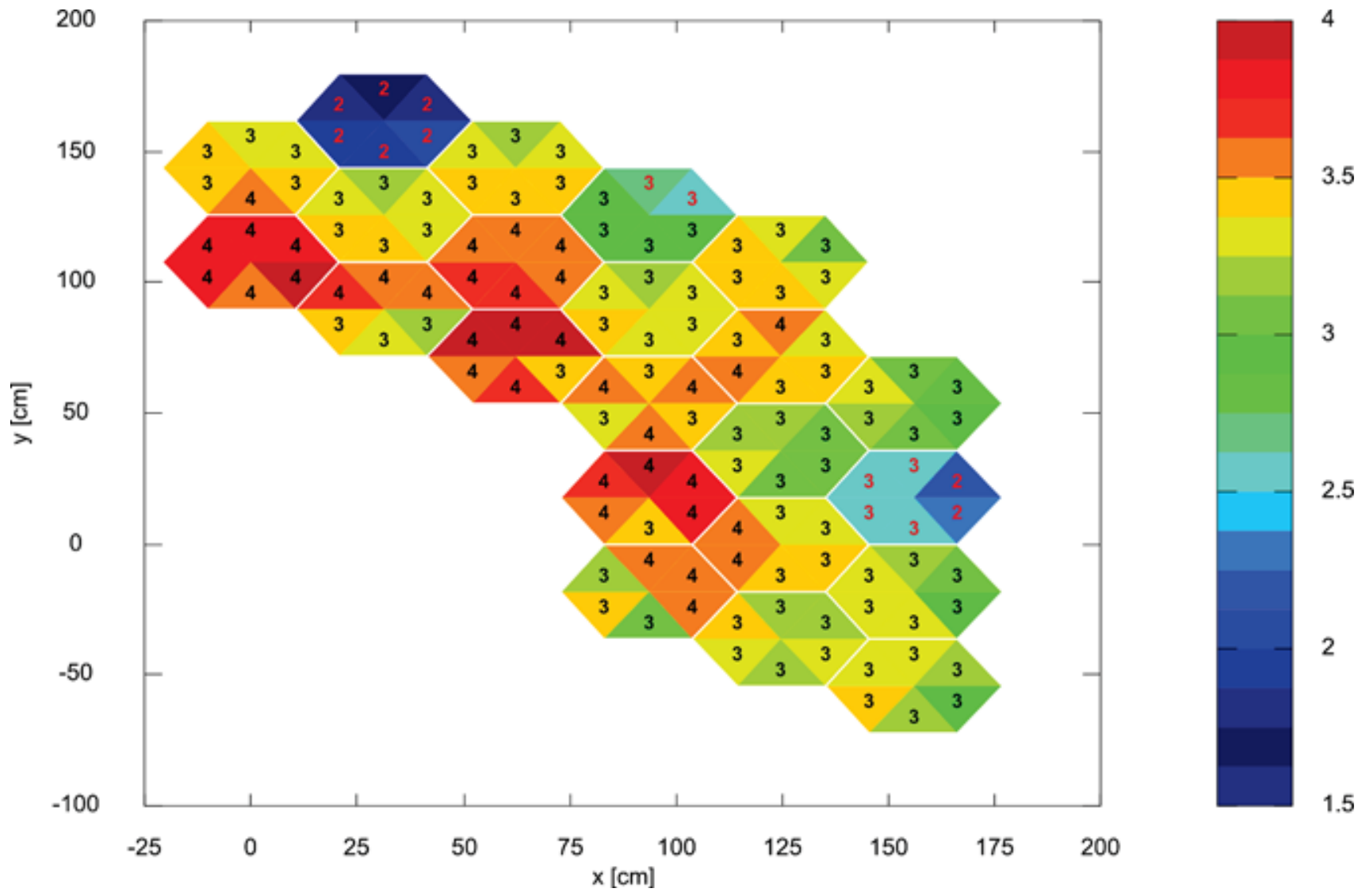

Figure 36. Average fuel temperature difference (\%) between Exercise $2 b$ and Exercise $2 c$ on Axial Level 10 (top of core level) for the block model.

\subsection{Exercise 2d: Results and Discussion}

Exercise $2 \mathrm{~d}$ combines the effects of bypass flows and variable thermophysical properties. The difference between Exercise $2 \mathrm{c}$ and Exercise $2 \mathrm{~d}$ is the specification that the participant must use the real geometry of the MHTGR-350 to determine the converged bypass flows in the $2 \mathrm{~mm}$ gaps that exist between all blocks, as well as the $3.5 \mathrm{~mm}$ gap between the outer reflector and the CB. This Exercise is designed to capture the high resolution and fidelity of provided by Computational Fluid Dynamics (CFD) is capable. Since the intended design use of RELAP5-3D is typically thermal system analysis of a lower fidelity, the current RELAP5-3D model can only approximately the real geometry of these gaps with a network of 1D pipe elements.

A comparison of the RELAP5-3D bypass flows obtained for Exercise $2 \mathrm{c}$ and Exercise $2 \mathrm{~d}$ is presented in Table 15 for both the ring and block models. A target of $11 \%$ was set for Exercise $2 \mathrm{c}$, and although the exact spatial distribution between the seven channels was not fully achieved, the relative inner reflector, core and outer reflector bypass flows were obtained by introducing artificial flow resistance factors in the bypass pipes. For Exercise 2d, the flow resistance factors were all set to zero, and the resultant total bypass flow determined by RELAP5-3D is between $2.7 \%$ (ring model) and 3.2\% (block model) higher than the Type I fixed flow specification. 
Table 15. Comparison of RELAP5-3D bypass flows (\% of total flow) obtained for Exercise $2 \mathrm{c}$ and Exercise 2d.

\begin{tabular}{|ll|c|c|c|c|c|}
\hline \multicolumn{1}{|c|}{ Component } & $\begin{array}{c}\text { Exercise 2c } \\
\text { Target }\end{array}$ & $\begin{array}{c}\text { Exercise 2c } \\
\text { Ring }\end{array}$ & $\begin{array}{c}\text { Exercise 2c } \\
\text { Block }\end{array}$ & $\begin{array}{c}\text { Exercise 2d } \\
\text { Ring }\end{array}$ & $\begin{array}{c}\text { Exercise 2d } \\
\text { Block }\end{array}$ \\
\hline 1. & In-core & 1.50 & 1.63 & 2.34 & 2.26 & 2.85 \\
\hline 2. & Inner Reflector & 0.50 & 0.70 & 0.77 & 0.66 & 0.74 \\
\hline 3. & Inner CR Cooling & 1.20 & 0.78 & 0.72 & 0.74 & 0.60 \\
\hline 4. & Outer CR Cooling & 1.80 & 1.79 & 2.33 & 2.90 & 2.59 \\
\hline 5. & Outer Reflector (First Ring) & 1.38 & 1.35 & 0.48 & 1.47 & 0.46 \\
\hline 6. & Outer Reflector (Second Ring) & 1.62 & 1.55 & 1.78 & 1.48 & 1.71 \\
\hline 7. & Permanent Side Reflector & 3.00 & 3.11 & 2.40 & 4.67 & 4.70 \\
\hline & Total & $\mathbf{1 1 . 0 0}$ & $\mathbf{1 0 . 9 0}$ & $\mathbf{1 0 . 8 0}$ & $\mathbf{1 4 . 1 9}$ & $\mathbf{1 3 . 6 6}$ \\
\hline
\end{tabular}

The differences between Exercise $2 \mathrm{c}$ and Exercise $2 \mathrm{~d}$ for the total bypass flow and spatial distribution are small enough that the temperature data differ by very small margins. Only three examples are presented here: the relative difference (\%) between the Exercise 2c and Exercise 2d helium (Figure 37), graphite (Figure 38) and fuel (Figure 39) temperatures. None of the relative temperature differences between these two Exercises are larger than $4 \%$.

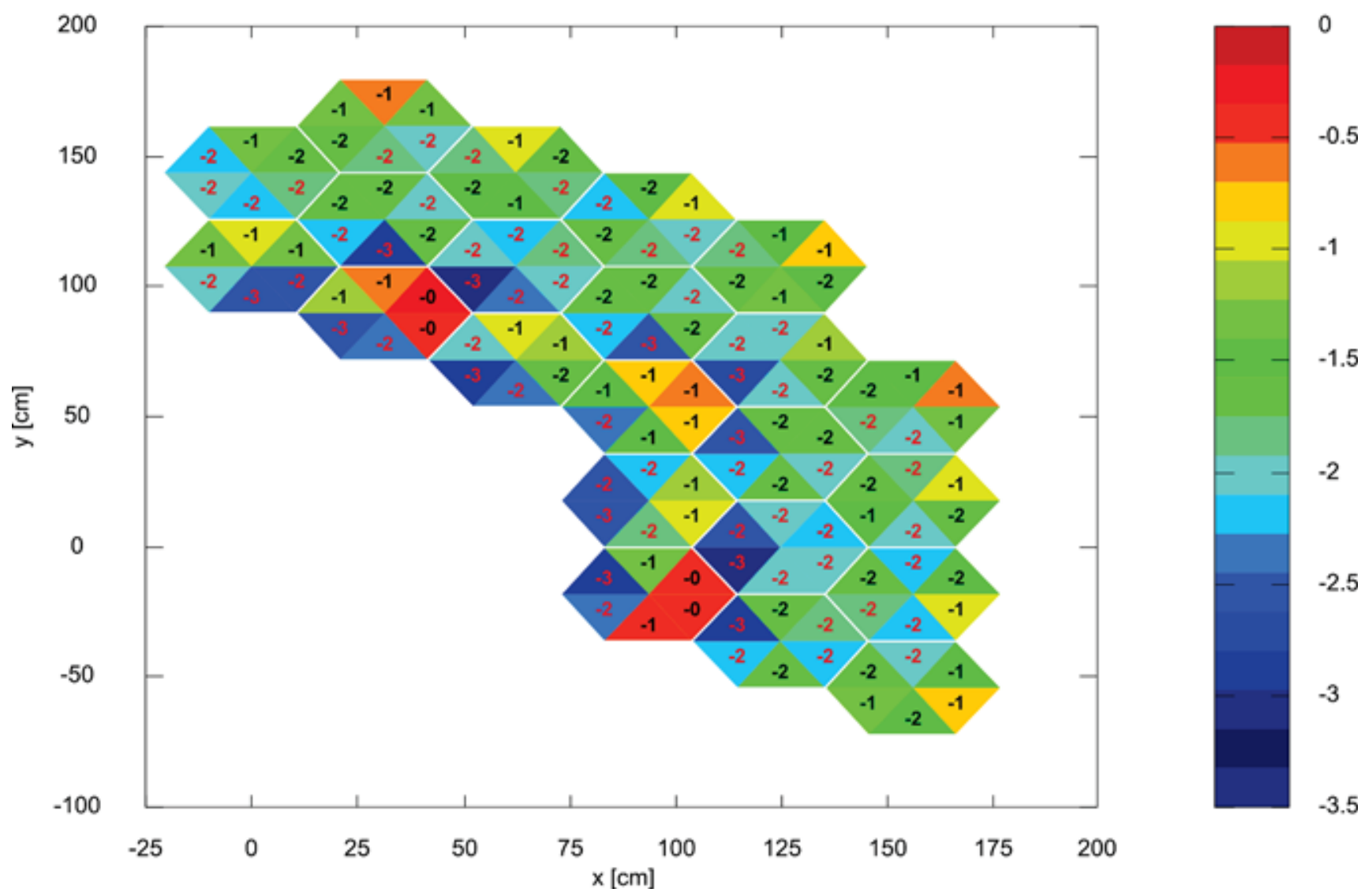

Figure 37. Average helium temperature difference (\%) between Exercise $2 \mathrm{c}$ and Exercise $2 \mathrm{~d}$ on Axial Level 1 (first bottom core level) for the block model. 

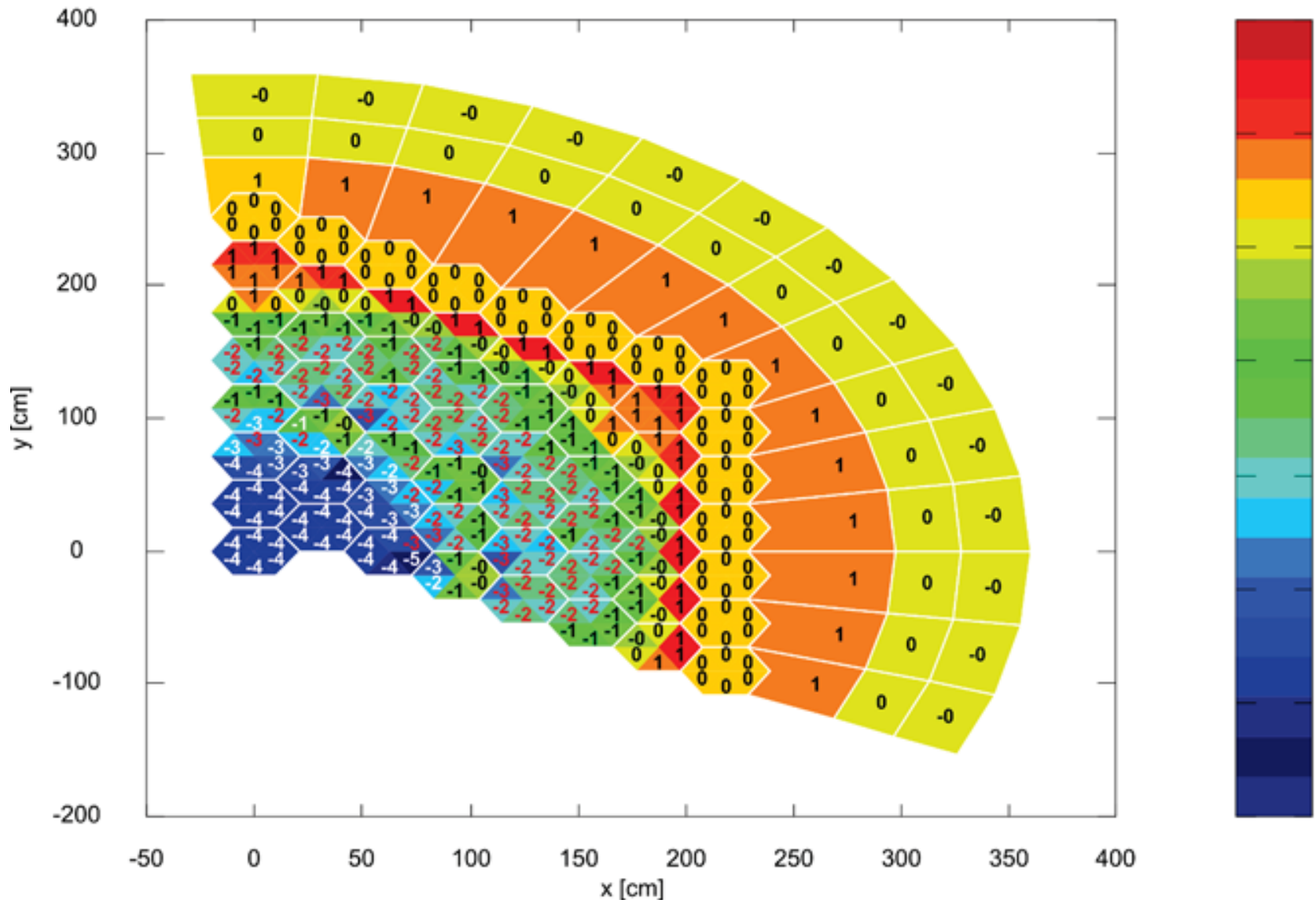

Figure 38. Average graphite temperature difference (\%) between Exercise $2 \mathrm{c}$ and Exercise $2 \mathrm{~d}$ on Axial Level 1 (first bottom core level) for the block model. 

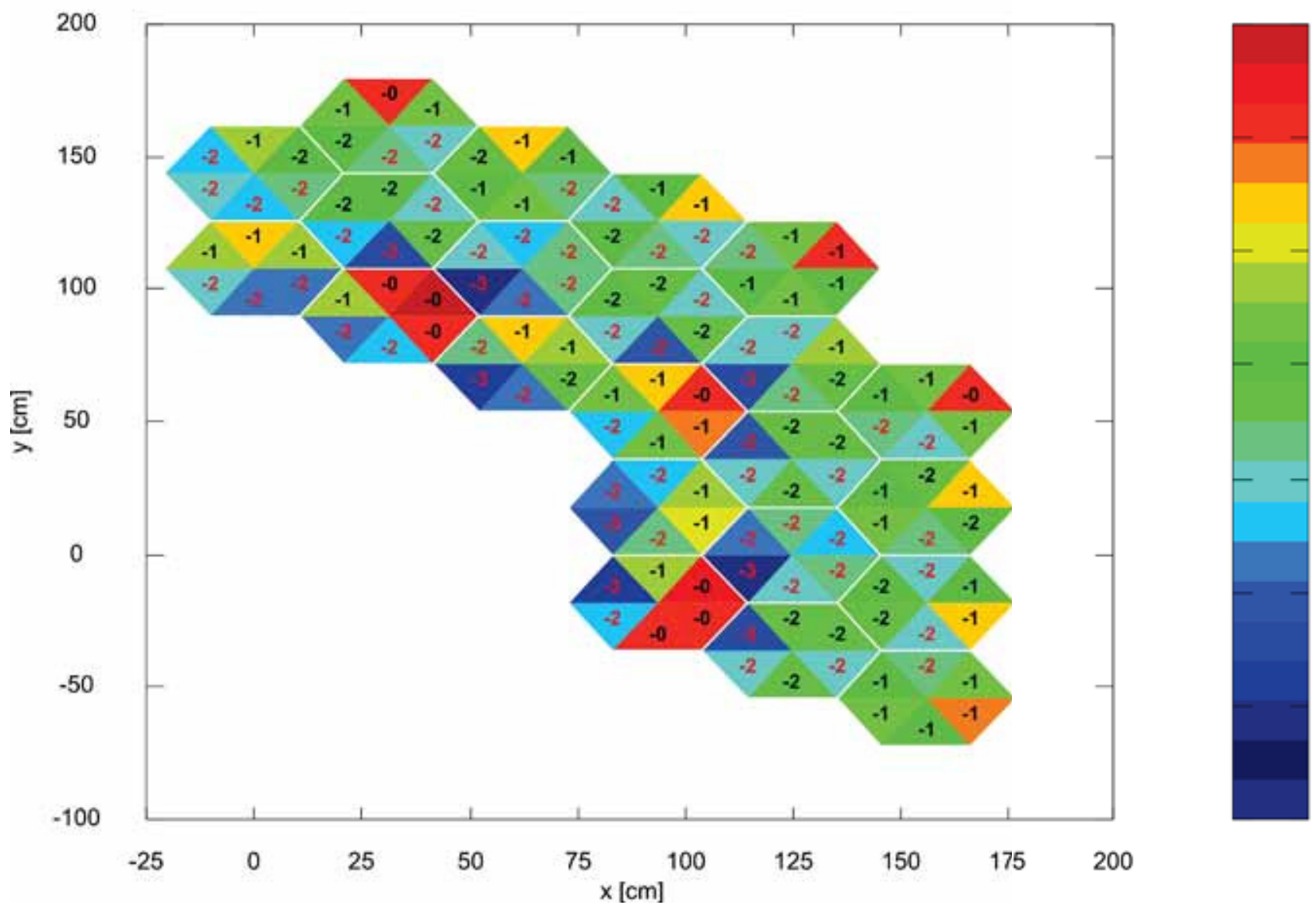

0

Figure 39. Average fuel temperature difference (\%) between Exercise 2c and Exercise 2d on Axial Level 1 (first bottom core level) for the block model.

\section{PHISICS/RELAP5-3D RESULTS FOR PHASE I: EXERCISE 3}

Exercise 3 combines the solutions of the neutronics and thermal fluid domains, and therefore requires the use of a coupled solution methodology. For Exercise 3a, a PHISICS/RELAP5-3D model is created by combining the RELAP5-3D standalone thermal fluid model developed for Exercise 2c (bypass flow Type I, variable thermophysical properties) with a RELAP5-3D kinetics section that defines the mapping to cross-section data contained in the temperature and xenon-135 dependent library lib.xml. The only variation between Exercise $3 a$ and Exercise $3 b$ occurs in the definition of the bypass flows, i.e., Exercise $2 \mathrm{c}$ forms the thermal fluid basis model for Exercise $3 \mathrm{a}$ and Exercise $2 \mathrm{~d}$ is used as the basis for Exercise 3b.

As a first step in the PHISICS/RELAP5-3D (PR5) solver scheme, the xenon equilibrium is obtained by using MRTAU to "burn" the core in 4 time steps of 2.5 days each, i.e., for a total of 10 days. This process involves four recalculations of the flux with INSTANT after every 2.5 days. During the depletion phase, the fuel and reflector temperatures for the cross-section evaluation are kept constant. For each flux recalculation with INSTANT, the macroscopic cross-section sets are first interpolated for the new xenon density. The new xenon absorption contribution for each node is then calculated with the updated xenon density and added to the macroscopic cross-section sets. Since the core is only burned for a very small duration, the assumption that all the material number densities apart from xenon remain constant is acceptable. Once xenon equilibrium is reached, RELAP5-3D iterates with INSTANT to obtain a converged temperature field for this xenon distribution. After this initial 
MRTAU-INSTANT-RELAP5-3D iteration, MRTAU burns the core again for 2.5 days to find the new xenon equilibrium corresponding to the new temperature distribution. This scheme (shown in Figure 5) is iterated until converged temperature, flux and xenon distributions are found.

As with Exercise 2, the block and ring models are again compared here to investigate the possible advantages of using a much more detailed representation of the MHTGR-350 design. The feedback between the thermal fluid solution (temperature of fuel and graphite regions from RELAP5-3D) and the neutronics solution (heat source distribution from INSTANT) is obtained via a kinetic zone mapping defined in the RELAP5-3D input file. During an iteration, RELAP5-3D uses the heat source distribution determined by INSTANT to solve an updated temperature field, and passes the information back to INSTANT for an update in the flux and poison (xenon, samarium) distributions.

A comparison between the eigenvalues and CR worths for Exercise $3 \mathrm{a}$ and Exercise $3 \mathrm{~b}$ is summarized in Table 16 for the ring and block models. These tables can also be compared with the data presented for Exercise 1 (Table 8), although it should be noted that the two Exercises use two different libraries and are calculated at significantly different state points. For Exercise 3a, the difference between the ring and block models are relatively small (less than $160 \mathrm{pcm}$ ), and the largest difference is again observed for the all rods in (ARI) case. The predicted CR worths are within $80 \mathrm{pcm}$ for the two models. A slightly different pattern is observed for Exercise 3b, where the block eigenvalues are less than the ring model values. The ARI delta $\mathrm{k}$ is also much closer to the $\mathrm{CR}$ nominal and $\mathrm{CR}$ out delta $\mathrm{k}$ values, and the two $\mathrm{CR}$ worths are almost identical. The only differences between the two cases are the fuel (Doppler) and moderator temperatures due to the slight changes in the bypass flow distribution. These temperature differences are the drivers for the small variances calculated for the two Exercises.

Table 16. Comparison of PHISICS/RELAP5-3D keff and CR worths for Exercise $3 \mathrm{a}$ and $3 \mathrm{~b}$ ring and block models

\begin{tabular}{|c|l|l|l|c|}
\hline $\begin{array}{c}\text { PHISICS-RELAP5-3D } \\
\text { Model }\end{array}$ & CR Nominal & CR All Out & CR All In & $\begin{array}{c}\text { CR Worth Delta k/k } \\
\text { (pcm) }\end{array}$ \\
\hline $3 a$ & & & & 888 \\
\hline ring & 1.03447 & 1.03593 & 1.02673 & 965 \\
\hline block & 1.03394 & 1.03511 & 1.02513 & \\
\hline delta k & 53 & 81 & 160 & 926 \\
\hline $3 b$ & & & & 922 \\
\hline ring & 1.03336 & 1.03450 & 1.02493 & \\
\hline block & 1.03384 & 1.03503 & 1.02549 & \\
\hline delta k & -48 & -52 & -56 & \\
\hline
\end{tabular}

A few of the global parameters for Exercise $3 a$ and Exercise $3 b$ are summarized in Table 17. With the exception of the core pressure drop, the values are almost identical, since the changes in bypass flow distribution should not affect these global variables. 
Table 17. Comparison of Phase I Exercise 2 and Exercise 3 PHISICS/RELAP5-3D thermal fluid results for the ring model.

\begin{tabular}{|l|c|c|c|c|c|}
\hline Model & $\begin{array}{c}\text { Memperature } \\
\left({ }^{\circ} \mathrm{C}\right)\end{array}$ & $\begin{array}{c}\text { Maximum RV } \\
\text { Temperature } \\
\left({ }^{\circ} \mathrm{C}\right)\end{array}$ & $\begin{array}{c}\text { System Inlet } \\
\text { Pressure } \\
(\mathrm{MPa})\end{array}$ & $\begin{array}{c}\text { Pressure Drop } \\
\text { Over Core } \\
(\mathrm{kPa})\end{array}$ & $\begin{array}{c}\text { Heat Loss from } \\
\text { RV Boundary } \\
(\mathrm{MW})\end{array}$ \\
\hline Ring & \multicolumn{7}{|l}{} \\
\hline ex_3a & 263 & 206 & 6.412 & 22.1 & 0.712 \\
\hline ex_3b & 263 & 206 & 6.411 & 20.9 & 0.712 \\
\hline Block & 255 & 205 & 6.412 & 21.7 & 0.706 \\
\hline ex_3a & 255 & 205 & 6.412 & 22.1 & 0.706 \\
\hline ex_3b &
\end{tabular}

The power density distribution reaches a maximum axial value on level 8. A comparison is shown between the power densities for Exercise $3 a$ and Exercise $3 b$ in Figure 40 and Figure 41, where it can be seen that the values for Exercise $3 b$ is only slightly higher compared to the Exercise $3 a$ data. In Figure 42 and Figure 43, fast and thermal flux data examples are shown for two of the 26 groups. The Exercise $3 a$ data shown here was taken at axial level 8 where the power profiles reach a maximum value. The fast flux peak in the fuel regions of the core is clearly visible in Group 2 (Figure 42), whereas the peak thermal flux occurs in Group 21 and in the inner reflector as the fast neutrons are thermalized. 

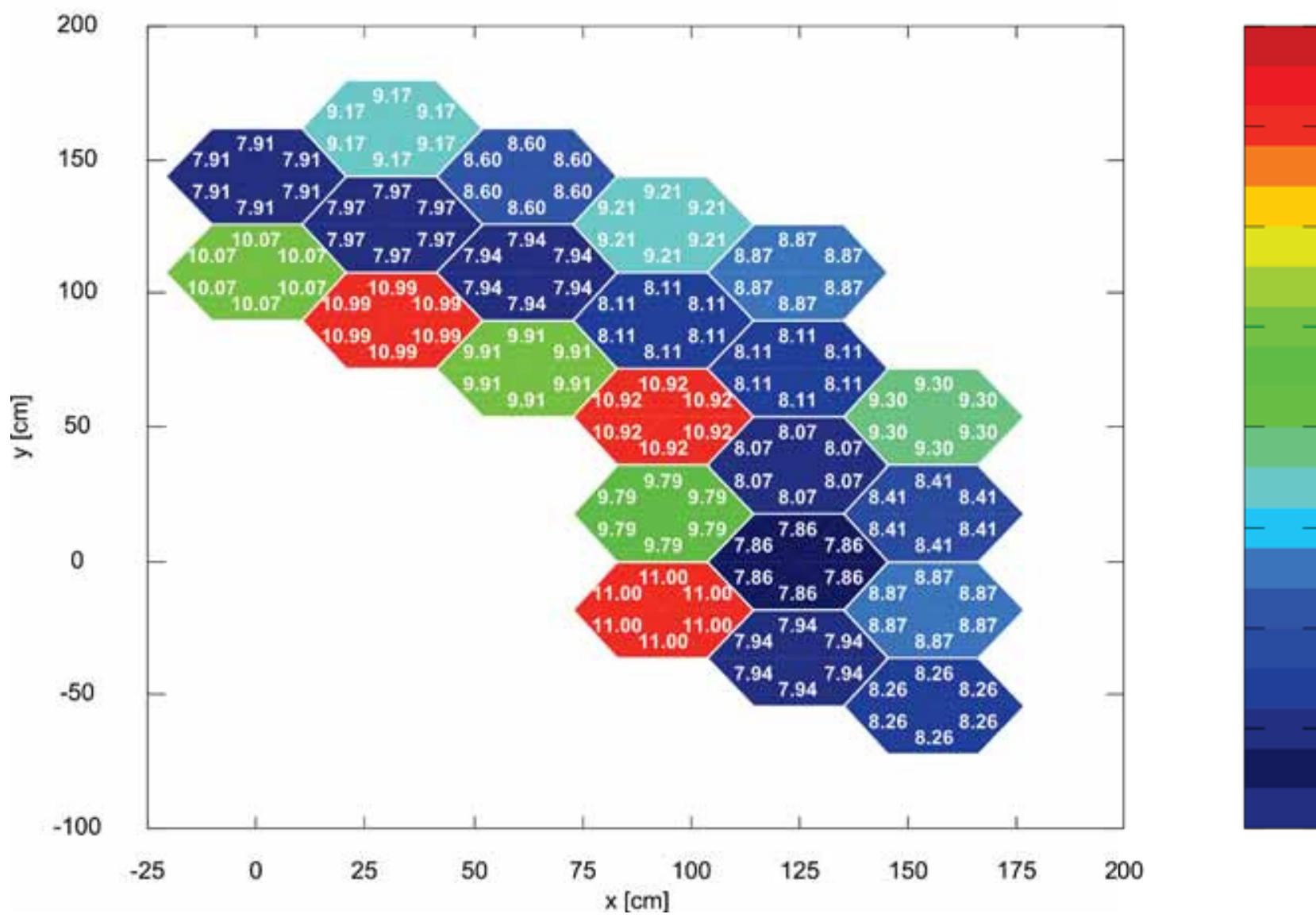

11.5

11

10.5

10

9.5

9

8.5

8

7.5

Figure 40. Exercise 3a - Power density $\left(\mathrm{W} / \mathrm{cm}^{3}\right)$ distribution on Axial Level 8 for the block model. 


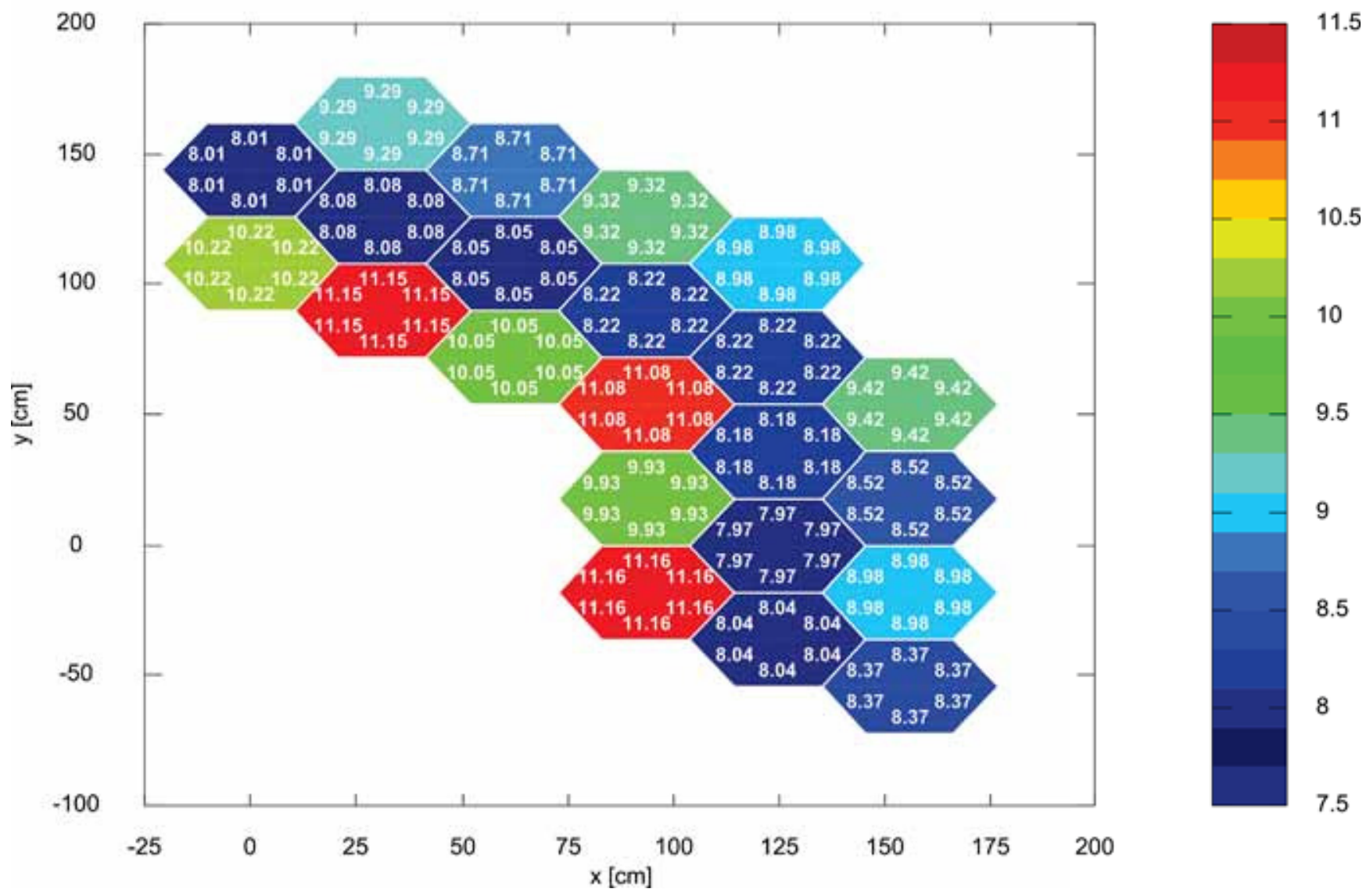

Figure 41. Exercise 3b - Power density $\left(\mathrm{W} / \mathrm{cm}^{3}\right)$ distribution on Axial Level 8 for the block model. 


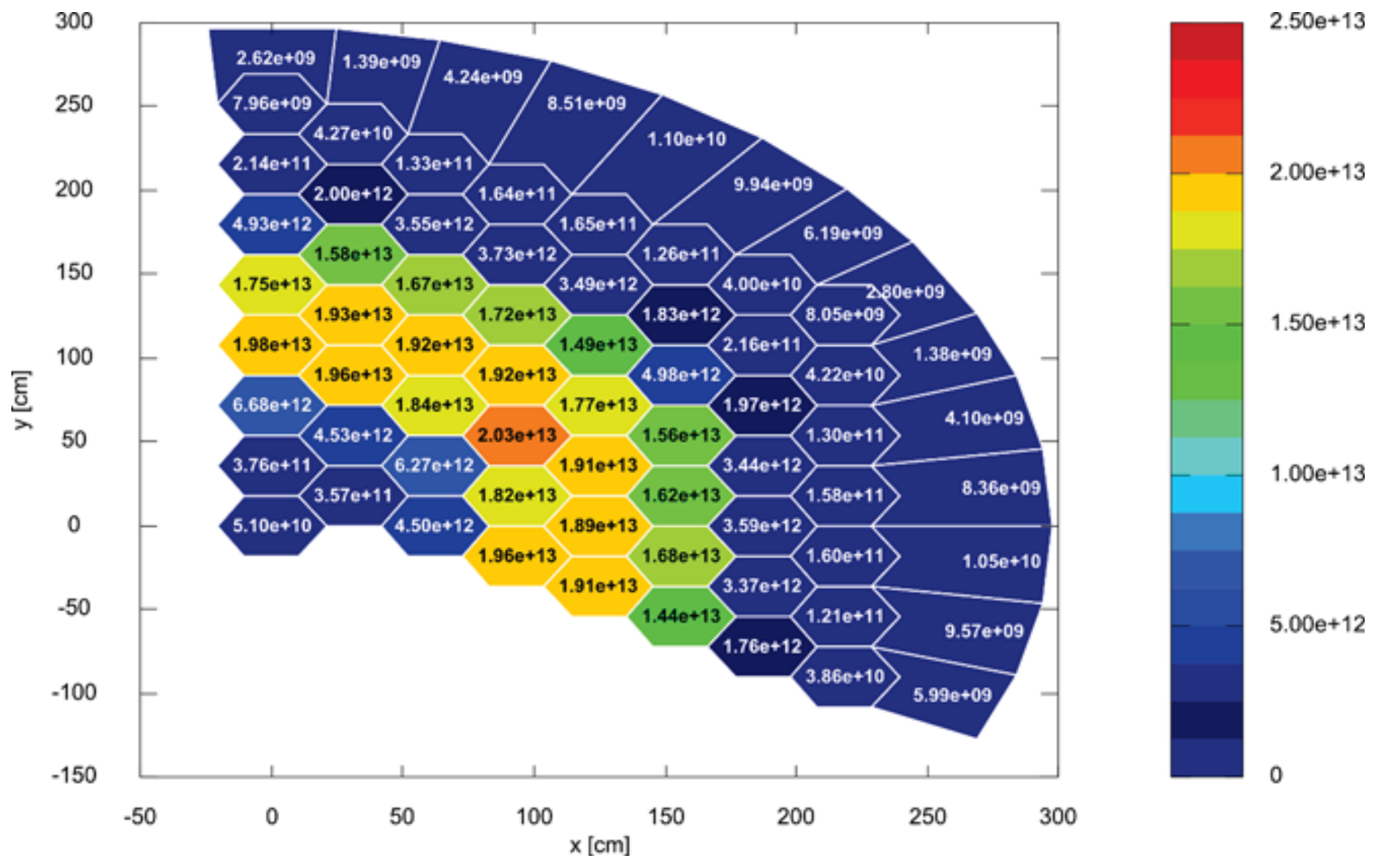

Figure 42. Exercise 3a - Group 2 flux distribution on Axial Level 8 for the block model (fast peak value). 


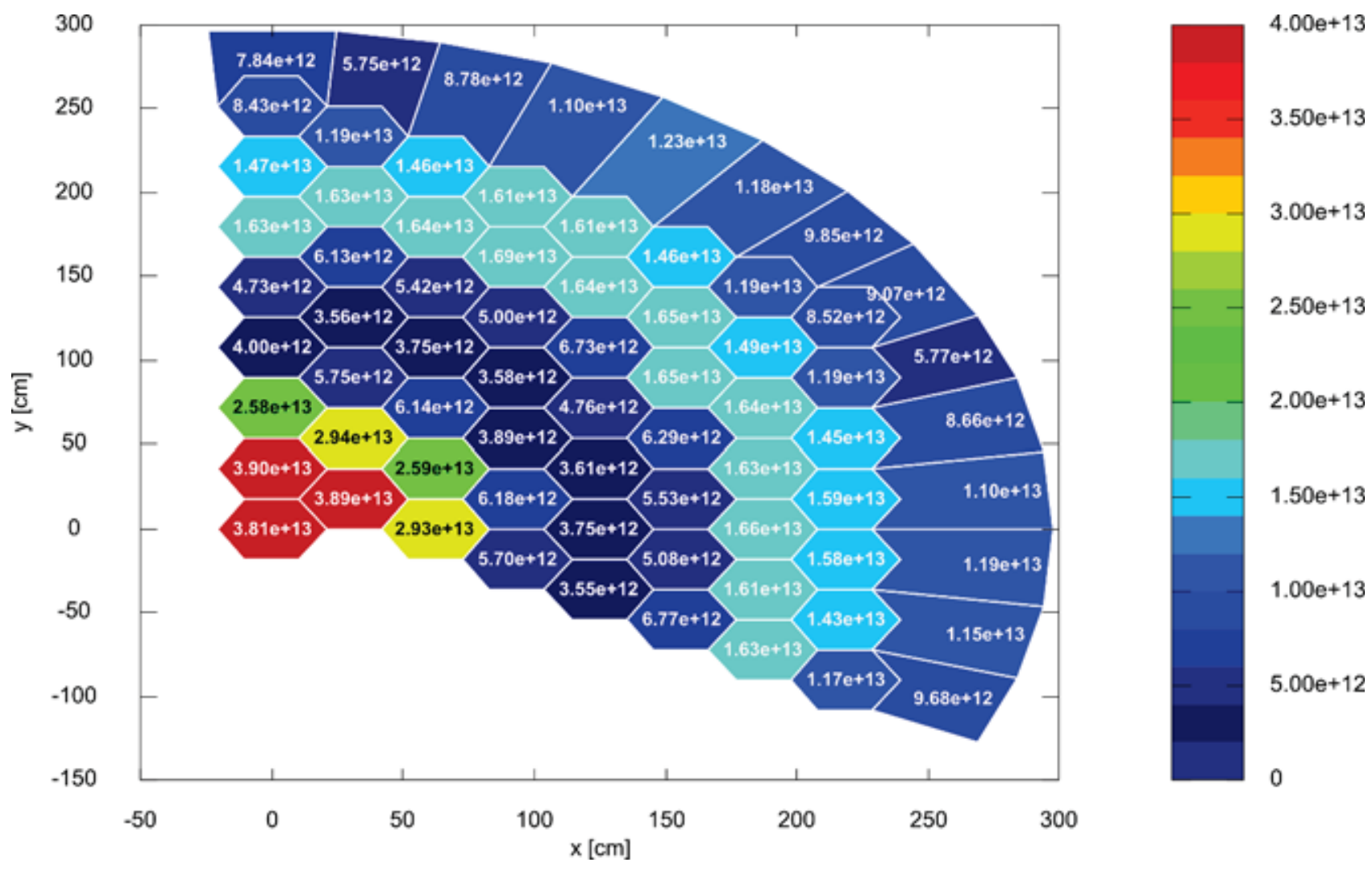

Figure 43. Exercise 3a-Group 21 flux distribution on Axial Level 8 for the block model (thermal peak value).

The final examples in this section provide a small subset of the available temperature data for Exercise $3 \mathrm{a}$ and Exercise $3 \mathrm{~b}$. The relative difference (\%) in the helium temperature distribution between Exercise $2 \mathrm{~d}$ and Exercise $3 \mathrm{~b}$ is shown in Figure 44 for the bottom of the core. The values here differ less than $7 \%$ (colder), but differences as high as $12 \%$ are observed in the upper region of the core (Figure 45). A similar pattern is seen for the average fuel temperatures (Figure 46 and Figure 47), and even higher differences up to $23 \%$ is calculated for Block 29 . 


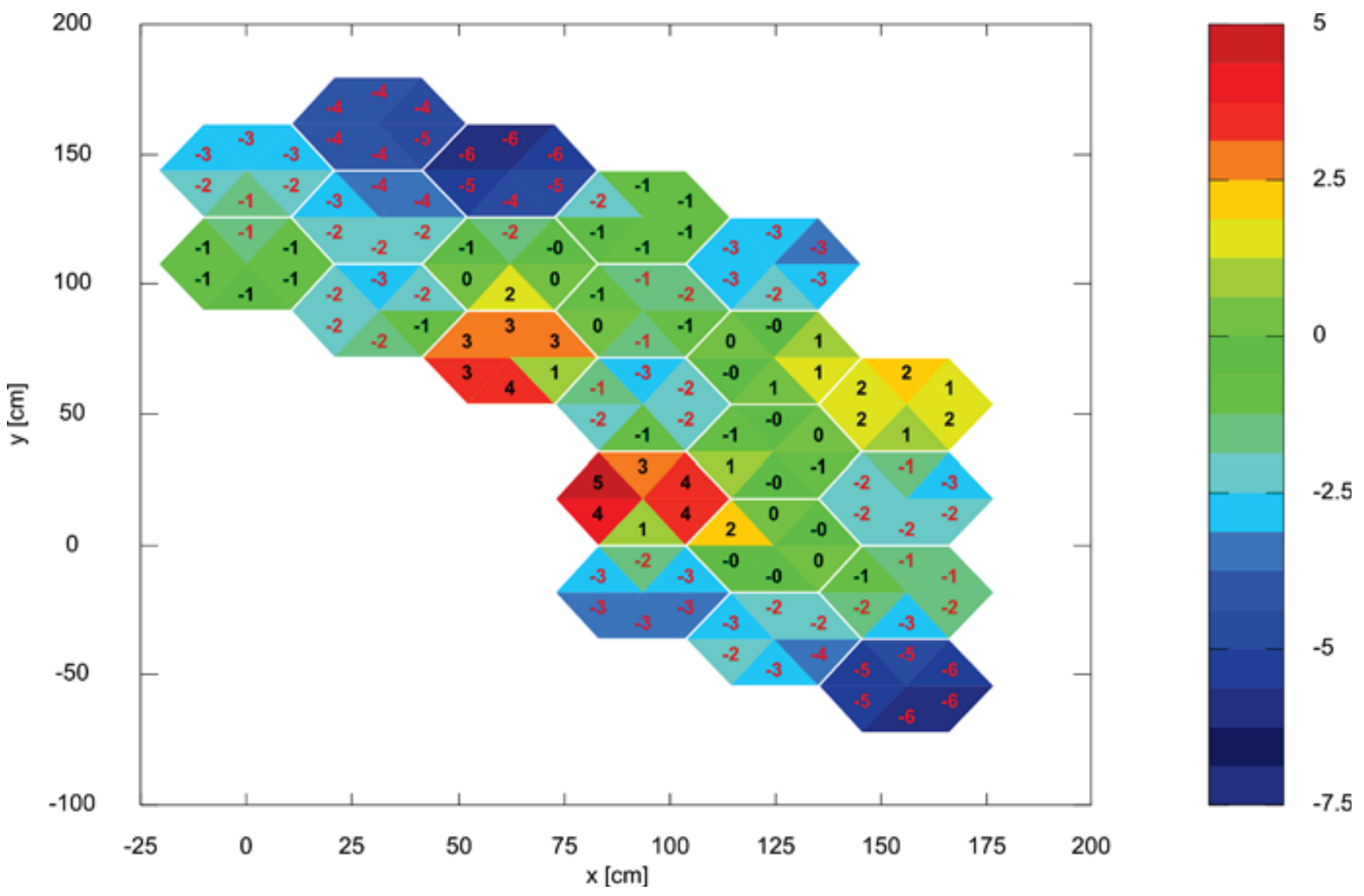

Figure 44. Average helium temperature difference (\%) between Exercise 2d and Exercise $3 \mathrm{~b}$ on Axial Level 1 (first bottom core level) for the block model. 


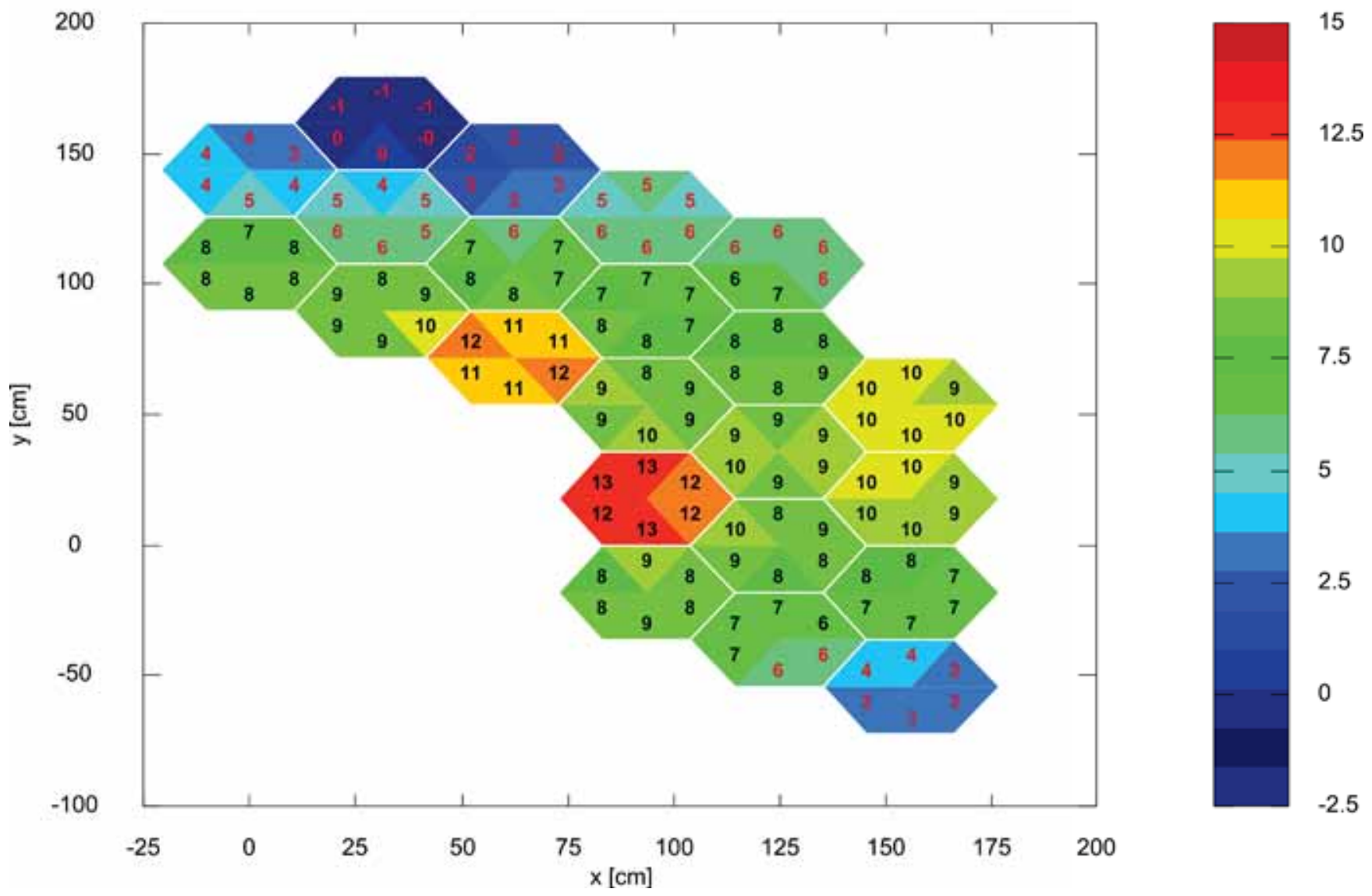

Figure 45. Average helium temperature difference (\%) between Exercise $2 \mathrm{~d}$ and Exercise $3 \mathrm{~b}$ on Axial Level 10 (top of core) for the block model. 


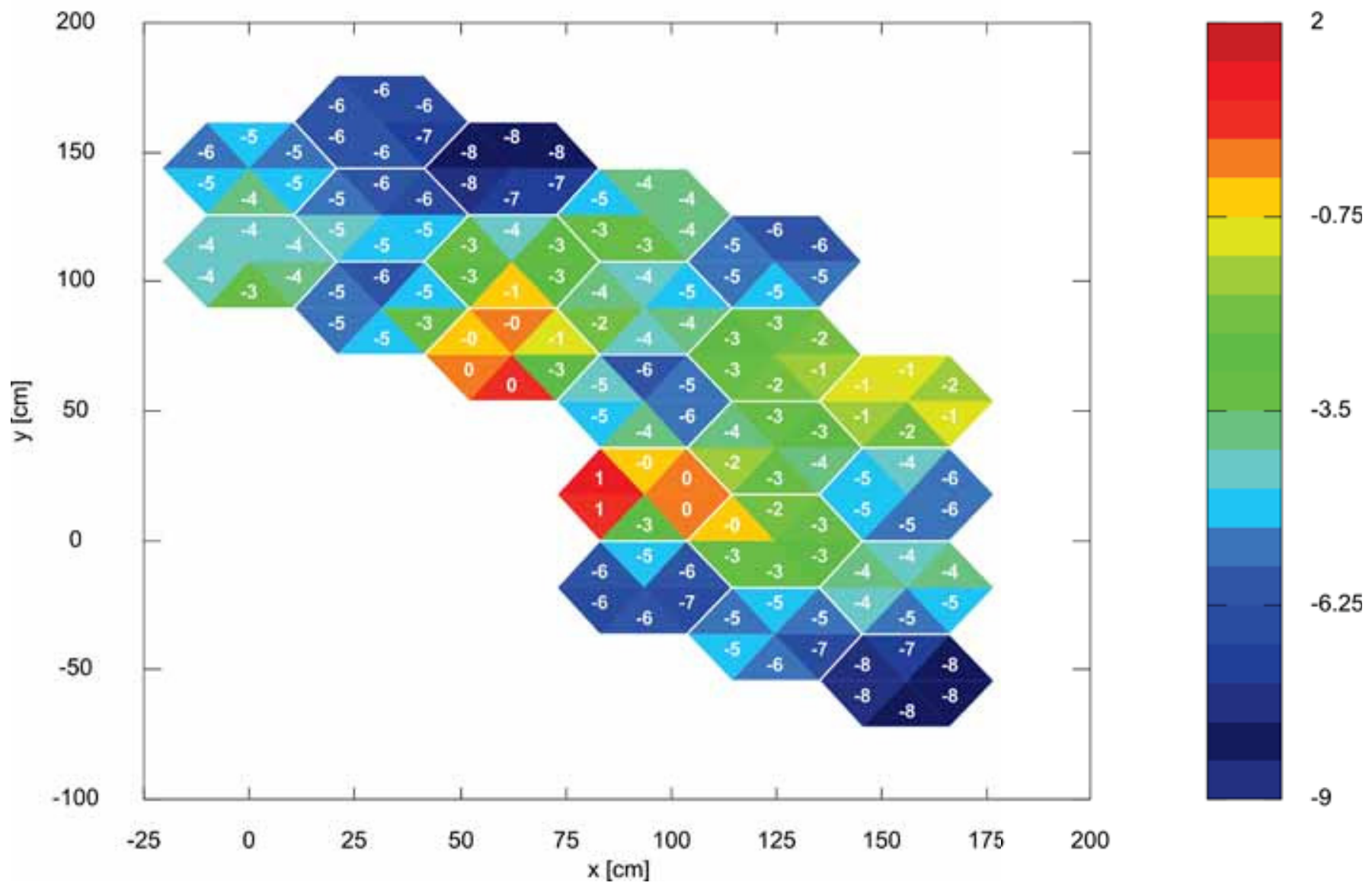

Figure 46. Average fuel temperature difference (\%) between Exercise $2 \mathrm{~d}$ and Exercise $3 \mathrm{~b}$ on Axial Level 1(first bottom core level) for the block model. 


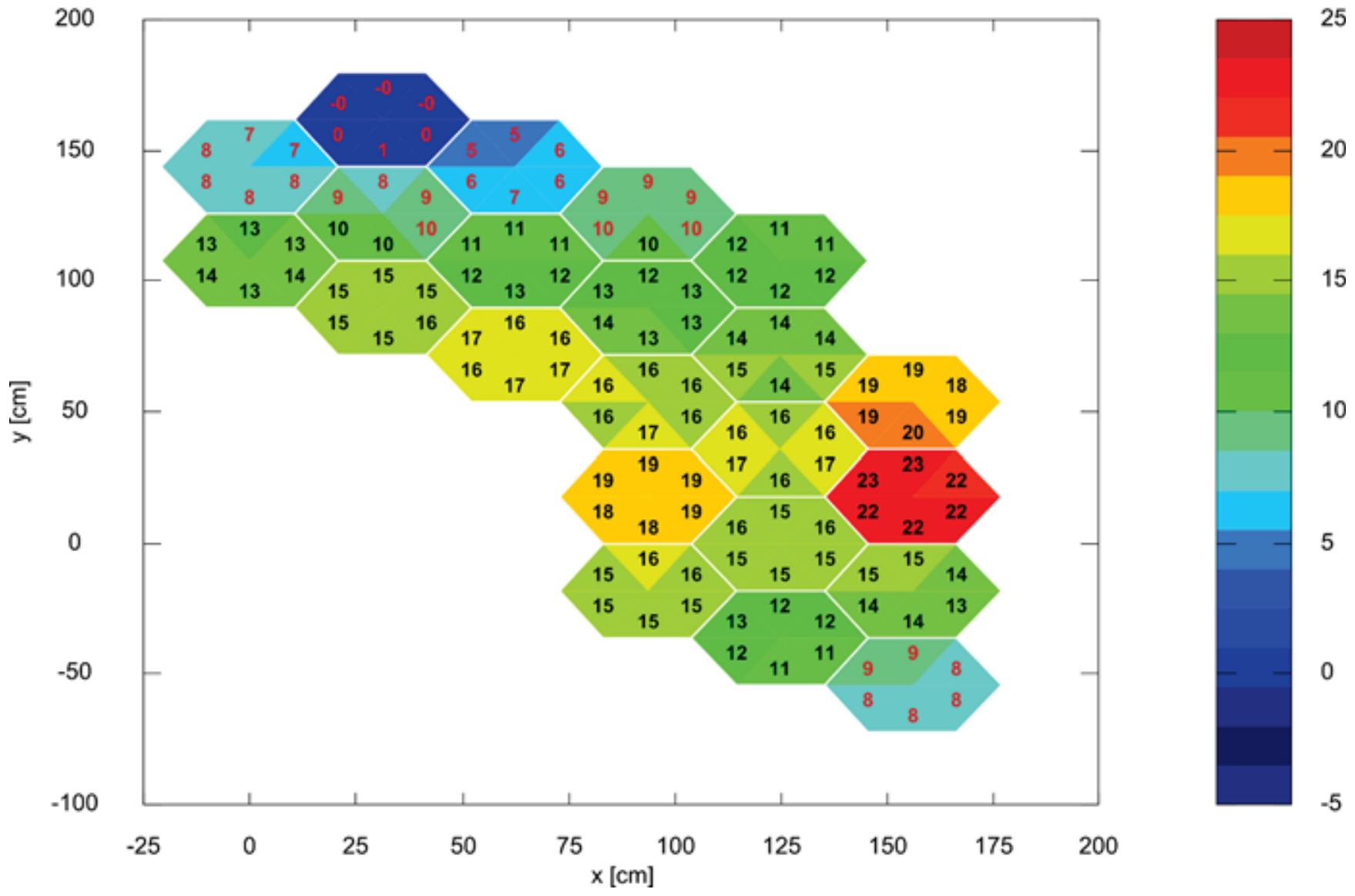

Figure 47. Average fuel temperature difference (\%) between Exercise $2 \mathrm{~d}$ and Exercise $3 \mathrm{~b}$ on Axial Level 10 (top of core) for the block model.

A comparison of the axial temperature and power density profiles for block 9 are presented in Figure 48 and Figure 49 for Exercises 1, 2d, 3a and 3b, respectively. The power density axial profile for Exercise 1 is closer to the classical cosine shape since all cross-sections were evaluated at the same basis temperature $\left(900^{\circ} \mathrm{C}\right)$, whereas the feedback effects of xenon, the control rod position and the fuel and moderator temperatures in Exercise 3 shift the power production significantly upwards (the primary influence is the temperature effect). The fixed power profile for Exercise $2 \mathrm{~d}$ (specified as input) is inbetween the profiles of Exercise 1 and 3b, but a significant difference is still observed in the fuel temperatures between Exercises $2 \mathrm{~d}$ and $3 \mathrm{~b}$, where the upper cooler regions of the core lead to a pronounced increase in power density when the temperature feedback is taken into account. 


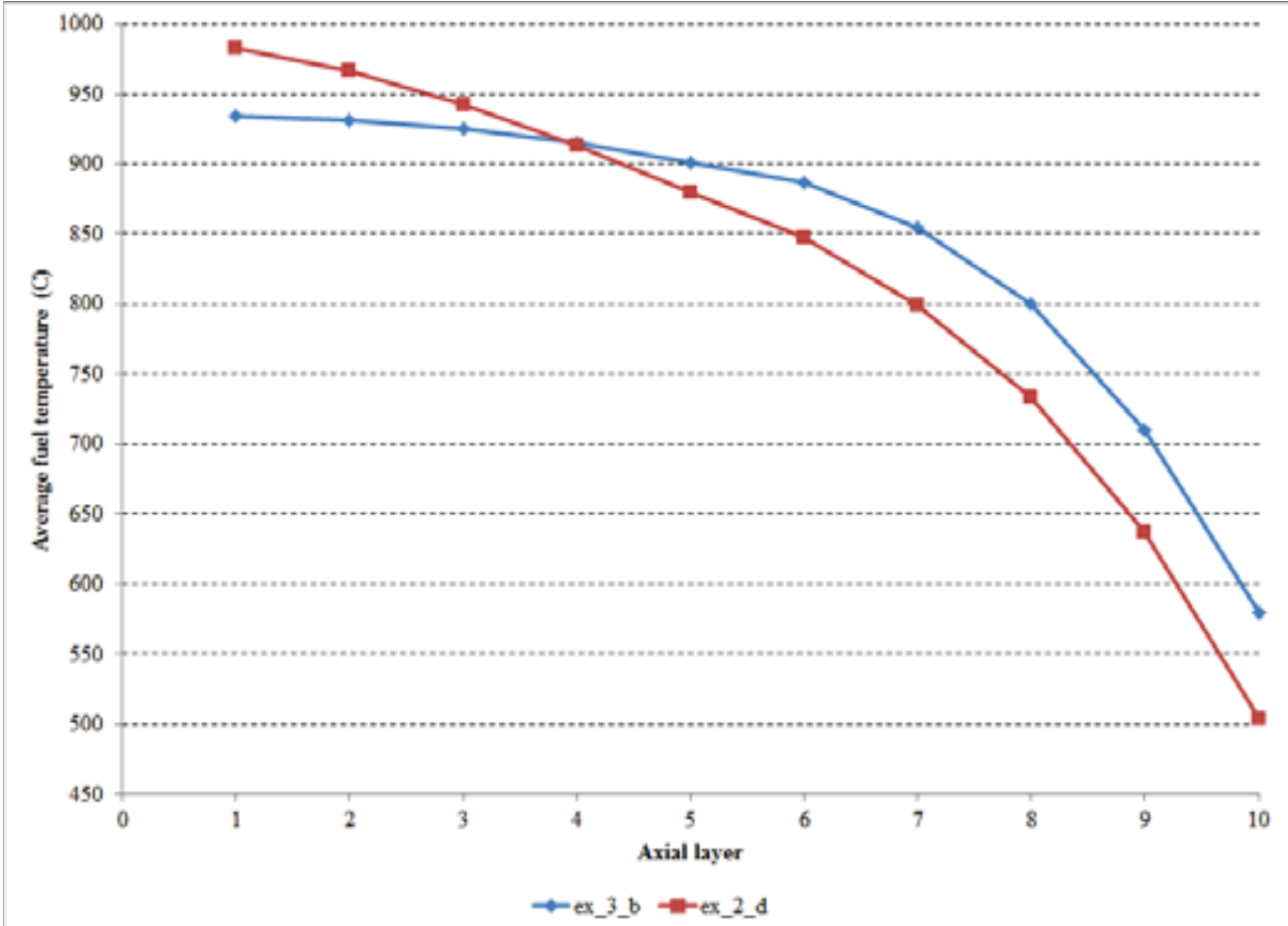

Figure 48. Comparison of Block 9 axial average fuel temperature $\left({ }^{\circ} \mathrm{C}\right)$ profiles for Exercise $2 \mathrm{~d}$ and Exercise $3 b$.

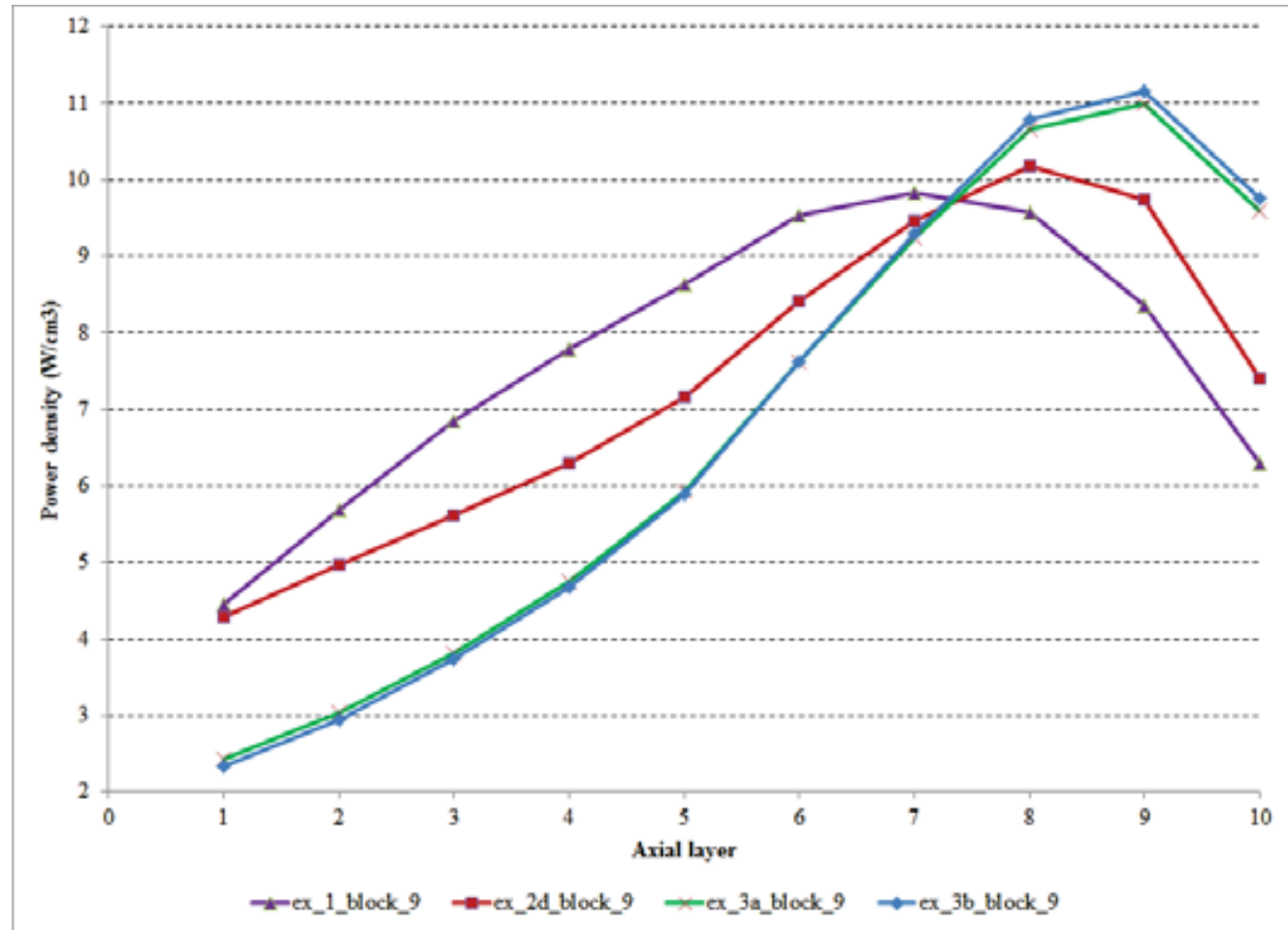

Figure 49. Comparison of Block 9 power density profiles $\left(\mathrm{W} / \mathrm{cm}^{3}\right)$ for Exercises $1,2 \mathrm{~d}, 3 \mathrm{a}$ and $3 \mathrm{~b}$. 


\section{PHASE III RESULTS}

\subsection{Description of the Exercises}

The traditional two-step method of analysis (modeling of individual fuel blocks using lattice codes to provide homogenized cross-sections for subsequent whole-core calculations) does not adequately capture the long range neutronic coupling of the various regions within high temperature reactors. Conventional application of the method introduces errors of magnitudes not observed when it is applied to LWRs or fast reactors. In LWRs, assembly-level heterogeneities are significant but for the most part localized, allowing an assembly to be homogenized independently of where it is placed in the core. Fast reactors pose the opposite challenge; core characteristics are much less sensitive to heterogeneities within the individual driver assemblies but it is very important to account for the coupling between them in the whole core simulation. High temperature reactors fall in between. Block-level heterogeneity (compacts, graphite, coolant channels, and absorber elements) is significant enough to require detailed lattice calculations but the longer migration length of neutrons in graphite (relative to that in water) means that the effects will spill over into the neighboring blocks. The dominant spectral effects in prismatic high temperature reactors are, for the most part, distributed over larger regions; but with lower magnitude, mostly due to the specific properties of graphite. Methods employed for pebble bed reactors such as the 1-D supercell approach used in PEBBED [32] or the few-group buckling treatment used in VSOP [33] are inadequate for their prismatic counterparts because of the considerable multi-dimensional asymmetry of the blocks. Considerable challenges exist in the modeling of blocks in the vicinity of reflectors, which, for current small modular reactor designs with thin annular cores, include the majority of the blocks. Additional challenges involve the treatment of Fixed Burnable Poisons (FBP), operational and shutdown CRs, and core depletion. The use of a large domain for cross-section preparation provides a better representation of the neutron spectrum, enables the proper modeling of FBPs and CRs, allows the calculation of equivalence parameters, and generates a relative power distribution that can be used in compact power reconstruction.

The purpose of this analysis is to quantify the effects of the reflector and FBPs on a low enriched uranium prismatic design and better understand the fuel depletion. This work employs a supercell geometry that should capture the long-range effects of neutrons and produces higher fidelity depletion in the presence of reflectors. The conclusions from these studies will be used in the generation of crosssection preparation schema to achieve higher fidelity models for design an analysis calculations.

The supercell dimensions are given in Table 18 and the geometric representation is shown in Figure 50. There are three major regions defined: 1) central fresh fuel region (depleting region), 2) homogenized burned fuel region at the bottom (non-depleting region), and 3) reflector region at the top (non-depleting region). In the design of a prismatic core, one would not necessarily introduce FBPs in each vertex of the fuel block, especially near other fuel, but for research purposes the benchmark uses 6 FBP, one in each corner of the central block. One important feature is that the FBP is composed of burnable poison particles, which poses a further complication in the modeling tasks with a great improvement in design flexibility. Since the poison material is imbedded in a coated particle it allows two more degrees of freedom in the design and optimization of FBPs: the size of the FBP kernel and the quantity of particles. The challenge is the need to treat the FBP as a doubly heterogeneous (DH) region, just as the fuel. The absorption reaction rates in those regions will show weaknesses in the DH treatment of the codes.

The exercises are structured to provide a good comparison between the benchmark participants. Calculations are repeated twice, once without BP and once with a BP in each of the six locations in the block. Both cases are first run at zero burnup at $293.6 \mathrm{~K}$ in all regions (Exercises 1a and 1b). This initial calculation will show the differences between the models that would otherwise affect the depletion 
Exercises. In the case without burnable poisons, block graphite is placed in each of the FBP locations. The depletion calculations, Exercises $2 \mathrm{a}$ and 2b, are performed at higher temperatures, near 1000-1200 K, depending on the region. Depletion is performed at a constant power of $100 \mathrm{MW} /$ tonne initial uranium, assuming continuous burnup with no downtime. Only the central fresh fuel block is depleted in the domain.

Table 18. Dimensions for supercell calculations.

\begin{tabular}{|c|c|c|c|}
\hline & & Dimension & Units \\
\hline \multirow{8}{*}{$\begin{array}{l}\text { TRISO Fuel } \\
\text { Particle }\end{array}$} & Kernel Radius & $2.125 \mathrm{E}-02$ & $\mathrm{~cm}$ \\
\hline & Porous Carbon Buffer OR & $3.125 \mathrm{E}-02$ & $\mathrm{~cm}$ \\
\hline & IPyC OR & $3.475 \mathrm{E}-02$ & $\mathrm{~cm}$ \\
\hline & $\mathrm{SiC}$ OR & $3.825 \mathrm{E}-02$ & $\mathrm{~cm}$ \\
\hline & OPyC OR & $4.225 \mathrm{E}-02$ & $\mathrm{~cm}$ \\
\hline & TRISO Packing Fraction & 0.35 & \\
\hline & Compact Radius & 0.6225 & $\mathrm{~cm}$ \\
\hline & Gap Radius & 0.635 & $\mathrm{~cm}$ \\
\hline \multirow{7}{*}{$\begin{array}{l}\text { Fixed } \\
\text { Burnable } \\
\text { Poison } \\
\text { Particle }\end{array}$} & Kernel Radius & $1.00 \mathrm{E}-02$ & $\mathrm{~cm}$ \\
\hline & Kernel Density & 2.4696 & $\mathrm{~g} / \mathrm{cm}^{3}$ \\
\hline & Porous Carbon Buffer OR & $1.18 \mathrm{E}-02$ & $\mathrm{~cm}$ \\
\hline & PyC OR & $1.41 \mathrm{E}-02$ & $\mathrm{~cm}$ \\
\hline & BP Particle Packing Fraction & 0.109 & \\
\hline & BP Compact Radius & 0.5715 & $\mathrm{~cm}$ \\
\hline & Gap Radius & 0.635 & $\mathrm{~cm}$ \\
\hline \multicolumn{2}{|c|}{ Large Coolant Channel Radius } & 0.794 & $\mathrm{~cm}$ \\
\hline \multicolumn{2}{|c|}{ Small Coolant Channel Radius } & 0.635 & $\mathrm{~cm}$ \\
\hline \multicolumn{2}{|l|}{ Pin pitch } & 1.88 & $\mathrm{~cm}$ \\
\hline \multicolumn{2}{|c|}{ Block Flat-to-Flat Width } & 36.0 & $\mathrm{~cm}$ \\
\hline \multicolumn{2}{|c|}{ Supercell Flat-to-Flat Width } & 108.0 & $\mathrm{~cm}$ \\
\hline
\end{tabular}




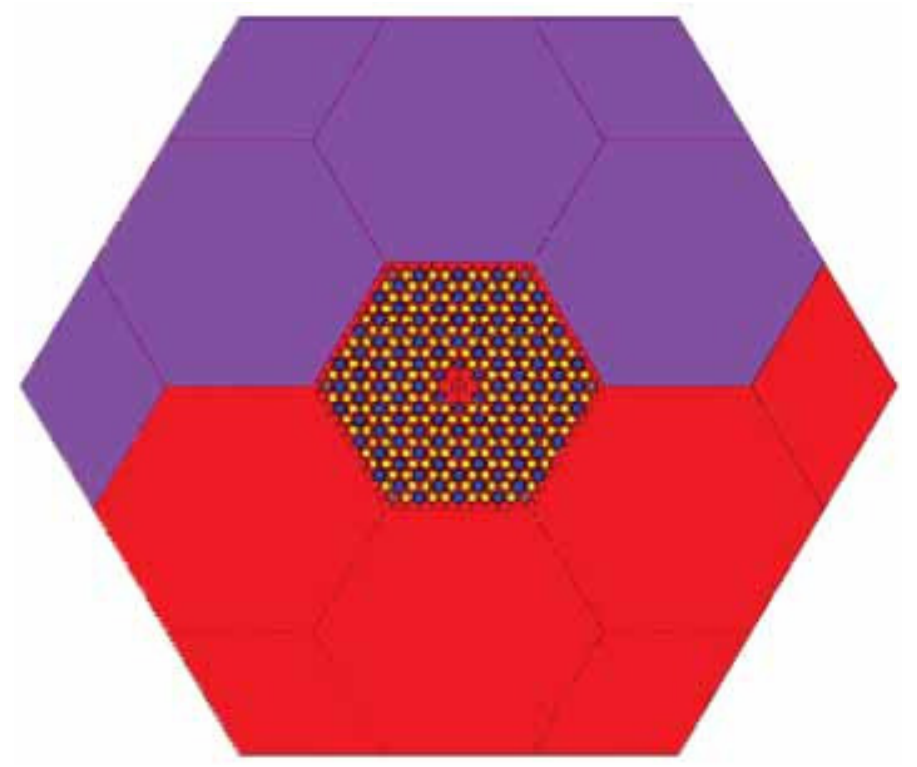

Figure 50. Phase III supercell geometry.

The benchmark requires that the relative compact powers be reported for all the fuel compacts (210 locations) in the fresh fuel region for a series of burnup points. The numbering of the compacts/pins starts at the upper left-hand corner (near the reflector region) and proceeds from left to right. Note that the numbering includes the FBP pins. There are 16 fuel and three burnable poison reporting locations in the central block that will include additional information, shown in Figure 51. These 16 fuel reporting regions include relative powers, spectral indices, actinides, fission products, and spectrum data. The FBP reporting locations include the B-10 concentration and the spectrum.

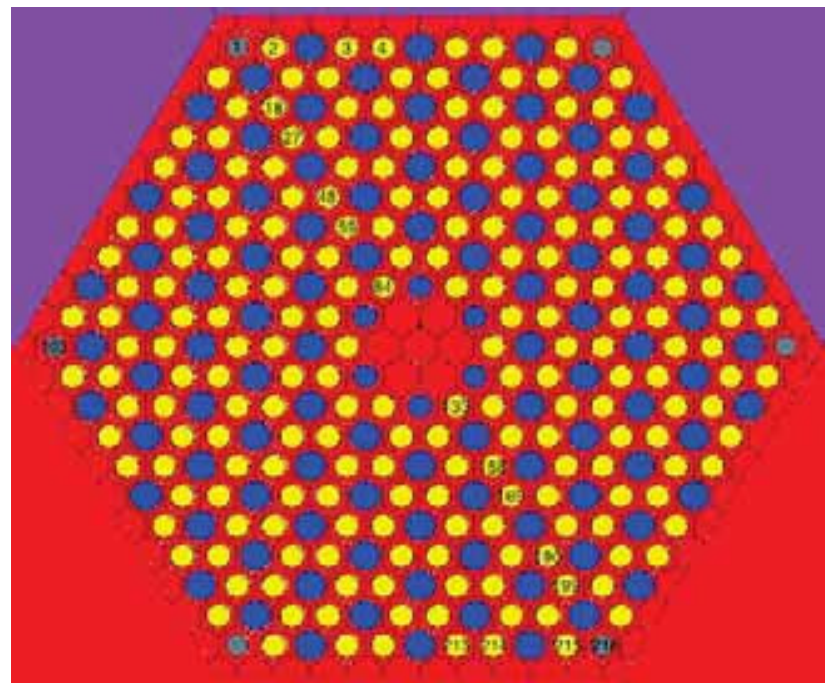

Figure 51. Phase III reporting locations. 


\subsection{Analysis Tools}

Serpent version 2.1.13 was used for this work because of its advanced depletion capability and potential use in cross-section preparation [6], [27]. The cross-section data is from ENDF/B-VII.r0. Serpent uses a Predictor-Corrector time-stepping scheme, which leads to a higher order representation of the time domain. The solution to the exponential matrix problem formed from the Bateman equations is solved with a Chebyshev Rational Approximation Method with polynomials of order 14. The code was initially benchmarked against MCNP5 [24]. Table 7.3 includes the comparisons of the infinite multiplication for various configurations. The results for the homogenized medium and homogenized fuel compact in a cell show excellent agreement. Both results are within the statistical uncertainty of MCNP5. The modeling of the randomized coated particles $(\mathrm{DH})$ shows a $250 \mathrm{pcm}$ difference, which is in the range of that observed with TRIPOLI4 [29]. The MCNP5 model uses a fixed rectangular lattice to obtain the correct packing fraction, and randomly positions fuel kernels within its rectangular cell. The Serpent code uses an explicitly randomized TRISO distribution within the compact.

Table 19. Serpent infinite multiplication comparisons to MCNP5.

\begin{tabular}{|l|c|c|}
\hline \multicolumn{1}{|c|}{ kinf } & Serpent & MCNP5 \\
\hline Homogeneous Fuel & $1.39130 \pm 8 \mathrm{pcm}$ & $1.39138 \pm 8 \mathrm{pcm}$ \\
\hline Cell with a Homogenized Fuel Compact & $1.43532 \pm 9 \mathrm{pcm}$ & $1.43543 \pm 7 \mathrm{pcm}$ \\
\hline Cell Fuel Random Lattice (DH) & $1.34454 \pm 9 \mathrm{pcm}$ & $1.34118 \pm 7 \mathrm{pcm}$ \\
\hline
\end{tabular}

\subsection{Results and Discussion}

In the discussion of the results from this work the following definitions of the energy ranges are employed: thermal $\mathrm{E}<4 \mathrm{eV}$, epithermal $4 \mathrm{eV}<\mathrm{E}<1 \mathrm{E} 5 \mathrm{eV}$, and fast $\mathrm{E}>1 \mathrm{E} 5 \mathrm{eV}$.

The larger infinite multiplications factors in Table 20 are primarily due to the presence of the reflector, since the lower fuel to moderator ratio in this HTGR allows for more thermalization, higher neutron production, and reduced resonance absorption. The higher temperature leads to a decrease in the eigenvalue near 4,057 pcm for the unshimed case and 5,160 with FBPs. The worth of the FBPs under cold conditions $(7,692 \mathrm{pcm})$ is significantly less than that of the hot condition $(8,753 \mathrm{pcm})$ and is mainly due to the spectral shift in the reflector regions, which lowers the absorption of neutrons in those regions and increases the effectiveness of the FBPs.

Table 20. Infinite multiplication factors.

\begin{tabular}{|c|c|c|l|}
\hline Exercise & $\begin{array}{c}\text { Implicit Infinite } \\
\text { Multiplication }\end{array}$ & $\begin{array}{c}\text { Relative Error } \\
(\mathrm{pcm})\end{array}$ & \multicolumn{1}{|c|}{ Description } \\
\hline $1 \mathrm{a}$ & 1.23582 & 15 & Cold Conditions Without FBP \\
\hline $1 \mathrm{~b}$ & 1.14076 & 15 & Cold Conditions With FBP \\
\hline $2 \mathrm{a}$ & 1.18568 & 13 & Hot Condition Without FBP \\
\hline $2 \mathrm{~b}$ & 1.08189 & 14 & Hot Condition With FBP \\
\hline
\end{tabular}

The reactivity curves with and without the FBP are included in Figure 52. The curve with no FBP is the traditional reactivity curve with its initial fission product buildup period and the subsequent linear behavior. The curve with the FBP shows the characteristics of a lumped burnable poison with a flatter reactivity swing. In this design, the effective absorption cross-section of the BPs is reduced by lumping the poison, mainly due to spatial self-shielding effects. This approach allows to better control the burn-out rate of ${ }^{10} \mathrm{~B}$. 
Figure 53 shows the ${ }^{10} \mathrm{~B}$ depletion of the three FBP reporting regions: one near the reflector, one near the burned fuel, and an intermediate position. The BP loading is not well optimized for the supercell configuration since the BP controls the burnup all of the way until the end of life of the fuel. Ideally, one seeks a flat reactivity that meets the uncontrolled curve before the end of the first cycle at just critical. One of the reasons for this effect is the fact that the benchmark specifies loading in each FBP location in the central block.

Initially, the BP particles act as "black" absorbers, since the radius of the burnable poison particle is small compared to the neutron mean free path outside the particle and the neutron mean free path inside the particle is very small. As the number density of ${ }^{10} \mathrm{~B}$ atoms decreases so does its macroscopic absorption cross-section and the reaction rate. The FBP near the reflector region experiences the highest burnup due to the large number of neutrons in the thermal range that have slowed in the reflector region. The FBP near the burned region experiences a harder spectrum as shown in Figure 54 and Figure 55. There are two clear spectral regions. The region near the reflector is characterized by a significant spectrum gradient as the neutron spectrum hardens during the interaction with fuel. This region extends roughly half of the block across-the-flats distance. The half of the block near the burned fuel region, experiences no significant changes to the spectrum.

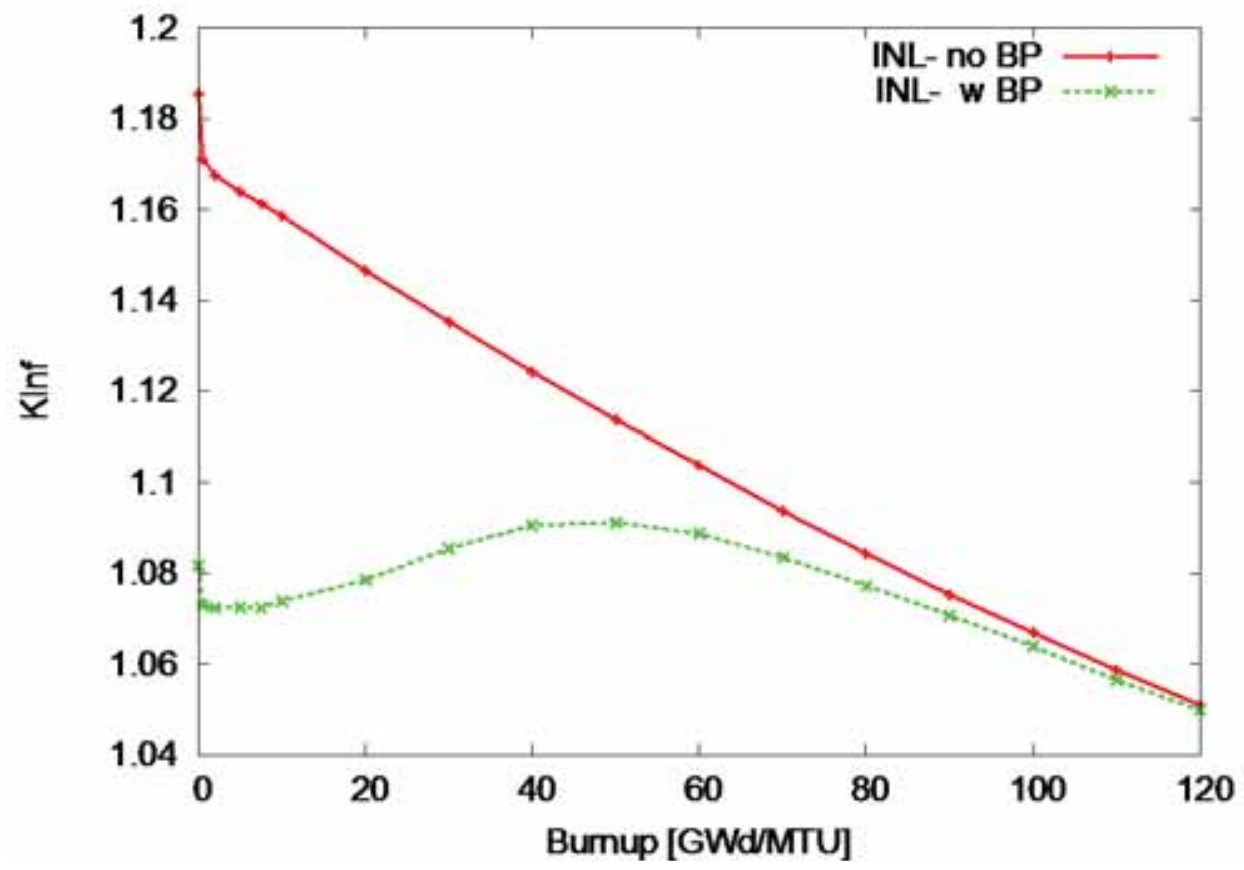

Figure 52. Reactivity curves for Exercises $2 \mathrm{a}$ and $2 \mathrm{~b}$. 


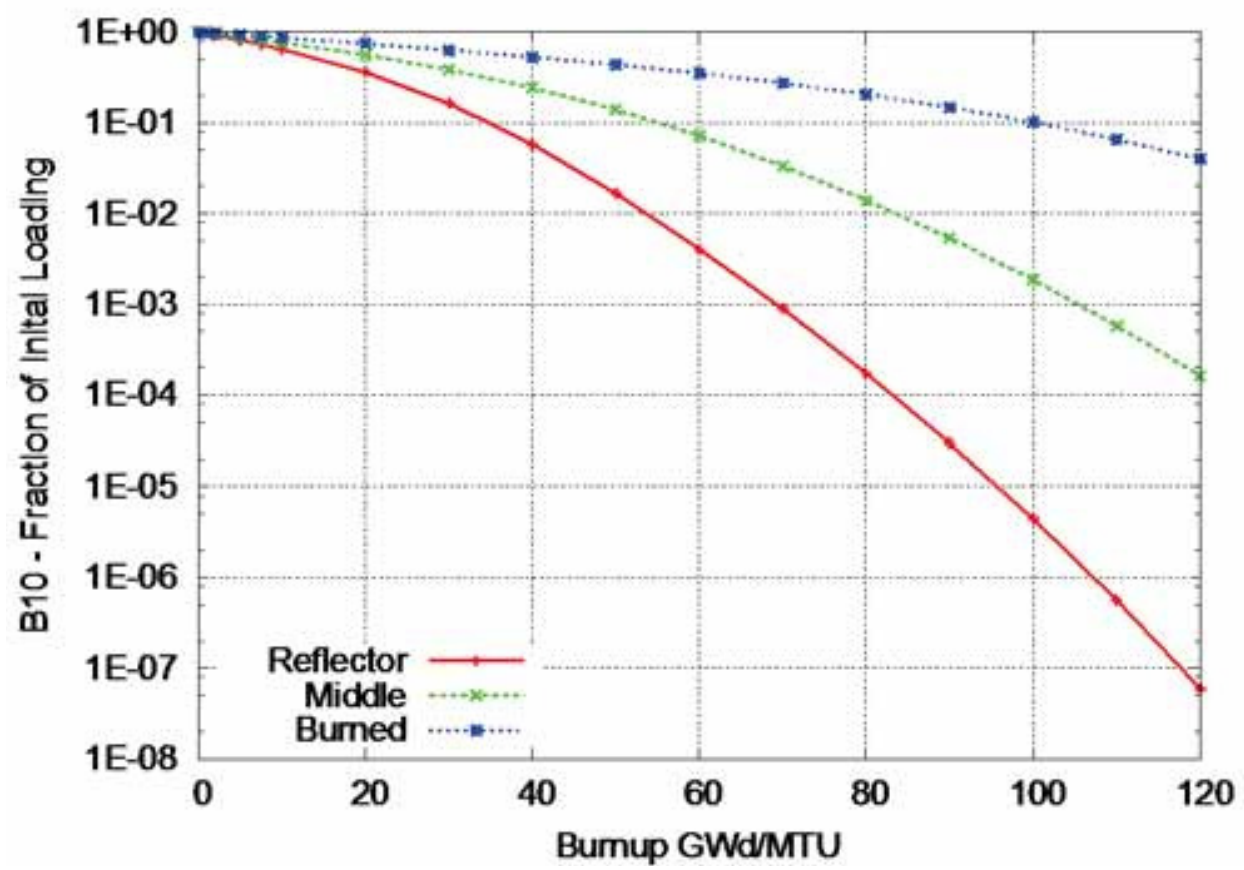

Figure 53. B-10 depletion for Exercise 2b.

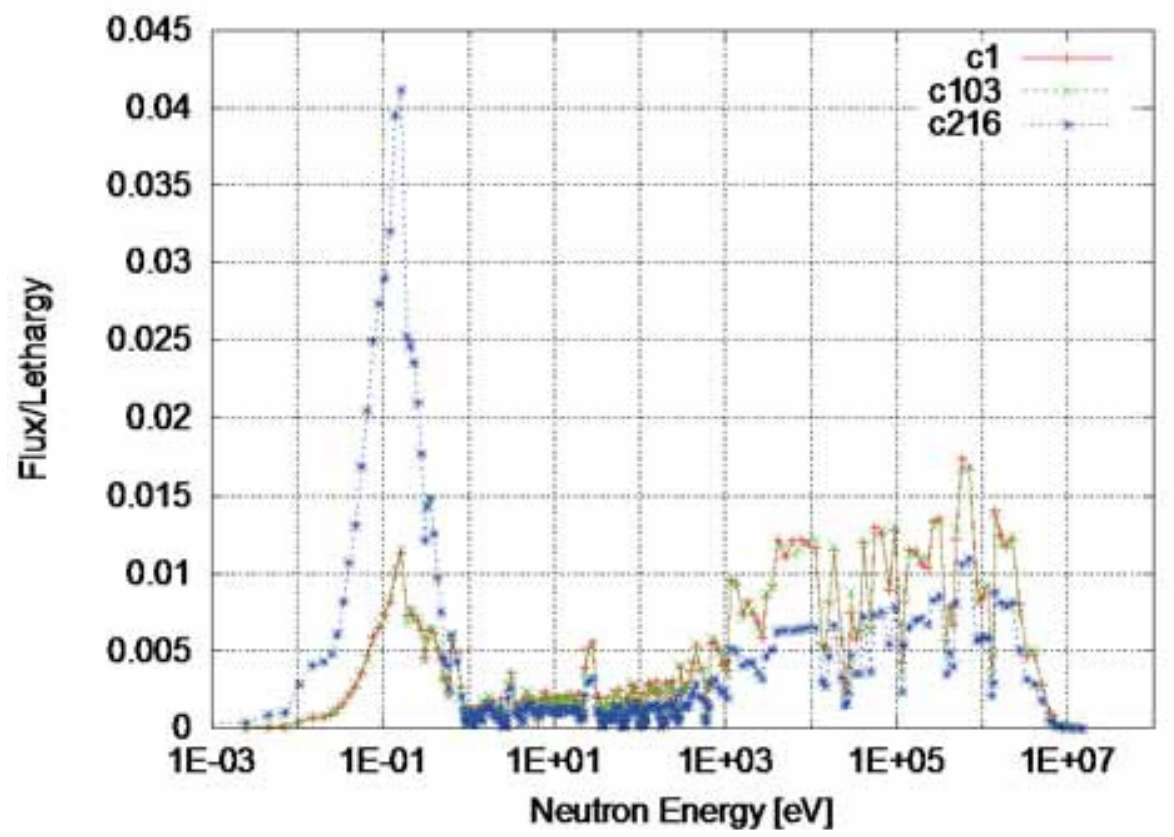

Figure 54. Neutron spectrum at three FBP positions $0 \mathrm{GWd}$ /MTU hot conditions. 


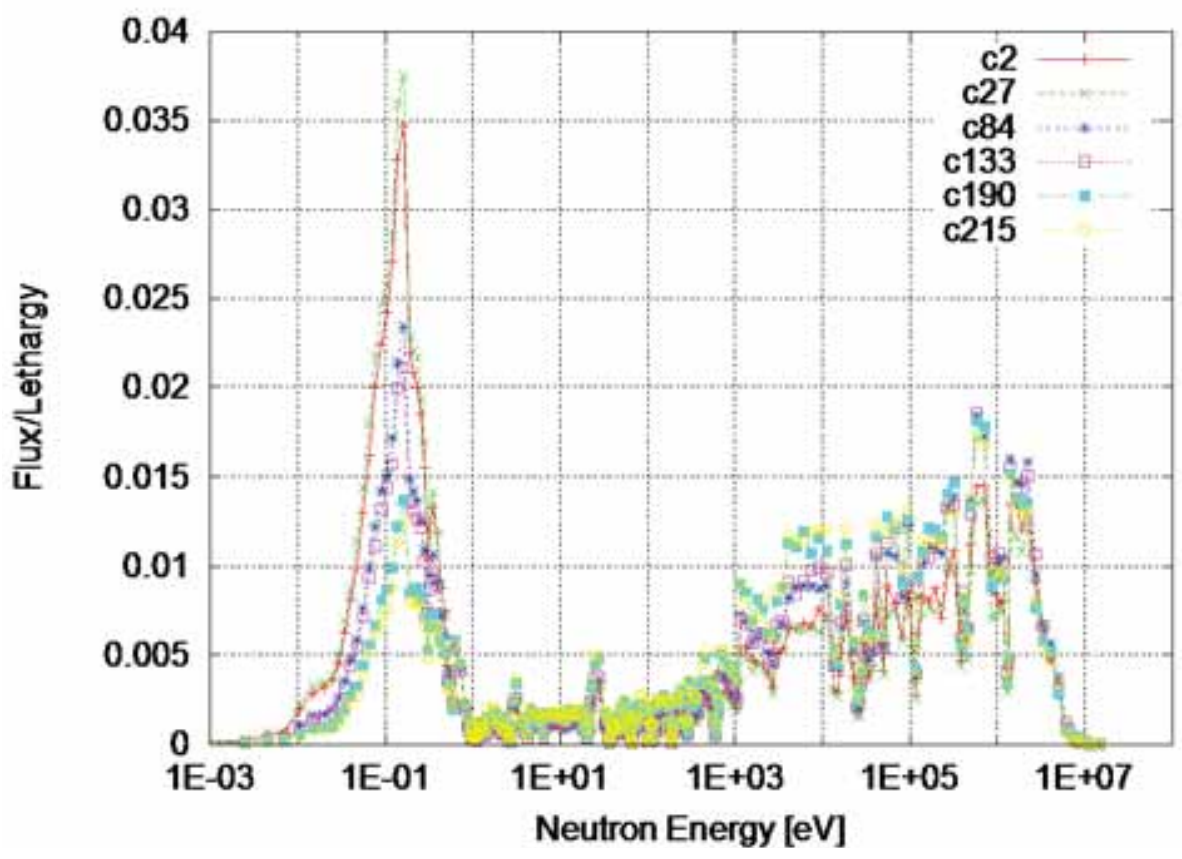

Figure 55. Neutron spectrum at various fuel positions $0 \mathrm{GWd} / \mathrm{MTU}$ hot conditions.

One of the important parameters for the Exercise is the behavior of the power distribution during the depletion. Figure 56 shows the behavior of the power distribution with and without FBP at various burnup steps. At $0 \mathrm{GWd} / \mathrm{MTU}$ the power is heavily peaked near the reflector, with a maximum relative value of 1.95 without FBPs. The addition of the FBP's decreases the maximum peaking to 1.75 .

Another key factor in the analysis of the results is the gradient in the power field across the block. For the uncontrolled case the power changes by a factor of 3.5 across the block, this values decrease to 3.0 when FBPs are present for fresh fuel. Placing the BPs in all locations hardens the spectrum across the block, thus, reducing the number of thermal neutrons available for fission and promoting more resonance interactions. The range of influence of the BPs seems to extend $11 \mathrm{~cm}$ into the block from the reflector side before at zero burnup. Using FBPs only near the reflector region could make additional improvements to the power distribution, by allowing more thermal neutrons in this harder spectral region near the burned fuel.

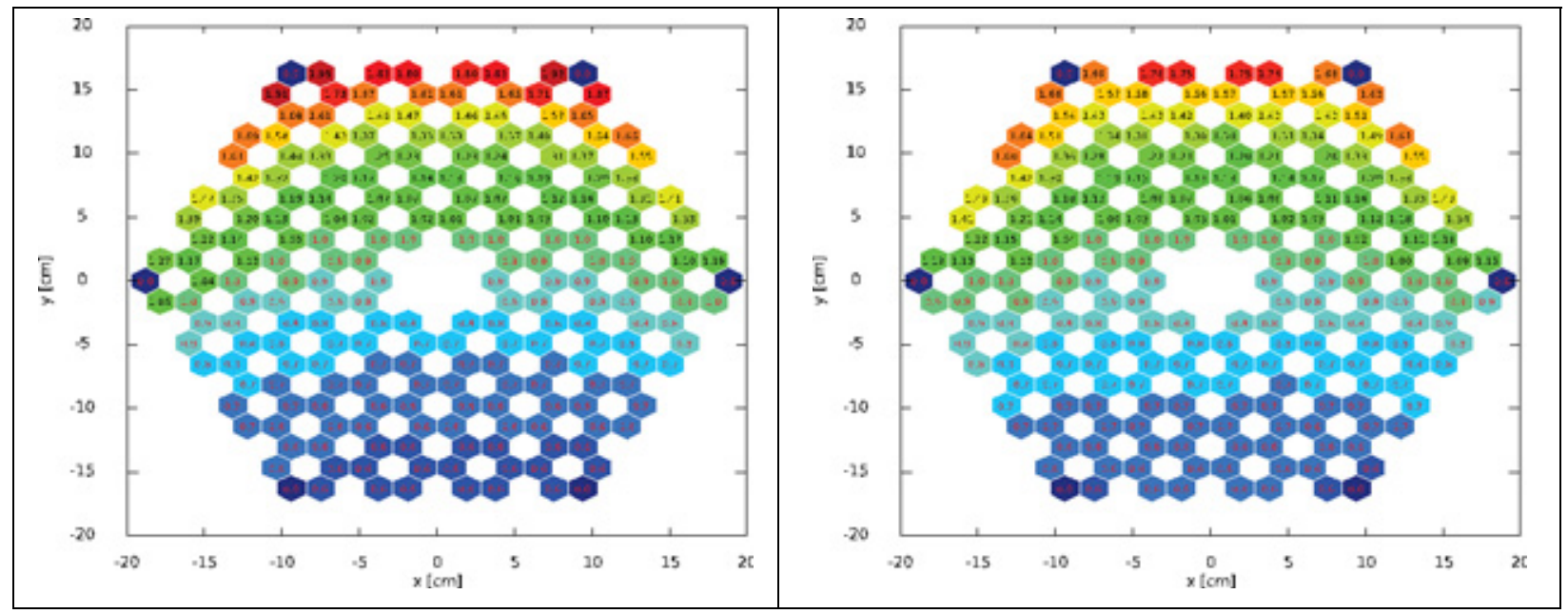




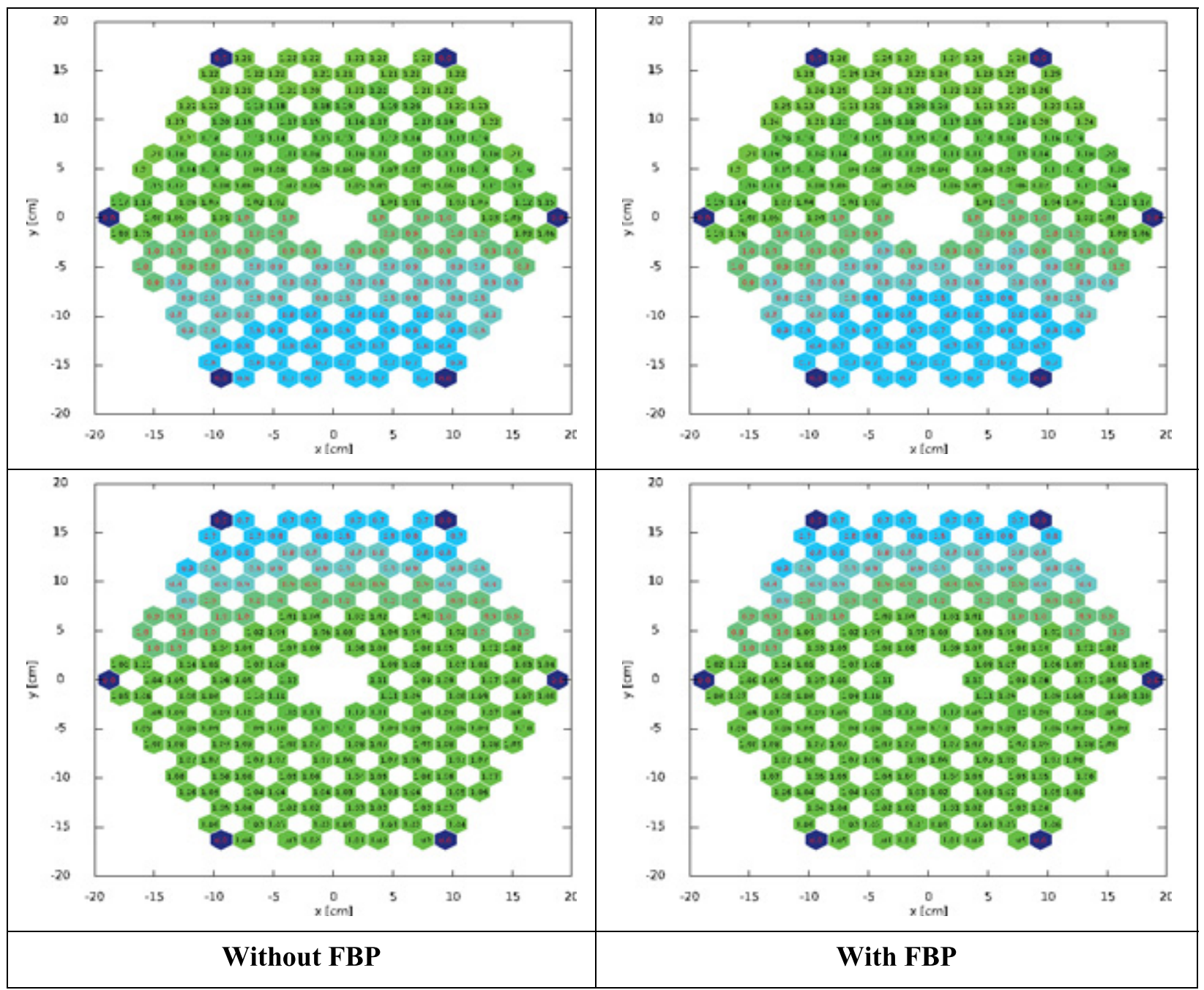

Figure 56. Pin power distribution at 0,60 , and $120 \mathrm{GWd} / \mathrm{MTU}$.

During the burnup evolution the power tends to flatten as a fissile isotope gradient develops across the block. Two major effects take place in this configuration: 1) the high burnup rate of ${ }^{235} \mathrm{U}$ in the soft spectrum reflector region, and 2) the higher capture rate of ${ }^{238} \mathrm{U}$ in the harder spectrum region that leads to higher ${ }^{239} \mathrm{Pu}$ production. The ${ }^{235} \mathrm{U}$ depletion is depicted in Figure 57 and Figure 58. Interestingly, the depletion of ${ }^{235} \mathrm{U}$ is not significantly affected by the presence of FBPs. Even the distribution of the isotope across the block is unchanged for both cases. At $60 \mathrm{GWd} / \mathrm{MTU}$ the change in the ${ }^{235} \mathrm{U}$ mass across the block is roughly a factor of 2.23 without FBPs and 2.13 with FBPs. This difference increases to a factor 8.1 and 7.73 , respectively, at $120 \mathrm{GWd} / \mathrm{MTU}$. 


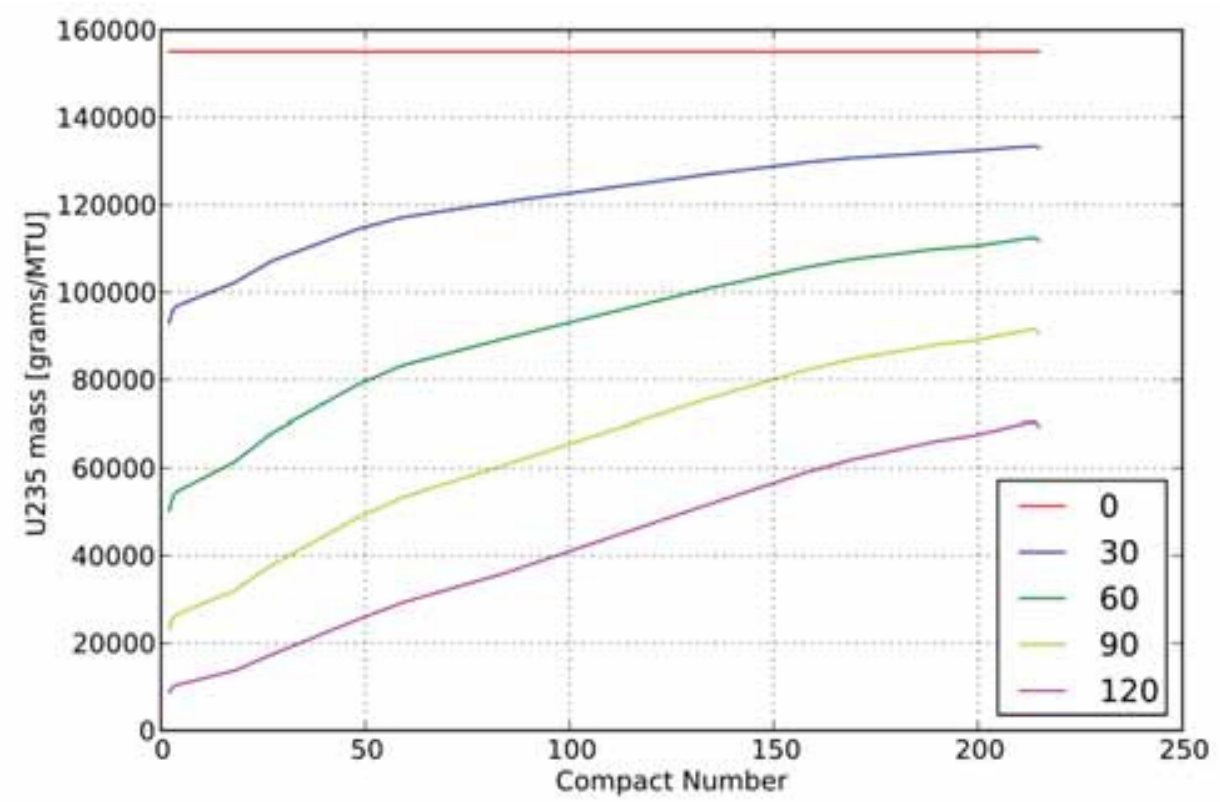

Figure 57. ${ }^{235} \mathrm{U}$ mass [grams/MTU] without FBPs.

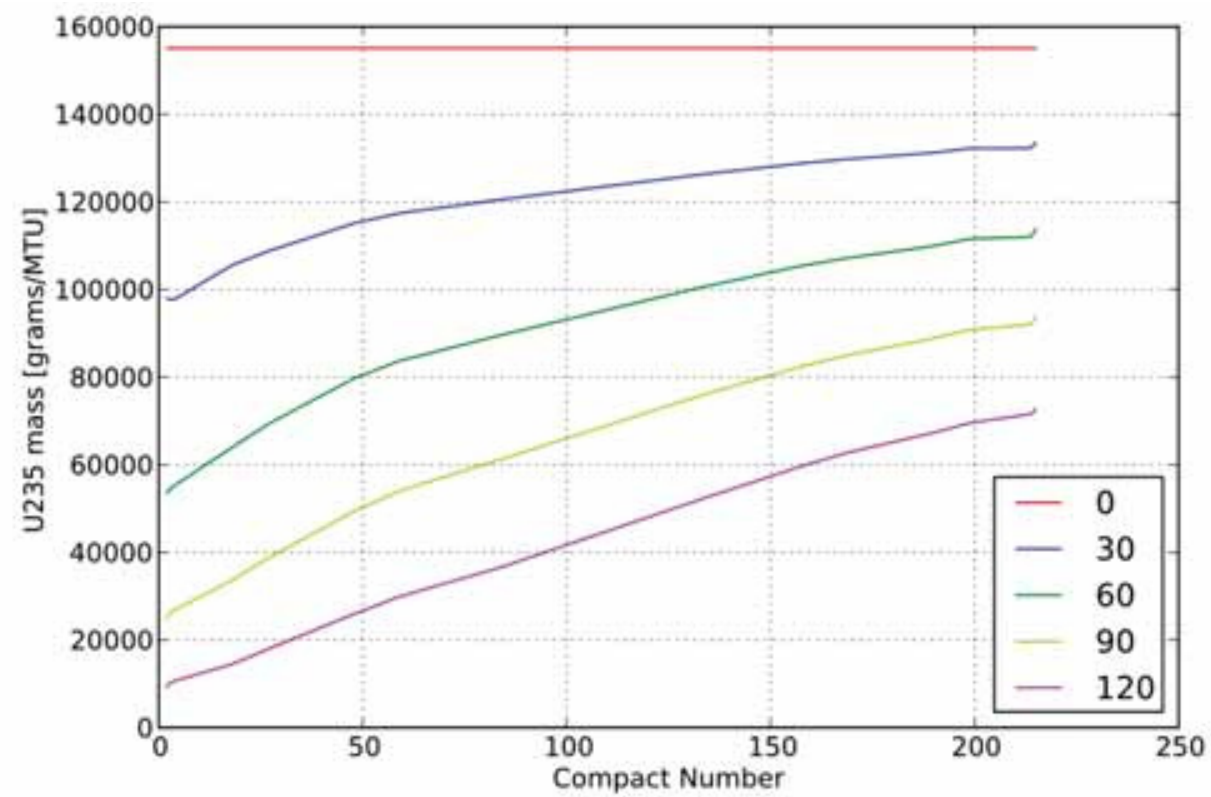

Figure 58. ${ }^{235} \mathrm{U}$ mass [grams/MTU] with FBPs.

The presence of FBPs promotes the production of ${ }^{239} \mathrm{Pu}$ early on, especially in the hard spectrum regions. This is illustrated in Figure 59 and Figure 60 for 0.5 and $30 \mathrm{GWd} / \mathrm{MTU}$, respectively. The composition across the fuel block changes by a factor of 3.54 and 3.91, without and with FBPs, at 60 GWd/MTU. The difference becomes smaller at the end of the depletion due to the efficient burn of ${ }^{239} \mathrm{Pu}$ and effectively remaining at 5.22 and 5.56, respectively. Overall, the ${ }^{239} \mathrm{Pu}$ concentrations increase in the central block by $25-30 \%$ due to the hardening of the neutron spectrum. At the end of the depletion the central fuel block is "driven" by the burned fuel next to it and the power has tilted towards the burned fuel region. At this point the power distributions are not overly sensitive to the FBPs. 


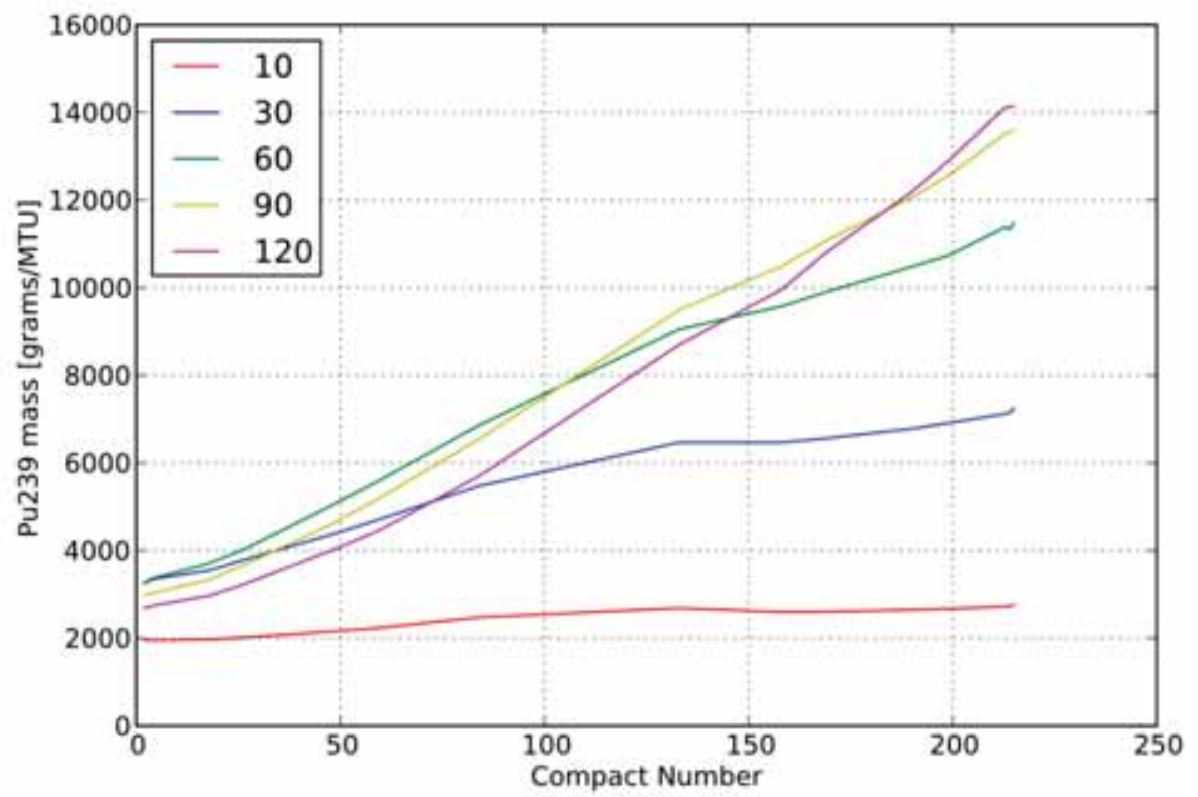

Figure 59. ${ }^{239} \mathrm{Pu}$ mass [grams/MTU] without FBP.

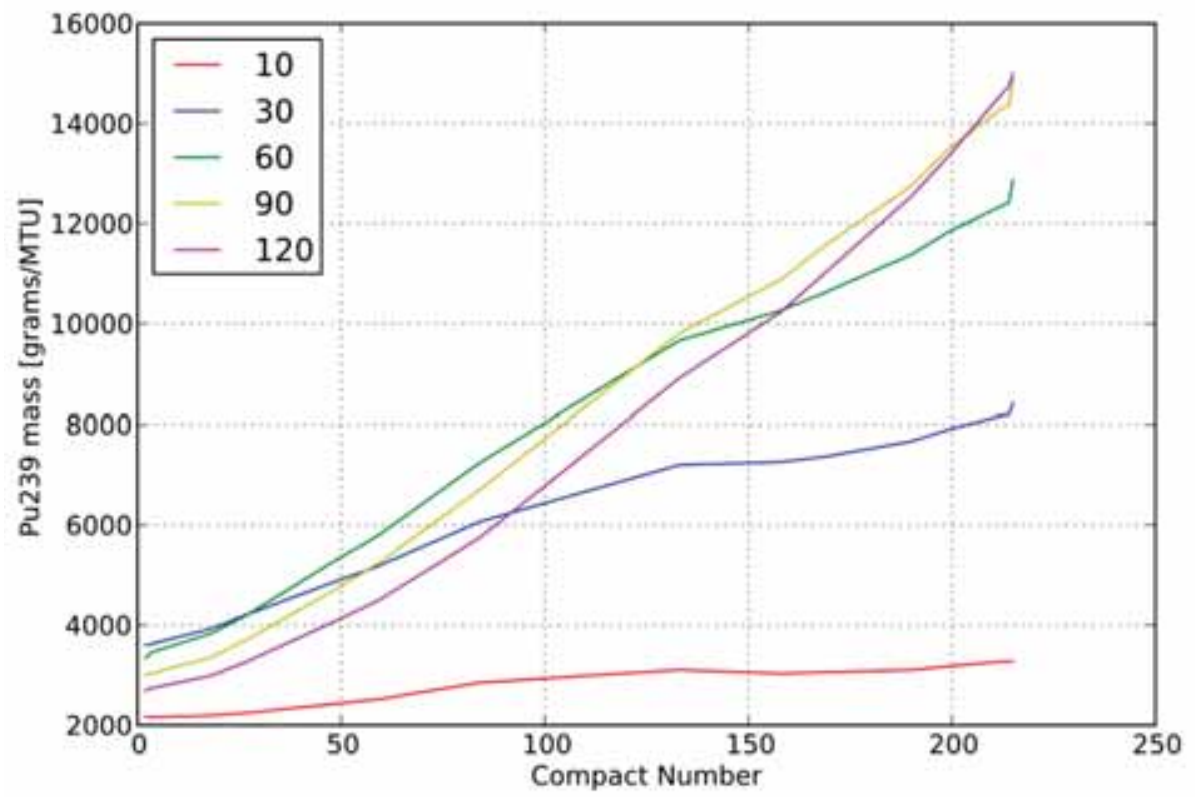

Figure $60 .{ }^{239} \mathrm{Pu}$ mass [grams/MTU] with FBP.

\section{SUMMARY}

This report summarized the latest INL results for Phase I (steady state) and Phase III (lattice depletion) of the OECD MHTGR-350 benchmark. The INSTANT, Pronghorn and RattleS $\mathrm{n}_{\mathrm{n}}$ ake codes were utilized for the standalone core neutronics modeling of Exercise 1, and good agreement was found (within $30 \mathrm{pcm}$ ) between the diffusion solutions (RattleS $\mathrm{n}_{\mathrm{n}}$ ake and Pronghorn) and the INSTANT $\mathrm{P}_{1}$ results for both the nominal eigenvalue and the CR worth calculations. Differences arise from the spatial 
discretization since the diffusion solutions use a finer mesh, and INSTANT results for a hexagonal and triangular mesh discretization were presented.

Exercise 2 of Phase I requires the standalone steady-state thermal fluids modeling of the MHTGR-350 design, and the results for the systems code RELAP5-3D were presented for four variations of Exercise 2 that included the modeling of bypass flows and the use of fixed or variable thermophysical properties. The difference between the results of the sub-cases was mostly minimal, with the exception of the reflector temperatures that showed large variances when the bypass flows were included in the models. The main focus of the stand-alone RELAP5-3D Exercise 2 section was the comparison of a traditional MHTGR-350 ring model and a much more detailed block model, where each of the core fuel blocks and the reflector blocks next to the core region were sub-divided into six triangular elements. The purpose of this detailed block model was to investigate to what degree RELAP5-3D can be used to provide more detailed information on fuel temperatures and flux profiles via the increased spatial resolution. The second, more important issue was a comparison of the ring and block model fuel temperatures, since it was expected that the typical volume-averaged ring values would be lower than the more resolved triangular element temperatures. This was confirmed for all four sub-cases in Exercise 2, as well as the subsequent analysis of Exercise 3 using the same models.

It was found that the ring model significantly under-estimates the peak fuel temperatures (up to $12 \%$ in high-power fresh fuel blocks), and that an increase in the RELAP5-3D model spatial resolution was not only possible, but a requirement if more accurate predictions of component temperatures are desired for fuel performance and safety studies. Since quite large uncertainty margins have traditionally been applied to transient accident modeling in safety case studies, a more detailed approach like this block model can be used to decrease these uncertainty margins, but still remain within the validated envelope of a wellestablished systems code like RELAP5-3D. This is an important aspect for the licensing of HTGR design by vendors and utilities, because even if high-fidelity CFD codes can deliver much more detailed data compared with RELAP5-3D, they typically do not have the same validation and qualified use status. It can however also be noted that the relative performance of the ring model is still suitable for scoping calculations, especially if the much faster simulation time is taken into account.

The coupled neutronics and thermal fluids steady-state analyses performed for Exercise 3, utilizing the newly developed PHISICS/RELAP5-3D code suit, confirmed the observations made for Exercise 2 in regard to the worth of a more detailed spatial model. The block model can readily be used to predict the location of the highest fuel temperatures in the core, and via the coupled kinetic zones, the feedback effects of fuel and moderator temperatures, xenon and the control rod location can be assessed on a block level.

The Serpent lattice depletion models and results obtained for Phase III stressed the importance of performing depletion in the correct spectral environment. In addition to a comparison of the global variables, the power gradient across the block was also compared for several configurations with and without burnable poisons. The range of influence of the burnable poison seems to extend $11 \mathrm{~cm}$ into the block from the reflector side before at zero burnup, and their presence promotes the production of ${ }^{239} \mathrm{Pu}$ early in the depletion sequence, especially in the hard spectrum regions.

A discussion was also presented in Appendix A on the database developed at INL for the storage, analyses and comparison of participants' results. The tool, consisting of a MySQL server and a collection of PYTHON scripts, proved to be an effective way to compare more than $10 \mathrm{~GB}$ of data so far, and the use of automated routines minimizes the risk of user errors compared to simpler methods (e.g. spreadsheets).

The second Appendix included a discussion on the status of the Pronghorn code and its application to Exercise $2 \mathrm{a}$ of the benchmark. Although results are not yet available for the full model, significant progress has been made in 2013 on smaller prismatic and pebble bed test problems, and several issue have 
been solved. The results for the Phase I steady-states will be included in the 2014 status report, as well a sub-set of transients from Phase II.

The MHTGR-350 benchmark proved to be a challenging simulation set of problems to model accurately, and even with the simplifications introduced in the benchmark specification this activity is an important step in the code-to-code verification of modern prismatic VHTR codes. A final OECD/NEA comparison report will compare the Phase I and III results of all other international participants in 2014, while the remaining Phase II transient case results will be reported in 2015. Exercise 3a will form the basis steady-state for all of the transient cases currently specified, and it is expected that the block model will continue to provide a much more detailed and accurate prediction of important safety parameters. 


\section{REFERENCES}

[1] NQA-1-2008;1a-2009, “Quality Assurance Requirements for Nuclear Facility Applications”, ASME Standards (2009).

[2] R. Sherman and R. A. Rucker, MHTGR Nuclear Physics Benchmarks, General Atomics report to DOE, DOE-HTGR-90406, (February 1994).

[3] J. Ortensi, "Supercell Depletion Studies for Prismatic High Temperature Reactors," Proceedings of HTR2012, Tokyo, Japan (2012) (INL/CON-12-24395).

[4] "International Handbook of Evaluated Reactor Physics Benchmark Experiments," OECD/NEA 7140 (March 2013).

[5] J. F. Briesmeister, Editor, MCNP - A General Monte Carlo N-Particle Transport Code - Version 4C, Los Alamos National Laboratory report LA-13709-M (March 2000).

[6] 13709-M (March 2000) J. Leppänen, "Development of a New Monte Carlo Reactor Physics Code," D.Sc. Thesis, Helsinki University of Technology, VTT Publications 640 (2007).

[7] Wemple C A, H-N.M. Gheorghiu, R.J.J. Stamm'ler, E.A. Villarino (2007) "Recent Advances in the HELIOS-2 Lattice Physics code," International Conference on the Physics of Reactors (PHYSOR08), Interlaken, Switzerland, 2008.

[8] Marleau, G., A. Hébert, and R. Roy, 2010, “A User Guide for DRAGON Version4,” Technical Report IGE-294, École Polytechnique de Montréal.

[9] H. Park, et al., "Tightly Coupled Multiphysics Algorithms for Pebble Bed Reactors," Nuclear Science and Engineering, 166, pp. 118-133 (2010).

[10] S. Shiozawa, et al, "Overview of HTTR Design Features," Nuclear Engineering and Design, 233, Issues 1-3, pp. 11-21, October 2004.

[11] J. Ortensi, et al., "OECD Benchmark for Prismatic Coupled Neutronics/Thermal Fluids Transient of the MHTGR-350 MW Core Design: Benchmark Definition," Tech. Rep. NEA/NSC/DOC (2013) Draft version 07/16/2013.

[12] G. Strydom, A. Epiney, "Relap5-3D results for Phase I (Exercise 2) of the OECD/NEA MHTGR-350 MW benchmark," Proceedings of ICAPP2012, Chicago, USA (2012) (INL/CON-12-24604).

[13]A. Epiney, et al., "New Multi-group Transport Neutronics (PHISICS) capabilities for RELAP5-3D and its Application to Phase I of the OECD/NEA MHTGR-350 MW Benchmark," Proceedings of HTR2012, Tokyo, Japan (2012).

[14] RELAP5 ref: RELAP5-3D ${ }^{\odot}$ Code Manual, Vol.1-5, Rev. 3, INEEL-EXT-98-00834 (2009).

[15]D. Gaston, "MOOSE Enhancements Towards Delivery of an Integrated Framework," INL/EXT-1329814 (July 2013).

[16] F. Reitsma, et al., "PBMR coupled neutronics/thermal hydraulics transient benchmark the PBMR-400 core design." Tech. Rep. NEA/NSC/DOC (2007).

[17]P. J. Turinsky, et al., "NESTLE: A Few-Group Neutron Diffusion Equation Solver Utilizing the Nodal Expansion Method for Eigenvalue, Adjoint, Fixed-Source Steady State and Transient Problems," EGG-NRE-11406, Idaho National Engineering Laboratory (June 1994).

[18] C. Rabiti, et al., "PHISICS: a New Reactor Physics Analysis Toolkit," Transactions of the American Nuclear Society, Vol. 104, Hollywood, USA, INL/CON-11-21116 (2011).

[19] Y. Wang, C. Rabiti, G. Palmiotti, "Krylov Solvers Preconditioned with the Low-Order Red-Black Algorithm for the PN Hybrid FEM for the INSTANT Code," Proceedings of M\&C 2011, Rio de Janeiro, Brazil (2011). 
[20]E. Lewis, C. B. Carrico and G. Palmiotti, "Variational Nodal Formulation for the Spherical Harmonics Equations," Nucl. Sci. Eng., 122 (1996).

[21] A. Epiney, et al., "PHISICS Multi-group Transport Neutronic Capabilities for RELAP5," Proceedings of ICAPP'12, Chicago, USA (2012).

[22] C. Rabiti, A. Rineiski, "Extension of KIN3D, a Kinetics Capability of VARIANT, for Modeling Fast Transients in Accelerator Driven System," Proceedings of PHYSOR 2004, Chicago, USA (2004).

[23] S. Bays, et al., "Transmutation Dynamics: Impacts of Multi-Recycling on Fuel Cycle Performances," INL/EXT-09-16857 (2009).

[24] A. Alfonsi, et al., "PHISICS Toolkit: Multi-reactor Transmutation Analysis Utility- MRTAU," Proceedings of PHYSOR 2012, Knoxville, USA (2012).

[25] PHISICS/RELAP5-3D ref: A. S. Epiney, et al., "New Multi-group Transport Neutronics (PHISICS) Capabilities for RELAP5-3D and its Application to Phase I of the OECD/NEA MHTGR-350 MW Benchmark," Proceedings of HTR 2012, Tokyo, Japan, INL/CON-13-29811 (2012).

[26] G. Strydom, "TINTE uncertainty analysis of the maximum fuel temperature during a DLOFC event for the 400 MW Pebble Bed Modular Reactor," Proceedings of ICAPP 2004, Pittsburgh, USA (2004).

[27] J. Leppänen, "Randomly Dispersed Particle Fuel Model in the PSG Monte Carlo Neutron Transport Code," Proceedings of M\&C + SNA 2007, Monterey, USA (2007).

[28] F. B. Brown, et al., "MCNP Version 5," LA-UR-02-3935, Los Alamos National Laboratory (2002).

[29] F. Damian, et al., "VHTR Neutronic Calculation Scheme," Proceedings of M\&C 2005, Avignon, France (2005).

[30] IAEA TECDOC 1694, "Evaluation of High Temperature Gas Cooled Reactor Performance: Benchmark Analysis Related to the PBMR-400, PBMM, GT-MHR, HTR-10 and the ASTRA Critical Facililty," (2013).

[31]F. P. Incropera, D. P. DeWitt, "Fundamentals of Heat and Mass Transfer" (6th ed.). Hoboken: Wiley. pp. 490, 515. ISBN 978-0-471-45728-2 (2007).

[32] H. D. Gougar, et al., "Multiscale Analysis of Pebble Bed Reactors," Proceedings of HTR 2010, Prague, Czech Republic, INL/CON-10-19081, (October 2010).

[33] Teuchert, E., U. Hansen, and K. Haas, 1980, "VSOP - Computer Code System for Reactor Physics and Fuel Cycle Simulation,” Kernforschungsanslage Jülich, JÜL-1649, (March 1980).

[34] Y. Zheng and M. Stempneiwicz, "Investigation of NACOK air ingress experiment using different system analysis codes," Nuclear Engineering and Design 251, pp. 423-432, (October 2010). 


\section{Appendix A \\ Benchmark Data Analysis and Comparison Tools}

\section{Benchmark Data Analysis and Comparison Tools}

Participants in the MHTGR-350 produce large data sets that need to be validated, stored and analyzed in an efficient way. Easy access to specific query sets on the data collection is necessary for comparison and understanding of the results. To reach the above goal, a collection of Python scripts was written. These scripts use a MySQL-database server for storing participants' data in an easy accessible and efficient way. Validation checks are performed on the completeness and validity of the data sets before committing the data into the database to assure consistent sets and to detect possible errors early. The database server provides the ability for indexing the data and accessing it by these indices. This feature allows the user to create focused subsets of the data; for example all fluxes on a single axial layer, axial cuts or time-dependent views on single blocks. The user can also visualize the results directly from the database via line and map plots. The general steps in the process flow are shown in Figure 61:

- Participants convert their respective code outputs (usually in ASCII format) to Extendible Markup Language (xml) files.

- The xml files are tested for conformance to the required data formats, completeness and other requirements, as specific in the MHTGR-350 benchmark specification.

- The contents of the xml files are submitted into the MySQL database.

- Analysts at INL (tasked with creating the comparison results) can commence analyzing the data.

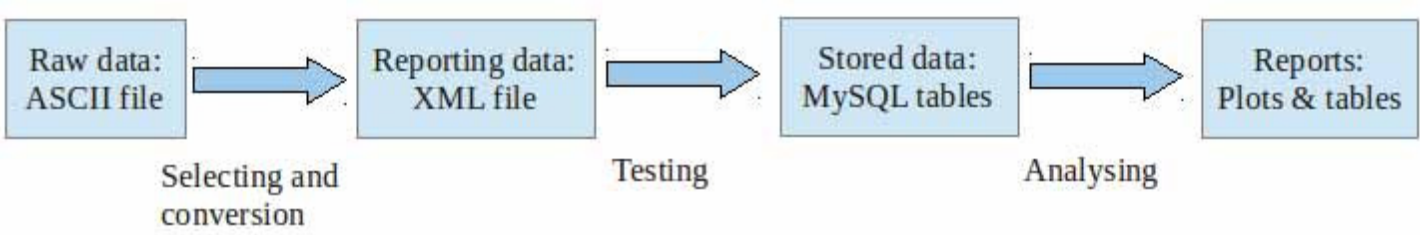

Figure 61. General benchmark data process flow.

\subsection{Database}

MySQL is an open source relational database management system (RDBMS) that runs as a server providing multi-user access to a number of databases. MySQL is currently developed by ORACLE and is designed to store and process large amounts of data. The syntax for database queries is the Structured Query Language (SQL).

The database for the MHTGR-350 benchmark is divided into sub-databases ("schemes" in MySQL) for each phase and Exercise. These schemes group the tables containing the data together. For Phases 1 and 2 of the benchmark three different types of tables are used.

- Solution information: The table for the solution information data contains all information about a specific solution reported by a participant. A unique identifier (sId) is assigned to this solution, and is used to link all data records to the solution. 
- Global data: The second table type stores the time-dependent global values (e.g., / keff, CR worth, etc.). The connection to the solution information is made through the sId, and an additional index is also added here to identify the data report time step. Values that are not reported are set to null entries.

- Map data: The map table type store the spatial distributions reported by the participants (e.g., graphite temperatures or fluxes). The indexing for this table type is sId, time step, axial layer and block number. For the neutron flux an additional index group number is added. This indexing gives the possibility to access each reporting section and time step individually.

The consistency of the indexing is assured through user-defined keys. The keys connect the index in the data tables to the row in the solution info table, and any operator actions will update all dependent data rows. This preserves the relational links and prevents inconsistent data sets. An example of the data base structure for some of the data required for Phase I Exercise 3 is shown in Figure 62.

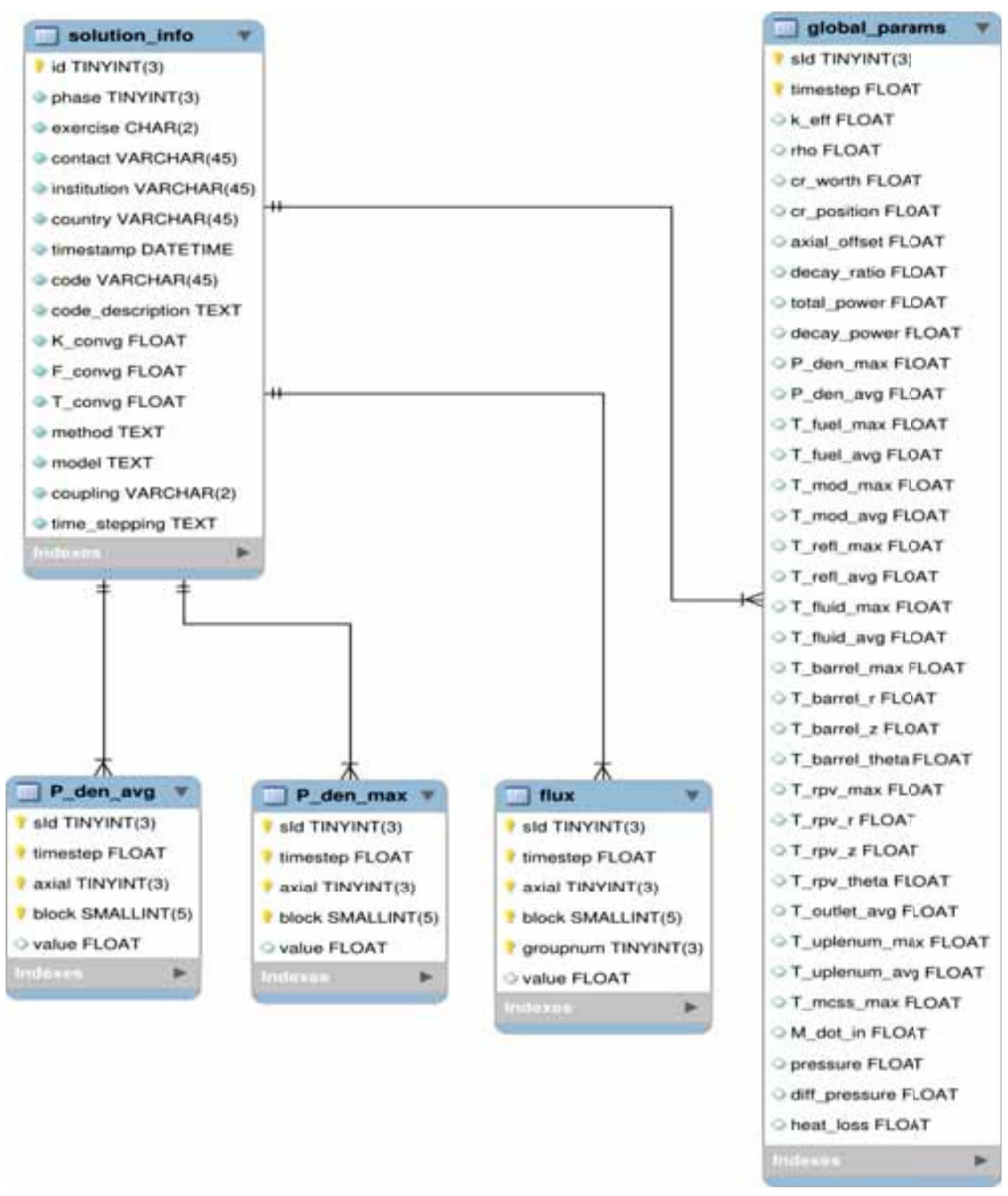

Figure 62. Data base structure for a subset of the Phase I Exercise 3 data. 
A similar structure was developed for the Phase III schemes. The solution info table stores again all global values for one solution and assigns a key, which is used in a table for the time steps. This table also stores the sId (solution identifier), the tId (time step identifier) and global time-dependent values like k-inf. Each row in these tables stores the sub values and the corresponding relative errors reported for one variable. An additional index was assigned for the energy in the spectrum, as shown in Figure 63.

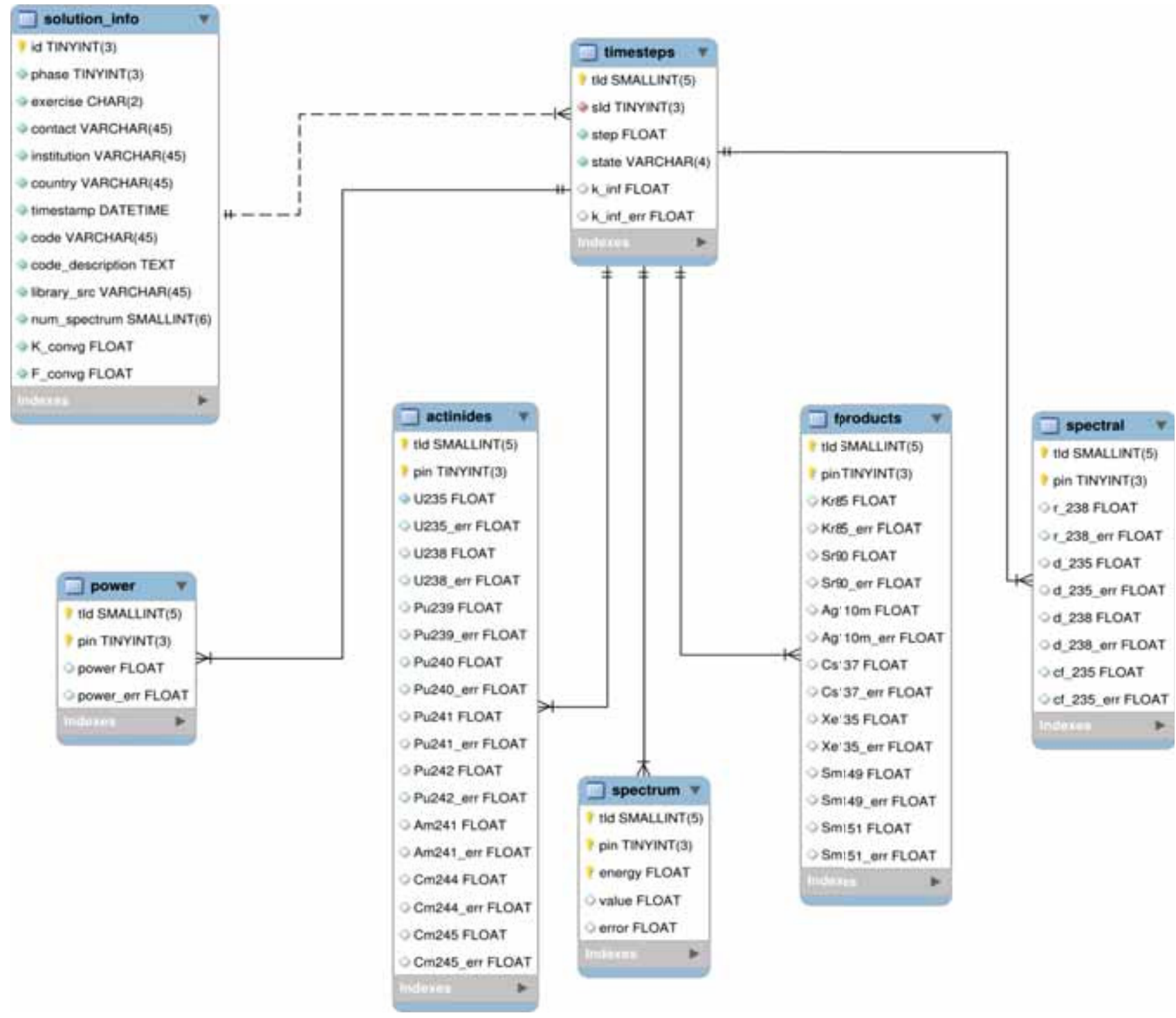

Figure 63. Data base structure for a subset of the Phase III data. 


\subsection{Python Package}

The package of Python scripts provides all the necessary functions to validate, insert and access the reported data. The scripts were written in version 3 of the Python language and use the object oriented features of Python. Three additional external Python packages are used within the scripts:

- NumPy is a mathematical library providing an n-dimensional array, as well as basic and advanced mathematical operations on this array.

- DefusedXml is a special $\mathrm{xml}$ implementation that fixes possible attack vectors using $\mathrm{xml}$ (e.g., denial of service attacks (DoS) and access to the file system).

- MySql is the interface package to the MySql database server. It provides all functions to communicate with the server and querying data. Plotting ability is provided by the PlotScripts package, which provides an easy way to process and plot structured data. In addition to line plots, the package also offers map plots.

The database is constructed by the benchmark scripts through the parsing of the submitted xml files. During this process, the file is checked for the correct xml syntax, and individual data values are checked against an interval of expected values to identify possible errors. Depending on the Phase, it either reads the global parameters and distribution files (Phases I and II) or continues to read the pin distribution (Phase III). The schemes on the database server are created during the first run of the Python scripts. After the reading of a file is finished, the data is inserted into the database and the script continues with the next $\mathrm{xml}$ file. When all core distributions have been read, the data set is tested for completeness and double entries. This is only possible after reading the whole solution, since variables can be reported in chunks scattered over separated files to reduce the size of the files. If the data passes all tests, the inserted data is committed to the database, or if not, a rollback is performed undoing all the temporary changes. This process is similar for Phase III, and is illustrated in Figure 64. 


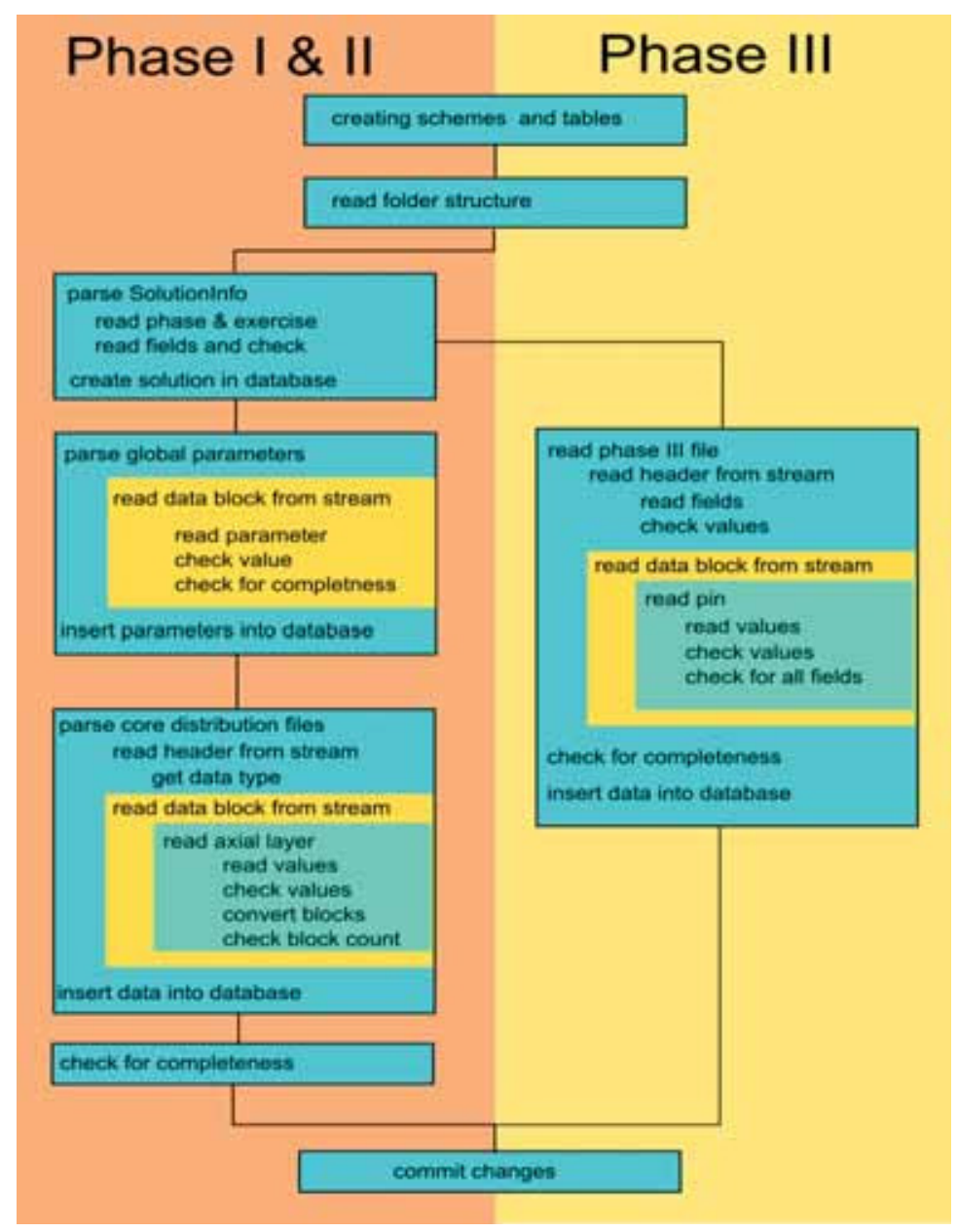

Figure 64. Overview of Python package flow for Phases I-III.

For the analysis of the data the plotScripts package is used. It is a modular package designed for plotting cross-section data and core distributions. An interface was developed to access the stored data in the database. An advanced indexing allows nearly unrestricted access to the data from values for a single block up to time-dependent core distributions. An in-line condensation of energy groups for the neutron flux is also possible within the queries. The input for the plotScripts is written as a Python script that makes all programming features accessible for an easy querying. The benchmark script package also provides a module for converting the PHISICS-RELAP5-3D output into the required reporting xml format via the use of "key" files. The key files allow flexibility and provide all information about the mapping between the PHISICS-RELAP5-3D model structures and the reporting mesh. The reporting can be done in both hexagonal and cylindrical representations.

All important values are stored in a single Python module making changes easily. This includes a mapping for the reporting variable names, definitions on number of layers and blocks, the boundaries for the value check and the lists of required parameters and distributions for each Exercise. Changes in this one file will propagate the new values throughout the whole script package. Additionally the module provides a function to create a table structure which is used by the database modules to create the database. A more detailed description of the Python package can be found in the benchmark database documentation, and can be provided by the authors to interested readers on request. 


\section{Appendix B}

\section{Pronghorn Application to Exercise 2a of the MHTGR-350 Benchmark}

In the past couple of years various thermal fluid capabilities were added to the Pronghorn code and applied successfully to several benchmarks, etc. such as the PBMR-400 benchmark [16]. All of the simulations that Pronghorn was used for were Pebble Bed High Temperature Reactors and most of these cases were 2-dimensional. The utilization of the Pronghorn code for the modeling of Exercise 2a of the MHTGR-350 benchmark was started in the third quarter of 2013. The Pronghorn thermal fluid kernels that are required for the simulation of Exercise 2 were updated or created if they did not already exist. A thermal fluid mesh of the MHTGR-350 has been developed in Cubit for the simulation of Exercise 2.

\subsection{Description of the Thermal Fluid Model}

The first draft meshes/models for the MHTGR-350MW benchmark were created using Cubit 13.2 with the intention of solving coupled neutronics, fluid flow and solid heat conduction using Pronghorn. This is a three-dimensional $120^{\circ}$ symmetric model. Two models comprising three independent meshes have been created so far. The single mesh model combines neutronics, fluid flow and heat conduction on a single mesh and is intended for use on the current version of MOOSE, which has only limited support for multiple meshes. For the multiple mesh model independent solid and fluid meshes have been generated. This model is intended for use with future versions of MOOSE, which is expected to have full multi-mesh capabilities.

\subsubsection{Basic Solid Modeling Geometry}

All model geometry is based on the materials and geometry specified in the MHTGR-350MW benchmark specification. This may be divided into a core region, solid region and fluid region, as illustrated in Figure 65. 


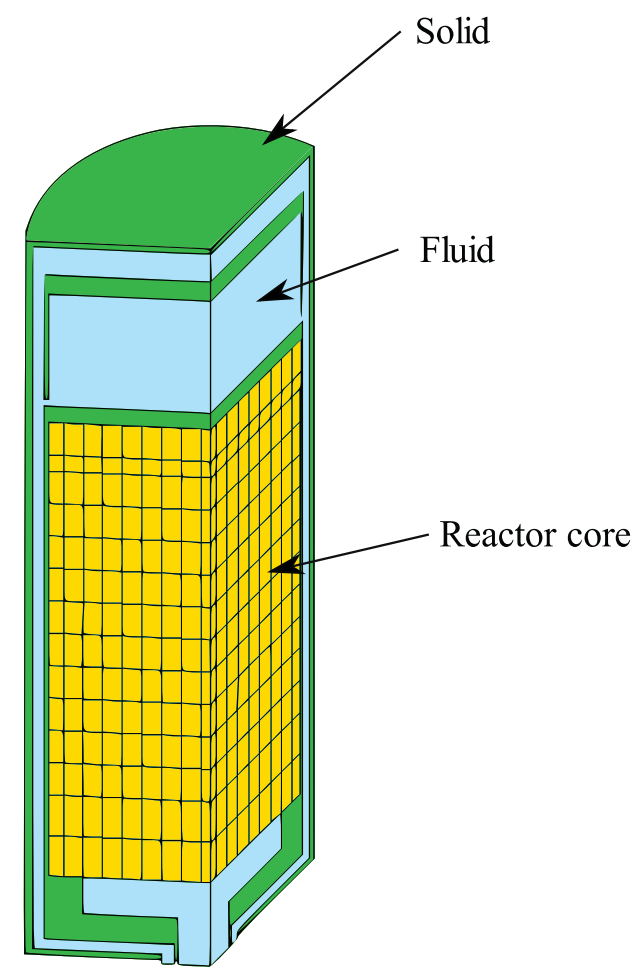

Figure 65. Solid, Fluid and Core Regions.

\subsubsection{Block Definitions}

All blocks are named and should be referred to by their names since the block numbers may vary from one mesh to another. In certain cases where different element types have been used for different regions of the same component the block name is followed by $1,2,3$, etc.

\subsubsection{Core Blocks}

The core region comprises the fuel, RSC fuel, $\mathrm{CR}$, reflector and permanent reflector blocks arranged in the numbering scheme defined in the MHTGR benchmark specification, with 71 blocks per layer stacked in 14 layers (Figure 66). Layer 1 is at the bottom of the core. The core restraint elements are not numbered as for the core but are rather separated into fuel, RSC fuel, CR, reflector and permanent reflector core restraint blocks. 

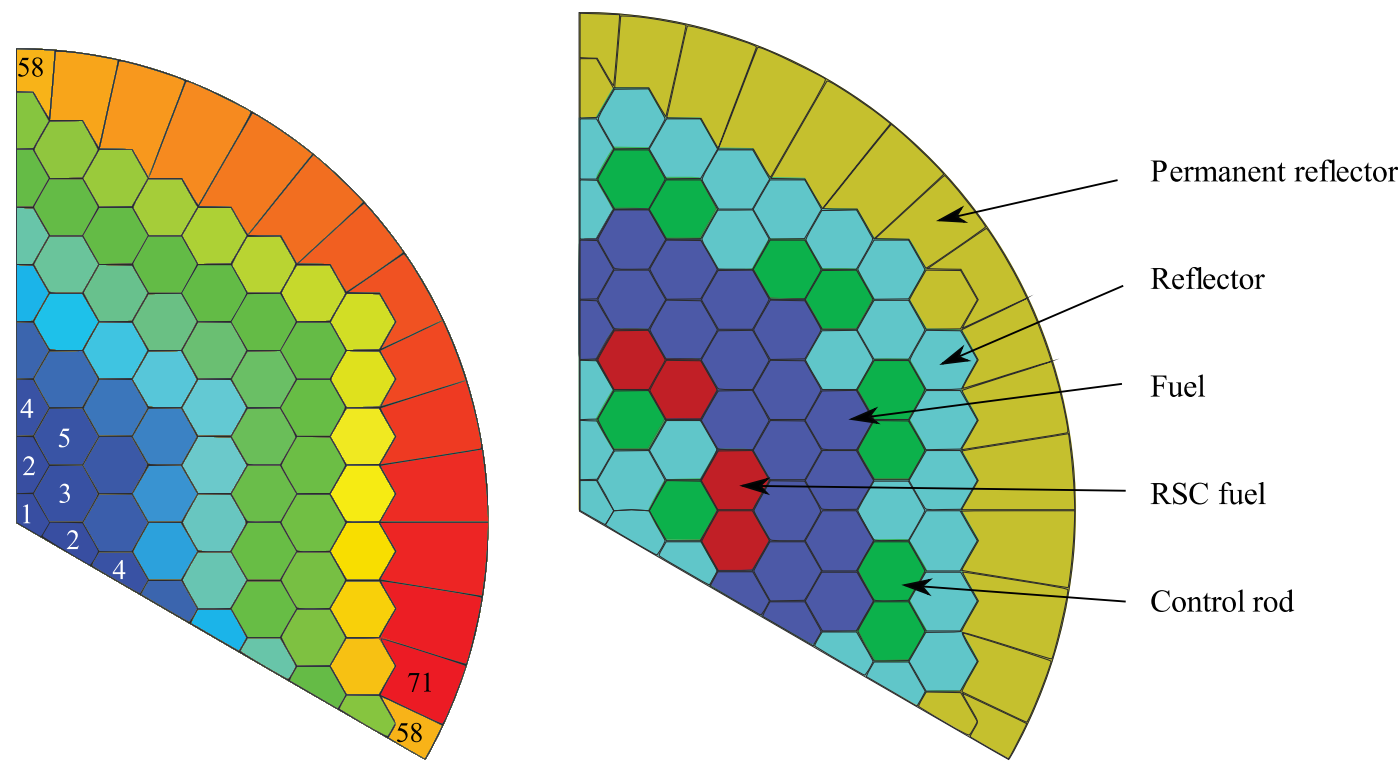

Figure 66. Core Block Numbering and Regions.

\section{Solid and core material block definitions (see Figure 67)}

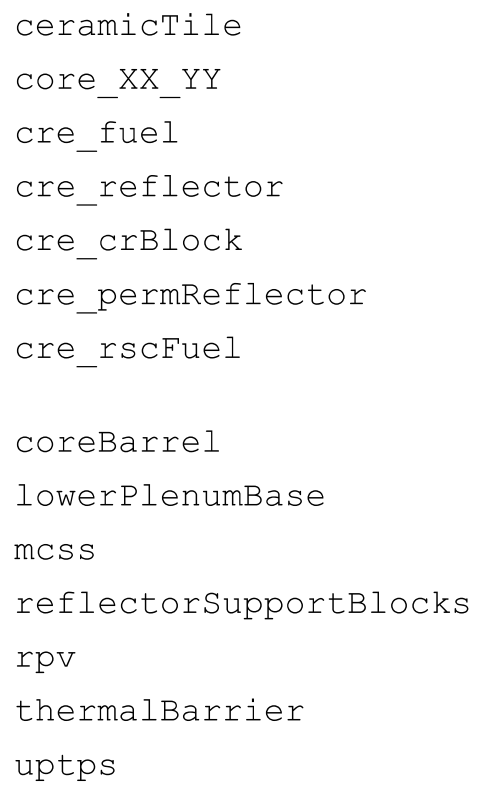

\section{Fluid block definitions (Figure 68, Figure 69)}

cbRpvGap

inletPlenum

lowerPlenum

outletPipe

risers

upperPlenum
Ceramic insulation layer below the lower plenum

Block $Y Y$ of Layer $X X$ in the core

Core restraint elements above the standard fuel elements

Core restraint elements above reflector blocks

Core restraint elements above the $\mathrm{CR}$ blocks

Core restraint elements above the permanent reflector blocks

Core restraint elements above the reserve shutdown control fuel elements

CB

Graphite blocks forming the base of the lower plenum

Metallic core support structure

Graphite blocks forming the sides of the lower plenum

Reactor pressure vessel (RPV)

Thermal barrier between the inlet and outlet ducts

Upper thermal protection system (UPTPS)

Annular gap between the CB/riser channels and RPV. This also includes the gap between the UPTPS and RPV.

Inlet duct and cavity below the metallic core support structure

Below-core plenum cavity

Interior of outlet duct

Interior of riser channels

Above-core plenum cavity 


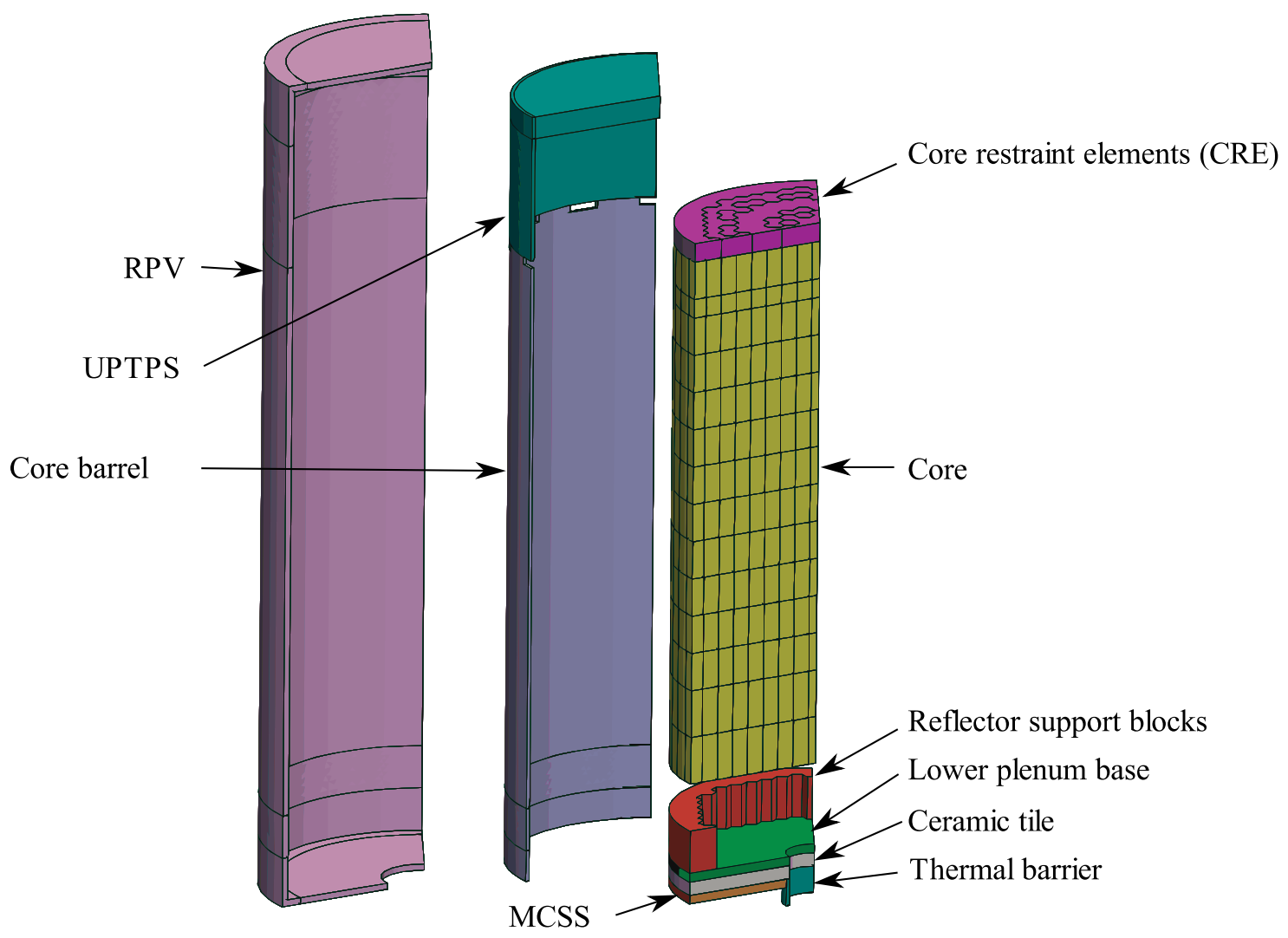

Figure 67. Solid Block Definitions. 

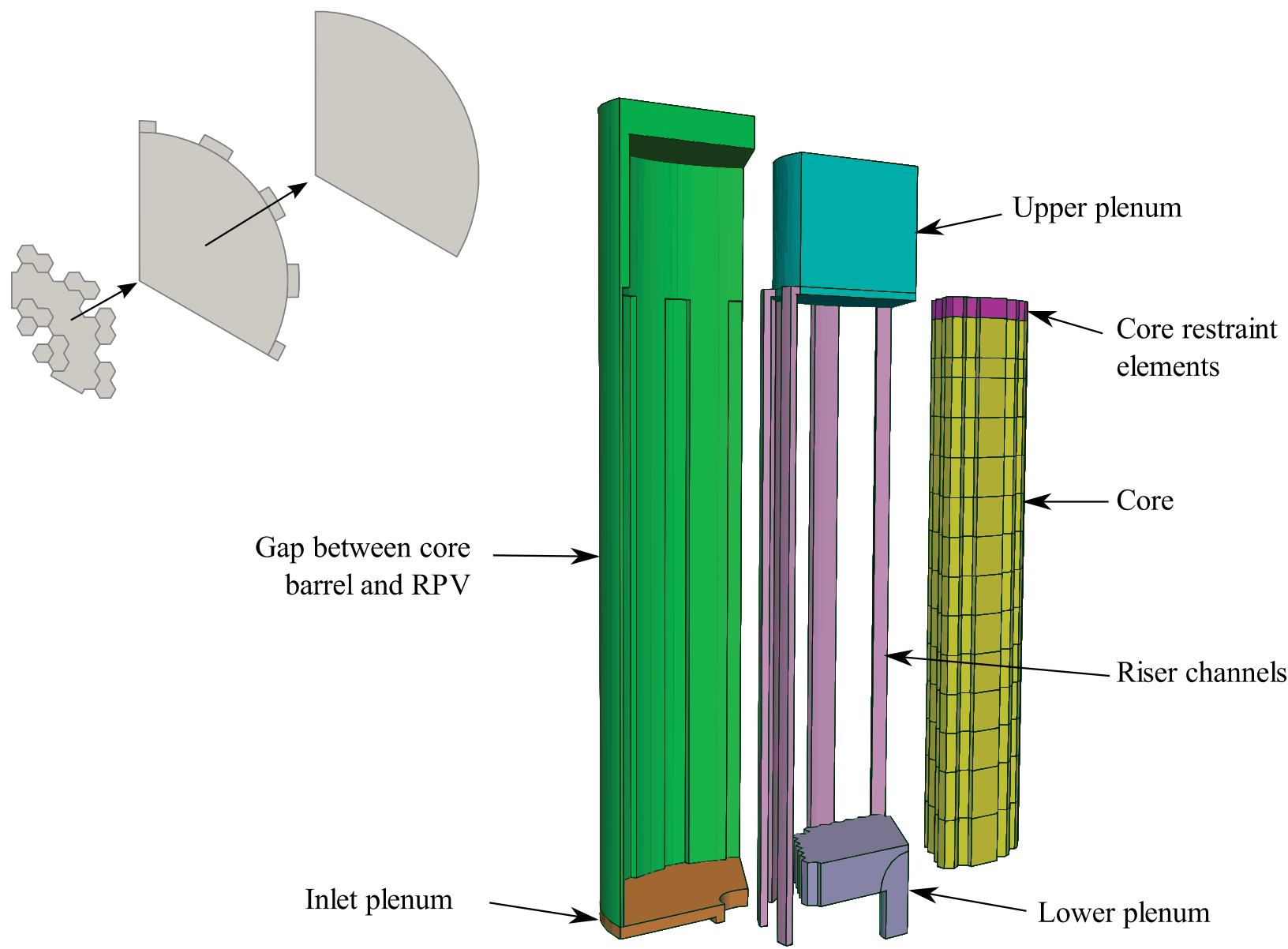

Figure 68. Fluid Block Definitions.

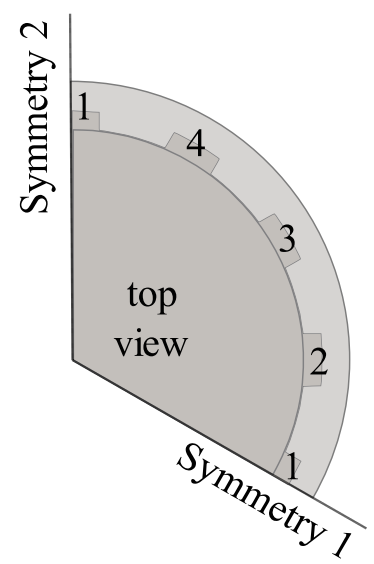

Figure 69. Riser Channel Numbering and Symmetry Plane Definition.

\section{Sideset Definitions (Figure 70 to Figure 73)}

Sidesets have been defined on both boundary surfaces and several internal surfaces, e.g., at interfaces between solid and fluid regions where conjugate heat transfer is to be modeled. In many cases the orientation of the sideset is important since this dictates in which direction the surface normal points and 
also which block the sideset belongs to, i.e., the sideset faces always point outwards from the block on which they are defined.

Below is a list of the sidesets that have been defined. Where relevant, the basic orientation of the sideset is given. Several figures have also been provided to illustrate the placement of the sidesets and their orientation.

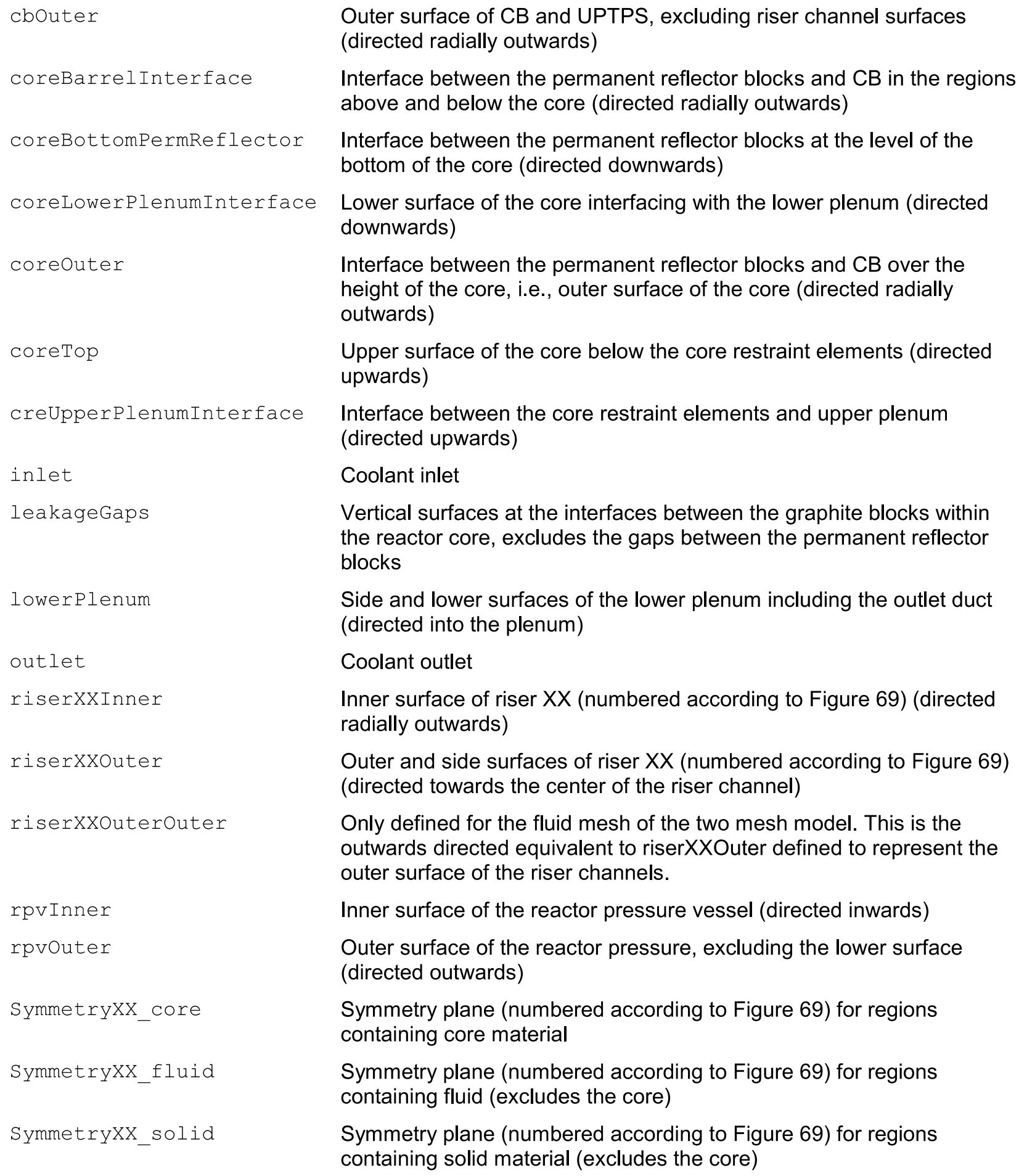

Outer surface of CB and UPTPS, excluding riser channel surfaces (directed radially outwards)

Interface between the permanent reflector blocks and CB in the regions above and below the core (directed radially outwards)

Interface between the permanent reflector blocks at the level of the bottom of the core (directed downwards)

Lower surface of the core interfacing with the lower plenum (directed downwards)

Interface between the permanent reflector blocks and CB over the height of the core, i.e., outer surface of the core (directed radially outwards)

Upper surface of the core below the core restraint elements (directed upwards)

Interface between the core restraint elements and upper plenum (directed upwards)

Coolant inlet

Vertical surfaces at the interfaces between the graphite blocks within the reactor core, excludes the gaps between the permanent reflector blocks

Side and lower surfaces of the lower plenum including the outlet duct (directed into the plenum)

Coolant outlet

Inner surface of riser XX (numbered according to Figure 69) (directed radially outwards)

Outer and side surfaces of riser XX (numbered according to Figure 69) (directed towards the center of the riser channel)

Only defined for the fluid mesh of the two mesh model. This is the outwards directed equivalent to riserXXOuter defined to represent the outer surface of the riser channels.

Inner surface of the reactor pressure vessel (directed inwards)

Outer surface of the reactor pressure, excluding the lower surface (directed outwards)

Symmetry plane (numbered according to Figure 69) for regions containing core material

Symmetry plane (numbered according to Figure 69) for regions containing fluid (excludes the core)

Symmetry plane (numbered according to Figure 69) for regions containing solid material (excludes the core) 


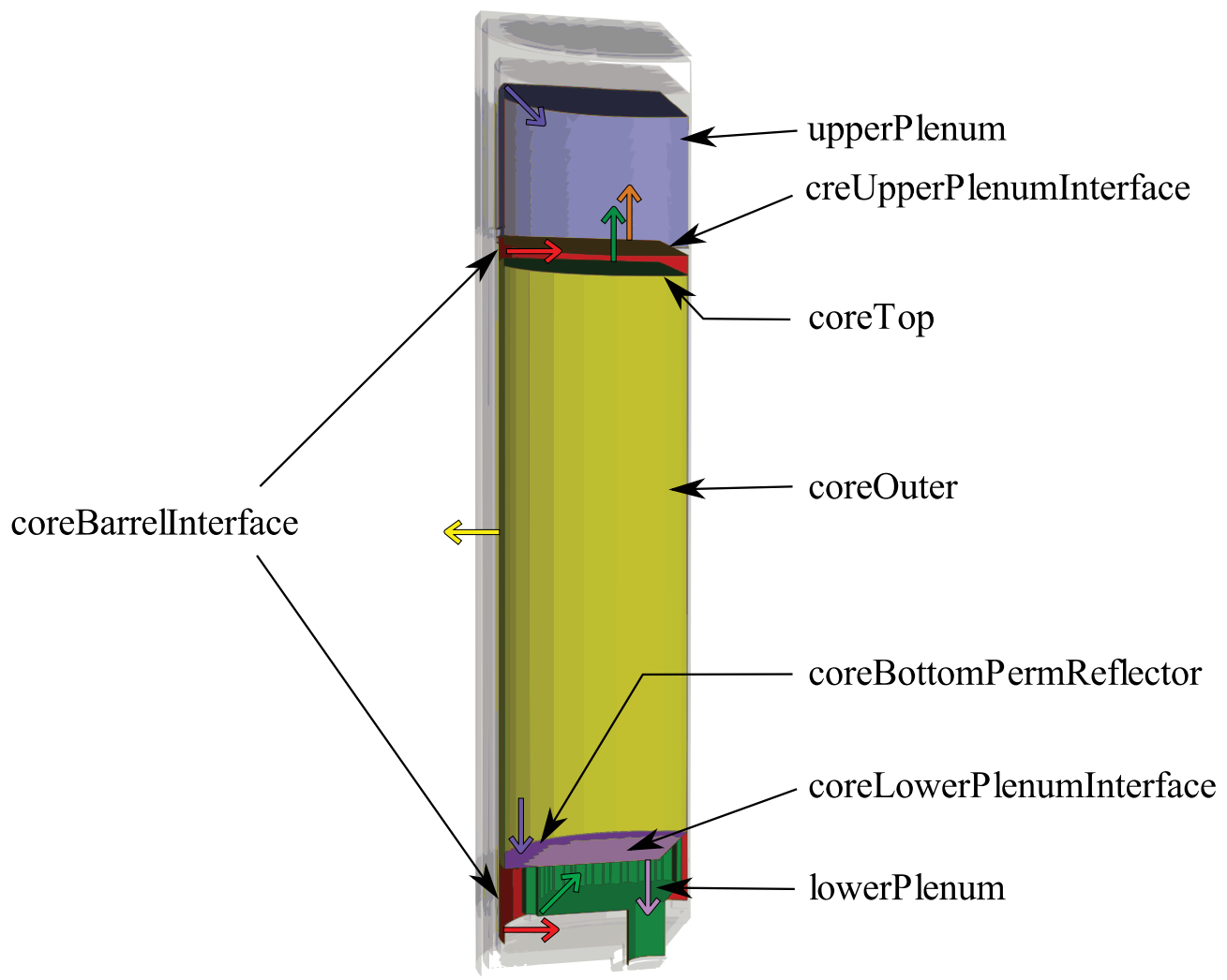

Figure 70. Sideset Definitions showing Normal Vectors.

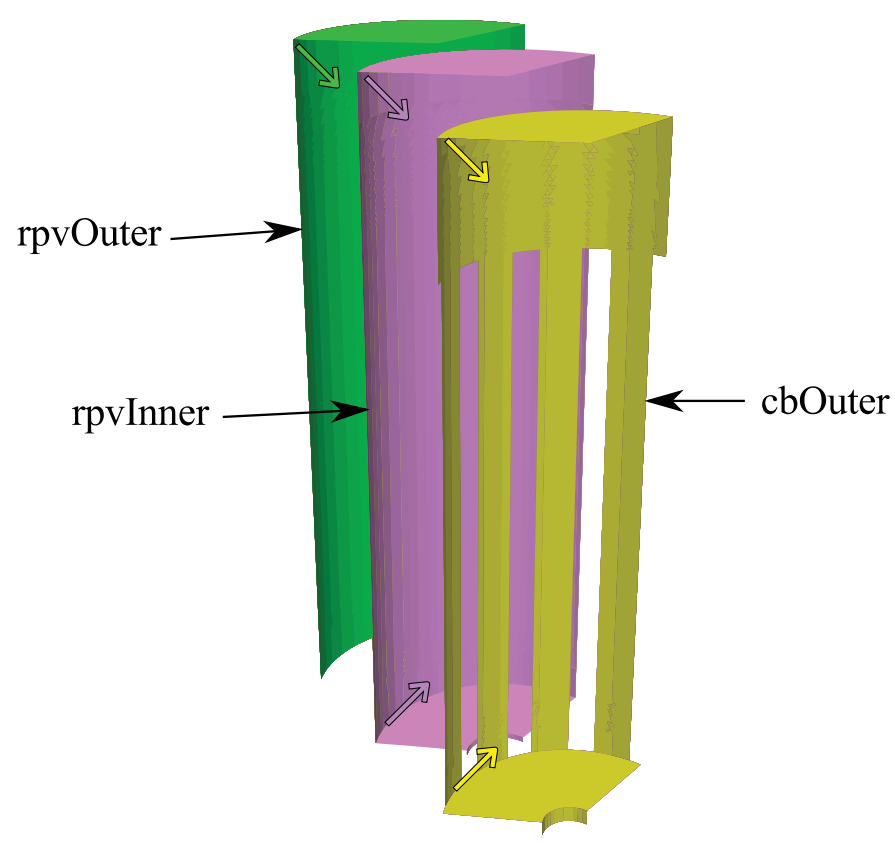

Figure 71. Sideset Definitions showing Normal Vectors (Continued). 


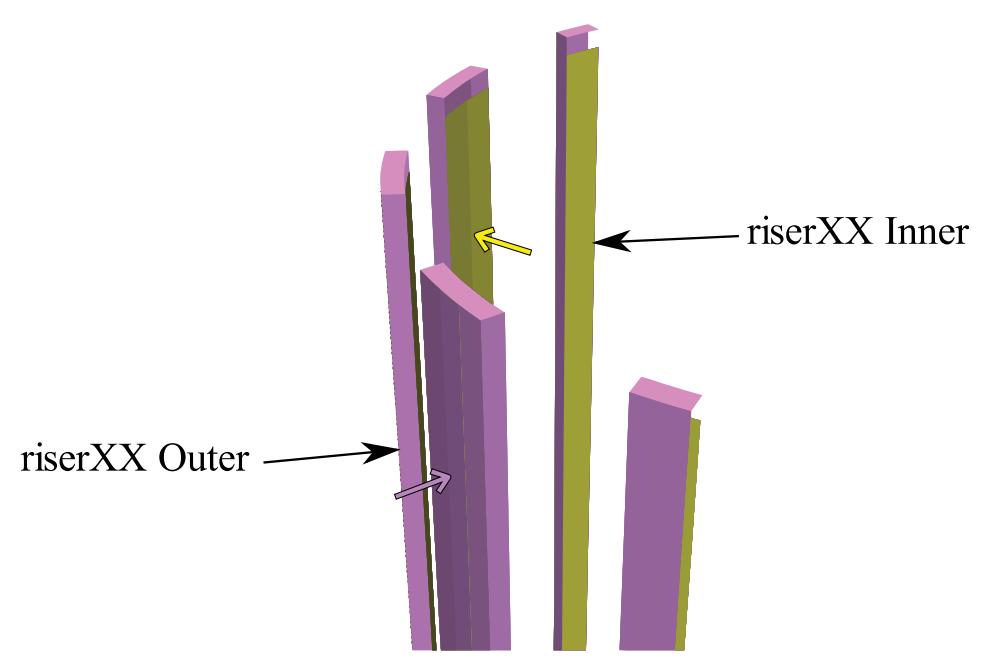

Figure 72. Sideset Definitions showing Normal Vectors (Continued).

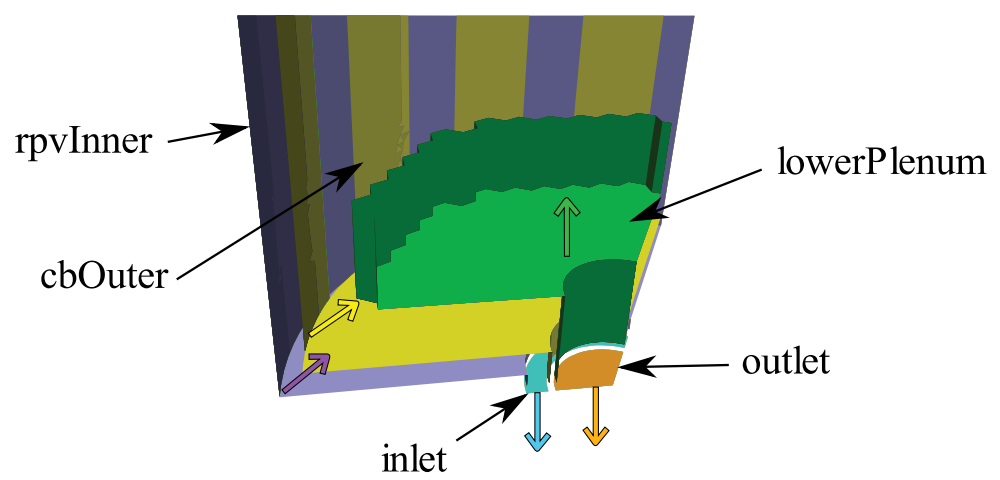

Figure 73. Sideset Definitions showing Normal Vectors (Continued).

\subsection{Pronghorn Thermal Fluid Kernels}

The porous medium approach has been used extensively in the high temperature reactors, especially in Pebble Bed Reactors (PBR) HTRs for validation experiments have been performed [34]. These models in Pronghorn have already been developed and successfully applied to several cases in the past [33]. For the thermal fluid modeling of the MHTGR-350 benchmark these models will be used with some updates.

\subsubsection{Porous Medium Flow Model Kernels}

Pronghorn was initially developed to model PBRs and to analyze the PBMR400 benchmark [26] and a simple porous Darcy-Flow model was implemented. These kernels were updated in such a way that the friction coefficient and the thermal conductivities are represented by tensors so that an anisotropic media such as prismatic reactors can be represented. The kernels are also updated in such a way that the momentum equation is solved for the mass flux, so that there will be no discontinuity of the solution over the regions where the porosity changes drastically. The simulation of Phase II Exercise 2 requires the ability to model the natural convection, flow regime in which the viscous terms are important. Therefore, viscous terms have also been added to these kernels. 


\subsubsection{Incompressible Navier-Stokes Kernels}

Incompressible Navier-Stokes (INS) kernels are developed to be able to model the helium coolant riser channels. Even though the coolant in MHTGR-350 is a compressible gas, the flow in the riser channels can be approximated by the INS equations since the density change is insignificant. A typical temperature and pressure change in a riser of an HTR is less than $5^{\circ} \mathrm{K}$ and $1 \mathrm{kPa}$, respectively.

\subsubsection{Auxiliary Kernels}

Auxiliary kernels have been developed for calculating the heat transfer coefficient between fluid and solid is modeled using the Gnielinski correlation [31], the friction coefficients and for the heat sources.

\subsubsection{Conjugate Heat Transfer Model}

The need to model conjugate heat transfer (CHT) between solid and fluid components across an interface is commonly encountered in CFD applications. The typical approach that is followed is to match the solid and fluid temperatures and heat fluxes at the boundary, taking into account boundary effects. This typically requires mesh refinement near the boundary. In the case of Pronghorn, however, our aim is to use coarse mesh methods and we therefore choose to model the heat transfer at surfaces using heat transfer coefficients based on Nusselt number correlations. Numerous correlations for the Nusselt number are available for various geometries. In general this approach assumes fully developed flow and thermal equilibrium. Previously, the CHT was implemented by using the PenetrationLocator class in MOOSE, which locates the adjacent nodes on overlapping sidesets and provides the information needed for transferring values between the sidesets. However, it was found that the functionality of this class fails if the variables are defined block-by-block, i.e. for separate fluid and solid regions. As a workaround for use of this class the solid temperature was defined in all the regions. This approach is not valid for modeling pipe flows or engineered bypass channels. Therefore, instead of the PenetrationLocator class, the NearestNodeValueAux class, which assigns the value of the paired variable to an auxiliary variable at the nearest node, was used. This auxiliary variable is then used in the CHT boundary condition as the coupled solid or fluid temperature.

All the kernels and models updated or developed code were tested with different geometries. These kernels and models are all needed for the simulation of the MHTR-350 Benchmark. Since the model of the MHTR-350 benchmark is quite large, the simulation was already started with smaller subsets of the MTHR-350 thermal fluid model, described in the previous section, using some boundary conditions. No Pronghorn results from the MHTGR-350 benchmark are presented in this report as the simulation is not yet complete. More model development is required to capture radiation heat transfer and to construct the drag coefficient tensor.

\subsection{Test Results}

The test cases, which are used for the developed and updated models, contain arbitrary but physical input parameters. The results are only used to test if the models converge for different geometries and conditions that might result during the simulation of the MHTGR-350 Benchmark.

\subsubsection{Hexagonal (HEX) Block Test Model}

This test model includes 7 prismatic blocks of which heat is generated in four. The center block contains a cylindrical pipe to represent the CR channels in the MHTGR-350 Benchmark. A solid cylindrical reflector is present around the prismatic blocks. The pipe flow model implementation includes the relevant friction and heat transfer correlations. Some results from the HEX Block test model are shown in figures from Figure 74 to Figure 77. 


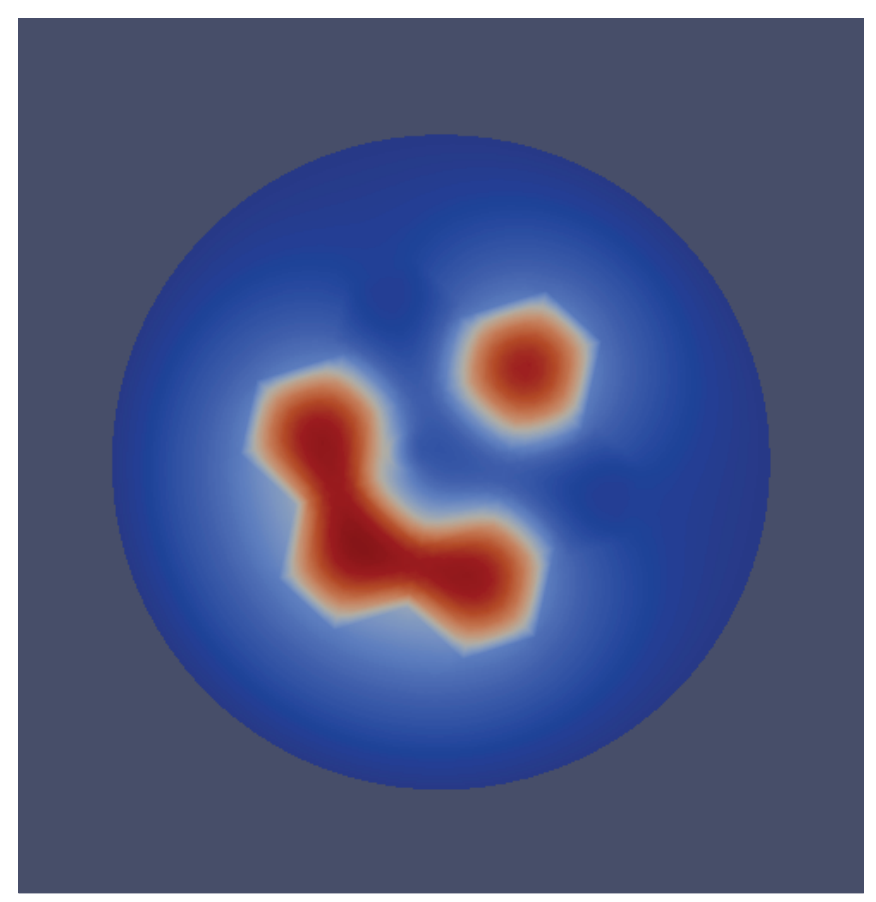

Figure 74. Solid temperatures of the HEX Block test model. 7 HEX blocks in a cylinder 4 producing power. The center HEX block contains a coolant channel.

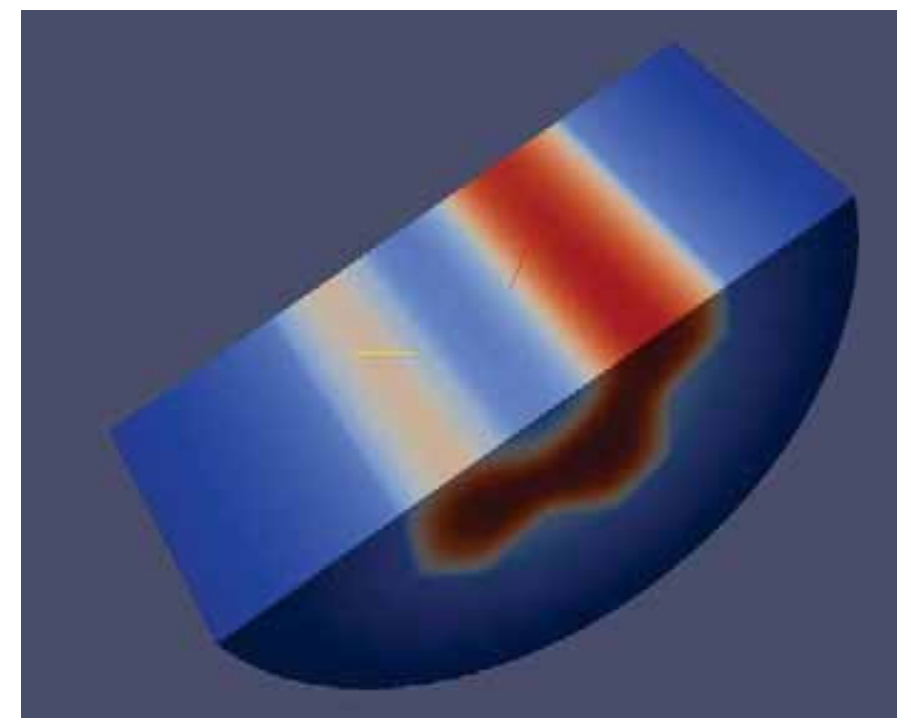

Figure 75. Solid Temperatures of HEX Block Test model. 


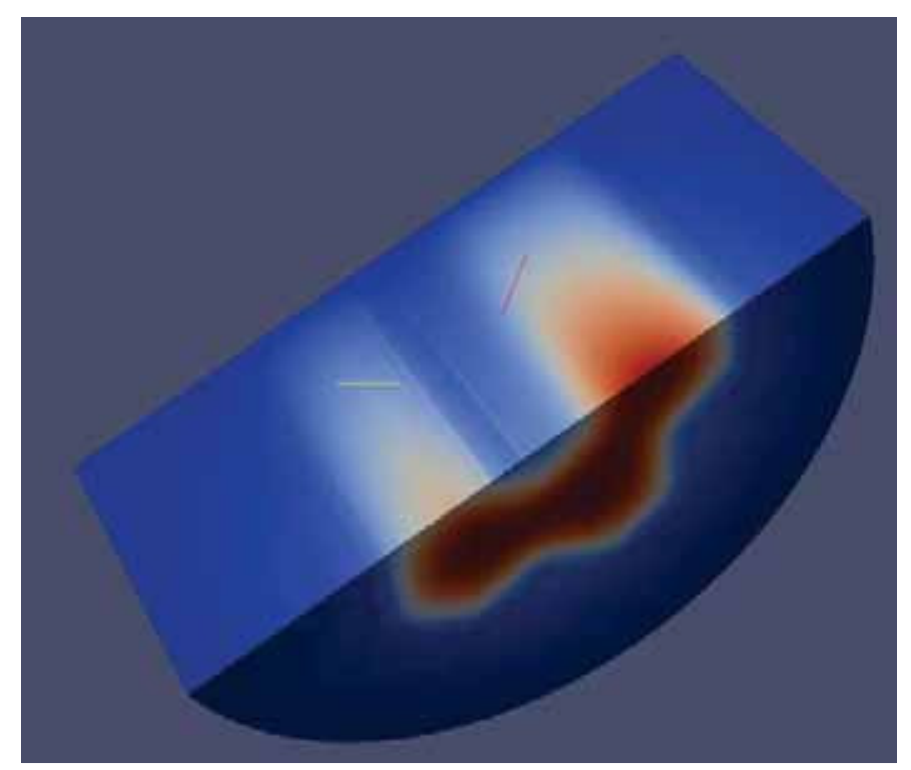

Figure 76. Fluid Temperatures of HEX Blocks test model.

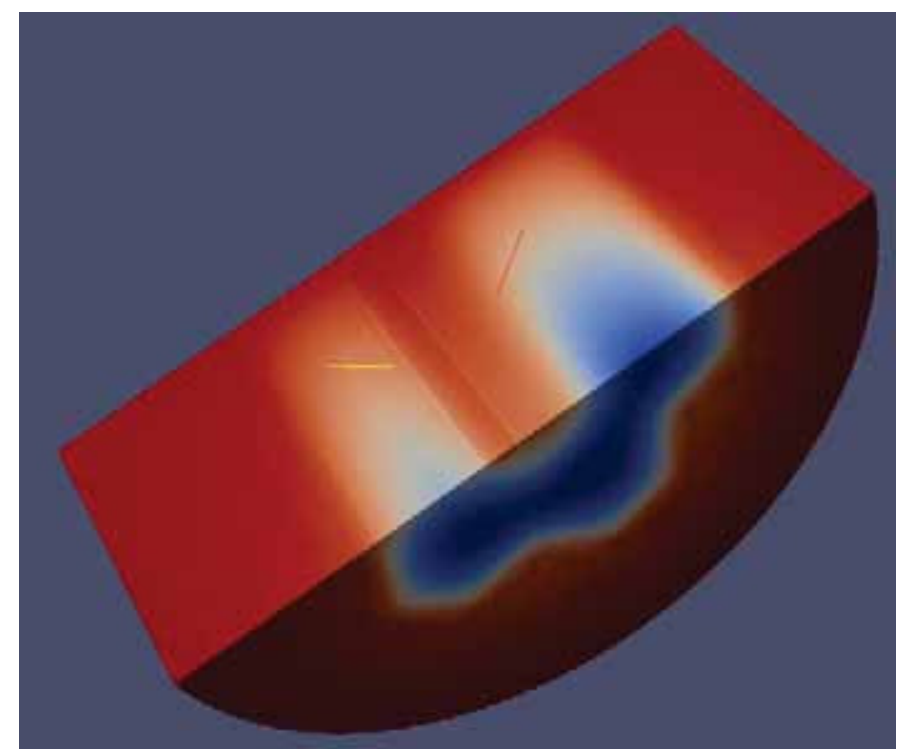

Figure 77. Fluid density: HEX Block test model.

\section{Incompressible Navier-Stokes Test Cases}

The INS kernels are tested with using the common test case "lid driven cavity" and with a single pipe flow. The "lid driven cavity" problem geometry is simple and 2-dimensional. Dirichlet boundary conditions (flow specified at the boundaries) are applied to all sides, with three stationary and one moving side with velocity tangent to the side.

The INS kernels are tested with using the common test case "lid driven cavity" and with a single pipe flow. The "lid driven cavity" problem geometry is simple and 2-dimensional. The boundary conditions of the domain are Dirichlet boundary condition on all sides, with three stationary and one moving side with velocity tangent to the side. 


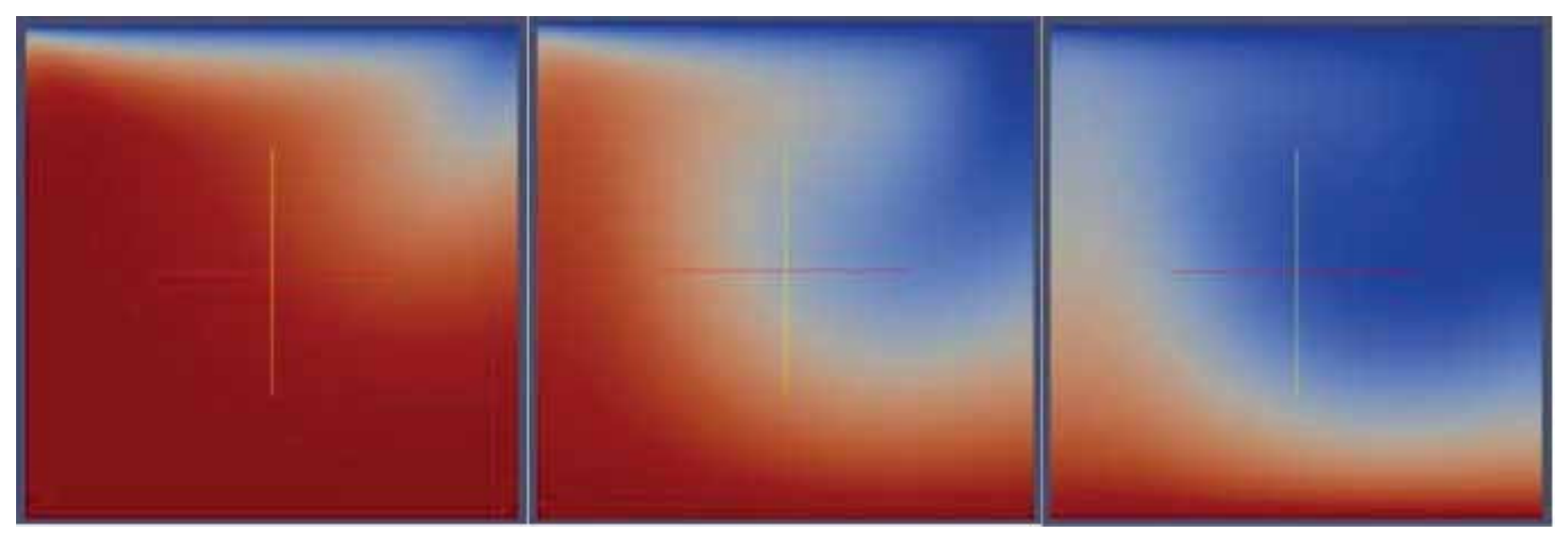

Figure 78. The fluid temperatures for the "lid driven cavity" test, for $\mathrm{t}=0.01 \mathrm{~s}, \mathrm{t}=0.04 \mathrm{~s}$ and equilibrium from left to right, respectively.

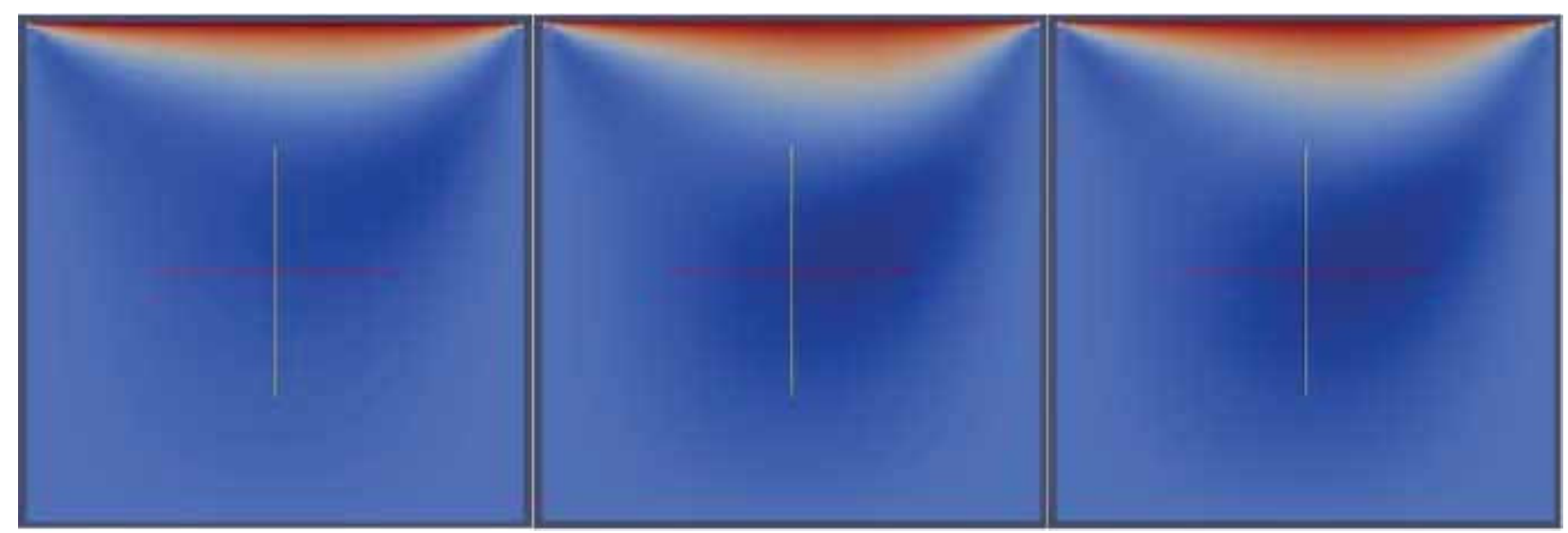

Figure 79. The $\mathrm{x}$-direction velocity for the "lid driven cavity" test, for $\mathrm{t}=0.01 \mathrm{~s}, \mathrm{t}=0.04 \mathrm{~s}$ and equilibrium from left to right, respectively.

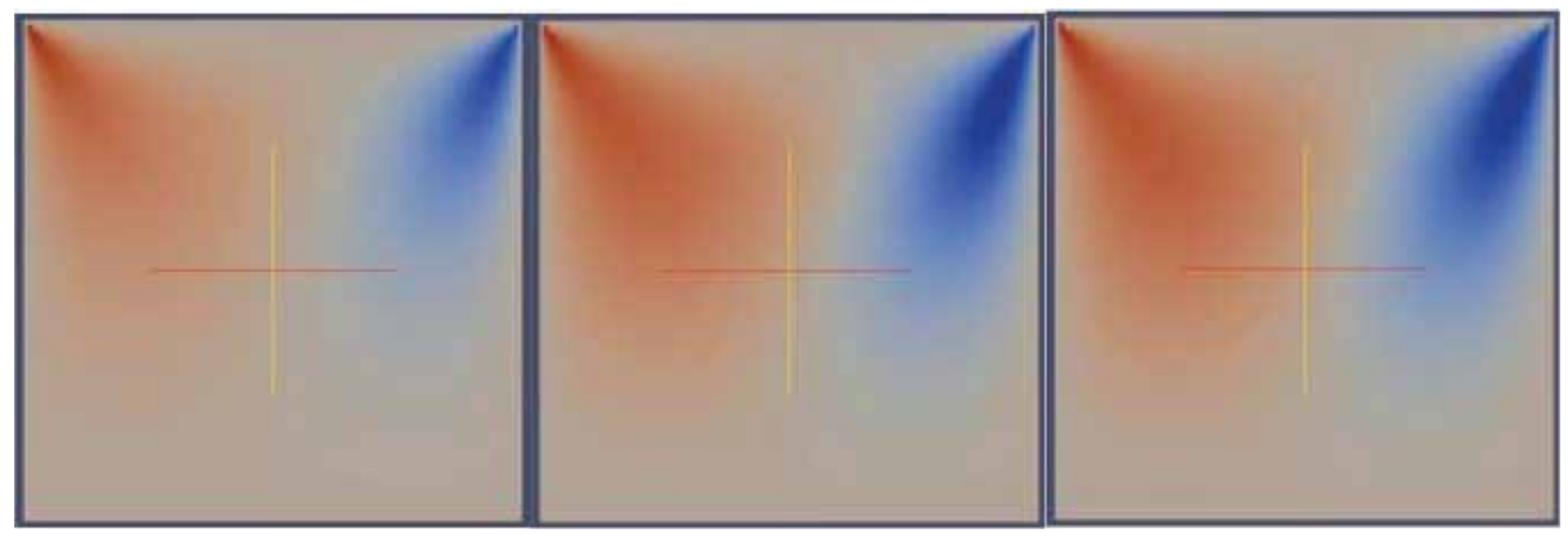

Figure 80. The $y$-direction velocity for the "lid driven cavity" test, for $\mathrm{t}=0.01 \mathrm{~s}, \mathrm{t}=0.04 \mathrm{~s}$ and equilibrium from left to right, respectively. 
Another test case for the INS kernel is cylindrical pipe flow with Dirichlet boundary conditions at the side and the inlet. The fluid flows from top to bottom. The fluid inlet temperature is lower than the side temperature to simulate the heat source outside. Results of the cylindrical pipe flow test case are illustrated in Figure 81.
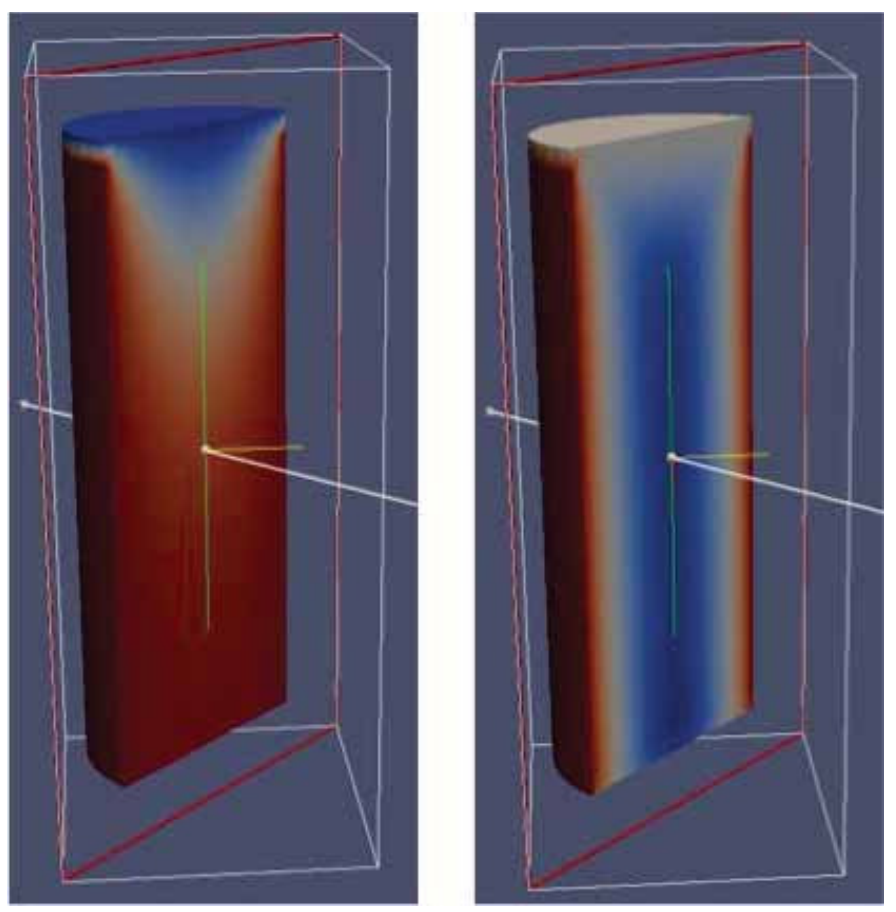

Figure 81. Results for the INS kernels cylindrical pipe flow test case. Left: Fluid temperature, and Right: Velocity in z-direction.

\subsubsection{Natural Convection Test Cases}

The natural convection kernels are tested in both annular (heated from center) and cubic geometries. The results of the cubic test case are illustrated in Figure 82 and Figure 83. The porous cube domain is heated from three surfaces while the other three surfaces (not seen on Figure 82 ) are kept at constant temperature at the boundaries. 


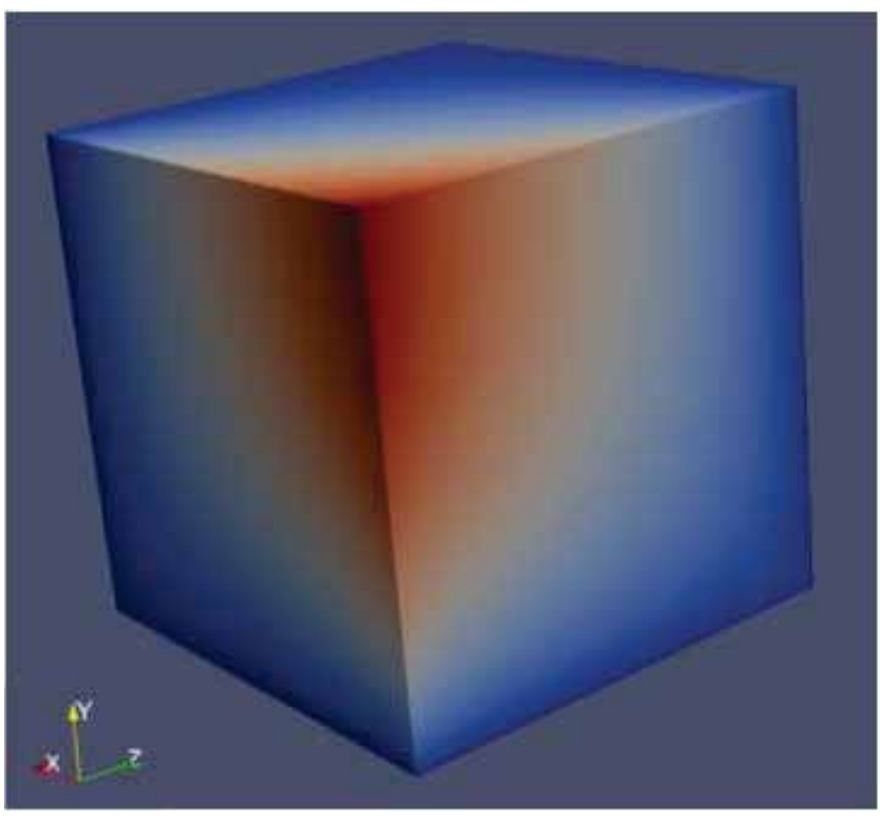

Figure 82. Natural convection cubic test case: Solid Temperatures.

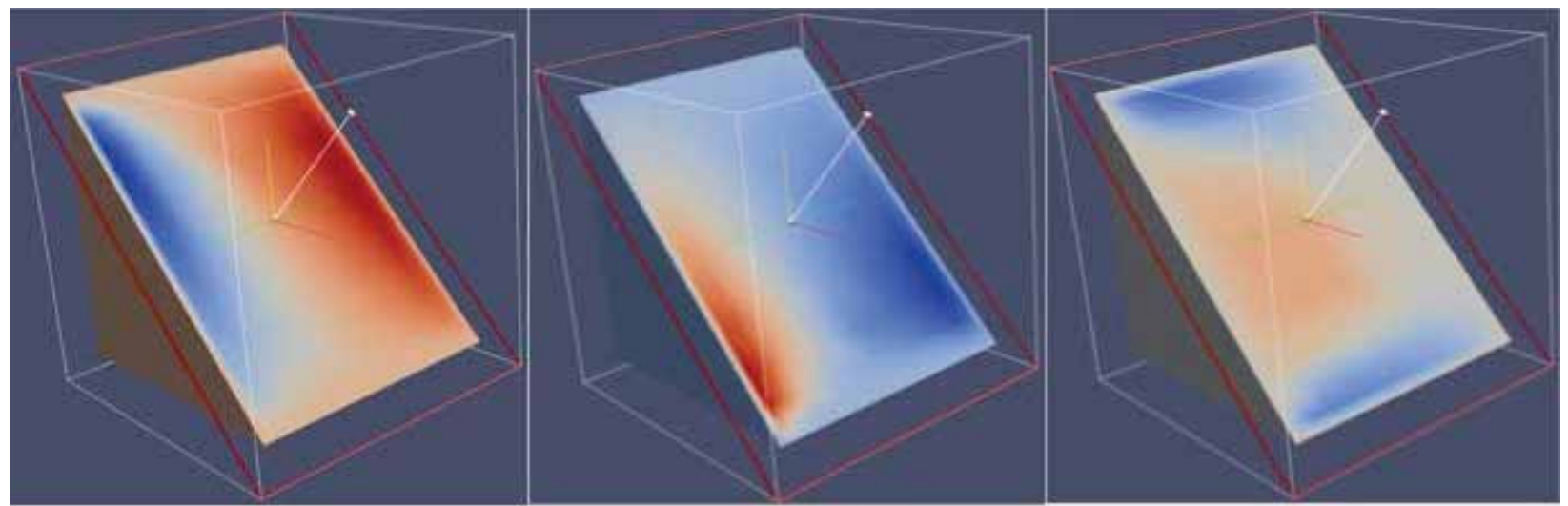

Figure 83. The $\mathrm{x}$ (left), $\mathrm{y}$ (middle), and the $\mathrm{z}$ (right) direction momentum in natural convection cubic test case.

The results of the annular natural convection test case are illustrated in Figure 84. This is a porous annular geometry heated from the center and with an external heat sink defined by a Dirichlet (temperature specified) boundary condition. 


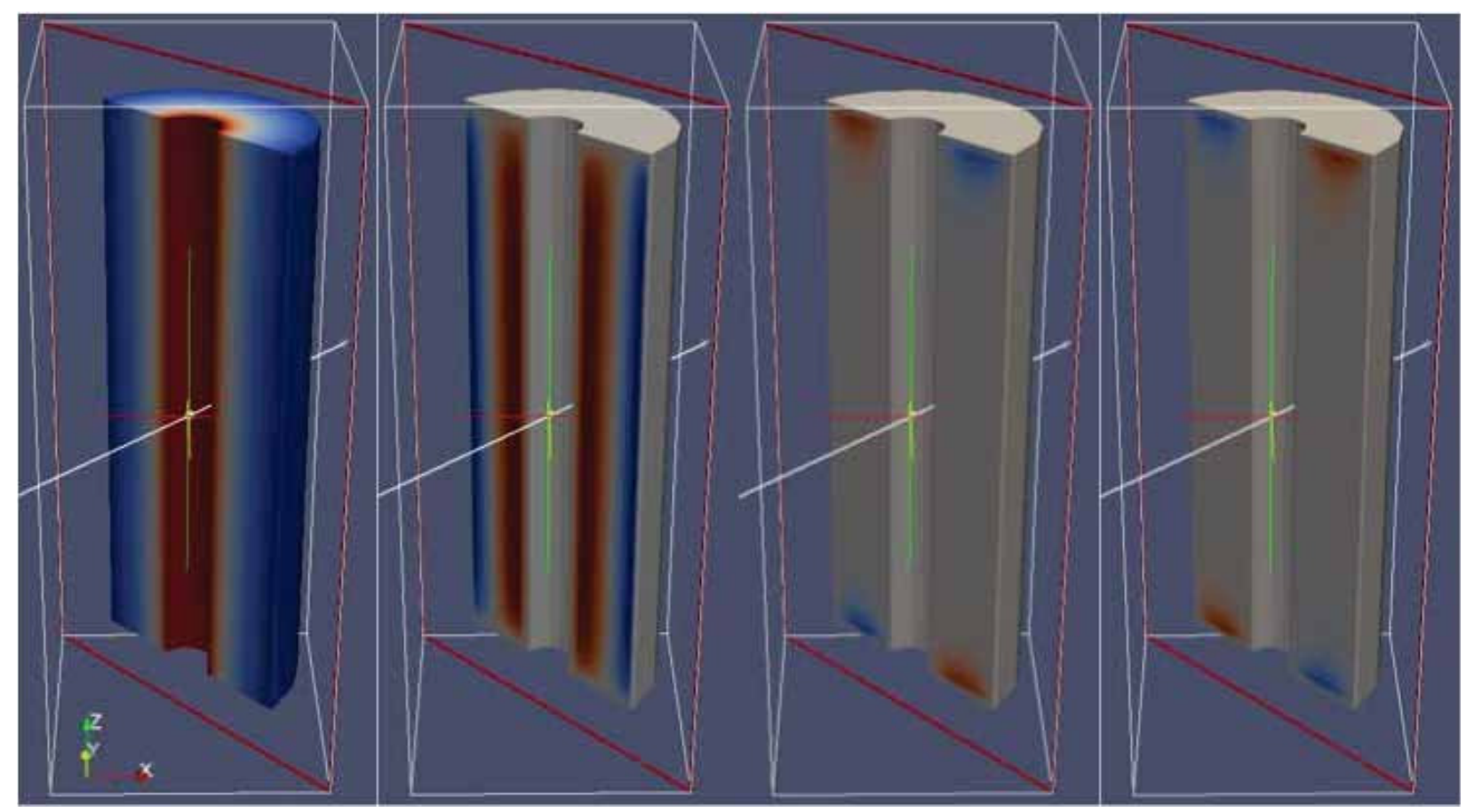

Figure 84. Solid temperatures, $\mathrm{z}, \mathrm{y}$, and $\mathrm{x}$ direction momentum from left to right, respectively, in the annular natural convection test case.

\subsubsection{Conjugate Heat Transfer Boundary Condition Test Cases}

A crude 3D thermal fluid model of a pebble bed reactor has been established and successfully tested, where a flat power profile was used. The resulting solid temperatures are shown in Figure 85. The coolant flows from the top of the pebble bed through the top reflector and exits through the bottom reflector. The effect of the CHT boundary conditions is seen at the pebble bed - reflector interfaces. These results are obtained by using Darcy-Flow model. 


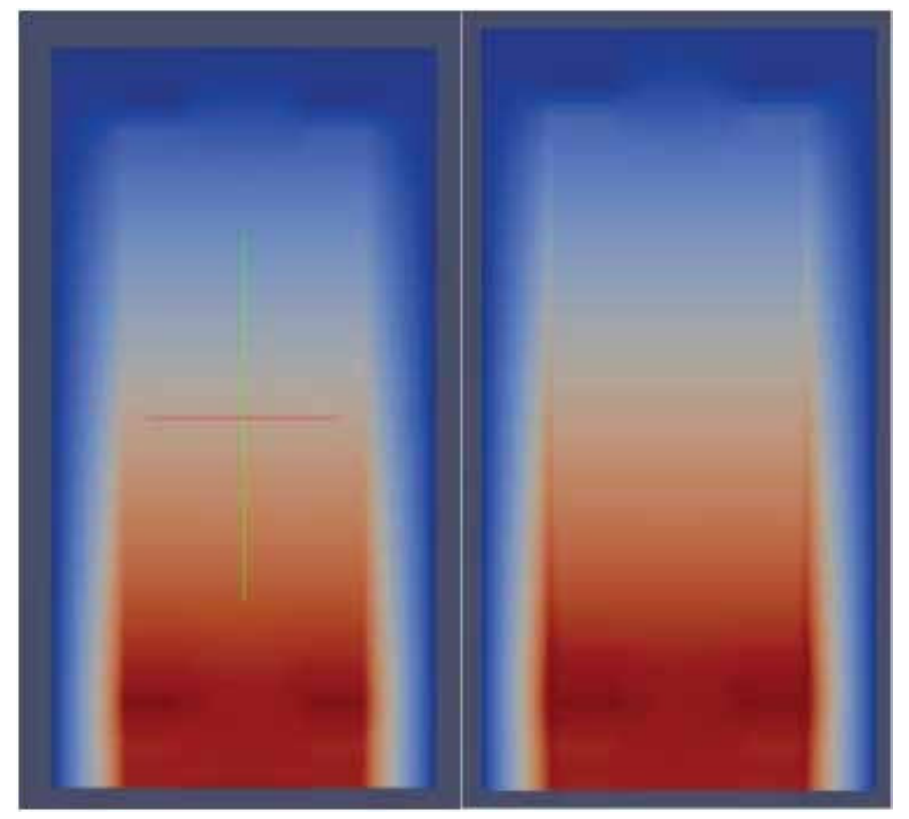

Figure 85. Pebble Bed Test Model Solid Temperatures. (left: no CHT Boundary condition, right: with CHT Boundary condition). 